\title{
State-of-the-art and SWOT analysis of building integrated solar envelope systems
}

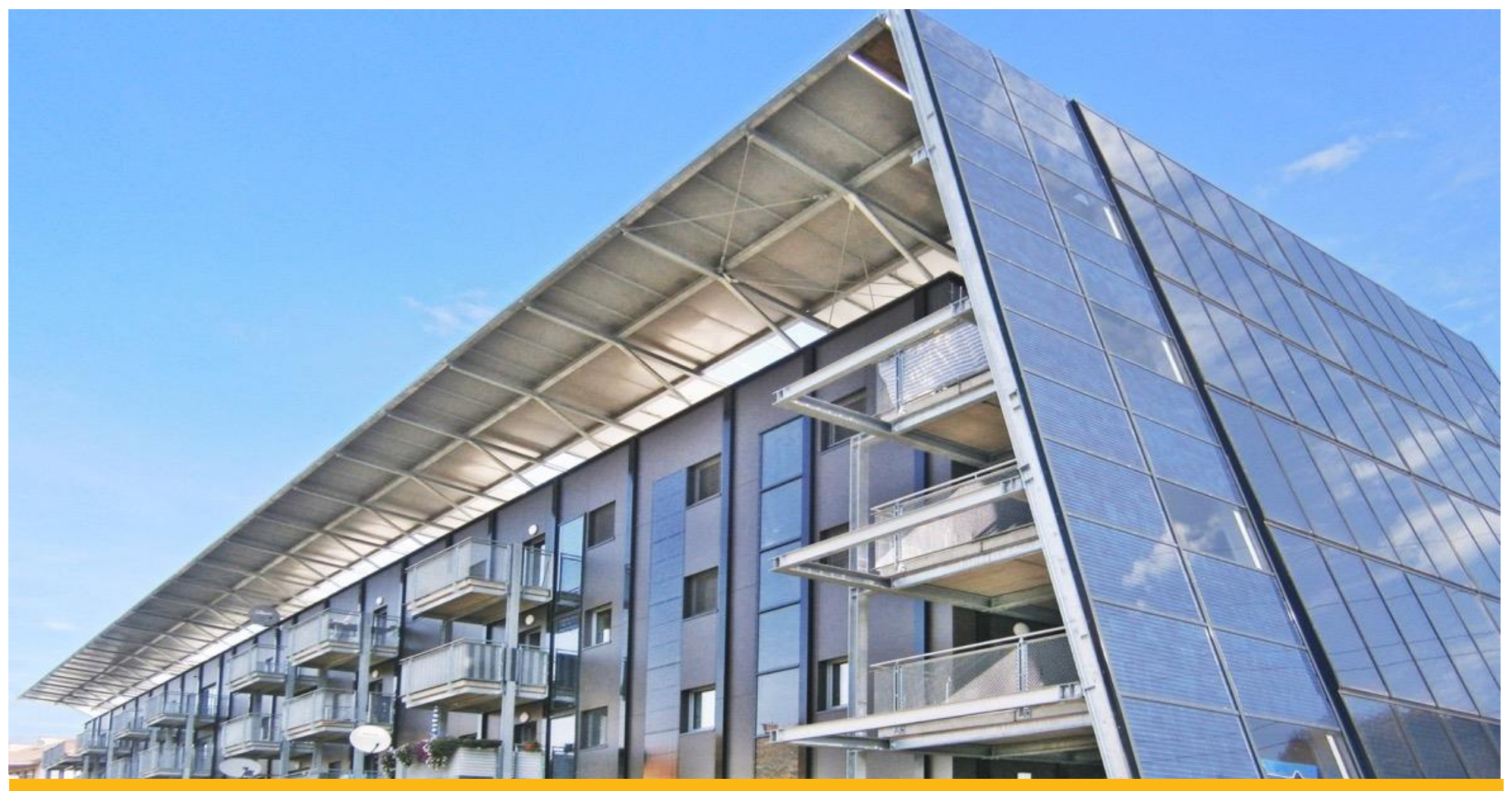

IEA SHC TASK 56 | Building Integrated Solar Envelope Systems for HVAC and Lighting 


\title{
State-of-the-art and SWOT analysis of building integrated solar envelope systems
}

\author{
Deliverables A.1 and A.2
}

Editors: Paolo Bonato, Roberto Fedrizzi, Matteo D'Antoni, Michaela Meir

Contributors to the solar envelope systems review (in alphabetical order):

André Kostro, BASF Schweiz AG, Switzerland

Andreas Hafner, BASF Schweiz AG, Switzerland

Antía Varela Souto, Eindhoven University of Technology, The Netherlands

Beñat Arregi, Tecnalia, Spain

Benedetta Copertaro, Dalarna University, Sweden

Brian Wilkinson, Matrix Energy Inc, Quebec, Canada

Carolin Hubschneider, Fraunhofer IBP, Germany

David Geisler-Moroder, Bartenbach GmbH, Austria

Efstratios Rounis, Concordia University, Canada

Elena Rico, ONYX SOLAR, Spain

Ignacio González Pérez, ACCIONA Construcción, Spain

James Walshe, Technological University Dublin, Ireland

Jingchun Shen, Dalarna University, Sweden

Johann Aschauer, GAP Solutions $\mathrm{GmbH}$, Austria

Johannes Franz, OKALUX GmbH, Germany

John Hollick, SolarWall, Canada

Julen Astudillo, Tecnalia, Spain

Maarten de Haas, PHYSEE, The Netherlands

Martin Dietz, Solar Lightning Consultants ApS, Denmark

Matteo D'Antoni, Eurac Research, Italy
Michaela Meir, Aventa AS, Norway

Noel O'Neill, Technological University Dublin, Ireland

Paolo Bonato, Eurac Research, Italy

Paul-Rouven Denz, Priedemann Facade-Lab GmbH, Germany

Peru Elguezabal, Tecnalia, Spain

Philippe Lemarchand, Technological University Dublin, Ireland

Rafic Hanbali, Swissinso SA, Switzerland

Riccardo Pinotti, Eurac Research, Italy

Robert Weitlaner, HELLA Sonnen- und Wetterschutztechnik GmbH, Austria

Roberto Garay, Tecnalia, Spain

Roberto Lollini, Eurac Research, Italy

Roel Loonen, Eindhoven University of Technology, The Netherlands Sam Kin, Kindow, The Netherlands

Samuel de Vries, Eindhoven University of Technology, The Netherlands

Stefano Avesani, Eurac Research, Italy

Teodosio del Caño, ONYX SOLAR, Spain

Vickie Aagesen, Cenergia a part of Kuben Management, Denmark

Xingxing Zhang, Dalarna University, Sweden

Zissis loannidis, Concordia University, Canada

November 2019

DA.1 + DA.2, DOI 10.18777/ieashc-task56-2019-0001

The contents of this report do not necessarily reflect the viewpoints or policies of the International Energy Agency (IEA) or its member countries, the IEA Solar Heating and Cooling Technology Collaboration Programme (SHC TCP) members or the participating researchers. 
The Solar Heating and Cooling Technology Collaboration Programme was founded in 1977 as one of the first multilateral technology initiatives ("Implementing Agreements") of the International Energy Agency. Its mission is "To enhance collective knowledge and application of solar heating and cooling through international collaboration to reach the goal set in the vision of solar thermal energy meeting $50 \%$ of low temperature heating and cooling demand by 2050."

The members of the IEA SHC collaborate on projects (referred to as Tasks) in the field of research, development, demonstration (RD\&D), and test methods for solar thermal energy and solar buildings.

Research topics and the associated Tasks in parenthesis include:

- Solar Space Heating and Water Heating (Tasks 14, 19, 26, 44, 54)

- Solar Cooling (Tasks 25, 38, 48, 53)

- Solar Heat for Industrial or Agricultural Processes (Tasks 29, 33, 49, 62, 64)

- Solar District Heating (Tasks 7, 45, 55)

- Solar Buildings/Architecture/Urban Planning (Tasks 8, 11, 12, 13, 20, 22, 23, 28, 37, 40, 41, 47, 51, 52, 56, 59, 63)

- $\quad$ Solar Thermal \& PV (Tasks $16,35,60)$

- Daylighting/Lighting (Tasks 21, 31, 50, 61)

- Materials/Components for Solar Heating and Cooling (Tasks 2, 3, 6, 10, 18, 27, 39)

- $\quad$ Standards, Certification, and Test Methods (Tasks 14, 24, 34, 43, 57)

- $\quad$ Resource Assessment (Tasks 1, 4, 5, 9, 17, 36, 46)

- $\quad$ Storage of Solar Heat (Tasks 7, 32, 42, 58)

In addition to our Task work, other activities of the IEA SHC include our:

$>$ International Conference on Solar Heating and Cooling for Buildings and Industry

$>$ SHC Solar Academy

$>$ Solar Heat Worldwide annual statics report

> Collaboration with solar thermal trade associations

\section{Country Members}

Australia

Austria

Belgium

Canada

China

Denmark

European Commission

\section{Sponsor Members}

European Copper Institute International Solar Energy Society CCREEE

EACREEE

$\begin{array}{ll}\text { France } & \text { South Africa } \\ \text { Germany } & \text { Spain } \\ \text { Italy } & \text { Sweden } \\ \text { Netherlands } & \text { Switzerland } \\ \text { Norway } & \text { Turkey } \\ \text { Portugal } & \text { United Kingdom } \\ \text { Slovakia } & \end{array}$

\section{ECREEE}

PCREEE

RCREEE

SACREEE

For more information on the IEA SHC work, including many free publications, please visit www.iea-shc.org 


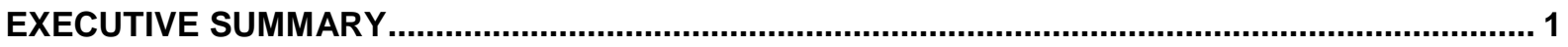

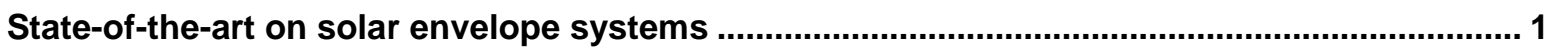

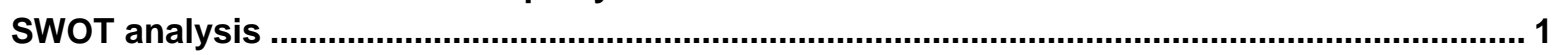

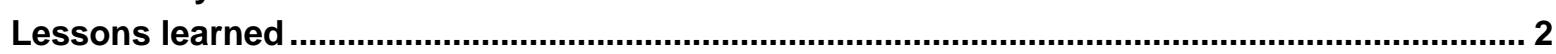

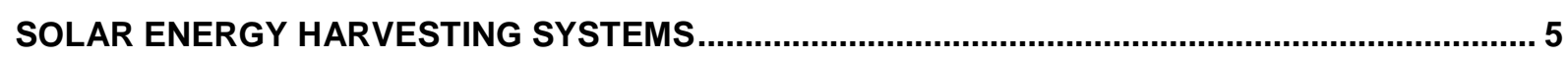

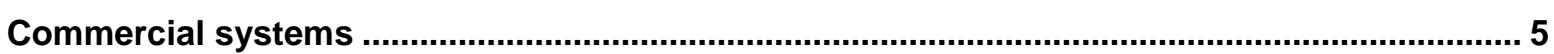

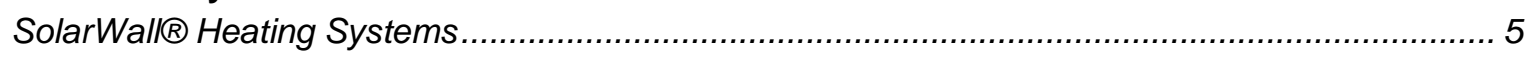

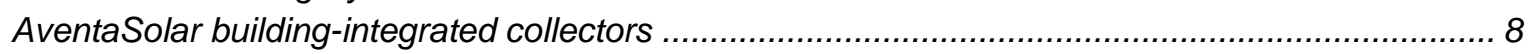

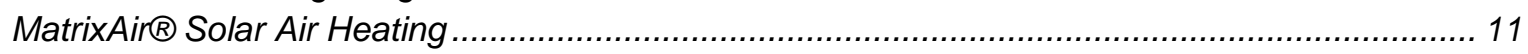

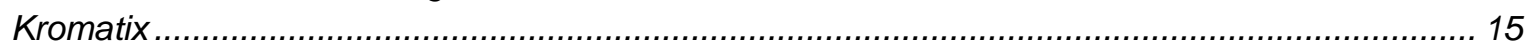

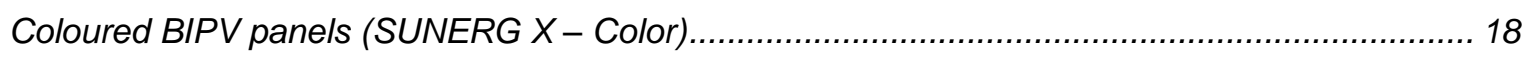

GAP:water - Facade-integrated solar domestic hot water generation .......................................... 21

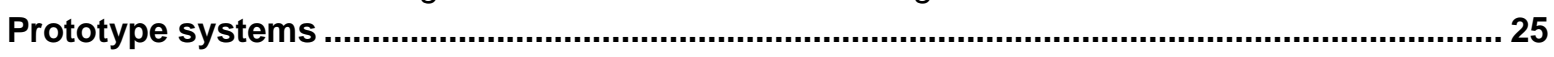

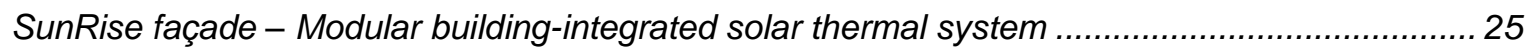

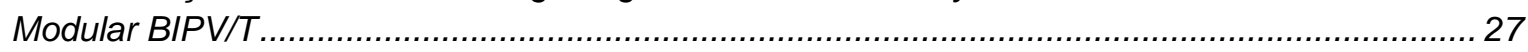

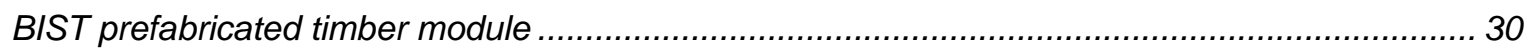

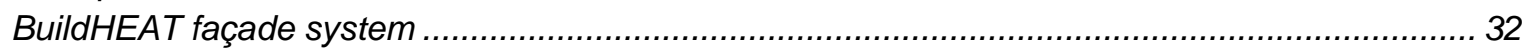

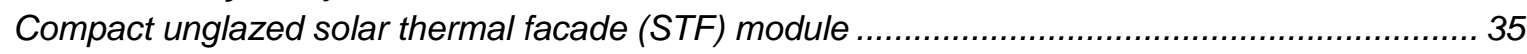

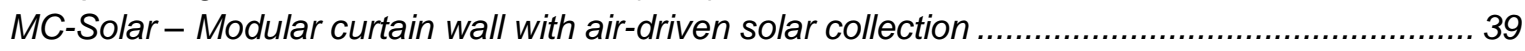

Façade-Integrated Air-Driven Solar Thermal Collectors......................................................... 42

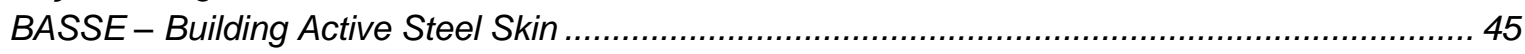

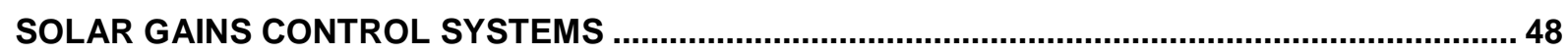

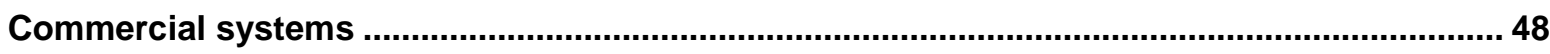

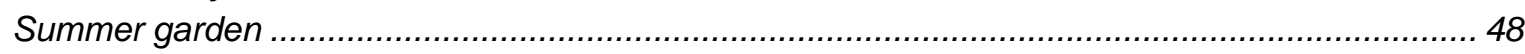

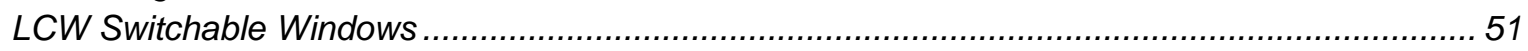

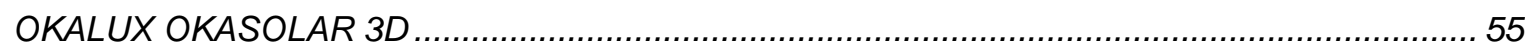

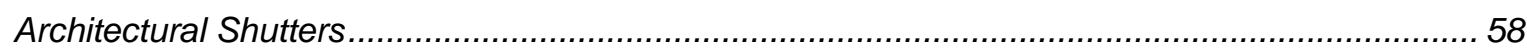

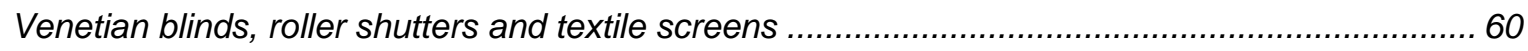

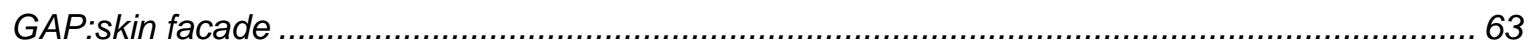

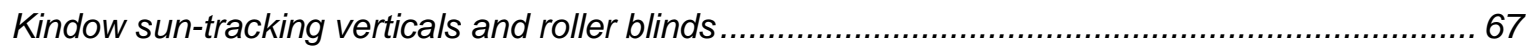

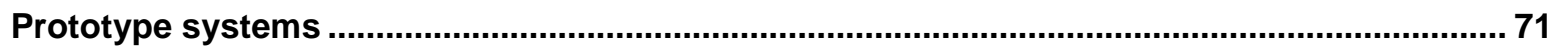

Facade integrated daylight and electric light illumination with micro-optics ................................. 71

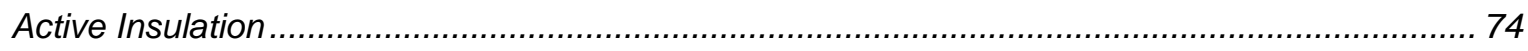

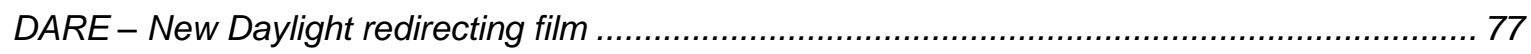

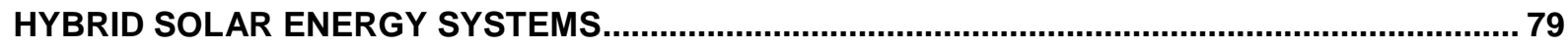

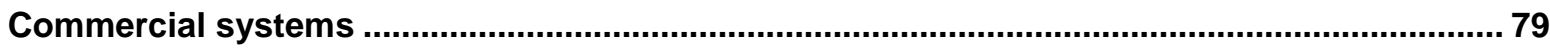

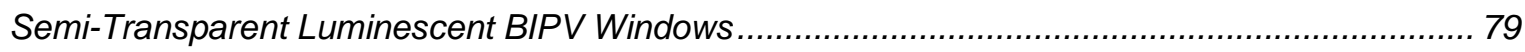

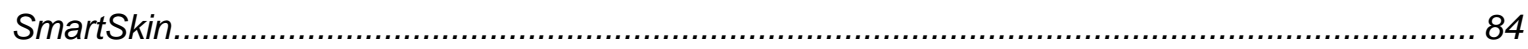

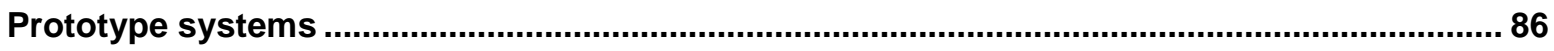

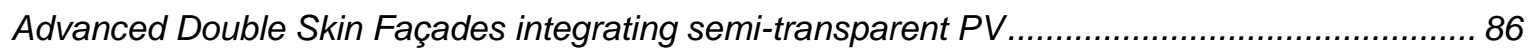

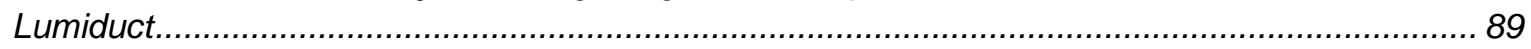

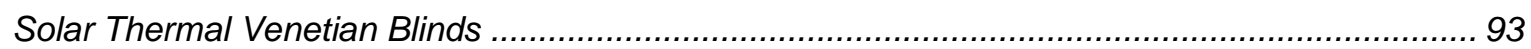

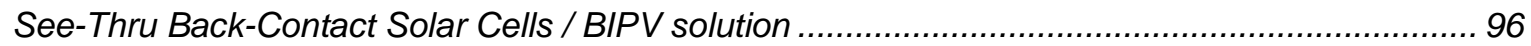




\section{State-of-the-art on solar envelope systems}

The present document includes a state-of-the-art review of solar envelope systems that are already on the market or that can potentially reach that stage in a short-medium timeframe (Technology Readiness Level $\geq 4$ ). The analysis focuses on the technological integration of such solutions in the envelope and building, but non-technical issues such as aesthetic, architectural integration and customer acceptance are also tackled. For the sake of simplicity, the solar envelope systems are classified in:

- $\quad$ Solar harvesting systems: systems that generate electricity or heat;

- Solar gains control systems: systems that control daylight / incident solar radiation entering the building, reducing the need for active heating and cooling;

- Hybrid systems: combination of solar harvesting and solar gains control systems.

\section{SWOT analysis}

In this study, a SWOT analysis was conducted to investigate a range of technologies and solar envelope system products. The SWOT analysis is a well-known product (or business) analysis method, whose purpose is to assist the strategic planning of a company by providing an insight on internal and external issues that have an impact on the success of the product. The process involves the identification of strengths (S) and weaknesses (W) of the product as well as opportunities $(\mathrm{O})$ for growth and threats $(\mathrm{T})$ presented by the external environment. More specifically, strengths and weaknesses are factors that have an internal origin over which there is some measure of control. Opportunities and threats are external factors that is hardly possible to influence.

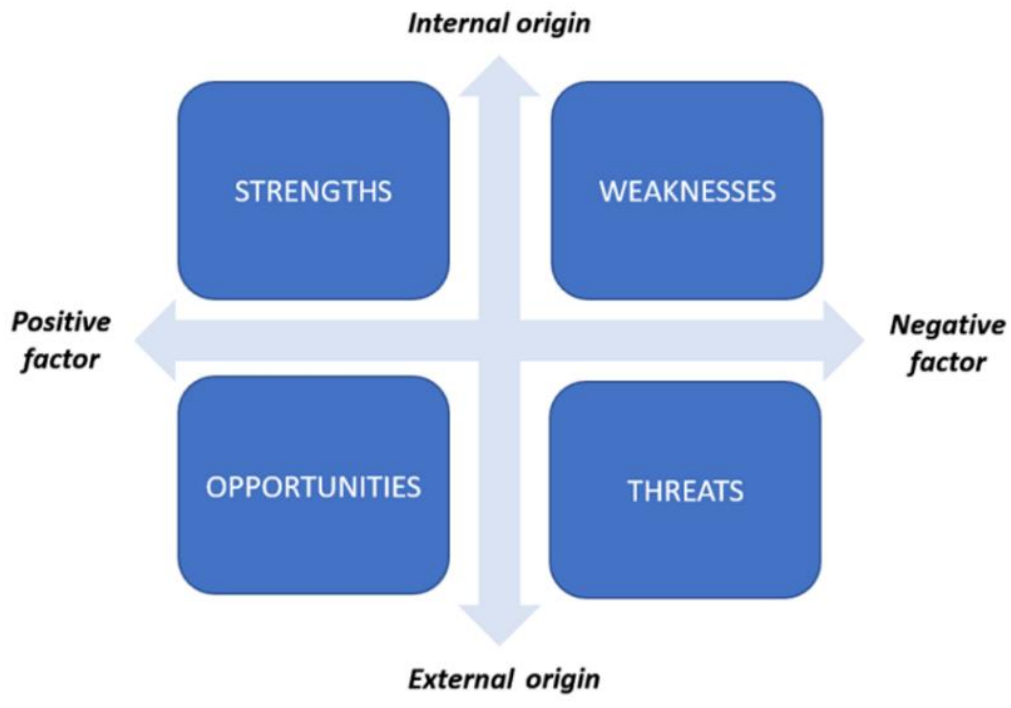

Figure 1. Visual representation of a SWOT analysis matrix.

In order to facilitate the process of identifying strengths, weaknesses, threats and opportunities, it is possible to ask the following questions:

\section{Strengths}

- What are the advantages of the product?

- What are the unique selling points?

- What qualities or aspects can persuade customers to choose this product?

\section{Opportunities}

- What are the opportunities for the new product?

- $\quad$ Are there changes in the market or government that can lead to opportunities?

\section{Weakness}

- What weakness could be improved in the design?

- How does our performance compare with our competitors?

- What issues should be avoided?

\section{Threats}

- Who are existing competitors?

- Will there be any shift in consumer behaviour, government or market that can affect the product success? 
Examples of topics tackled in the SWOT analysis conducted in this study are:

- Added value/Unique selling points

- Architectural integration (Freedom in choosing materials and colours, surface appearance)

- Technological integration (Stand-alone system vs integration with centralized system)

- Energy savings (Energy demand reduction / RES generation)

- Durability of components

- Maintenance

- Ease of installation

- Accessibility to sensible components

- Possibility to customize the product

- User-friendliness

- Customer/User satisfaction

- Potential for pre-fabrication

- Modularity
- Weight

- Performance over competitors

- Comfort enhancement

- Certifications

- Level of maturity of the product

- Payback-time / Investment cost / Disposal costs

- Economic incentives

- Economy of scale

- Typology and extent of reference market segment (High volumes market vs niche market)

- Global market trends

- Role of supply chain

- Number of players involved in the product life cycle

- LCCA / LCEA

- Legislative barriers vs legislative openings

- Social barriers

\section{Lessons learned}

In this section, we tried to draw some general conclusions deriving from the overall review of the solar envelope system products presented in the continuation of the report. The three analysed sectors (solar thermal integrated envelopes, photovoltaic integrated envelopes and natural lighting control solutions) are extremely different as well as their market readiness levels. Hence, the following considerations do not apply necessarily to all technologies in the same way. Nonetheless, some common points can be identified.

\section{Is there a common ground for building integrated solar envelope systems in the current panorama?}

To answer this question, common threats and opportunities reported by manufacturers are here presented and briefly commented:

- Building codes and building-integration: solar technologies integrated in the envelope of buildings must comply with construction codes and standards, which in most cases were developed for conventional envelope elements. The lack of adequate test methods and references as well as the presence of regulatory gaps is hindering the spread of innovative integrated products. This scenario is further complicated by the variegated panorama of codes and standards that differ from country to country when not from municipality to municipality. Nevertheless, the efforts of the scientific community and the lobbying action of growing industries can lead to a standardization process and the development of new norms, as done for Building Integrated PV (BIPV) solutions.

- Conservative construction sector: multiple producers report that the construction market is in general conservative compared to other sectors. While shading solutions are nowadays consolidated praxis in new-construction tertiary buildings, envelope integrated PV and solar thermal products are still a niche markets. Solar innovations can hardly find a place in building practices to show an established history of successful installations. Moreover, the use of simulation tools for preliminary performance assessments is becoming widespread in the construction sector. However, the slow penetration of the simulation models of newly developed solutions in standard software used in the industry can also represent a barrier to the adoption of new solutions before they gain traction. Support by decision makers to make public buildings available to these technologies could play an important role in promoting the adoption of solar envelope solutions in both public and private sectors.

- Buildings' construction process: achieving optimal building-integration of solar components requires adjusting the conventional design processes and roles, which may in turn alter 'well-oiled' procedures and be met with suspicion at first. Depending on the type of solar envelope product, the traditional roles of the façade manufacturer, HVAC installer, interior designer etc. can partially overlap during the building design process, as well as in the manufacturing and installation of solar envelope elements. Roles and responsibilities, information and material fluxes, liability in front of the costumer, warranties and maintenance become then relevant multifaceted issues that must be cleared and planned beforehand. 
With this respect, the progressive penetration of the BIM practice in the construction sector is believed to be a vehicle to a market uptake of the building integrated solar envelope solutions. In addition, although these processes may seem to create additional burdens on the companies involved in the construction process, the upside is that new opportunities can be generated based on innovative business models and partnerships between companies.

- Government policies: the policies adopted by national or supranational institutions (like European Directives devoted to promoting the n-ZEB standard for buildings) are perceived to be determinant for promoting the integration of different technologies contributing to the energy efficiency of the building. However, because this sector is highly diversified, with solutions ranging from $\mathrm{PV}$ and solar thermal systems to advanced shading solutions and daylighting management, it cannot be easily targeted with a single scheme or policy action. A possible relevant action includes policies that support solar energy production, energy efficiency, daylight and visual comfort. Likewise, some manufactures believe that $\mathrm{CO}_{2}$ emissions taxation would help the market uptake of many integrated solar envelope technologies.

- Increased awareness: over the last years, a rising interest for life-cycle sustainability and human comfort in buildings has spread in the construction sector and among the general public. These movements are drivers for the adoption of solar envelopes, and are often rewarded when it comes to decentralized green energy production, energy savings, black-out security and user comfort. Simultaneously, the building construction industry, especially building designers, are gradually becoming more aware of the possibilities offered by solar envelope solutions and more informed on the options viable for new constructions and retrofitted buildings. This progress is possible also thanks to the dissemination activities promoted by IEA.

\section{What future trends can be highlighted for solar envelope systems?}

A few significant development trends are identified, thanks in particular to the Task's review of products being studied and tested in laboratories that will be reaching the market in the coming years.

- New materials and applications: new materials entering the market are driving product innovation. For example, high-efficiency polymers are now used as absorbers in AVENTA building-integrated collectors and light shifting species in Semi-transparent luminescent BIPV windows. The progress in solar façade technology, however, doesn't stop with innovative materials, it also is pushing advances in the manufacturing and assembling of existing materials resulting in the development of new concepts, improvement of existing technologies and design of new applications from old concepts: an example is the use of solar envelope technologies for daylight management and electricity or thermal energy generation in residential to commercial sectors.

- Adaptivity: many solar envelope solutions can adapt their behaviour or characteristics to the local climatic conditions. The adaption process can be intrinsic and extrinsic and it occur at very different timescales, i.e. from seasonal processes (Summer Garden, GAP:skin facade), to instantaneous processes (LCW switchable windows). In doing so, they create a balance between offering opportunities for energy savings and improvements of the indoor environmental quality.

- Multifunctionality: a prevailing trend in façade technology is multifunctionality, where the envelope element is designed to be more than the barrier from the external weather and is invested with additional functions. Most of the solar envelope concepts analysed in SHC Task 56 integrate RES generation or advanced daylight control and solar protection. In some solutions this is pushed even further by replacing (part of) the building's central services, such as the artificial lighting system (Facade-integrated micro-optics) or entire parts of the HVAC system (SunRise façade).

- Prefabrication: the practice of assembling a variety of components on a structure at the manufacturing site is one of the most common practices in the analysed solar envelope solutions. Compared to traditional construction methods, prefabrication offers many advantages, such as the reduction of the construction/renovation time, the reduction of the cost of the manufacturing process and a better product quality. These aspects are particularly relevant since installing solar components in the envelope structure onsite would require multiple professionals (i.e. façade installers, plumbers and electricians) to cooperate at same time. Thanks to prefabrication, this can be carried out by trained technicians in controlled industrial conditions.

- Automation vs passive approach: the operation of several elements in an integrated solar envelope system is performed by automatic control logics based on a variety of inputs (e.g. indoor air temperature, solar irradiation, occupation) integrated at the component level, at the room/floor/building level or even at the multibuilding or cluster level, depending on the solution. Relevant examples are Kindow sun-tracking verticals and roller blinds and Solar Thermal Venetian Blinds. In some cases, as for SmartSkin, the envelope component becomes a data source for a smart management of the building, from the HVAC system to automated blinds. 
At the same time, in the exact opposite way, there is a trend toward completely passive components (for example Okalux, Okasolar 3D, DARE-Daylight redirecting film and Gap:skin facade) that once installed do not require any type of active control and do not include any actuator. Such solutions are usually advertised as low-tech, self-regulating and low/free maintenance. Being completely passive, they are usually durable and not subject to users' possible misuse.

- Architectural integration: as highlighted by many producers, architectural integration (appearance and design flexibility) is key for acceptance in the building sector. To appeal to architects and building designers many solar envelope producers (for example Kromatix, SolarWall, MatrixAir, SunERG X-Color) are investing in products that offer a range of colours, installation options and sizes (or even textures, transparency levels and materials) to allow for both seamless integrations and stand-out installations. In this sense, BIPV is a good example of how industry is evolving to meet the demand of architects and building designers for architecturally integrated solutions. In some other cases, the issue of aesthetics is overcome with (almost) invisible products (Active insulation, SmartSkin, Micro-optics) that cannot be distinguished from traditional construction materials and solutions. 


\title{
Solar Energy Harvesting Systems
}

\section{Commercial systems}

\author{
SolarWall® Heating Systems \\ by John Hollick, SolarWall, Canada
}

\section{Product description}

\section{Brief concept description}

SolarWall heating systems heat air used for ventilation and heating of buildings. SolarWall consists of a perforated metal panel absorber that is integrated into sun facing walls of large buildings and connected to the heating ventilation fans. The system has been available since the 1990's, with particularly positive results in climates where space heating represents a large share of the building's total consumption.

\section{Architectural and technological integration into the envelope}

SolarWall is a building integrated solution and, once installed, resembles other typical metal wall facades. The metal panels are spaced out several centimetres to create an air cavity with the main wall. This air cavity is then connected to the building's ventilation fans or HVAC units. The solar panel components are assembled on site to suit the existing wall dimensions and openings such as windows and doors.

The air collectors are unglazed or partially glazed depending on the desired temperature rise. The unglazed wall sections offer architects the ability to select from a range of dark colours, with black and dark brown being the most popular. Experience gained from thousands of installations over two decades shows that the durability and aesthetics of the wall are key factors in deciding whether to proceed with a solar heating technology. The ability to work with colours and shapes appeals to the design community for many higher profile buildings. Building integration allows the solar heating system to blend in and not become an eye sore. Some clients have resorted to including logos or sun images on their walls to identify it as being a solar heating wall rather than just another wall.

The air collectors have virtually no maintenance, which is especially relevant considering the long-term operation of such systems, typically several decades.

\section{Integration into the building: system and comfort}

All projects require coordination with the designers and installers for the panels, mechanical equipment and controls to achieve complete integration into the building and its heating and ventilation and controls systems. The SolarWall systems are daytime heaters using the solar energy when available. Heat storage is not generally an option due to higher costs and the fact that most commercial, industrial, school and government buildings have minimal occupancy at night. It is necessary to have auxiliary heat in buildings. The solar heat is programmed to be the first choice followed by the auxiliary heat when solar is insufficient to meet demand. Typical overall energy savings with SolarWall are designed to be in excess of $20 \%$. However, some buildings have reported savings over $50 \%$ without heat storage.

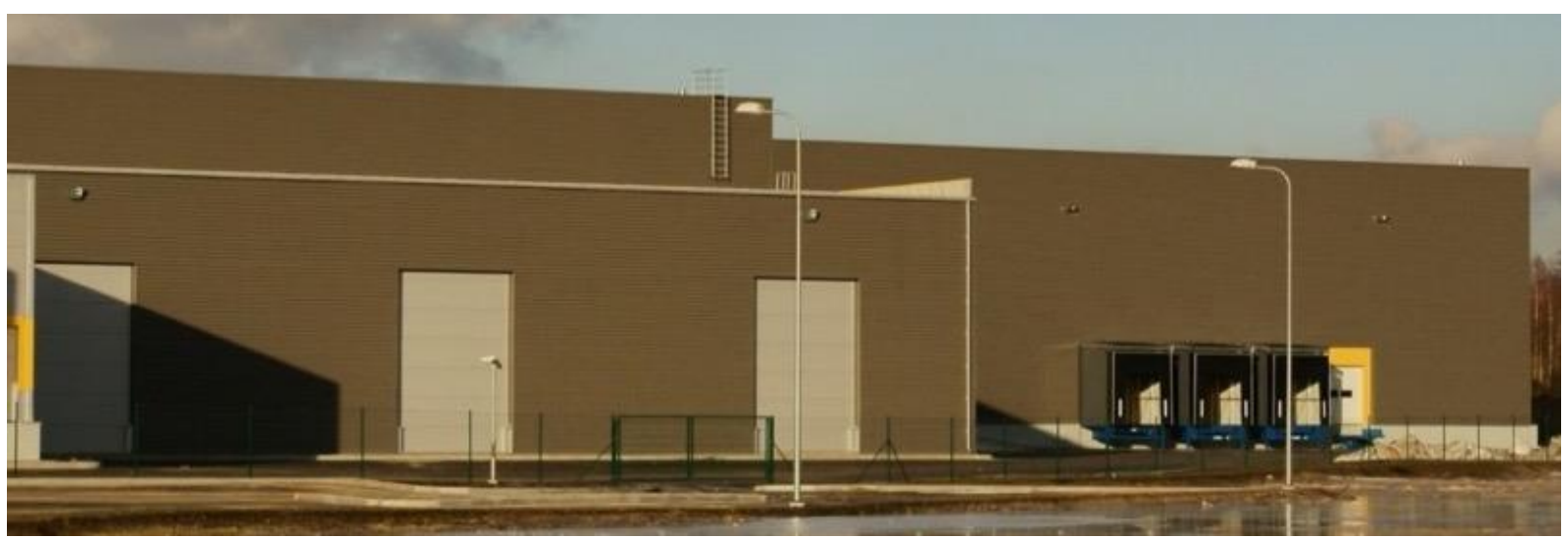

Figure 2. SolarWall installation on a warehouse in Latvia. 

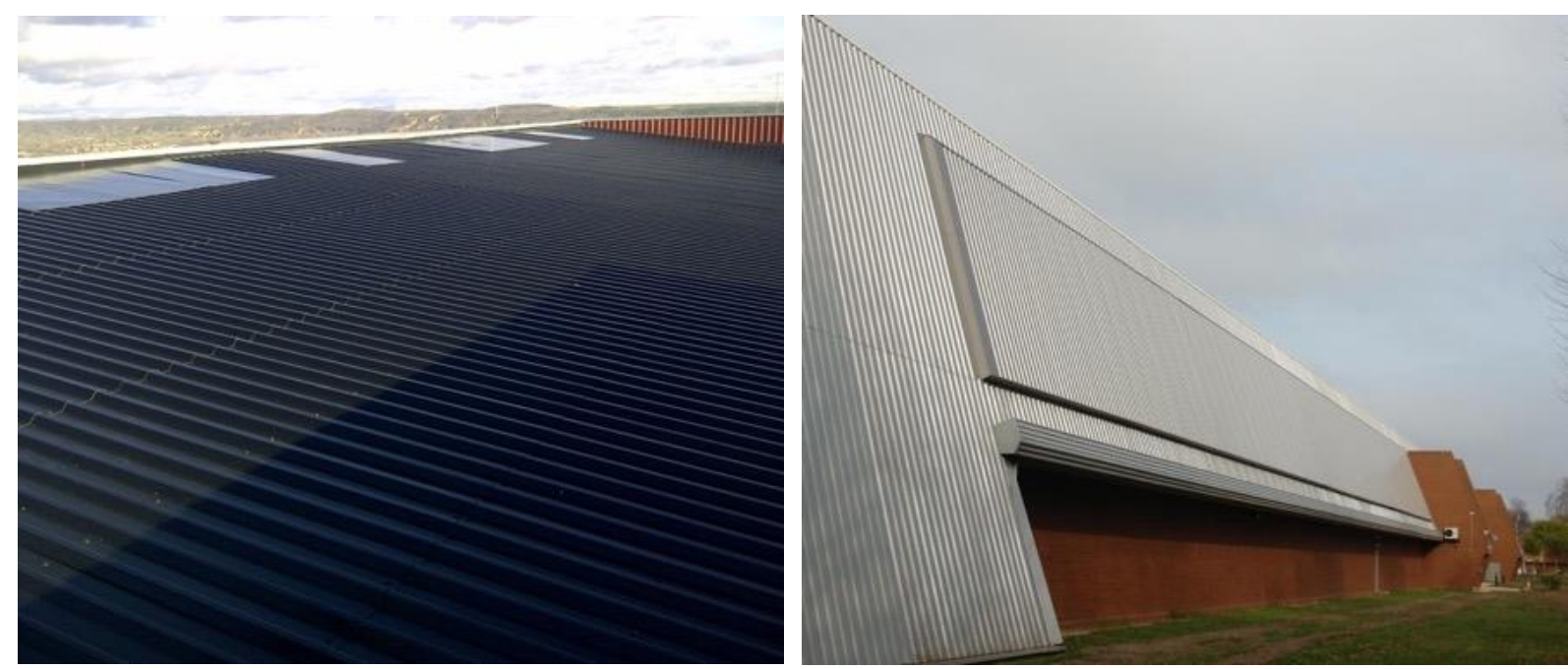

Figure 3. Roof-mounted SolarWall on a hospital in Spain (left) and Jaguar/Land Rover training centre in England with grey collectors to match the colour of the main wall (right).

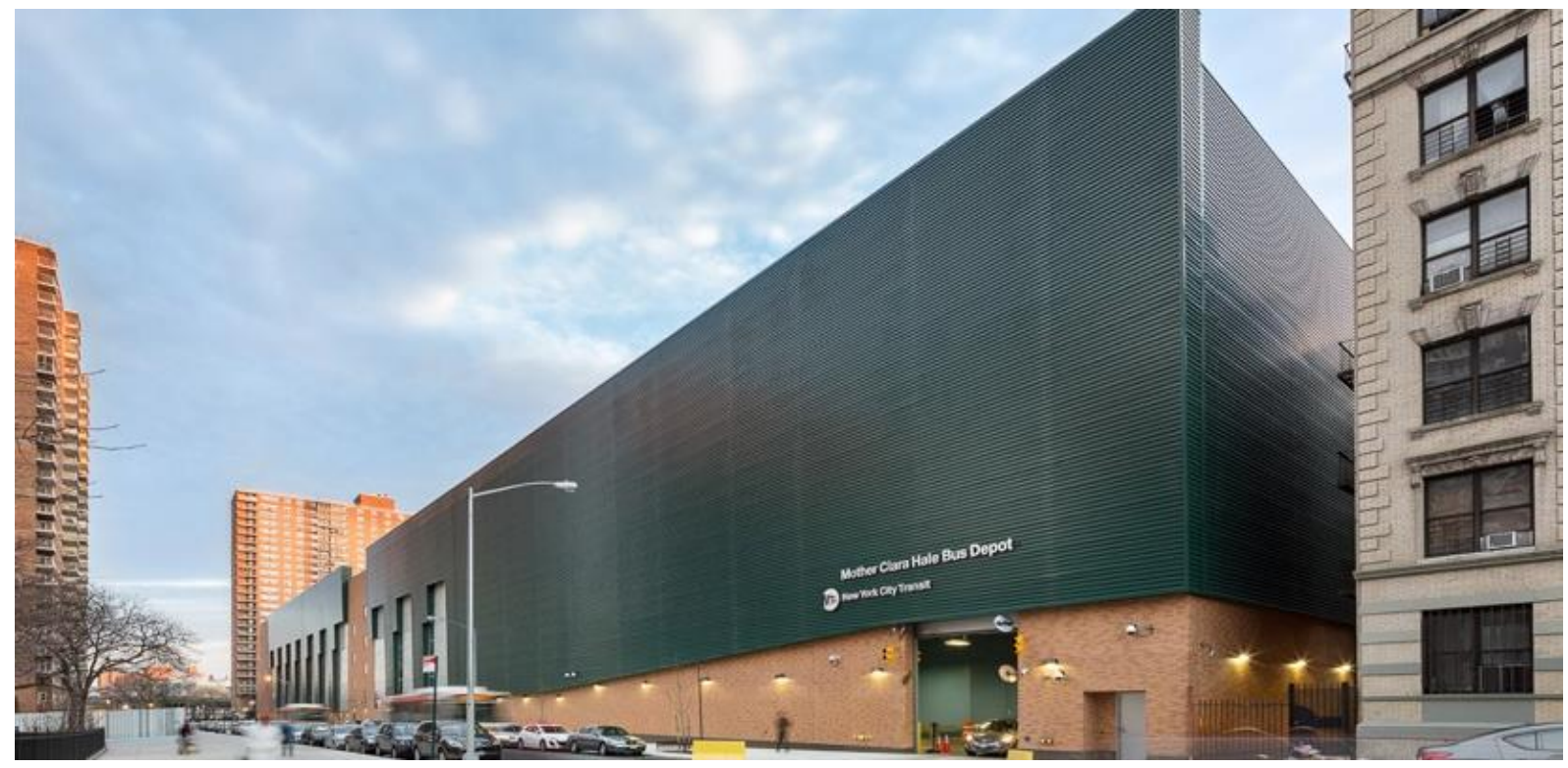

Figure 4. Dark green SolarWall collectors on three walls of a bus garage, New York City.

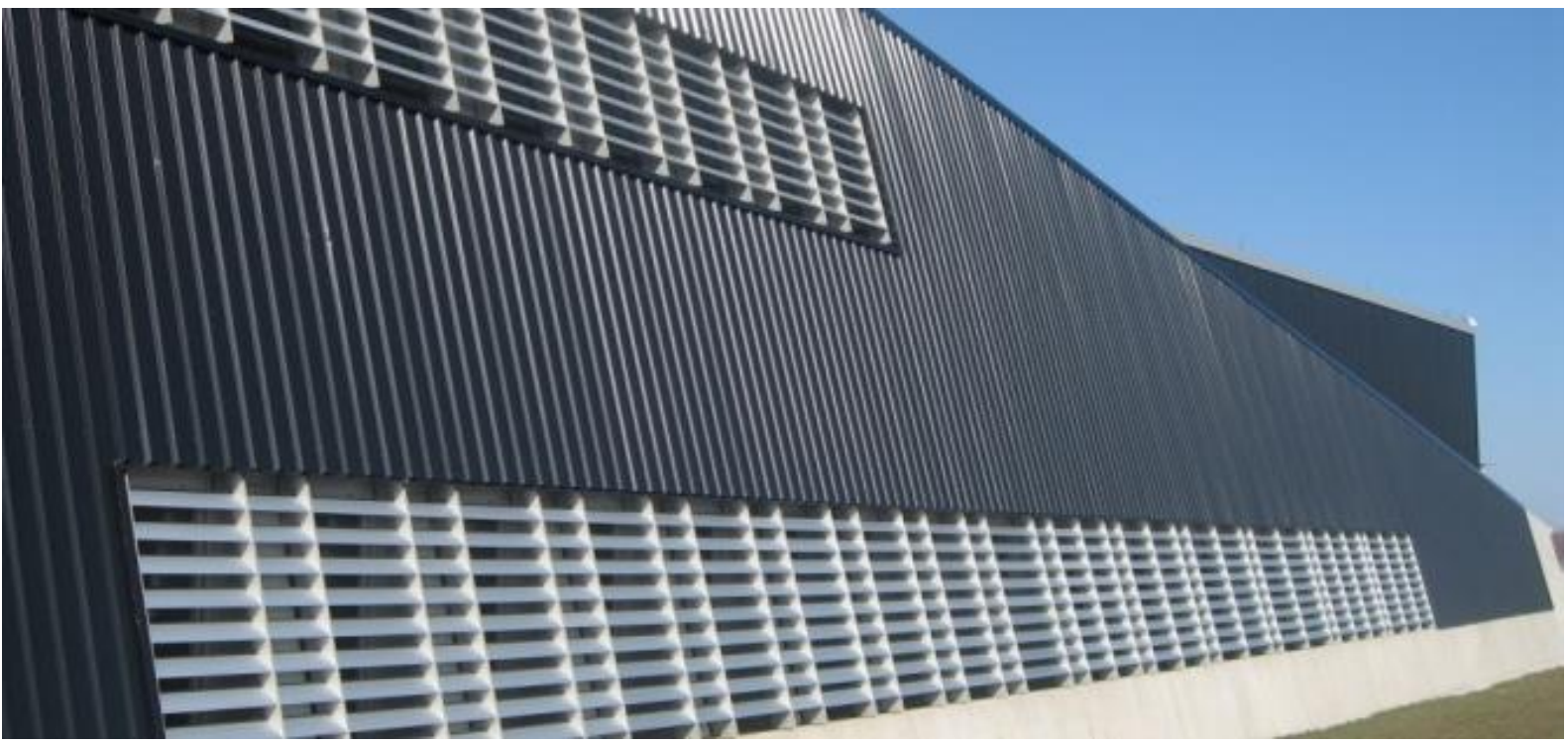

Figure 5. SolarWall installation on the Greater Toronto airport authority building, Canada. 


\section{SWOT analysis}

\section{Strengths}

- The system harvests solar heat with high solar collection efficiencies when the sun is shining and offers some solar preheating on cloudy days

- The solar collectors are architecturally integrated into facades and are available in various dark colours. The appearance resembles conventional metal walls

- The system utilises the existing wall for structural support and as the back side of the air cavity, achieving cost savings

- The air collectors are easily erected on site by metal wall and roof installers

- There are no snow accumulation issues

- No maintenance on the wall system is needed

- It is a proven technology installed on thousands of buildings since 1990

- The integration with the building automation controls is easy

- $\quad$ The upfront investment (cost per square meter) is lower with respect to solar liquid or PV collectors

\section{Opportunity}

- Awareness is growing in the building and design community about the topic of solar air heating

- The payback time is particularly favourable if the existing heat source is expensive

- Solar air heating can be easily included in energy simulation programs to be considered as a solution for meeting renewable targets for buildings

- Governments could include solar air systems in their incentive programs

\section{Weaknesses}

- Climates with a short heating season are less suited for solar heating applications

- It requires buildings with sufficient day time heating or ventilation needs, and is generally not suitable for residential homes

- It requires a sun facing wall with access to the ventilation heating system

- It requires custom design drawings for the integration into walls and the coupling with the ventilation system

- The installation of a glazing on the upper portions of the wall (2-stage system) is needed for high temperature applications

- There is no heat storage to cope with timeshifts between solar radiation availability and heating demand

- A bypass ducting is required to access to fresh air at ambient temperature when solar heat is not required

\section{Threats}

- Competitors might try to copy the panel construction without understanding the science behind the precision perforations in the panels

- Ventilation systems with heat recovery are competitors of solar air heating

- The cost of fossil fuels (e.g. natural gas) may remain low in the next years reducing the savings achieved with solar air heating

- Governments might abandon climate change concerns

\section{Lessons learned}

- $\quad$ Building-integrated solar technologies must be aesthetically appealing to be accepted by the architectural community.

- The initial approval or specifying person is normally the architect in new construction and the energy engineer in retrofit sales.

- Solar space heating is not included in many solar thermal programs which usually focus only on domestic hot water and not space heating.

- Heating buildings with air is not as common in Europe as it is in North America.

- Building integration requires more approvals in many countries than conventional solar panels which are not integrated into the wall or roof.

- Clients tend to prefer building integrated designs when offered a choice: architects want an aesthically appealing facade and have concerns with appearance of non integrated items such as solar panels.

\section{Further reading}

Company Website: http://solarwall.com/en/home.php 


\section{AventaSolar building-integrated collectors}

by Michaela Meir, Aventa AS, Norway

\section{Product description}

\section{Brief concept description}

AventaSolar collectors are building-integrated solar thermal panels that capture solar heat, which can then be used for domestic hot water preparation and/or space heating. The collectors are water-based and consist of a transparent cover and a structured hollow sheet of high-performance polymers used as absorber. As shown by Carlsson et al. (2014), the use of polymeric solar collectors offers better results in terms of Life Cycle Assessment (LCA) with respect to traditional solutions. Furthermore, AventaSolar collectors introduced the innovative use of high-performance polymers processed to twin-wall sheets: the process was demonstrated by Aventa and its partners worldwide for the first time during early 2010.

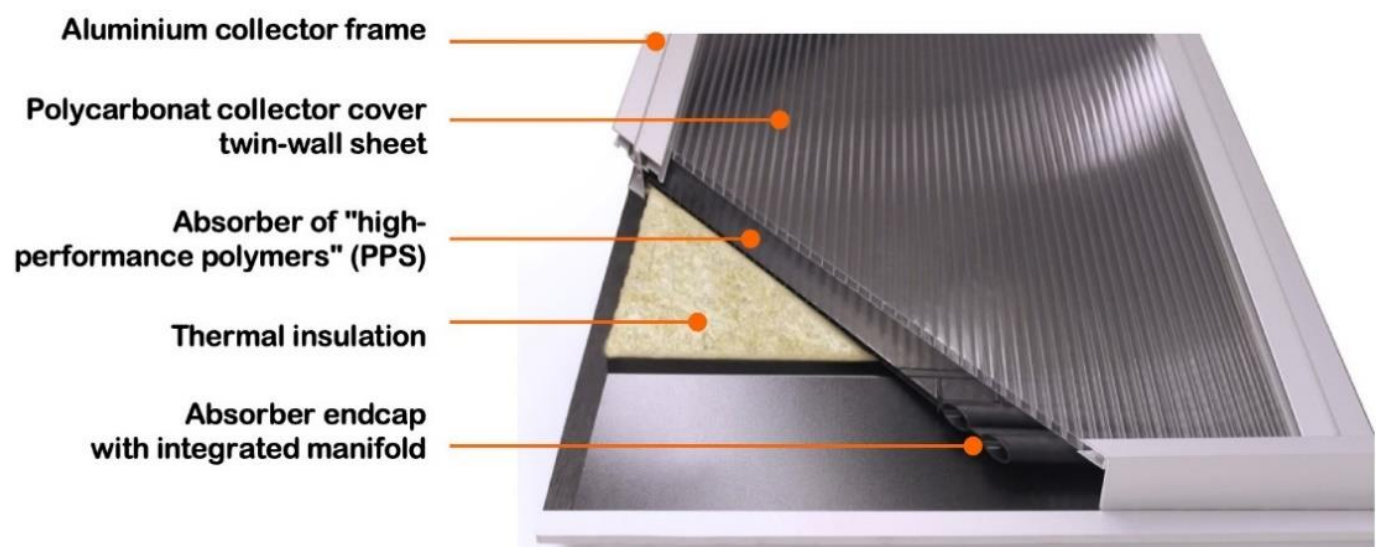

Figure 6. Cross-section of AventaSolar collectors.

\section{Architectural and technological integration into the envelope}

AventaSolar solar collectors are designed for building integration, since they are building envelope modules that replace regular roof or façade elements. AventaSolar collectors are available in different sizes and their installation can perfectly adapt to the building's envelope surface. The use of polymeric materials results in low-weight modules (approximately $8 \mathrm{~kg} / \mathrm{m}^{2}$ ) that are easy to handle and position. The installation can be carried out by any skilled building envelope installer without cranes or special equipment other than what is normally available on a building site, allowing to achieve time and cost savings.

\section{Integration into the building: system and comfort}

AventaSolar systems can be used in different scales, from small tap-water systems for private houses to large industrial or institutional systems. Preferred applications are in buildings with high domestic hot water demand and/or low temperature heating, such as hospitals, sport facilities, schools, multi-apartment buildings, row or single houses with floor heating. AventaSolar collectors are integrated to drain-back systems (shown in Figure 9), and pure water is used as heat carrier in place of a water-glycol mixture. With this solution, the use of a heat exchanger between collector loop and thermal storage is avoided and the overall hydraulic design is simplified since the collector circuit is open to atmospheric pressure. The solar system is automatically operated by means of a pump controller: water circulates in the collector loop when solar energy can be harvested but drains back to the thermal storage during system standstill to prevent overheating or freezing.

The overall concept is a considerable step forward to demonstrate that an aesthetic and easy integration of solar thermal solutions into the envelope is possible: the dimensional flexibility, the simple and non-pressurized hydraulic design, the use of standardized plug-and play components together with an appealing design allow AventaSolar collectors to overcome many of the barriers that hinder the spread of building-integrated solar thermal technologies. 

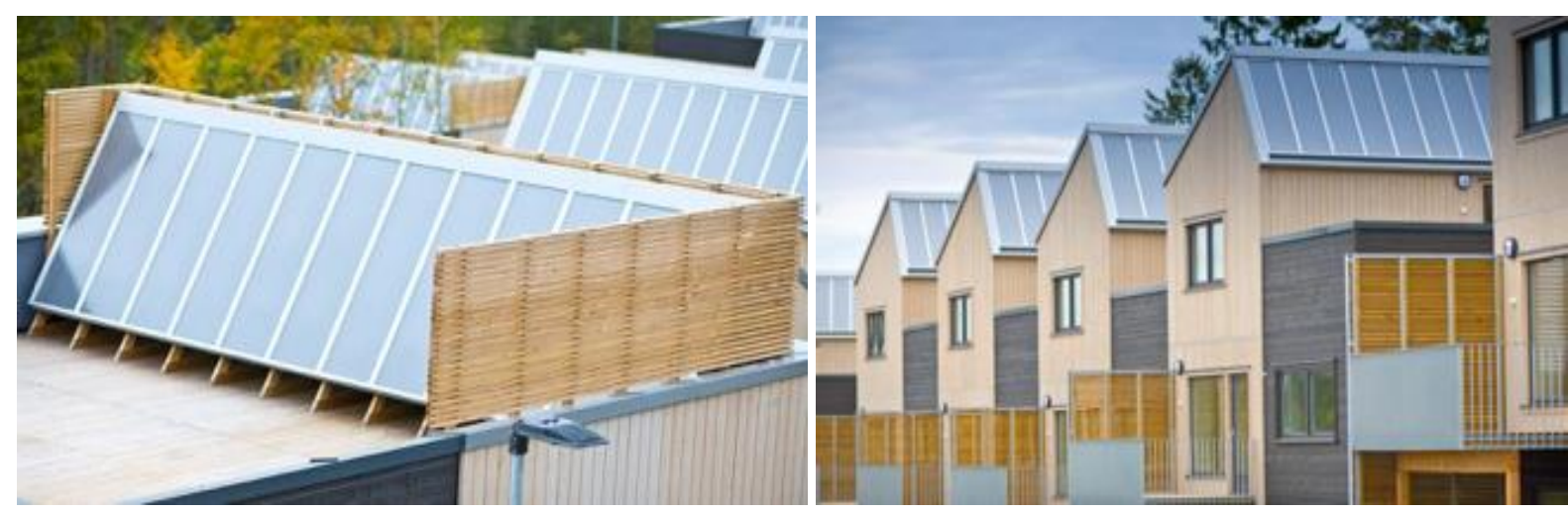

Figure 7. Roof-integrated AventaSolar collectors in a passive-house estate, Oslo, Norway (Photo: H. Kicker, JKU, Austria).
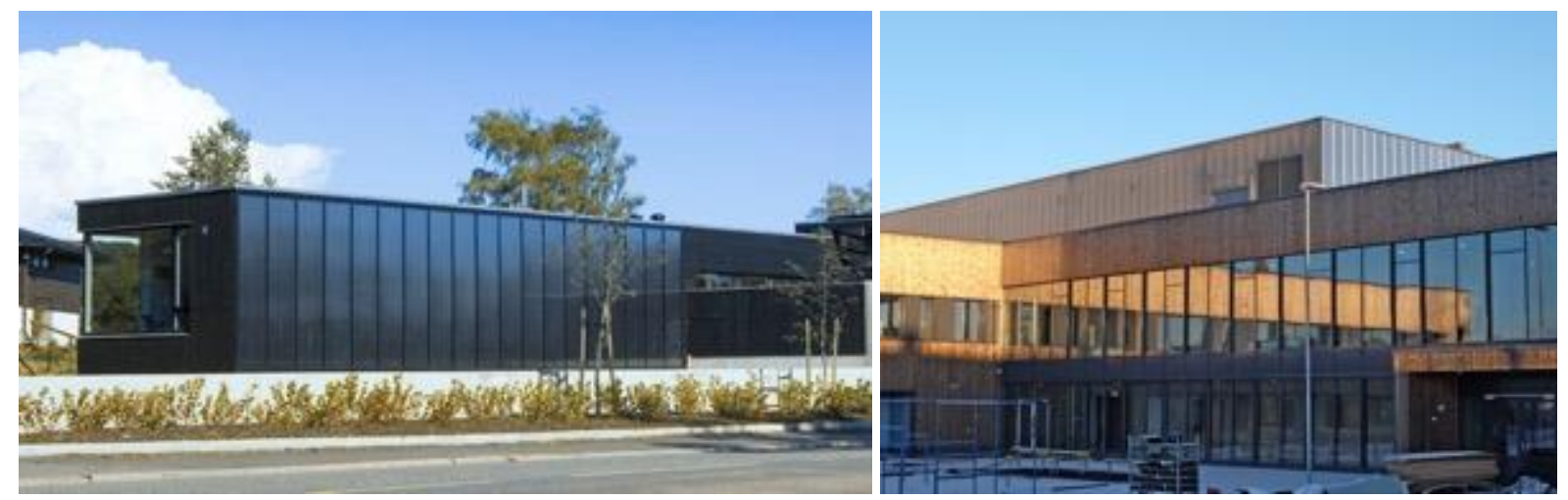

Figure 8. Facade-integrated AventaSolar collectors: installations in a multi-family atrium house (solar combi system and sound protection wall) on the left and on a school (DHW preparation) on the right.
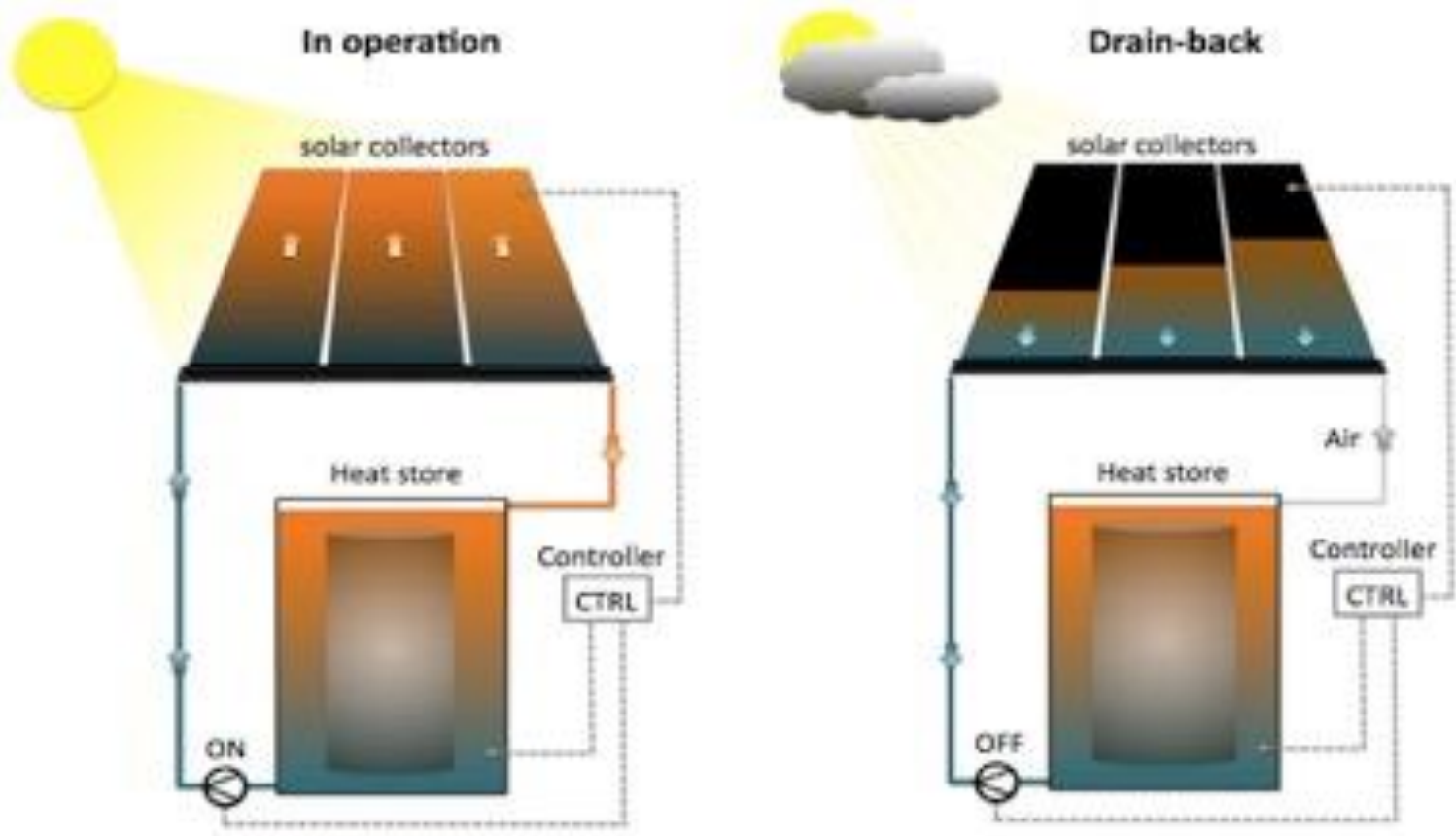

Figure 9. Schematics a drain-back solar system during operation (on the left) and standstill (on the right). 


\section{SWOT analysis}

\section{Strengths}

- Modular design: the customisable length of the collectors allows an easy and architecturally appealing integration into roof and facade

- The low weight of the panels ensures a troublefree handling during transport and installation

- Cost savings are achieved thanks to the methods for processing polymer materials, the installation of non-pressurised collectors and the implementation of simple drainback loop design

- The installation of the panels does not require HVAC specialists, rather it can be performed by any skilled building envelope installer

- The use of pure water as heat carrier makes the solution more environmentally friendly

\section{Opportunity}

- Successful integration examples could inspire architects and decisions-makers to adopt this solution

- European directives and global agreements on lowering carbon emissions in construction sector are fertile ground for cost-effective RES solutions

\section{Weakness}

- Non-pressurised collectors are not directly compatible with conventional solar system components

- The drainback collector loop design in highrise buildings requires solar pumps with significantly higher electricity consumption compared to conventional solar thermal systems

\section{Threats}

- $\quad$ Non-pressurised collector and solar loop have yet to become very common and are met with scepticism by the heating industry

- Scepticism or little knowledge on highperformance polymers might hinder market penetration

- National or regional building regulations prevent the integration of certain polymeric materials into the building envelope

\section{Lessons learned}

- The integration of solar systems and related infrastructure in the envelope need to be planned early in the building design process.

- Planners, architects and building designers are keen on technologies that are modular and flexible in dimensions so that their integration into the building envelope is easier. In general, it is important that the solar envelope elements are designed to have similar weight and size as typical building envelope modules.

- Working in close contact with the building industry is an opportunity to optimize the workflows and achieve cost savings in the installation process of solar envelope systems.

- There is still little knowledge about solar technologies operation and performance.

\section{Further reading}

Carlsson B., Persson H. Meir M., Rekstad J. A total cost perspective on use of polymeric materials in solar collectors - Importance of environmental performance on suitability. Applied Energy 125 (2014) 10-20.

Köhl M. et. al. (ed.) (2012). Polymeric Materials for Solar Thermal Applications. Wiley-VCH Verlagsgesellschaft. ISBN 978-3-572-33246-5. 393 pages.

Company website: www.aventasolar.com 


\section{MatrixAir® Solar Air Heating}

by Brian Wilkinson, Matrix Energy Inc, Quebec, Canada

\section{Product description}

\section{Background}

Transpired solar air heating technology was developed in Canada. Early findings have led to countless design iterations, project demonstrations and system monitoring, numerous research studies and thousands of installations to produce today's state of the art systems which offer predictable energy savings for the preheating of ventilation air in all new or existing commercial, industrial, institutional and multi-residential buildings.

\section{Brief concept description}

While resembling conventional exterior metal facades, unglazed transpired solar collectors (TSC) use a buildings HVAC system to create negative air pressure used to pull air inside the building through a finely perforated, sunfacing metal absorber. TSCs are cost-effective, efficient, simple, aesthetically pleasing systems that require virtually no maintenance over their estimated 40-year useful life.

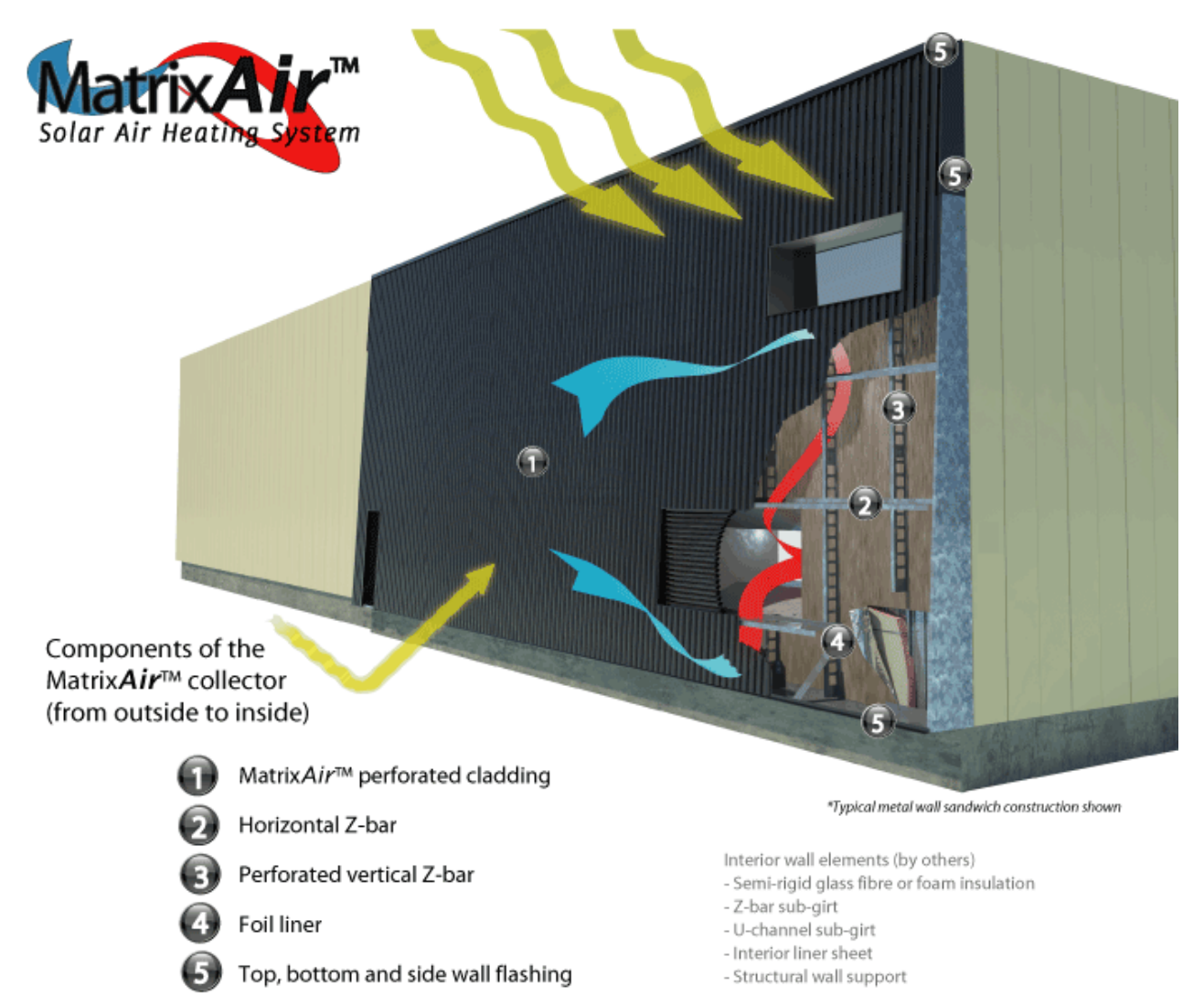

Figure 10. Close up of MatrixAir® absorber.

\section{Architectural and technological integration into the envelope}

MatrixAir $\circledast$ TR systems are specifically designed for harmonious building integration with a buildings' façade, blending seamlessly with its overall look and appearance. Systems may be as conspicuous or as inconspicuous as the building owner desires, since the exterior perforated absorber may be made using a variety of exterior profiles and dark colours and then site-installed in any orientation. Weighing $1-1.5 \mathrm{~kg} / \mathrm{m}^{2}$ of collector area, such systems are attached to the new or existing buildings' structure with a combination of vertical and horizontal framing components designed specific to each project. They also serve to create the air cavity in which the preheated air is collected and directed to the fresh air inlets. No special tools nor training is required of the exterior metal cladding contractors engaged to install such systems in accordance with the engineered MatrixAir@ installation drawings provided for each system. 


\section{Integration into the building: system and comfort}

In addition to its ease of architectural integration, transpired solar collectors work seamlessly with the buildings' heating, ventilation and control systems. Preheated air is ducted to the buildings' centralized HVAC system via equally spaced air outlets from the collector or via a top mounted plenum running across the top of the collector for distribution within the building. Motorized wall or roof mounted bypass louvers are activated for summer seasonal operation or when preheated air is not required.

Performance is susceptible to elevated ambient wind, thus unit air flow is an important design criterion. Façademounted, metal transpired solar collectors provide optimum return on investment when operated at flow rates of 75 to $165 \mathrm{~m}^{3} / \mathrm{h}$ per $\mathrm{m}^{2}$ of collector area; the higher unit air flows particularly suited to tall buildings such as multiresidential condominiums.

These are not stand-alone systems: while TSC's will cost effectively contribute $20 \%$ and up to $40 \%$ of the energy required for ventilation air heating providing a temperature rise of up to $25{ }^{\circ} \mathrm{C}$ over ambient temperatures, these systems will require an auxiliary heating source in most installations to ensure comfort of the building occupants.

On average, MatrixAir ${ }^{\circledR}$ systems typically yield 420 to $550 \mathrm{kWh} / \mathrm{yr}$ per $\mathrm{m}^{2}$ of collector area. Prefeasibility studies and energy savings estimates of the MatrixAir ${ }^{\circledR}$ solar air heating system may be made using RETScreen ${ }^{\circledR}$ software developed by Natural Resources Canada.

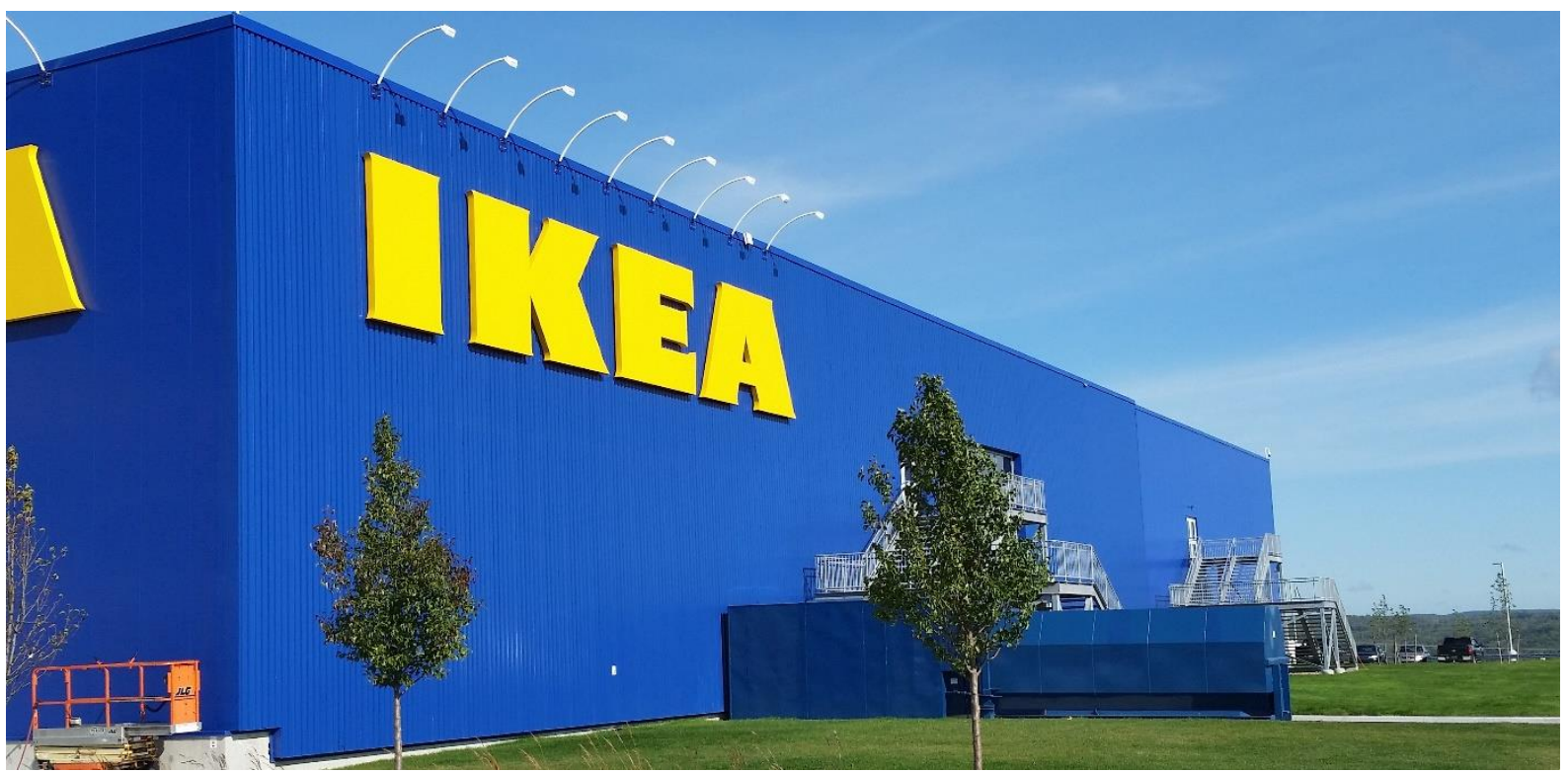

Figure 11. Installation on IKEA, Retail building.

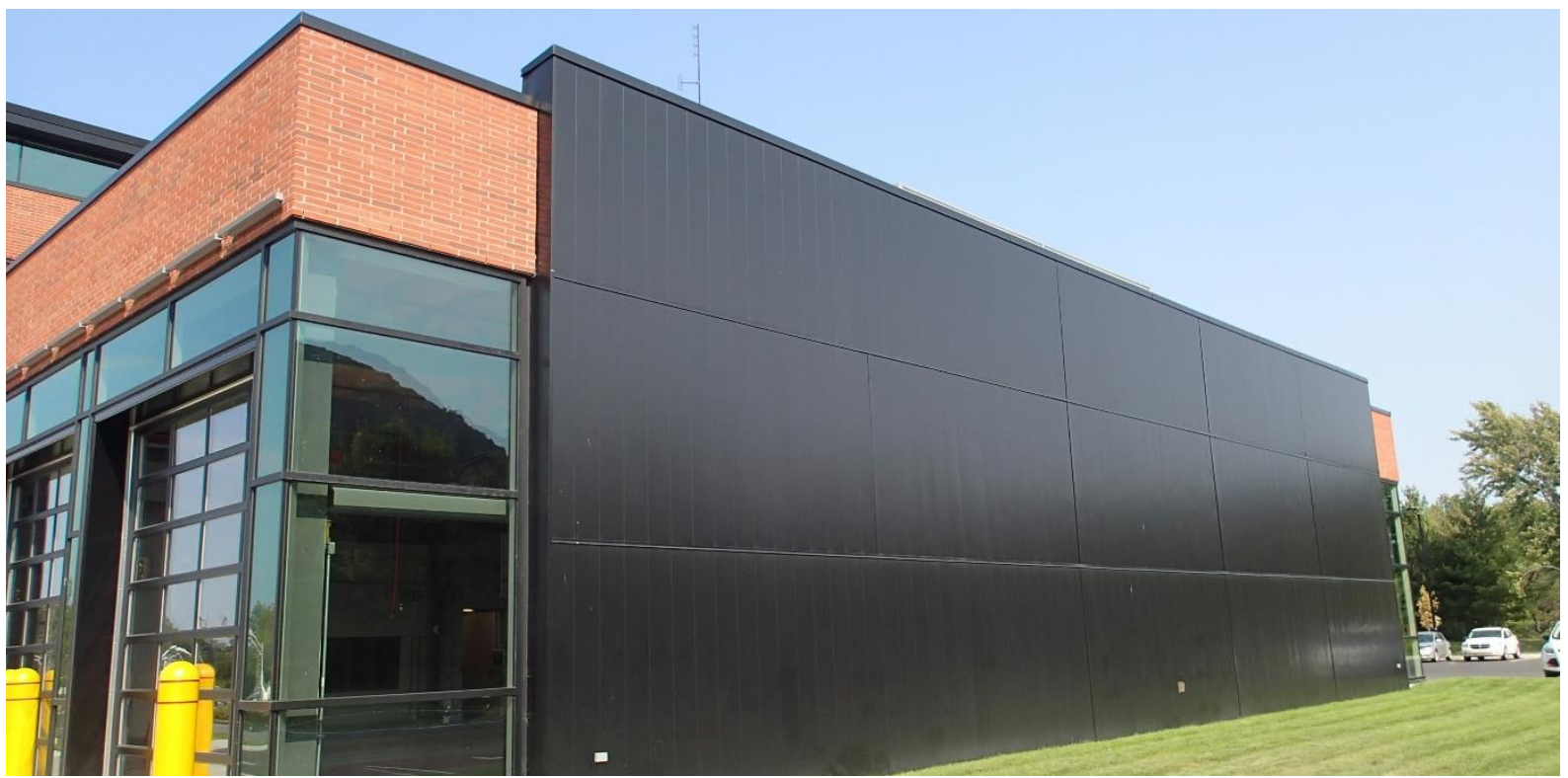

Figure 12. Installation on an emergency services and training facility, Municipal building. 


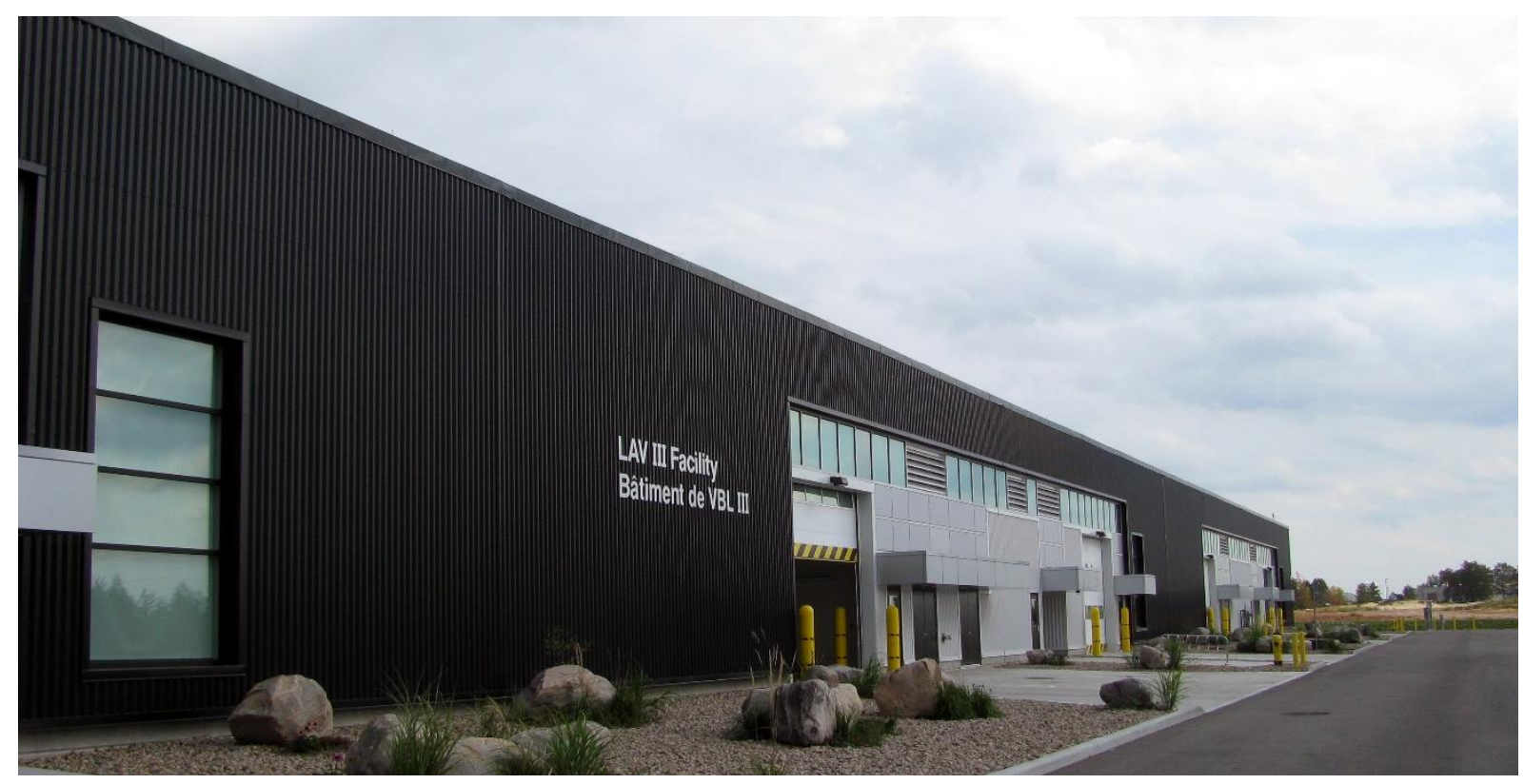

Figure 13. Installation on Light Armoured Vehicle Maintenance Facility, Military building.

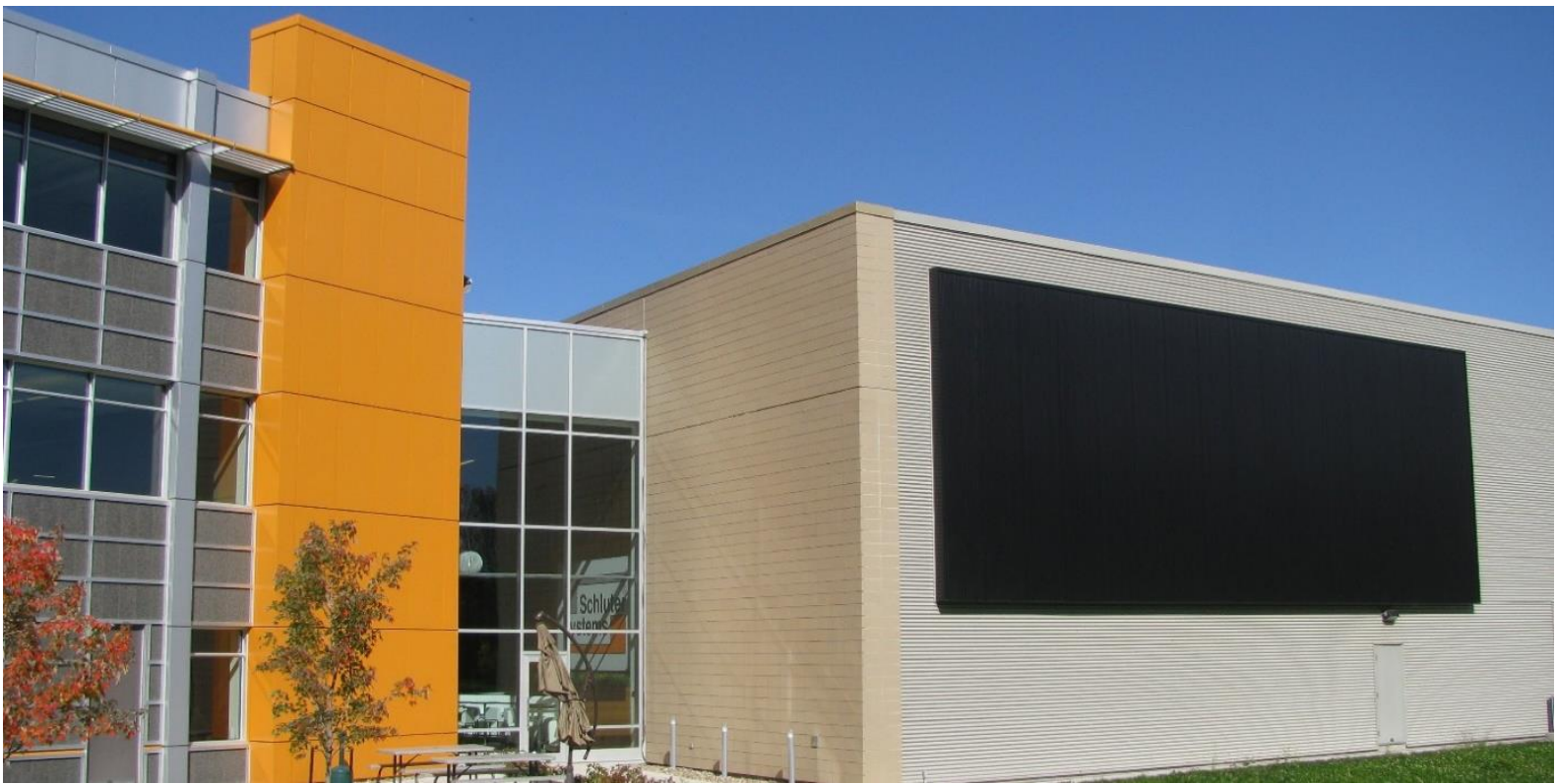

Figure 14. Installation on Schluter Systems office building, Industrial building.

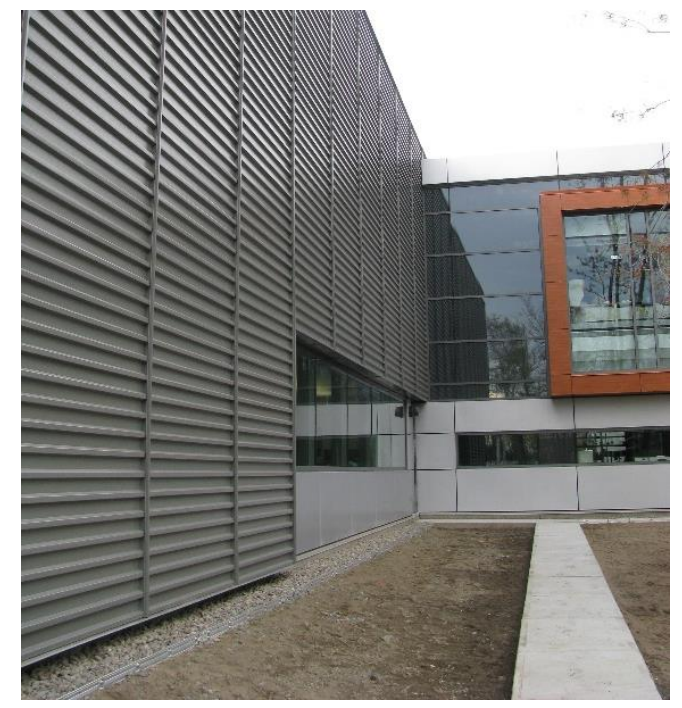

Figure 15. Installation on Quebec Animal Pathology Laboratory, Institutional building. 


\section{SWOT analysis}

\section{Strengths}

- The system is aesthetically versatile, with a simple design and several possibilities for customization

- It is a highly effective, low-cost and low-tech solution

- The system can be easily installed and integrated with the mechanical ventilation system

- $\quad$ Air filtration is induced by static electricity across the perforations

- The system is durable and has zero maintenance requirement as there are no moving parts other than the HVAC system to which it is connected

- It is comprised of recycled materials and can be easily recycled at end of use

- There is an extensive history of proven performance across a wide variety of applications

\section{Weaknesses}

- It requires auxiliary or supplemental heating system

- It requires south facing facades with negligible shading

- No thermal storage is available at this time to cope with time shifts between solar radiation and heating demand

- The colour choice is limited, as optimum system performance is coincident with dark absorber colours.

- Marginal operating costs are added to the HVAC system at higher flow rates due to higher operating static pressures

- It requires a proper design, installation and HVAC integration for best performance

\section{Opportunities}

- It is applicable to all buildings in the commercial, industrial, institutional and multiresidential markets in cold climates

- It is applicable to new or existing buildings

- Solar air heating may be integrated with other heating technologies such as heat recovery, geothermal and photovoltaics

\section{Threats}

- Ventilation integrating heat recovery is a competing technology

- The simplicity of design leads to naïve, inexperienced competition

- Low awareness about solar air heating might hinder the success of this kind of solutions

\section{Lessons learned}

- Transpired solar collectors (TSC) are a deceptively simple, effective, highly efficient and long-life solution for fresh air heating. However, their optimum performance is only gained via sourcing through experienced, TSC manufacturers offering independently certified products.

- Awareness of building integrated TSCs and their design for optimum performance amongst building professionals building owners remains low.

- The integration of TSCs with mechanical systems and the building's architecture is uncomplicated and straightforward when addressed during the initial stages of building design or renovation.

- The incremental cost of the TSC systems should only be used to gauge their simple return on investment.

- In new construction in particular, careful attention to the type and installation of the membrane used to separate the insulation from the preheated air cavity is required.

- While TSCs require no maintenance, and their perforated absorbers may be installed in any orientation, practice has shown that horizontal profiles do tend to accumulate more dirt and dust, than do vertical or diagonally installed absorbers, which may therefore impede their energy output.

- As ambient wind has considerable impact on their performance, TSCs installed in windy locations, or those installed on taller buildings should be designed at higher unit air flows per collector area for maximum cost efficiency.

\section{Further reading}

Company website: www.matrixairheating.com 


\section{Kromatix}

by Rafic Hanbali, Swissinso SA, Switzerland

\section{Product description}

\section{Brief concept description}

Kromatix modules are BIPV panels available in different sizes and colours. The physical vapor deposition on solar glass with specific atomic designs allows to produce coloured solar glass that can be coupled with any type of PV technology. The treatment of the outer glass surface results in diffused reflection, which prevents glare effects, masks PV cells and bus bars and offers a pleasant visual effect. The modules are designed for a full integration on buildings' facades and roofs, and guarantee high aesthetics, efficiency and durability.

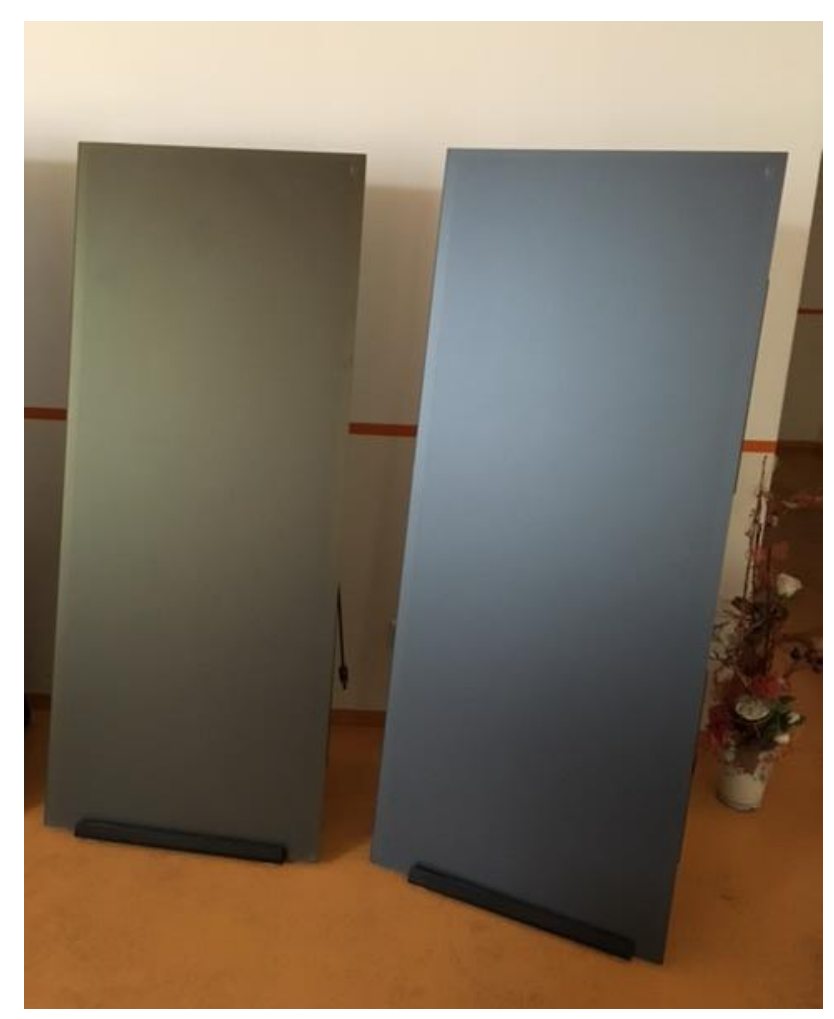

Figure 16. Kromatix modules, CIGS solar cells, grey and gold.

\section{Architectural and technological integration into the envelope and building}

Kromatix panels are fully integrated in the buildings' envelope and replace traditional façade materials with the additional benefit of producing electricity from solar energy. Kromatix panels are cut-to-size for each project so to guarantee a full geometrical design flexibility. Kromatix modules are available in a variety of colours (grey, blue, bronze, brass etc.) and offer a very eye-appealing appearance as they seem to change in colour based on the viewing angle, providing to viewers a pleasant dynamic effect. Durability and maintenance costs are the same as those of a normal passive glass façade.

The design of the modules is studied so that functional and performance requirements imposed by both construction regulations (for example fire regulations, glass thickness, wind load) and PV regulations are met. BIPV norms are written or in adaptation in different countries. Kromatix panels are installed as normal passive façade elements on a metallic sub-structure that supports the single envelope elements. The electrical cables need for the operation of the collectors are fixed to the sub-structure. The BIPV installation is completed by the connection to a solar inverter and an electricity meter. 


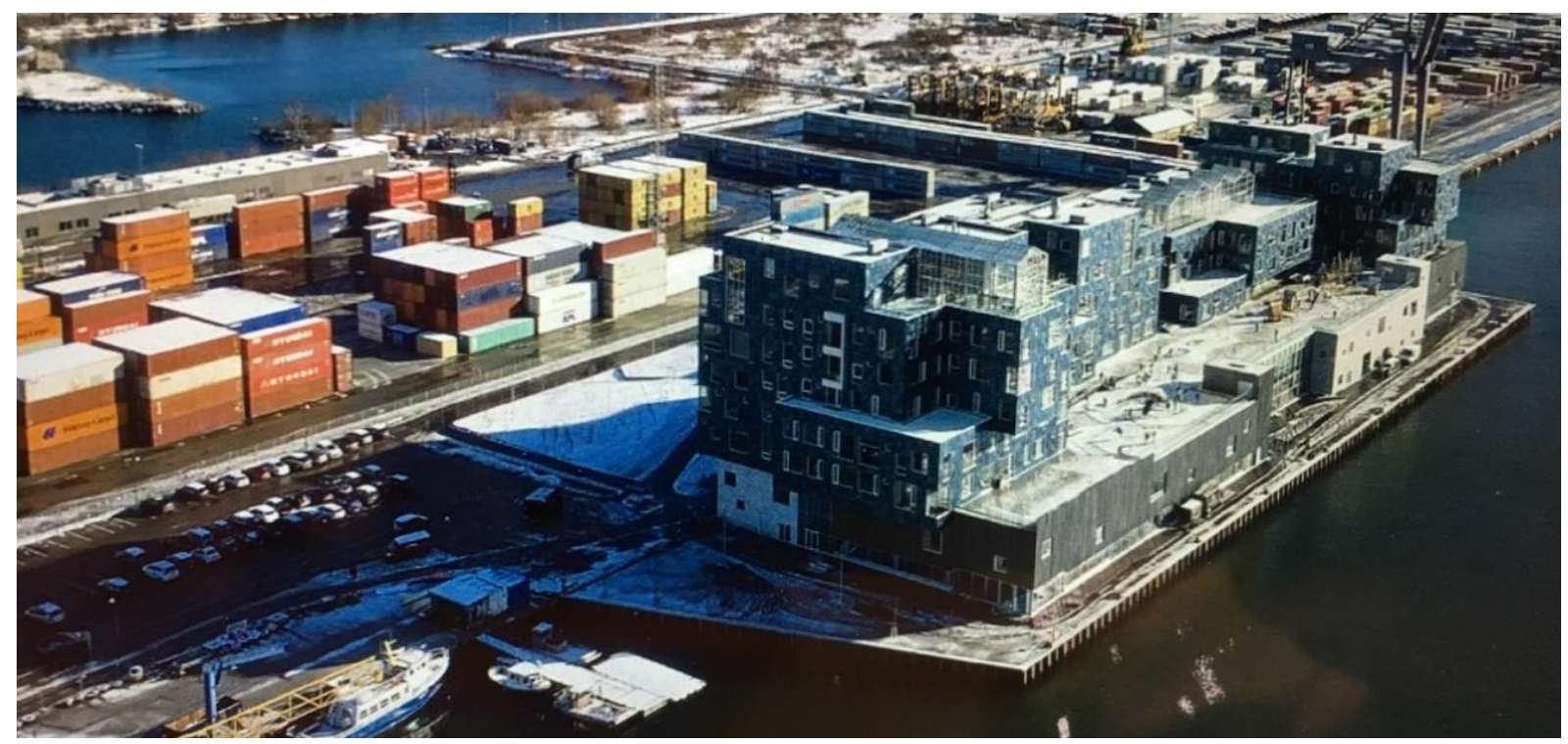

Figure 17. Kromatix installation at Copenhagen International School in Copenhagen, Denmark.

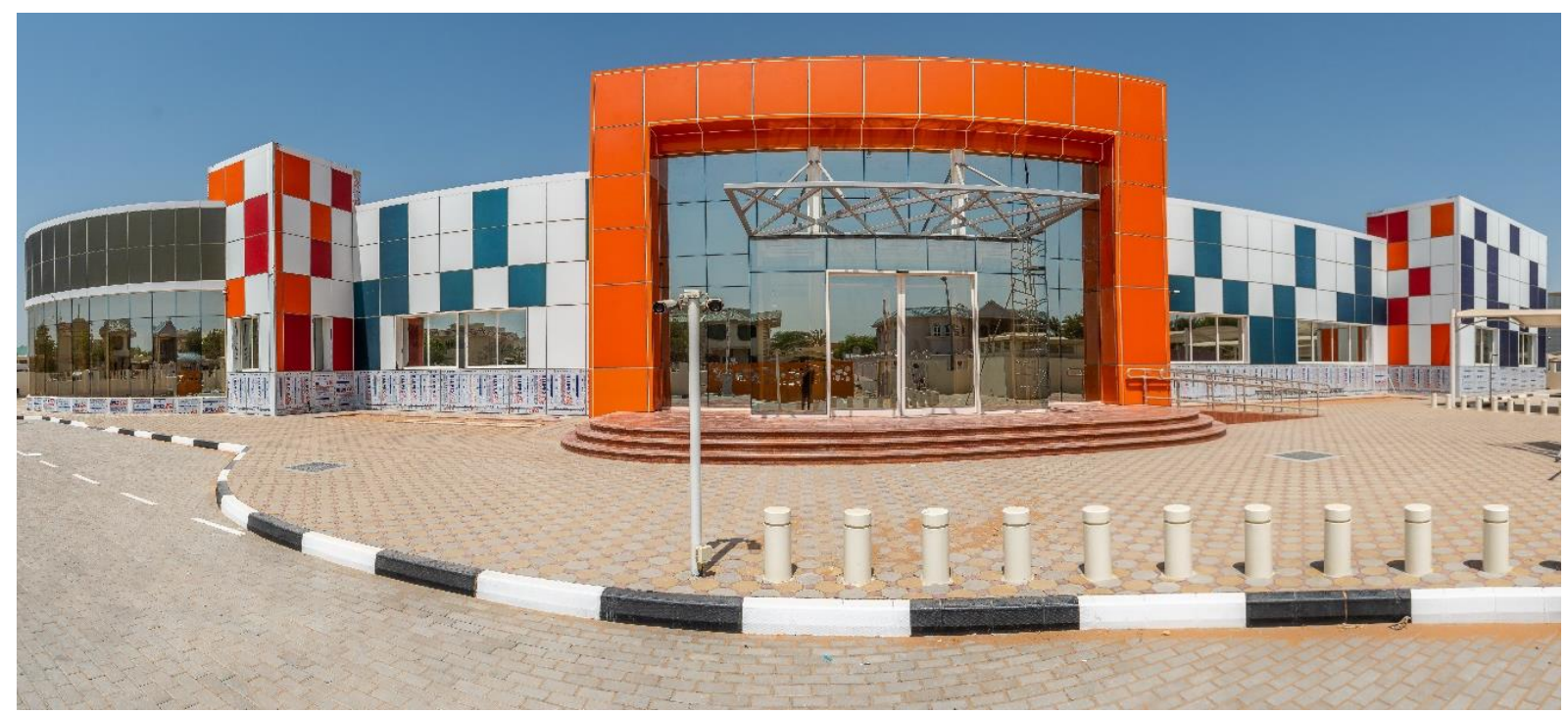

Figure 18. Kromatix installation on the façade of a kindergarten in Dubai, UAE.

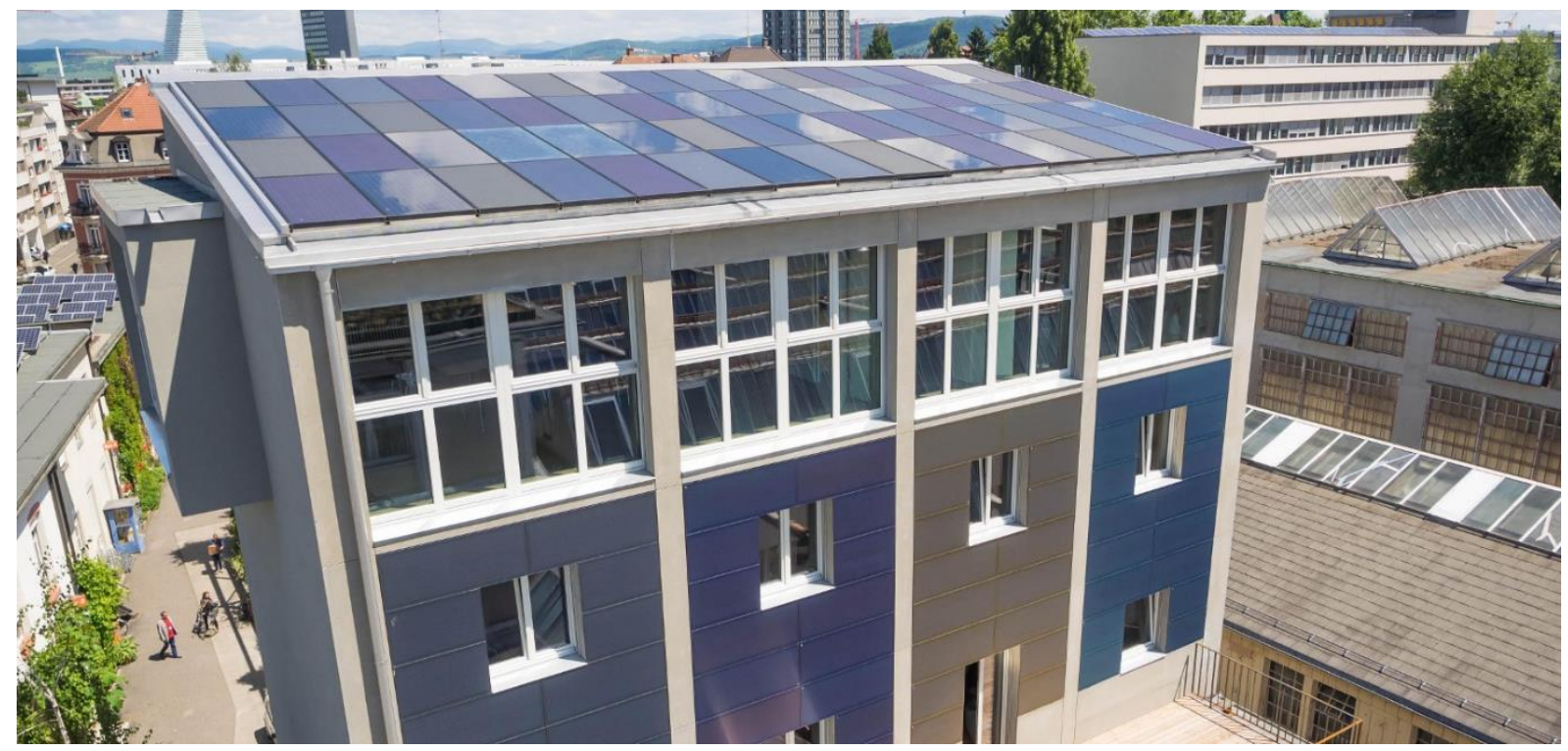

Figure 19. Redevelopment of a coal silo in Basel, Switzerland. 


\section{SWOT analysis}

\section{Strengths}

- It enables to harvest solar radiation and produce electricity with a high conversion efficiency

- It substitutes the normal passive facades for a modest additional cost

- It has a very eye appealing appearance

- Maintenance and durability are close to that of a passive glass facade

- It has proven to be a good investment (excellent ROI)

- Electricity is produced directly on site and no longer needs to be transferred from far production sites

\section{Opportunity}

- The market for this solution is large, as it can be applied to both new and refurbished buildings

- $\quad$ The legislation for green buildings imposed by more and more countries can boost the use of this kind of solutions

\section{Weaknesses}

- The investment cost is higher compared to passive solutions, which is a key factor for certain areas in the world

- The design phase for buildings is longer than for non-integrated solar solutions, such as roofs or ground-mounted solutions

\section{Threats}

- Solar envelopes encounter barriers in entering the construction industry market due to a lack of knowledge of the main actors (architects, contractors etc.) on how to handle installation, static calculations and electrical connections

- In certain countries, the legislation relevant to BIPV is not clear with regard to both construction-related aspects (wind load, fire regulations etc.) and electrical connection possibilities (on grid, self-consumption and net-metering)

- Competition from other technologies (solar glass with colouring pigments) is starting to show

\section{Lessons learned}

- The type of PV technology to be used may change from project to project (crystalline, back-contact, CIGS, CdTe, half-cells, smart-wire etc.) as the most convenient solution is realized. A key feature of Kromatix is it is about transforming the glass and thus it can be coupled with any PV technology and even with passive dummy modules installed in non-productive areas of the building.

- Clients show to be more sensitive to some arguments than others. From the past projects, it is found that generally speaking the priorities are usually aesthetics of the solution, possibility to create a green building (can be mandatory by law), costs and energy efficiency. This order can change case by case, also in reference to the geographic region. 


\section{Coloured BIPV panels (SUNERG X - Color)}

by Martin Dietz CEO, Solar Lightning Consultants ApS, Denmark

\section{Brief concept description}

The SUNERG X - Color Monocrystalline module, produced by the Italian company Sunerg, is a custom-made BIPV panel suited for both roof and facades applications that is available in a range of colours. Such solution targets a niche market where blue polycrystalline or black monocrystalline modules cannot satisfy aesthetics requirements due to colour and offers instead a range of options (mahogany brown, reddish brown, bottle green and black-grey) that can better match the architectural vision and the design of the building. The PV modules are produced in a standard size (275 Wp) with an aluminium frame and back sheet in the chosen colour.

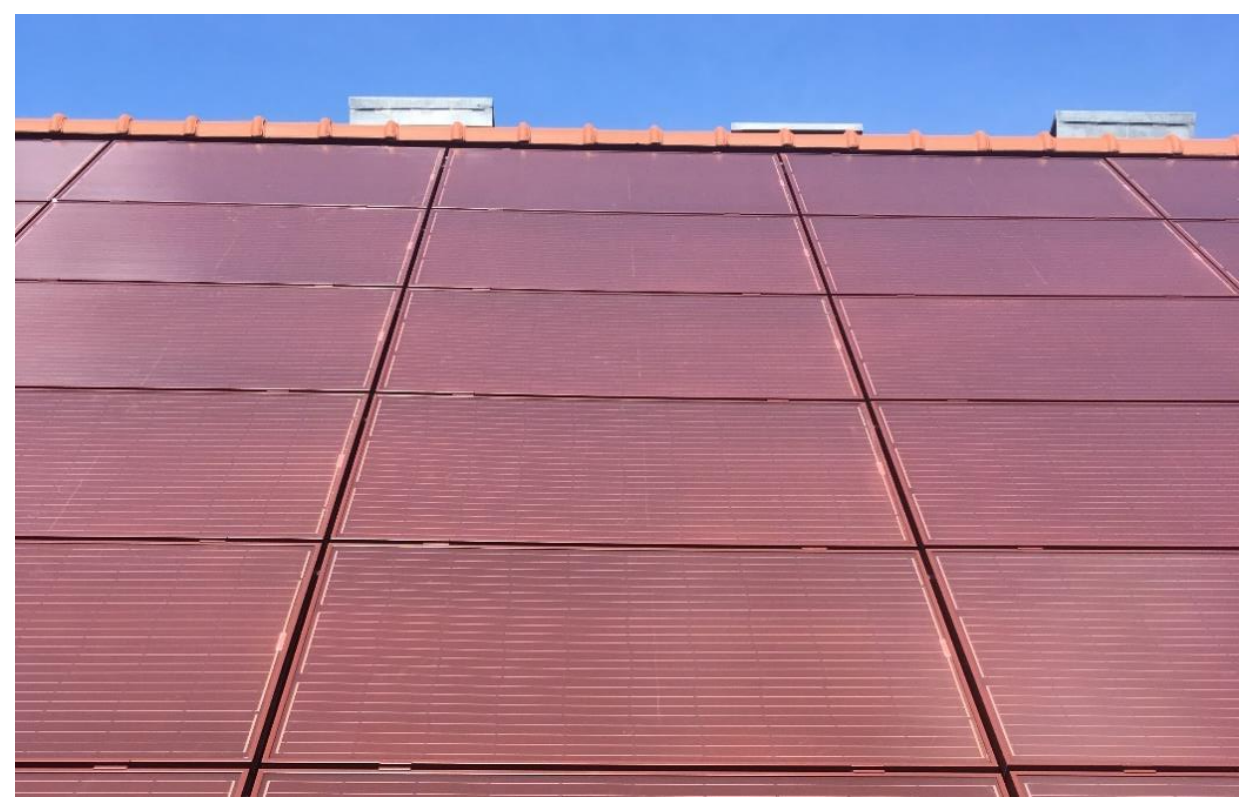

Figure 20. SUNERG X-Color monocrystalline modules in roof application, colour of the module: chestnut brown (RAL 8015) (Source: Solar Lightning Consultants ApS - Architect Martin Dietz (C)).

\section{Architectural and technological integration into the envelope and building}

SUNERG X - Color is available in a range of colours to match the design of the envelope where they are integrated. It is possible to have frames, clamps, cable box etc. coloured as the BIPV panels to achieve better aesthetics and a seamless integration. To add more flexibility, special dummies with mono cells and the same coloured glass, frame and back sheet can be attached to the envelope and adjusted to the size and dimension of the roof / BIPV design. Such dummies are not connected to the grid but have the same appearance of the other BIPV modules. Durability and maintenance cost are similar to that of a normal passive glass facade.

For roof applications, two kinds of envelope design approach, can be chosen: (A) full BIPV integration or (B) integration of the BIPV modules, where PV modules are installed in an "floating architectonic structure" on top of the roof (waterproof asphalt roofing underneath).

Concerning the technological integration into the envelope, the modules can be installed in a horizontal or vertical configuration according to the architectonic design of the roof or façade. In the project "AB Landsdommergaarden" in Copenhagen (Figure 21), the installation process of the BIPV system into the roof (envelope design approach B) can be detailed as follow: In a first step, the existing cover and wooden rails were removed and a waterproof of 2 layers asphalt roofing was laid on top of the ceiling. Then, a metal hook was fixed to support the aluminium rails and the rail structure was mounted. Wiring, cable trays and cable boxes were installed. Afterwards, the PV modules were fixed to the aluminium rails with clamps. A number of solar inverters and sensors (including a sun irradiation meter) were put in place to complete the DC installation. Finally, the AC cables were laid vertically along a back staircase and connected to a secondary electricity power meter to measure PV production and connected to a main electricity cabinet in the basement. 


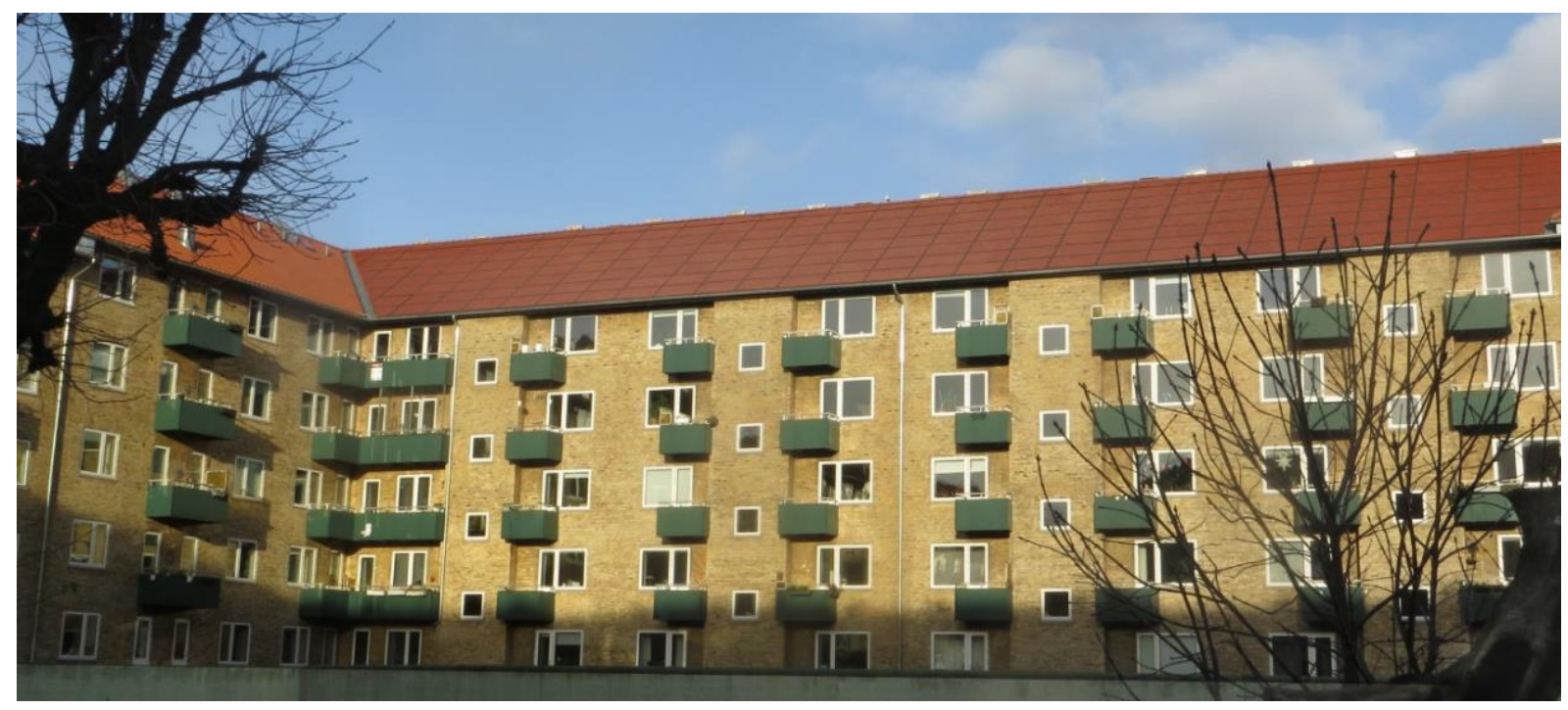

Figure 21. The 52,25 kWp BIPV installation on the roof of "AB Landsdommergaarden" in Copenhagen (Denmark) covers $22 \%$ of the residential electricity consumption. Electricity output: $47.340 \mathrm{kWh}$ during the first year. Estimated $\mathrm{CO}_{2}$ emissions saved $29.154 \mathrm{~kg}$ per year. (Source: Solar Lighting Consultants ApS).

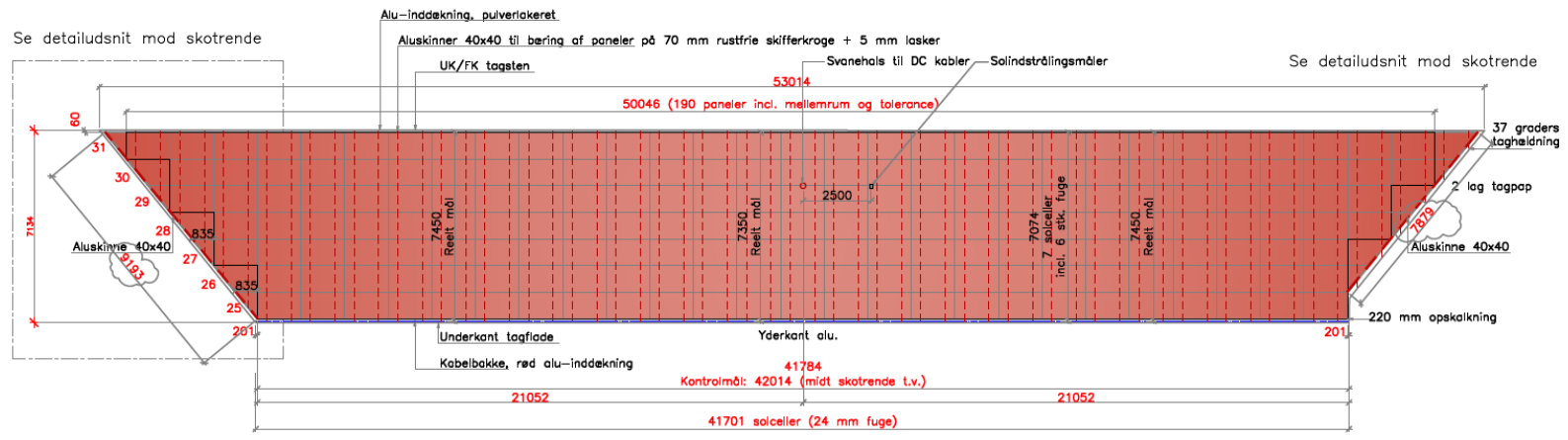

Rustic red/røde solcelle paneler - X-COLOR Monocristallino (horizontal/vandret), 275 WP RAL 8015, 190 stk.

Figure 22. Schematic drawings of the BIPV installation on the roof of "AB Landsdommergaarden" in Copenhagen, Denmark. (Source: Solar Lighting Consultants ApS).
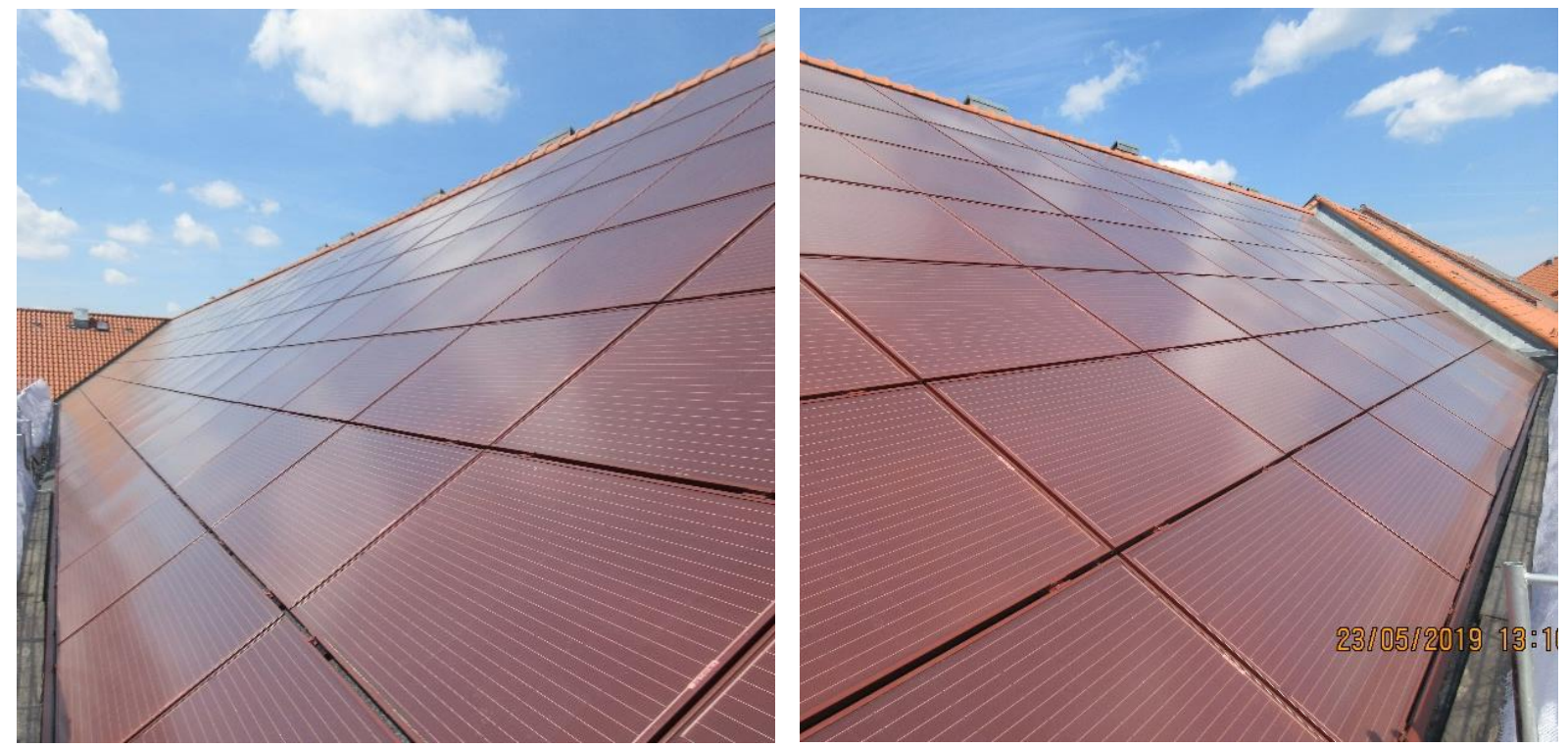

Figure 23. Views of the BIPV installation on the roof of "AB Landsdommergaarden" in Copenhagen, Denmark. (Source: Solar Lightning Consultants ApS - Architect Martin Dietz (C)). 


\section{SWOT analysis}

\section{Strengths}

- It has a very eye appealing appearance and can be adapted to the context (e.g. roof tiles), thanks to the range of colour options and the use of "dummies" modules

- It enables to harvest solar radiation to produce green electricity with high efficiencies

- The installation of BIPV can be a good investment with interesting payback-times

- Good warranties about product and minimum performance overtime are offered to customers

- Maintenance and durability are similar to that of a passive glass façade

\section{Opportunity}

- The market is large, as the modules can be applied to both new and renovated buildings' roofs and facades

\section{Lessons learned}

- From an aesthetic point of view, the SUNERG X - Color panels with the chosen RAL 8015 colour code $275 \mathrm{Wp}$ per module, which is most efficient, cannot perfectly match the surrounding red tile roofs in the project of "AB Landsdommergaarden", a lighter red colour would reduce the efficiency to 240-250 Wp.

- Coloured solar panels are still `in the luxury end` - small custom-made modules, and public incentives and financial support for the refurbishment of buildings are therefore needed to keep the payback time low enough.

- The scaffolding use is temporary, but still represents a high expense part (min.10 percent of the total investment).

\section{Disclaimer}

The information and views set out in this chapter of the report are those of the author and do not necessarily reflect the opinion of SUNERG Solar Srl. 


\section{GAP:water - Facade-integrated solar domestic hot water generation}

by Johann Aschauer, GAP Solutions $\mathrm{GmbH}$, Austria

\section{Product description}

\section{Brief concept description}

GAP Solutions is dedicated to the development and implementation of innovative, sustainable and value-enhancing passive solar system solutions for residential constructions, such as the GAP:water façade shown in Figure 1 conceived for solar domestic hot water generation.

Hot water preparation constitutes a relevant share of the energy demand in modern residential buildings, since the use of improved envelope systems and ventilation concepts drastically reduces the space heating energy demand: in highly energy efficient houses, domestic hot water generation represents at least $60 \%$ of the total heat requirement.

GAP:water is a new and patented low-tech solution that integrates a decentralised solar system for water heating into a prefabricated solution. The core element is a concrete storage solar absorber with a cast-in water heat exchanger which is installed into the building's envelope in the immediate vicinity of the point of consumption of hot water. The concrete absorber is covered by a very good insulating glass and enables to convert the impinging solar radiation into heat which is stored into its concrete structure. The embedded heat exchanger enables to access the stored heat to pre-heat the fresh water required for domestic use. At the outlet of the collector, a heat generator (e.g. a boiler) is used to heat the water flow to the desired temperature.

The energy savings are large, since the temperature of the solar pre-heating is in many cases already sufficient for hot water preparation. Unlike conventional solar systems, the use of large water distribution networks or water tanks including pumps and electronics (active control) is not required.
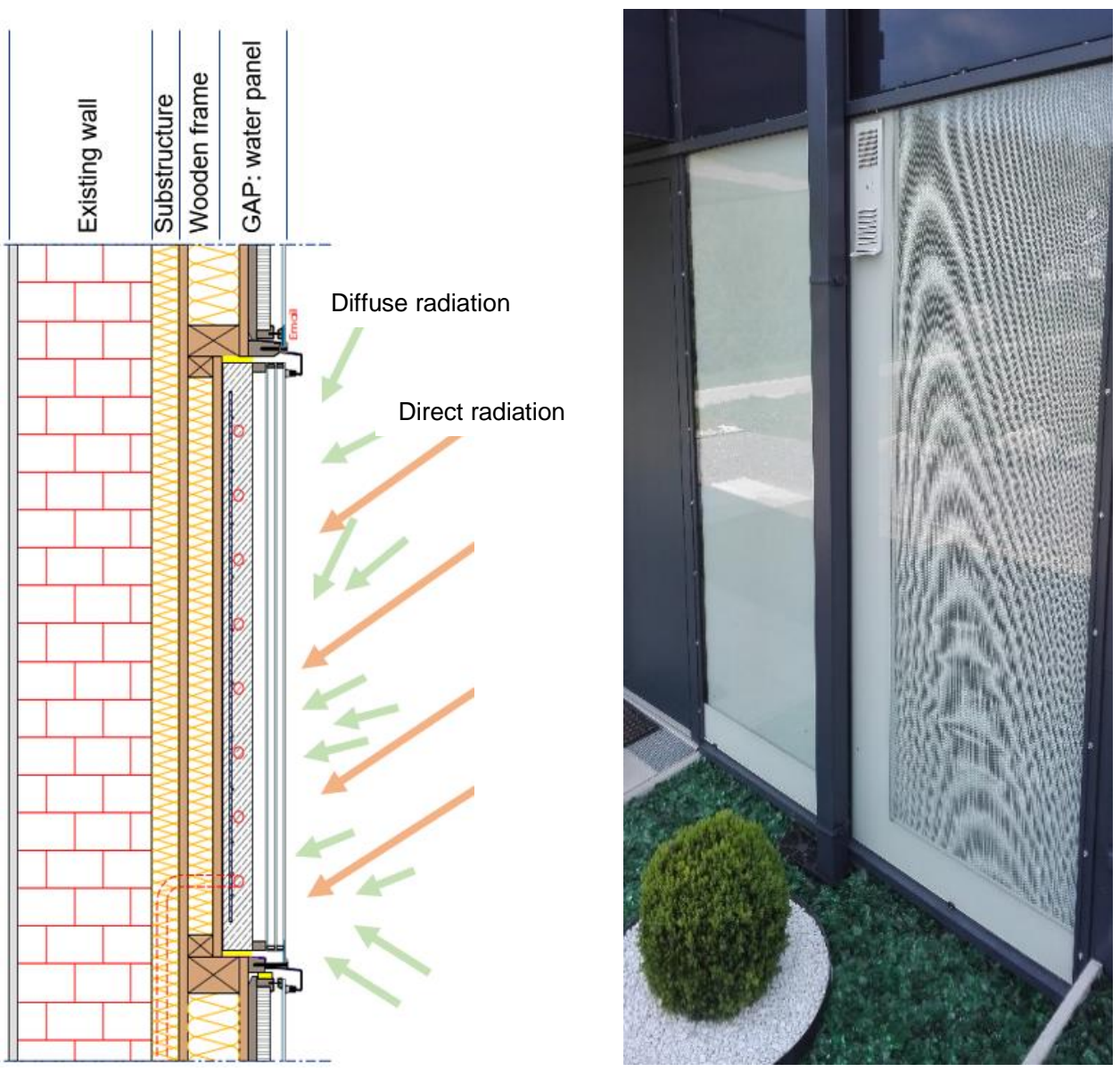

Figure 24. Schematic drawing (left) and view (right) of the GAP:water façade. 


\section{Architectural and technological integration into the envelope}

The GAP:water system is integrated into prefabricated structures as the GAP:skin façade (see dedicated chapter in the report). As seen, the main component of the GAP:water panel is a concrete storage/solar absorber that is enclosed in an insulating cover glass and integrates a heat exchanger. Such panel is installed in a wooden frame that is fixed to the levelling layer, which includes a wooden substructure and insulation material. Also at times when there is no hot water demand, GAP:water is a good thermal insulation layer.

The system does not require pumps, an active control or antifreeze protections. The combination of the storage mass of the concrete collector and the insulating glass properties ( $\mathrm{U}$-values $<0.6 \mathrm{~W} / \mathrm{m}^{2}$.K with g-values $>55 \%$ ) ensures high frost resistance. There is also no overheating of the concrete collector (hot water) throughout the year. The use of the collector is not limited to South-exposures.

To show the potential of this solution, Figure 25 presents the monthly energy balance for a GAP:water installation on a North and a South facade of a 2-people dwelling located in Frankfurt. Figure 26 shows a set of monthly temperatures simulated in the middle of the concrete core of the collector, i.e. temperature of the water heat exchanger. As it can be seen, the façade shows optimal performances for the South façade, but its use is also possible for North facades. It can also be observed how the minimum temperatures in the core of the concrete collector do never reach values close to the freezing point, even for low outdoor temperatures.
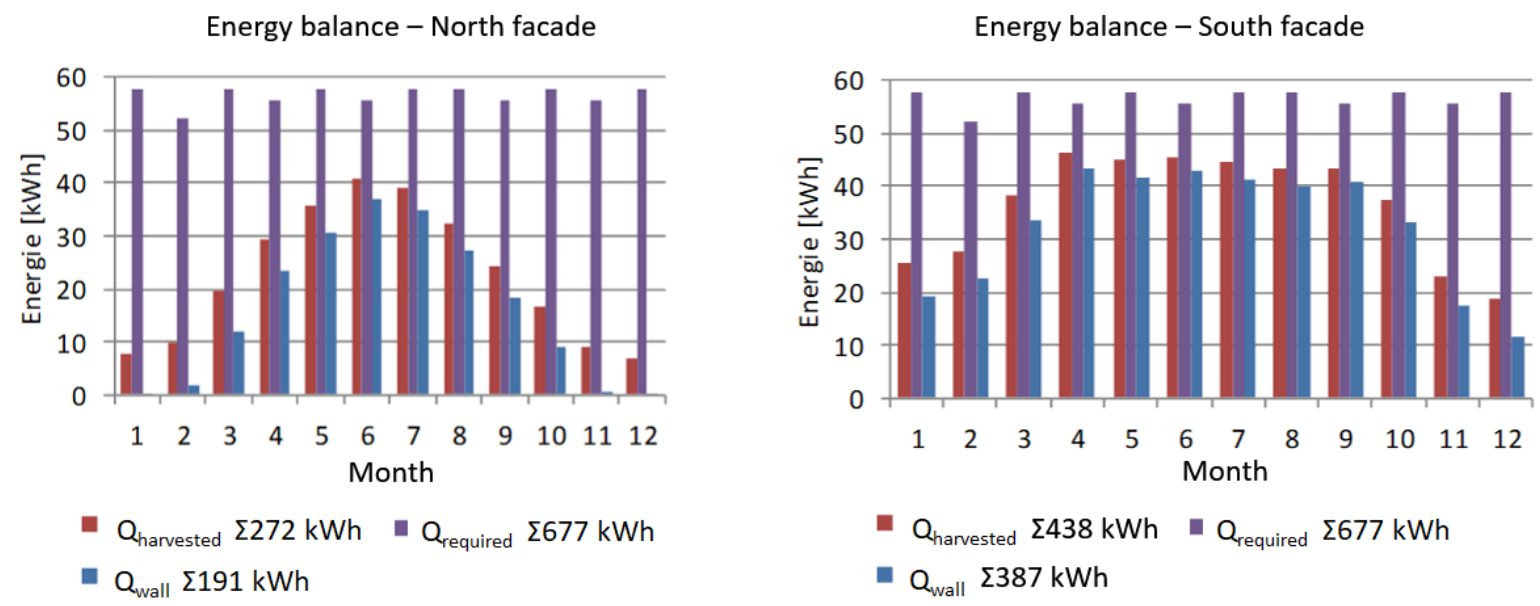

Figure 25. Simulated monthly energy balance for a GAP:water installation in Frankfurt (Germany) and a 2-people dwelling. Qrequired (purple) is the hot water preparation energy load, Qharvested (red) is the amount of energy harvested by GAP:water and $Q_{\text {wall }}($ blue) is the energy delivered to the room via the rear wall.
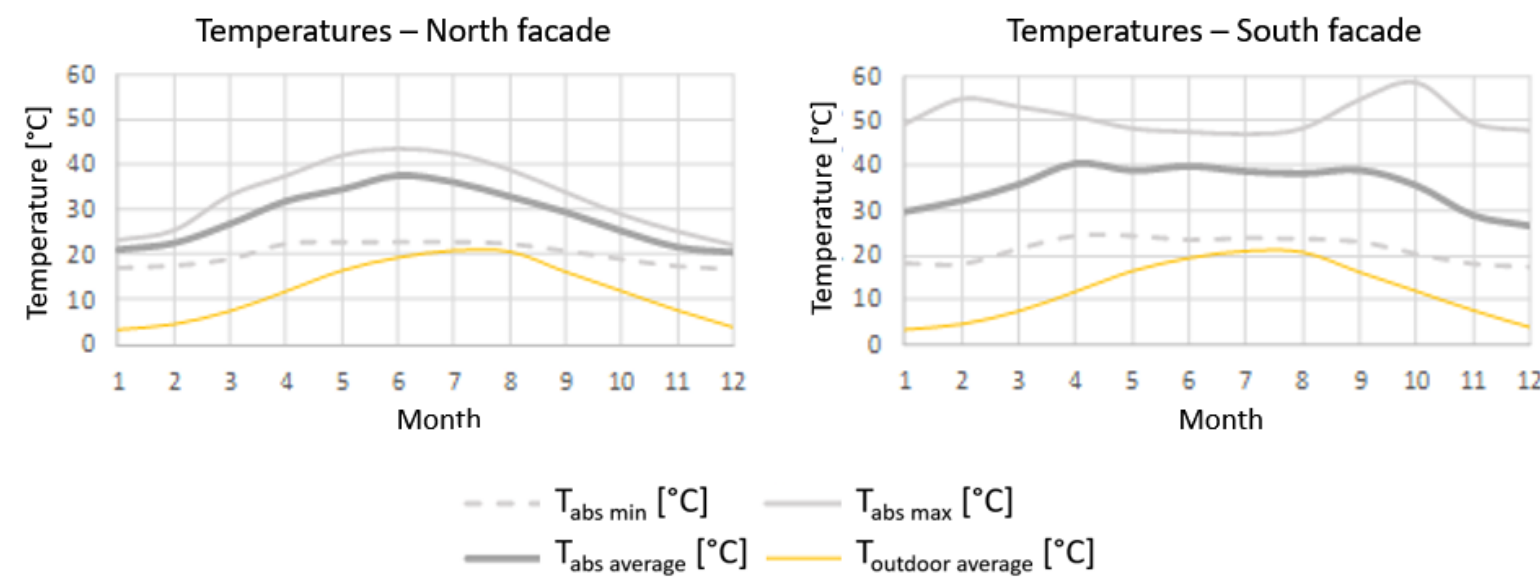

Figure 26. Temperature trends for a GAP:water installation in Frankfurt, Germany. $T_{a b s}$ min (grey dashed), $T_{a b s ~ m a x}$ (light grey) and $T_{\text {abs average are respectively the minimum, the maximum and the average temperatures }}$ in the middle of the concrete core (water pipe). Toutdoor average (yellow) is the average outdoor air temperature. 


\section{Integration into the building: system and comfort}

The pipe connections to the concrete collector reach the interior of the building through core drill holes in the existing wall. As this system is decentralized and close to the point of consumption, long supply lines and thus high distribution losses are prevented. As discussed above, GAP:water pre-heats fresh water but a generator is required to heat the water to the desired temperature. If needed, the system can also be integrated into the existing building services.

This system was already used in 2010 for the renovation of the residential complex in Leoben/Austria in 256 residential units with very good results (Figure 27). The system enables the production of domestic hot water over the year with energy savings between $35 \%$ (North side) and $75 \%$ (South side) with a 3 to $4 \mathrm{~m}^{2}$ concrete storage absorber for each dwelling.
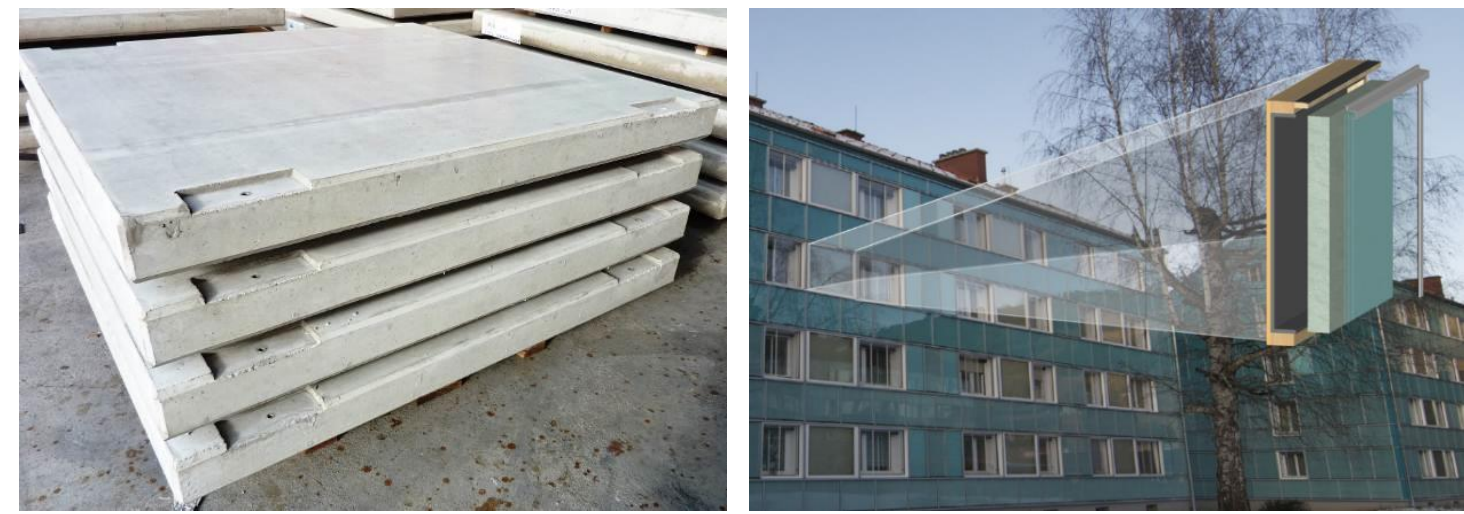

Figure 27. GAP:water panels (left) and GAP:water installation in Leoben, Austria (right).

\section{SWOT analysis}

\section{Strengths}

- It is a passive, low-tech system with no moving parts and low maintenance requirements

- The façade system is available in a variety of colours and can be architecturally integrated in GAP:skin facades

- The production is simple and can benefit of modularity and prefabrication

- No large distribution pipework / external water storage is needed

- Unique selling proposition / patent protection

- Environmentally sustainable: easy recyclability/separability of materials

- Maturity level: in use since 2010 for more than 500 residential units without complaints

\section{Opportunity}

- The goals of European Union are pushing toward solutions that achieve higher energy efficiency levels and increase RES share

- There is a new awareness for environmental issues that can reward sustainable solutions

- $\quad$ The building' energy load is reduced to a point where the remaining load can be easily covered with RES technologies as PV

- National and international requirements for buildings' and envelope energy performance can be easily met

- $\quad$ Decentralized energy supply \& blackout security are rising issues

\section{Weaknesses}

- The outer transparent glass pane is required

- No compatibility with listed facades

- There is a higher investment costs with respect to traditional retrofit interventions (although the advantages at LCC level are clear)

Threats

- $\quad$ There might be competition by facadeintegrated PV systems plus decentralized small air-to-water heat pumps in the future 


\section{Lessons learned}

- In simple terms, the "low-tech" approach adopted with GAP:water means that the abandonment of expensive, complicated technology and the exploitation of simple principles lead to optimum LCCs.

- Solar energy can be exploited also in North facades!

- The sun supplies more energy to any well-built building than its actual needs.

- Decentralizing domestic hot water heating significantly reduces the distribution line losses.

\section{Further reading}

The building stock is a major cause of $\mathrm{CO} 2$ emissions. Europe has already been built - that is why the conversion of Europe to $\mathrm{CO}$-free building management must start there. In renovated buildings, the proportion of hot water increases sharply in relation to the heating energy requirement. The technological implementation has been "grasped" for many years in best practice examples.

More information on Photovoltaic Water Solution is available here: Passive House Renovation Graz, facadeintegrated DC-based hot water preheating, final report: Reports from Energy and Environmental Research 00/2010 https://nachhaltigwirtschaften.at/de/hdz/projekte/photovoltaik-water-solution.php

Company Website: www.gap-solutions.at 


\section{Prototype systems}

\section{SunRise façade - Modular building-integrated solar thermal system}

by Matteo D'Antoni and Paolo Bonato, Eurac Research, Italy

\section{Product description}

\section{Brief concept description}

The SunRise facade is an innovative multifunctional metal and glass curtain wall façade module developed for the tertiary building sector. It integrates a solar-thermal system composed of a thermal collector, a small-size water storage and a radiant panel. Moreover, an "hydraulic unit" integrated in the parapet hosts the required hydronic components (pump, valves etc.), a dedicated control box and sensors integrated for metering purposes. The system can harvest solar radiation to cover space heating and hot water preparation loads but can also be used as terminal for the distribution of space heating and cooling energy with the use of the radiant panel. The hydronic circuit of the SunRise façade is connected with the building's central heating/cooling loop.

\section{Architectural and technological integration into the envelope}

Solar thermal collector, thermal storage and radiant panel are installed in the lower opaque section of the façade module, as shown in Figure 28. All the hydronic components in the parapet are hosted in a metal shell designed to guarantee airtightness and a robust structure to support the solar collector. Thanks to the modular structure of the solution, the hydraulic unit in one façade module can be shared with multiple inter-connected façade modules. Maintenance of solar active façades is an issue, especially in the case of high-rise buildings. In this solution, the radiant panel is removable to access the integrated components, minimizing the effort in case of failures. Concerning aesthetics, the radiant panel gives a pleasant homogeneous appearance from inside, whereas the presence of the solar-thermal collector defines the exterior visual appearance of the façade modules.
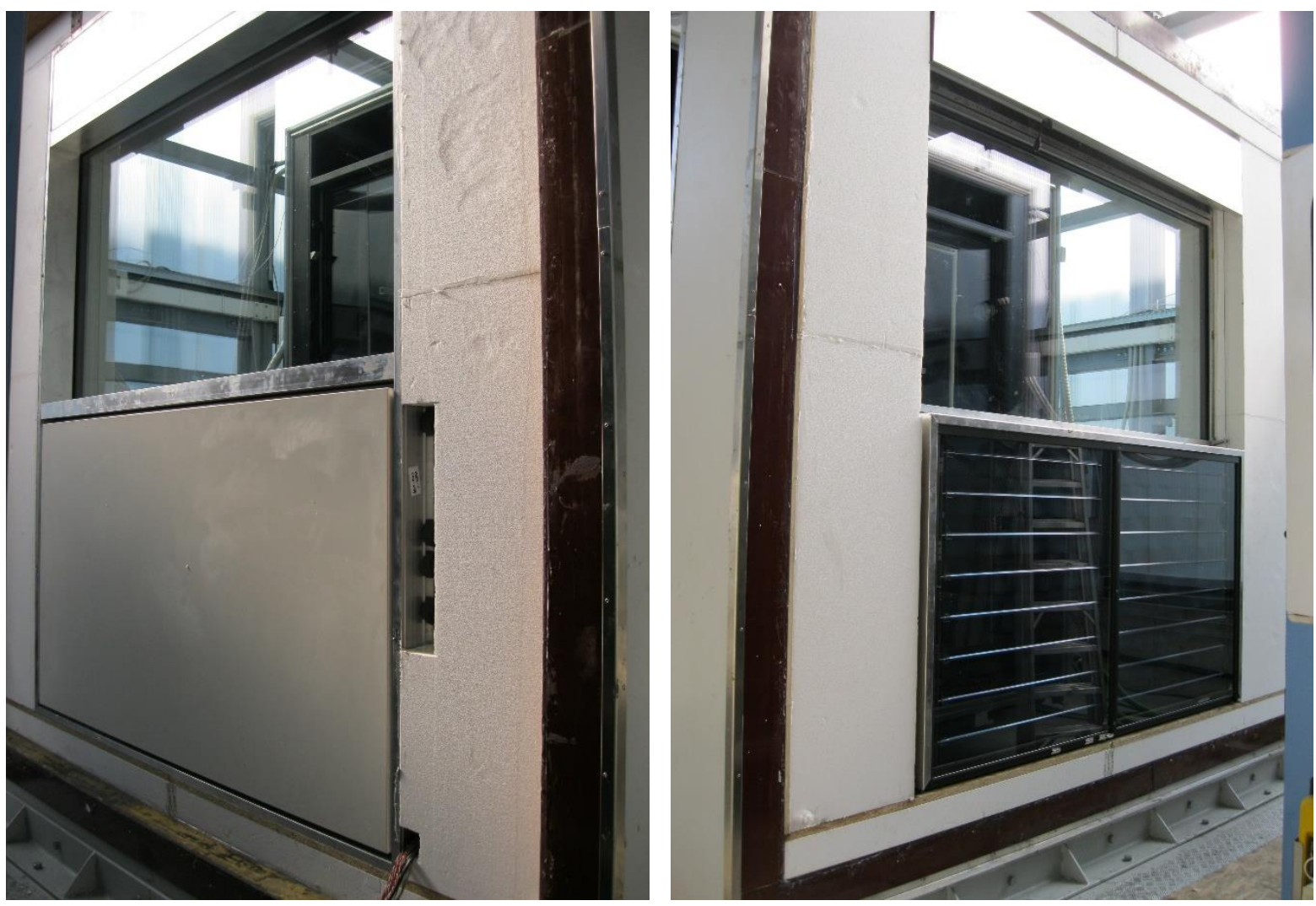

Figure 28. Internal (left) and external (right) views of the SunRise façade module installed in a test chamber at Eurac Research. 


\section{Integration into the building: system and comfort}

The SunRise façade integrates all safety and operational components required to work autonomously, such as safety valves, expansion vessel, deaerator, solar pump etc. The SunRise façade is coupled with the building's central energy generation and distribution system with a 2-pipe or 4-pipe connection, to cover all thermal loads including DHW preparation and space cooling delivery. The radiant panel integrated in the façade can deliver heating/cooling, but very deep rooms and the core of the building might require additional emission terminals for a proper climatization. In order to maximize exploiting solar irradiation and improve the local thermal comfort, the management of the heat fluxes from the collector to the integrated thermal storage and to the building's central system is key: an on-board control and monitoring unit manages the system.

\section{SWOT analysis}

\section{Strengths}

- Heating and cooling distribution is integrated in the façade, hence living area is not affected

- A hydraulic module functioning as hydronic, control and monitoring unit is used to manage the heat supply and to meter the heat fluxes

- The façade is modular and can be adapted to fulfil different width and height requirements

- $\quad$ The unit can be prefabricated using standardized components

\section{Opportunity}

- Solar thermal collectors with highly valued visual characteristics are entering the market

- Façades of high-rise buildings are rarely exploited for RES generation

- The solution can be adapted to multifamily buildings

\section{Weaknesses}

- $\quad$ solar-thermal collectors define the exterior visual appearance of the façade modules

- The investment cost is higher compared to conventional passive façade solutions

- The integration of components in the façade results in additional thickness and weight, which affects the installation burden in turn

- $\quad$ Space cooling, ventilation and space heating of the core of the building must be fulfilled by traditional systems

\section{Threats}

- Architects' awareness and acceptance is a major barrier to overcome

- Certification of safety and energy performance of the façade module is timeconsuming and expensive due to the wide range of national or international standards

- The cost of fossil fuel energy is comparatively low and incentive schemes often ignore innovation and $\mathrm{CO}_{2}$ emission savings, owing to technological advances

\section{Lessons learned}

- Solar thermal collectors designed to cope with high aesthetic value are largely missing on the market.

- Pipes in the façade structure produce a relevant issue that can compromise the airtightness of the façade if the joints are not adequately designed.

- The heat flow from solar collectors into the facade might be associated with vapour migration into the building structure and thus the airtightness of the façade has to be carefully evaluated.

\section{Further reading}

D'Antoni M., Bonato P., Fedrizzi R. "On the development of a façade-integrated solar water storage". Journal of Façade Design and Engineering, Vol. 6 Nr. 2, pp. 9-20, April 2018. DOI:

https://doi.org/10.7480/jfde.2018.2.2048. 


\section{Modular BIPV/T}

by Efstratios Rounis, Concordia University, Canada

\section{Product description}

\section{Brief concept description}

The Modular BIPV/T system allows the full integration of a photovoltaic/thermal system into the building envelope maintaining the potential of modular/unitized fabrication. The design of a typical curtain wall is here altered, so that an air channel is created between the PV layer and the insulated back surface and it is possible to cool down the PV layer collecting useful heat. In this case, multiple fresh air intakes can be used to boost the thermal performance of the system. The modular BIPV/T system can be applied to the opaque part of curtain wall facades, but is also suited for roof applications, as shown below.

A prototype of this system was developed at Concordia University in collaboration with Unicel Architectural and Canadian Solar (Figure 29, left) and a variant of such prototype was incorporated as a roof BIPV/T system in the Solar Decathlon House designed by TeamMTL for the event in China 2018 (Figure 29, right).
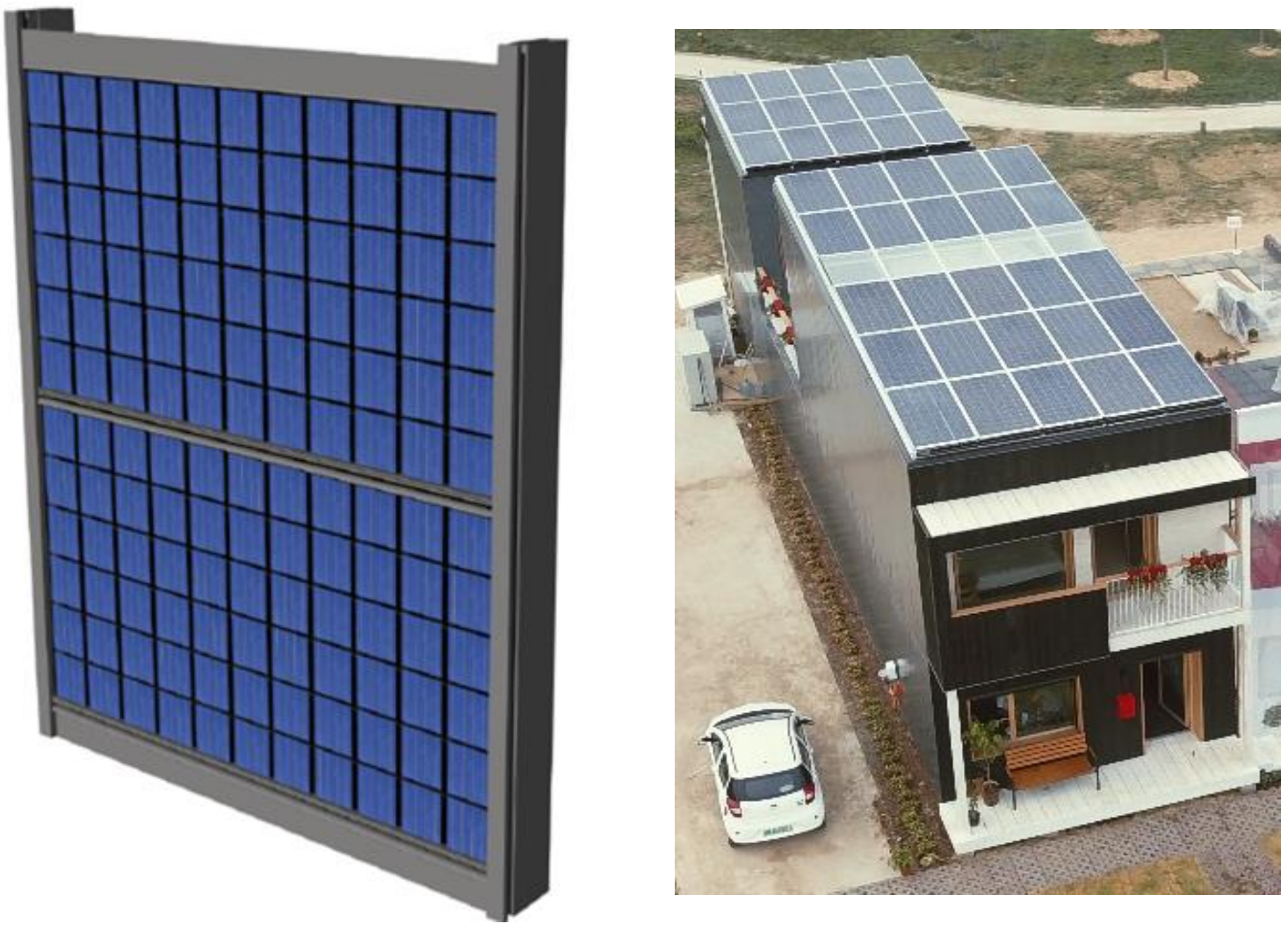

Figure 29. Architectural integration of BIPV/T in a curtain wall design on the left and example of the integration of the BIPV/T module in a roof (Solar Decathlon House, China 2018) on the right.

\section{Architectural and technological integration into the envelope}

This system is designed for full façade/roof integration as it replaces traditional envelope elements. It can be either incorporated as stick-built (assembled on-site) or it can be prefabricated in modular form. The PV panels are supported by pressure plates, point supports on a metal frame and an air gap is left to separate them from the rear surface. The layers on the back of the PV panels guarantee air and water tightness as well as thermal insulation. Figure 30 shows the cross section of the experimental BIPV/T curtain wall.

\section{Integration into the building: system and comfort}

Depending on the application and the outlet air temperature, the system can either deliver pre-heated fresh air either directly to the living space or convey it to a heating system (i.e. a heat pump) that works at a high COP levels, with a consequent reduction of the cost for space heating. 


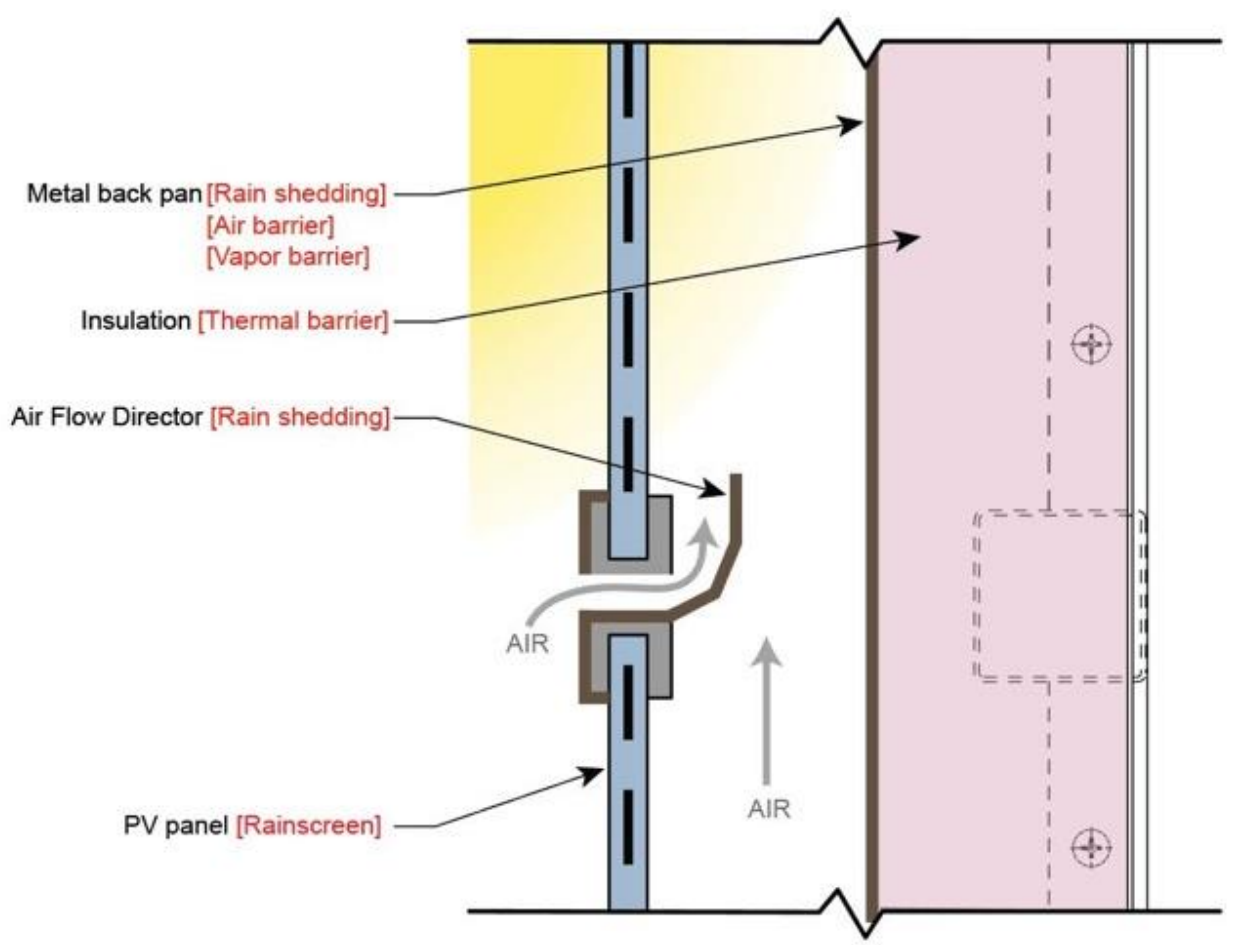

Figure 30. Cross section of the BIPV/T curtain wall system.

\section{SWOT analysis}

\section{Strengths}

- Full building integration of the BIPV/T system: the PV panels are seamlessly integrated into façade or roof with a superior architectural result replacing traditional envelope elements

- Design flexibility: PV modules of different typologies and sizes can be integrated

- Both electric and thermal energy is generated by the building's envelope

- Water- and airtightness as well as thermal insulation requirements are fulfilled by the BIPV/T module

- There is potential for modular fabrication and factory-controlled construction and testing

- The construction technique is simple and suited to the existing building practices

\section{Weaknesses}

- The electric wiring must be adapted: custom junction boxes may be required

- External shading can limit the performance of the system, especially for façade applications

- The orientation of the installation is critical, especially for the thermal output

- A good level of communication is required between PV module manufacturer and frame manufacturer

- The use of a fan is required. The optimization of the air flow in collector and manifold is then needed

- The heat collected can be used only in low temperature applications

\section{Opportunity}

- The solution could be standardized and introduced as building practice in the architectural and engineering community.

- Institutional buildings can be used as showcases to prove the technology and spread awareness

\section{Threats}

- The lack of significant government incentives and the low electricity prices reduce the cost-savings for costumers

- Architects may find difficult to incorporate new building techniques to the established ones 


\section{Lessons learned}

- The architectural result can be aesthetically pleasing, and the PV panels seamlessly integrated with the rest of the building (Team MTL, Solar Decathlon, China 2018).

- The curtain wall approach facilitates the implementation of skylights (daylighting), as well as thermal collectors (thermal boost) in series with the BIPV/T system.

- The construction sequence including wiring, grounding and material placement need to be carefully planned, especially in the case of stick-built approach (on-site assembly).

- The structural integration of the system needs to be considered in the early design stages of the building.

- The water and air tightness of the rear surface of the channel need to be ensured to guarantee the building envelope continuity.

- $\quad$ The BIPV/T operation and how it is coupled with the HVAC depend on the local climate. An early stage analysis is to be carried out to investigate optimal operation and sizing, depending on the intended use. In the same way, the manifold location, duct sizing and connections with the BIPV/T channels need to be addressed in the early design phases.

- The orientation of the installation (tilt, slope) is critical for the performance of the system. Restrictions from the building codes (maximum height) can affect the system performance.

- The collaboration between PV industry and building envelope manufacturers is essential for the development of standardized products that can be accepted and adopted by the constructions community. 


\section{BIST prefabricated timber module}

by Riccardo Pinotti, Stefano Avesani and Roberto Lollini, Eurac Research, Italy

\section{Product description}

\section{Brief concept description}

This prototype is a prefabricated timber-based multifunctional facade element for retrofit purposes that was developed within the European 4 RinEU project. The facade module can integrate active solar systems, such as a solar-thermal or PV panel, but also decentralized ventilation. The main structure of the prefabricated panels is composed of a timber frame, an insulation layer and an external cladding. Figure 31 shows a prefabricated timber module integrating a solar thermal system and a small decentralized ventilation unit. Such multifunctional façade elements can be prefabricated with the benefits of lower manufacturing costs, higher construction quality, a limited duration of the renovation process and less inconvenience for the occupants. At the same time, additional services such as RES generation or ventilation are integrated in the façade system solution.

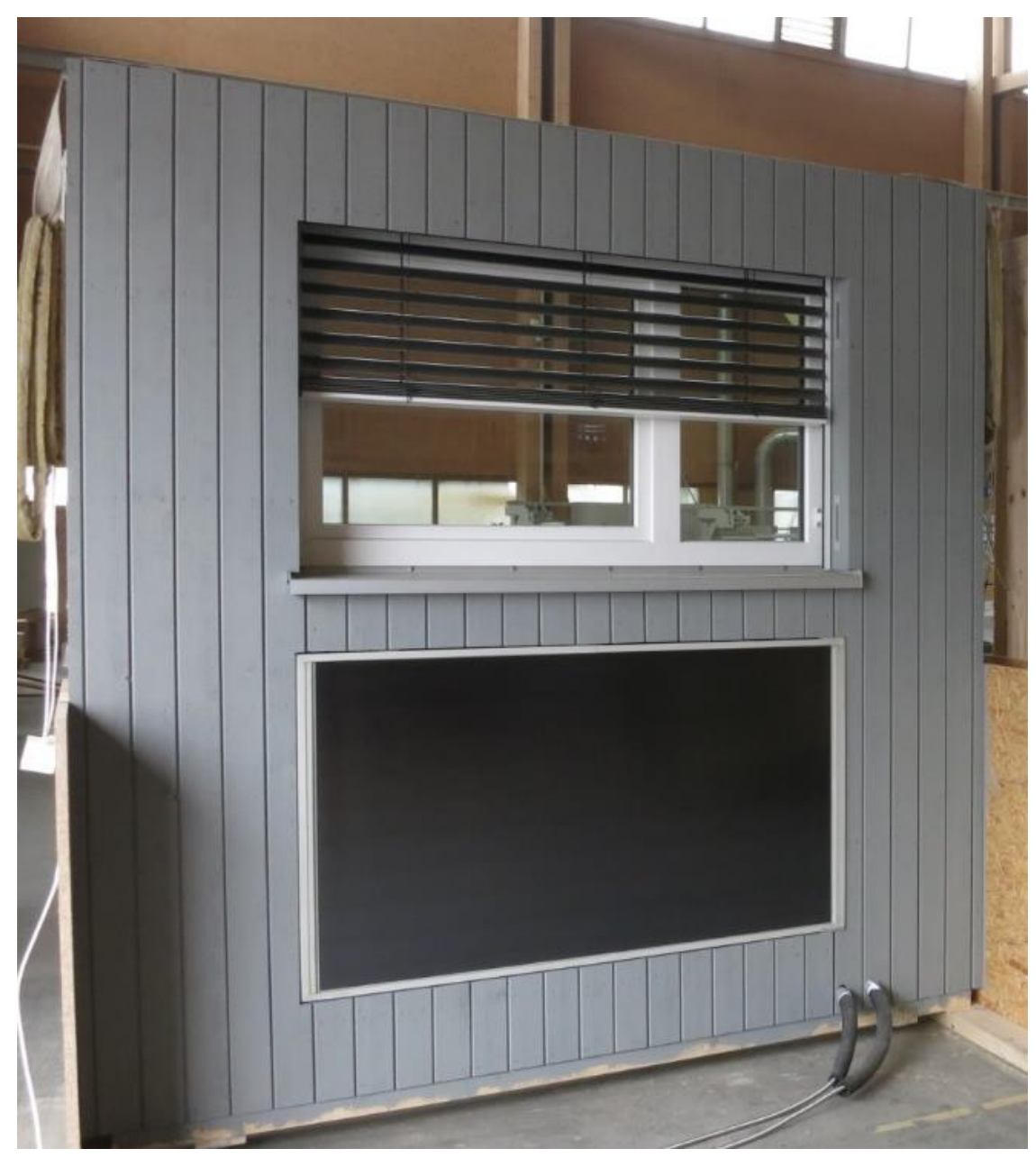

Figure 31. Prototype of a prefabricated timber module integrating a solar thermal collector and decentralized ventilation - produced by Gumpp\&Maier GmbH.

\section{Architectural and technological integration into the envelope}

In order to reach co-planarity between solar panels and external cladding, a thin solar collector is integrated into the prefabricated module. A small air cavity behind the panel and an insulation layer limit the thermal losses from the back of the solar collector. On the other hand, this kind of integration could bring along augmented vapor transfer from the inner to the outer layers of the envelope, during periods when sun is not available. This problem needs to be carefully considered and solved during the façade design. 


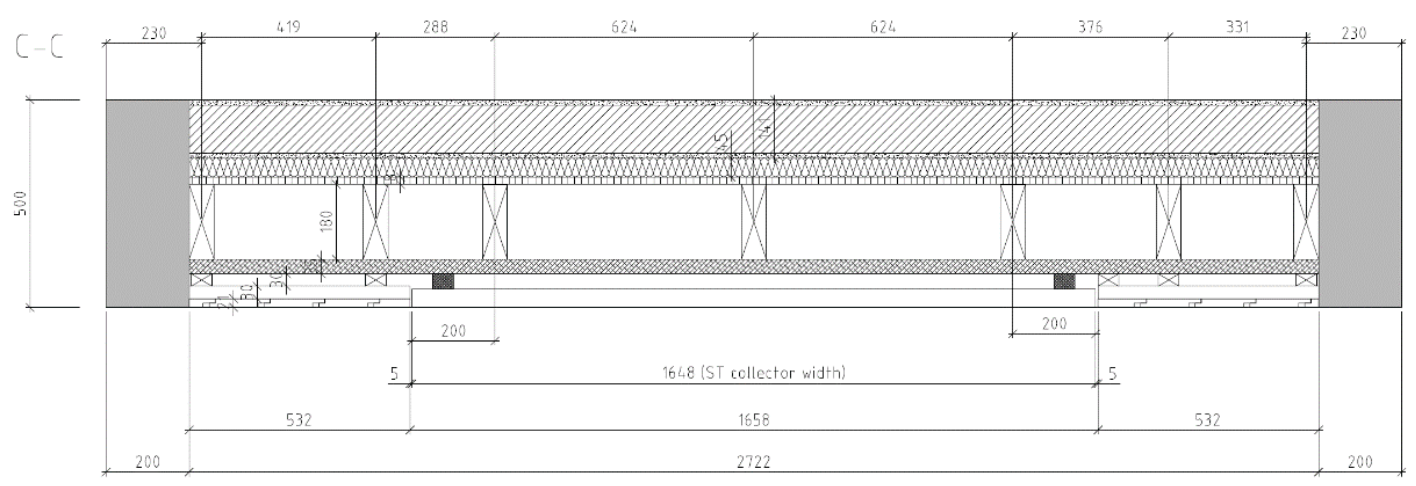

Figure 32. Horizontal section of the prototype, showing the solar thermal collector integration and the small cavity behind.

\section{Integration into the building: system and comfort}

The multifunctional prefabricated façade elements can be shipped to the building site in modules that can be up to 12 meters long and can cover the height of one floor. Transportation regulation is the main limit for the dimensions of such prefabricated panels. These modules are then anchored to the bearing structure of the existing building via timber beams and only finishing works are performed on-site. The type of solar harvesting system to be integrated in the prefabricated element can be easily adapted depending on the building location, geometry and loads. The façade structure can also integrate the ducts and wires needed to connect solar thermal or PV panels to energy storage and distribution system.

\section{SWOT analysis}

\section{Strengths}

- RES energy is generated exploiting the façade

- The integration of the solar active component in the façade is easy thanks to modularity principles

- The connection between solar active component and management/distribution systems is integrated in the prefabricated structure

- The prefabricated structure can be optimized in shape and materials for hosting solar thermal and PV panels

- Integrating solar collectors in prefabricated modules allows to save time compared to having separated interventions at different stages of the renovation process

\section{Opportunity}

- Retrofitting exiting buildings is a huge opportunity for improving energy efficiency and standardized products might find a place in the renovation building practice

- Large façade areas are currently unused and can be exploited for installing this solution

\section{Weaknesses}

- $\quad$ Maintenance must be performed from the outside and some cladding must be eventually removed

- In order to maintain the planarity between solar thermal/PV panels and cladding, the integrated components must be thin

- Solar collectors can be damaged during the installation process

- The design process required to assure good performance and a smooth installation is more complex than for traditional solutions

\section{Threats}

- The integration of solar thermal/PV panels in vertical façades may not be optimal for all the geographic location and orientations

- The construction of new buildings may shade the solar collectors, significantly reducing their performances

\section{Acknowledgment}

4RinEU project has received funding from the European Union's Horizon 2020 research and innovation programme under grant agreement No723829. 


\section{BuildHEAT façade system}

Ignacio González Pérez, ACCIONA Construcción, Spain and Stefano Avesani, Eurac Research, Italy

\section{Product description}

\section{Brief concept description}

BuildHEAT façade system is designed for building envelope retrofits aiming at facilitating the integration of solar devices and energy distribution systems. The solution is made of pre-assembled façade modules, each composed of a standardized aluminium anchoring frame that can host insulation between transoms and mullions and allow fixing different cladding panels, such as opaque cladding panels, but also photovoltaic panels or solar thermal collectors. The façade system also allows the installation of air ducts and new windows, coherently with the existing layout of the façade openings. Each module is anchored on the concrete slabs and covers the existing building façade.

Such constructive system enables to (1) reduce the duration of the installation process compared to regular second skin or ventilated façade systems, (2) allocate insulation and technical equipment as wires, ducts and pipes and (3) achieve a harmonic integration of photovoltaic panels/solar thermal collectors and standard opaque panels.

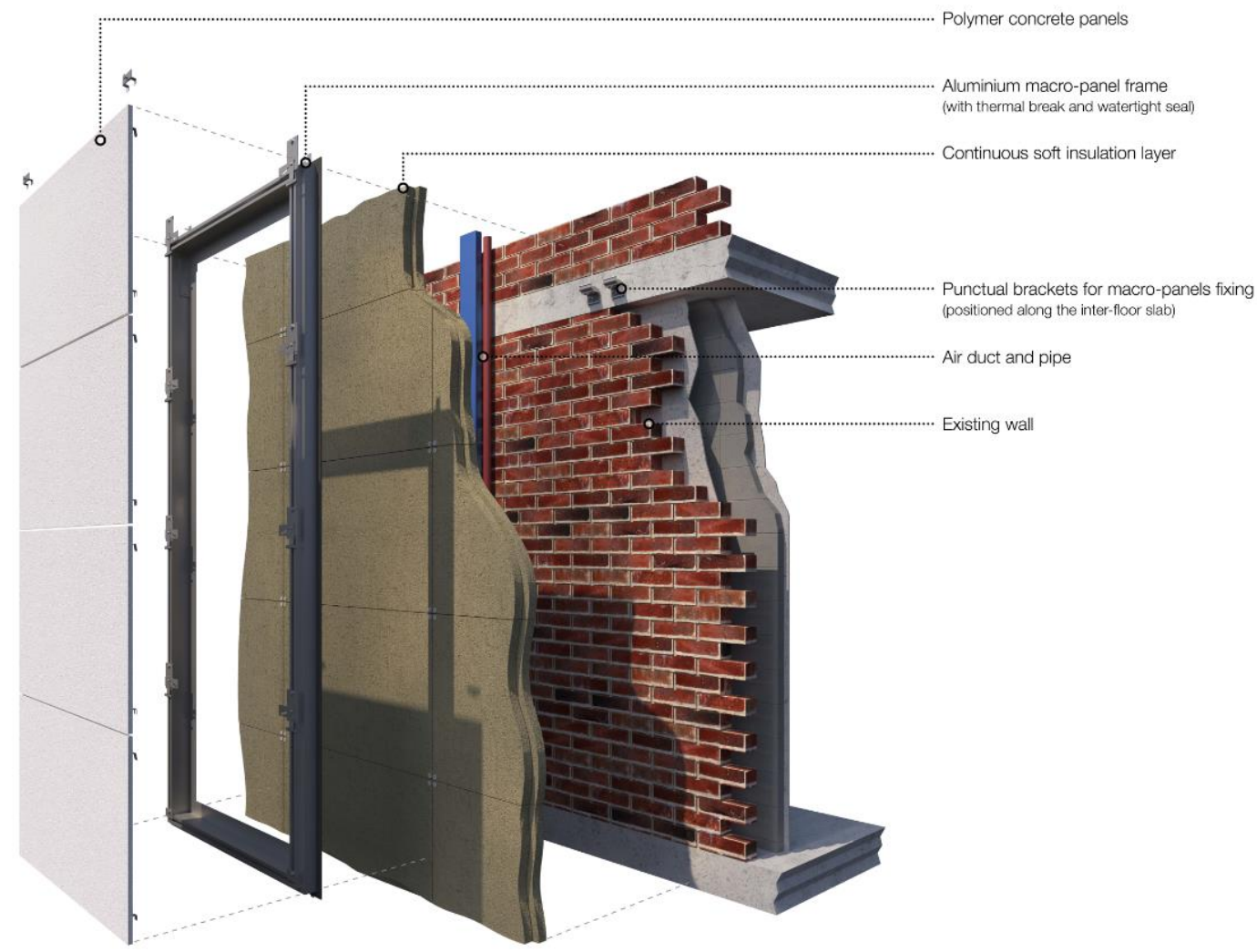

Figure 33. 3D sketches of the concept design of the BuildHEAT façade system, different layers highlighted (Source: ARUP).

\section{Architectural and technological integration into the envelope}

A wide range of façade layouts can be composed with the façade solution, as long as the height of the modules is equal than building floors' height. The variety of colours, technologies and compositions offers significant freedom to architects in re-designing the existing building appearance. The thickness differences of cladding panels and solar thermal collectors/ photovoltaic panels can be absorbed with simple adjustments in the fixing system, so that the external surfaces are coplanar and an enhanced aesthetics is achieved.

At the same time, technical space for installing wires and pipes is found in the cavity behind the cladding modules, where they are integrated in a soft insulation layer and fixed to the existing wall with traditional fixing systems. Solar thermal collectors can be mounted in the macro-panel with punctual brackets and, eventually, an additional transom to support the collector at the desired height. Passive and photovoltaic panels are fixed to the macro panel frame and can be mounted and unmounted thanks to a flexible fixing system that ensures the possibility of adjusting the cladding position. 

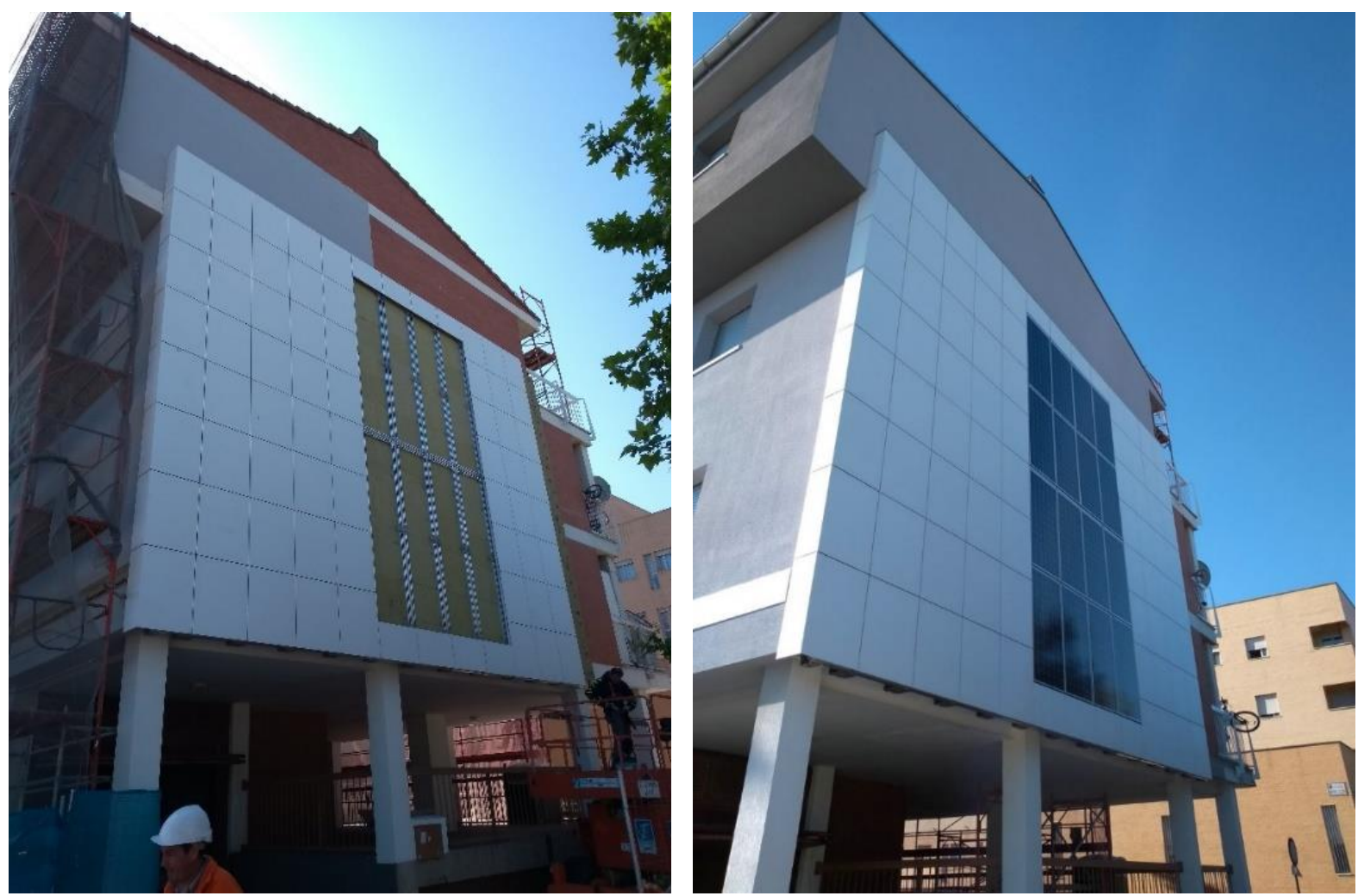

Figure 34. Installation of BHFS in a demo-building in Zaragoza, Spain (Source: ACCIONA Construcción).

\section{Integration into the building: system and comfort}

The generation of heat or electricity from PV panels and solar thermal collectors can significantly enhance the share of energy from renewable sources and avoid the purchase of fossil fuels. This said, the system is not designed to be connected to a specific heating or electric load, rather to make renewable heat/electricity available to the building plants by maximising the envelope exploitable surface and by making connections with centralised generation and dwelling installed distribution possible, along the external surface of the existing façade.

\section{SWOT analysis}

\section{Strengths}

- A wide range of layouts, in terms of customised façade design, is available

- Renewable energy generation is easily integrated in the façade system

- Better life cycle cost is achieved compared to regular passive construction systems as ETICS and ventilated façades by reducing manufacturing and transportation costs

- The prefabrication of façade modules reduces on-site installation time and errors

\section{Opportunity}

- Policies pushing toward the integration of RES can drive the adoption of façade systems integrating renewable energy generation

- Retrofitting of buildings is a large market

- Integral deep retrofit actions require systemic technological solutions

\section{Weaknesses}

- The final overall costs are still higher compared to traditional solutions (benchmarking passive traditional ventilated façade)

- The use of the metal frame determines a thermal bridge: the impact on the overall façade heat transmission has to be evaluated case by case.

\section{Threats}

- If the cost of regular ventilated façades with $\mathrm{PV}$ cladding is reduced drastically, the solution would hardly compete on the market 


\section{Lessons learned}

- Transportation costs of prefabricated modules could be very high if the packaging is not optimized and thus an analysis of the whole supply chain must be performed at the very beginning to define the best approach.

- Having a substructure able to host any kind of cladding system and active element might be not a marketable feature due to high materials' costs connected to the load-bearing sub-structure.

\section{Further reading}

BuildHeat project website: www.buildheat.eu/

\section{Acknowledgment}

The facade element has been developed in framework of the BuildHeat project, which has received funding from the European Union's Horizon 2020 research and innovation programme under grant agreement No. 680658. Besides the authors, Stefano Terletti (HALFEN) and Silvia llardi (ARUP) were the main developers of the façade systems. 


\section{Compact unglazed solar thermal facade (STF) module}

by Jingchun Shen, Benedetta Copertaro and Xingxing Zhang, Dalarna University, Sweden

\section{Product description}

\section{Brief concept description}

The "compact unglazed solar thermal façade module" is a multifunctional façade element that can harvest the impinging solar radiation to collect solar heat. The solution offers the advantages of a simple and low-cost structure, an aesthetically appealing appearance and an easy installation (plug \& play). The absorber panel is composed of two welded stainless-steel sheets: the interior sheet shows an embossed surface with arrays of pin-fin corrugations, whereas the exterior sheet, which works as absorbing surface, remains smooth. The two metal sheets are joint along the perimeter, so to form a single unity with a built-in channel structure that is designed to minimize the use of pipes and guarantee a high flexibility in the customization of the panel (size and shape). The compact unglazed modules work on the same principle as conventional unglazed solar thermal collectors and can meet the demand of a range of applications such as pool heating, DHW preparation, and radiant space heating, with especially high performance in climates with warm ambient air temperatures and good solar irradiations. The combination with photovoltaic panels is also possible.

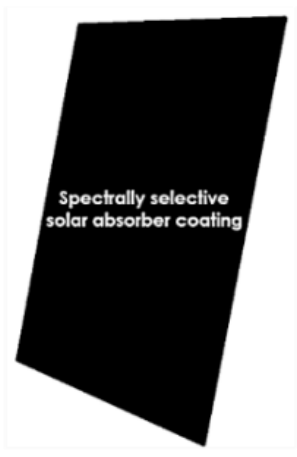

a) Compact STF (front view)

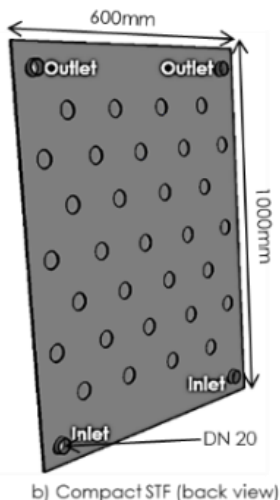

b) CompactSTF (back view)
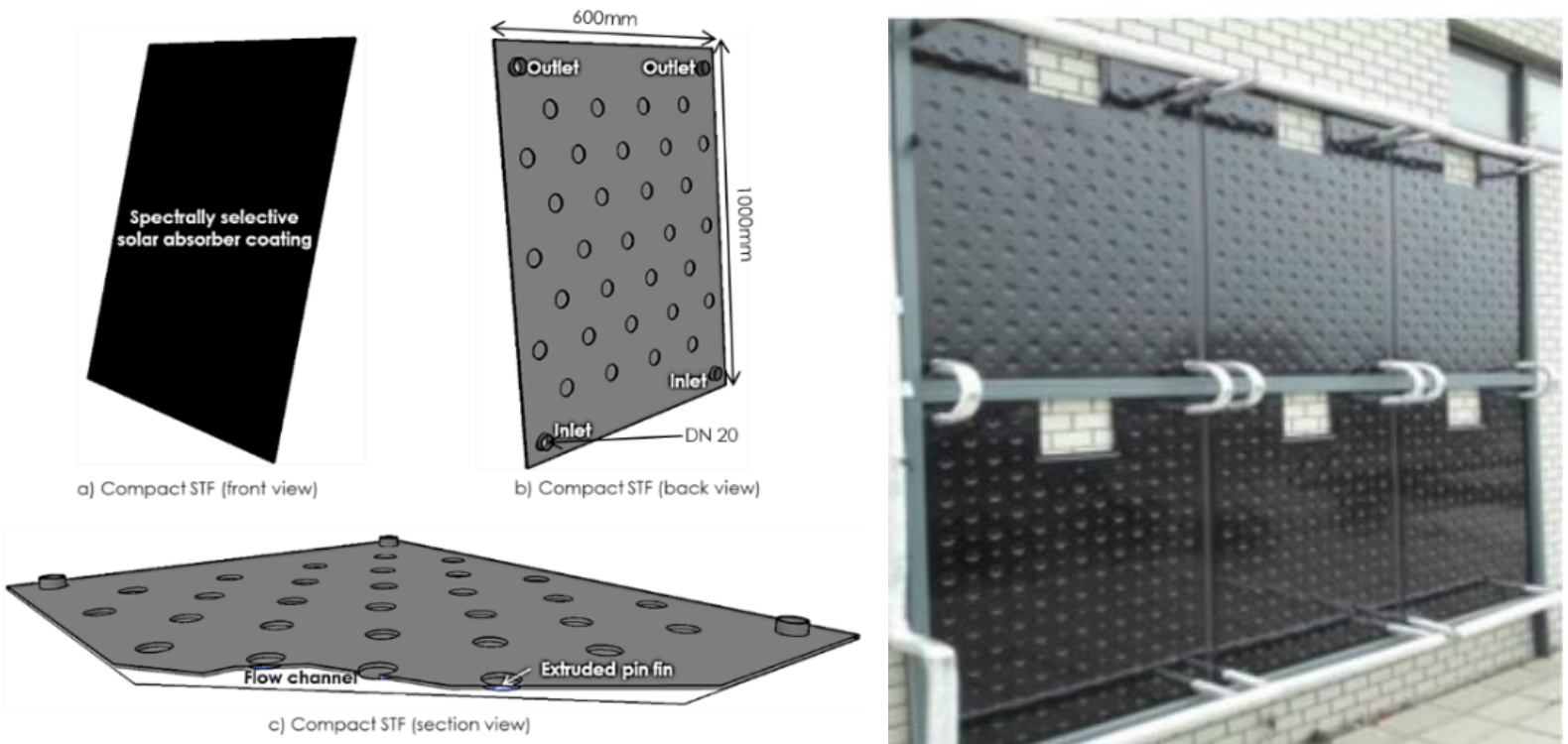

Figure 35. Schematic design of the compact STF panel with internally extruded pin-fin channels on the left and picture of a manufactured prototype flexible for integration with PV panels (back-view) on the right.

\section{Architectural and technological integration into the envelope}

The simple design of the compact unglazed modules guarantees high flexibility in terms of architectural and technological integration in the facade, with some of the alternative designs including different metallic materials, colours, textures, shapes, sizes, installation methods, array connections and applications. Some examples of the wide range of integration possibilities are shown in Figure 36, where they are used as opaque wall elements, balcony claddings and as vertical/horizontal shadings.
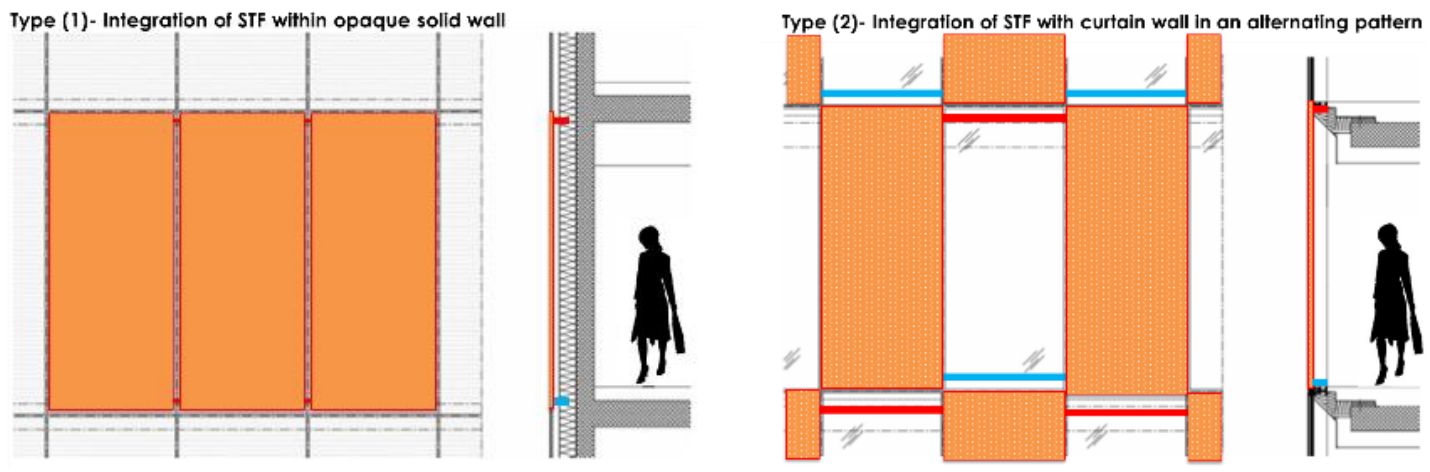

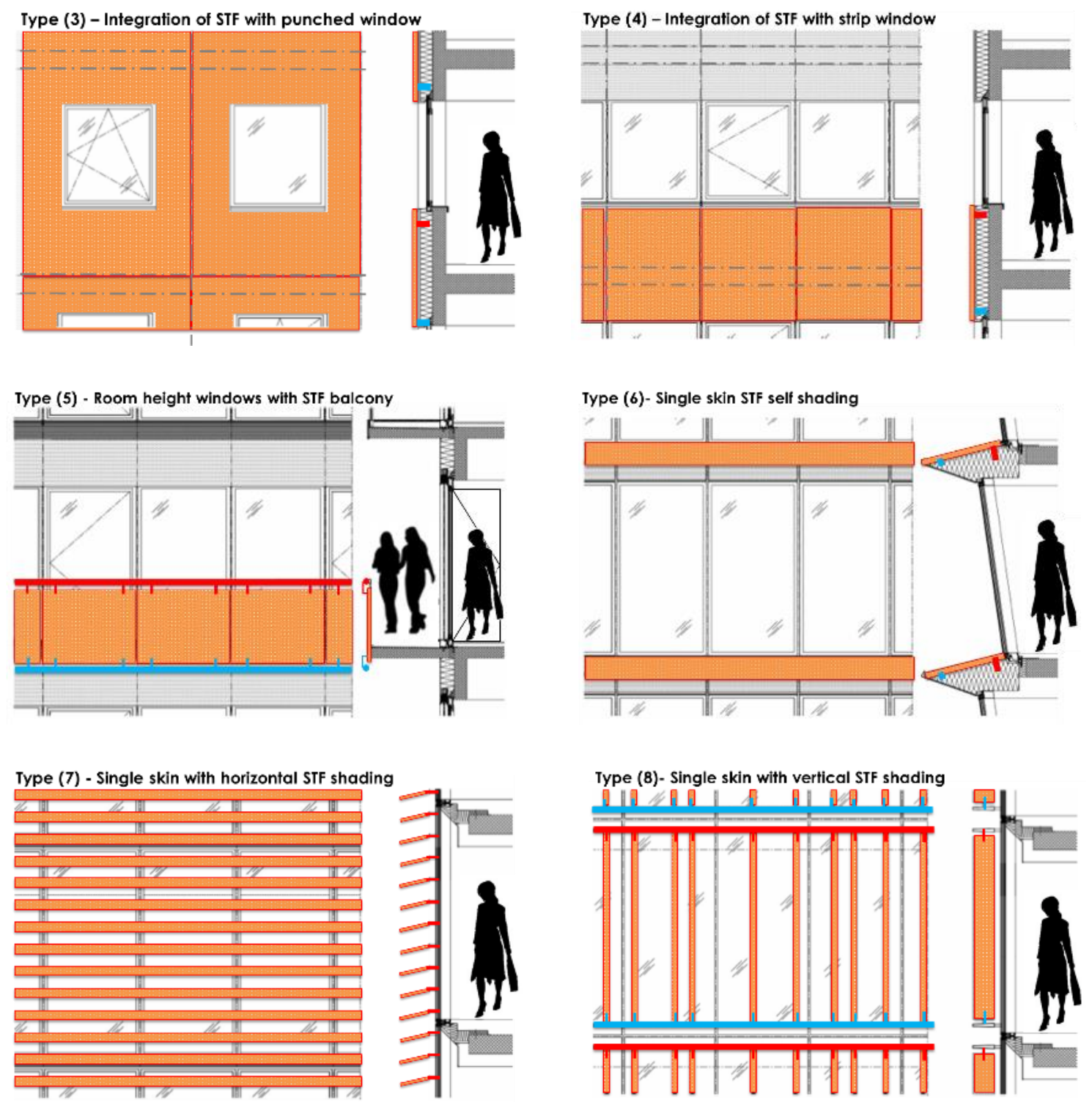

Figure 36. Schematic designs of compact STF modules installations for mid/high-rise buildings (revised drawings based on pictures from Emmer Pfenninger Partner AG, 2012).

\section{Integration into the building: system and comfort}

The compact unglazed modules can be used in installations at different scales, from residential houses to large industrial or institutional buildings. Preferred applications are the ones with high DHW demand and/or comfort floor heating (hospitals, sport facilities, schools, multifamily buildings). Depending on the application, the modules can be connected to each other in different configurations (in parallel or in series) and arrangements (centralized and decentralized).

Figure 37 presents a typical concept design where the modules are installed in a multifamily household and used for domestic hot water preparation and space heating. The modules are connected in a decentralized arrangement in each dwelling, so that harvested solar heat is effectively delivered to the end users minimizing the distribution heat losses.

Overall, the design of the modules allows to achieve not only high thermal performance and a versatile architectural design, but also the possibility to create a scalable and modular system that is configured to meet the requirements of the single application. 


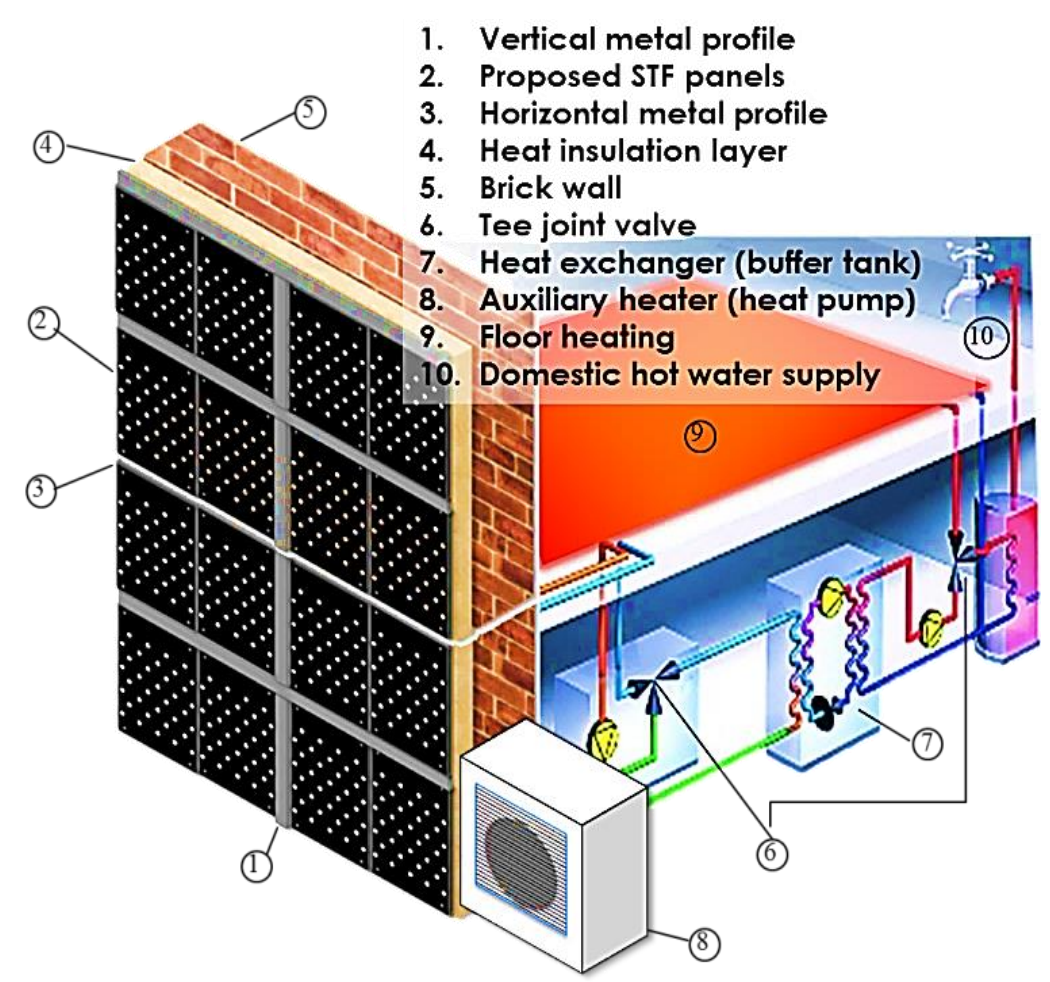

Figure 37. Conceptual design showing the compact STF modules integrated in a façade.

\section{SWOT analysis}

\section{Strengths}

- The architectural and technological integration is easy thanks to the wide range of installation options (window, balcony, overhang, roof and façade, with PV)

- Aesthetically versatile: the collectors resemble conventional metal walls and are available in various colours and shapes

- The collectors harvest solar heat with high thermal performance and lower dependence on weather conditions (such as dust, rain and snow) with respect to the conventional ones

- The investment cost is low with respect to traditional solar thermal collectors

- Easy handling during transport and installation is possible thanks to the low weight of the modules

- The collectors require low maintenance

\section{Weaknesses}

- Unglazed collectors are suited only for low temperature applications and require auxiliary or supplemental heating system

- A hot water tank or other thermal storage containers must be set up

- There are some risks due to the formation of mineral deposits, corrosion and leakage caused by freezing

- Heat dissipation is fundamental to prevent overheating in absence of heating demand

- Condensation may occur on the facade during the heating season

- High electricity consumption related to the circulation of the working medium

- Piping arrangement is critical in both building integration outlook and overall performance

\section{Opportunity}

- In some countries, the authorities include solar heating systems in their incentive programs

- Since some well-established large-scale industrial processes for metal sheets working are used, it is expected that significant cost reductions and various architectural and aesthetic requirements can be achieved with the increased flexibility in industrial mass production

- The movement toward "sustainable buildings", "green buildings" and even "zero energy buildings" is a strong driver for the adoption of solutions of this kind

\section{Threats}

- Proper design, commission and HVAC integration are needed to achieve good performances

- The apparent simplicity of the solutions might lead to a naive and inexperienced competition

- Different legislative constraints in each country can be an obstacle

- Architects and building designers are sceptical about relevant building integration solutions other than the established system application 


\section{Lessons learned}

- Building integrated solar façades must be aesthetically appealing and technically reliable to be accepted by architects and stakeholders.

- Building Information Modelling design is suggested to estimate the potential impact of the building integration considering the whole process. The associated features offer the valuable possibility for design professionals to assess multiple design alternatives against different priorities and resources (such as time, energy, budget), thus helping in the decision-making process towards a collaborative sustainable design.

- It is necessary to have specific guidelines or standards to address the integration constrains with regard to hygiene/ hydraulic/construction aspects.

- Hygrothermal analysis should be carried out to investigate the risk of moisture transfer in the exterior façade, especially for installations in households.

\section{Further reading}

J. Shen et al. (2018) A multifunctional facade with solar thermal technology: Investigation of a compact unglazed solar thermal facade for building integration, Lap Lambert Academic Publishing 2018, ISBN: 978-613-3-99092-0 X. Zhang, J. Shen et al. (2016) An initial concept design of an innovative flat-plate Solar Thermal Facade for building integration (Chapter 14), Sustainable Buildings and Structures; Page: 103-107; 2016 Taylor \& Francis Group, London, ISBN: 978-1-138-02898-2

J. Shen, X. Zhang et al. (2016) Characteristic study of a novel compact Solar Thermal Facade (STF) with internally extruded pin-fin flow channel for building integration, Applied Energy 2016; 168: 48-64. 


\section{MC-Solar - Modular curtain wall with air-driven solar collection}

by Beñat Arregi and Roberto Garay, Tecnalia, Spain

\section{Product description}

\section{Brief concept description}

MC-Solar is a modular double-skin curtain wall that harvests solar radiation to preheat fresh air conveyed to the ventilation system of a building. The air cavity between the internal and the external skin enables not only to exploit solar gains but also to recover the heat transmission losses from indoor. The system can supply the airflow required for ventilation with preheated fresh air, thereby reducing the energy consumption during the heating season, and even delivering net gains in favourable conditions. In cold weathers, the system aims to partially or fully cover the heat demand of the building with free solar heat gains. Whenever heating is not needed, a bypass element allows the evacuation of the excess heat by stack effect so that the façade operates as rear-ventilated façade system.

MC-Solar has been jointly developed by Uxama Fachadas Singulares, Enertec and Tecnalia. The main target market is the commercial sector, and in particular the renovation of office buildings. The system is conceived as an energy harvesting alternative to conventional curtain wall systems and can be coupled to any commercial air handling unit.
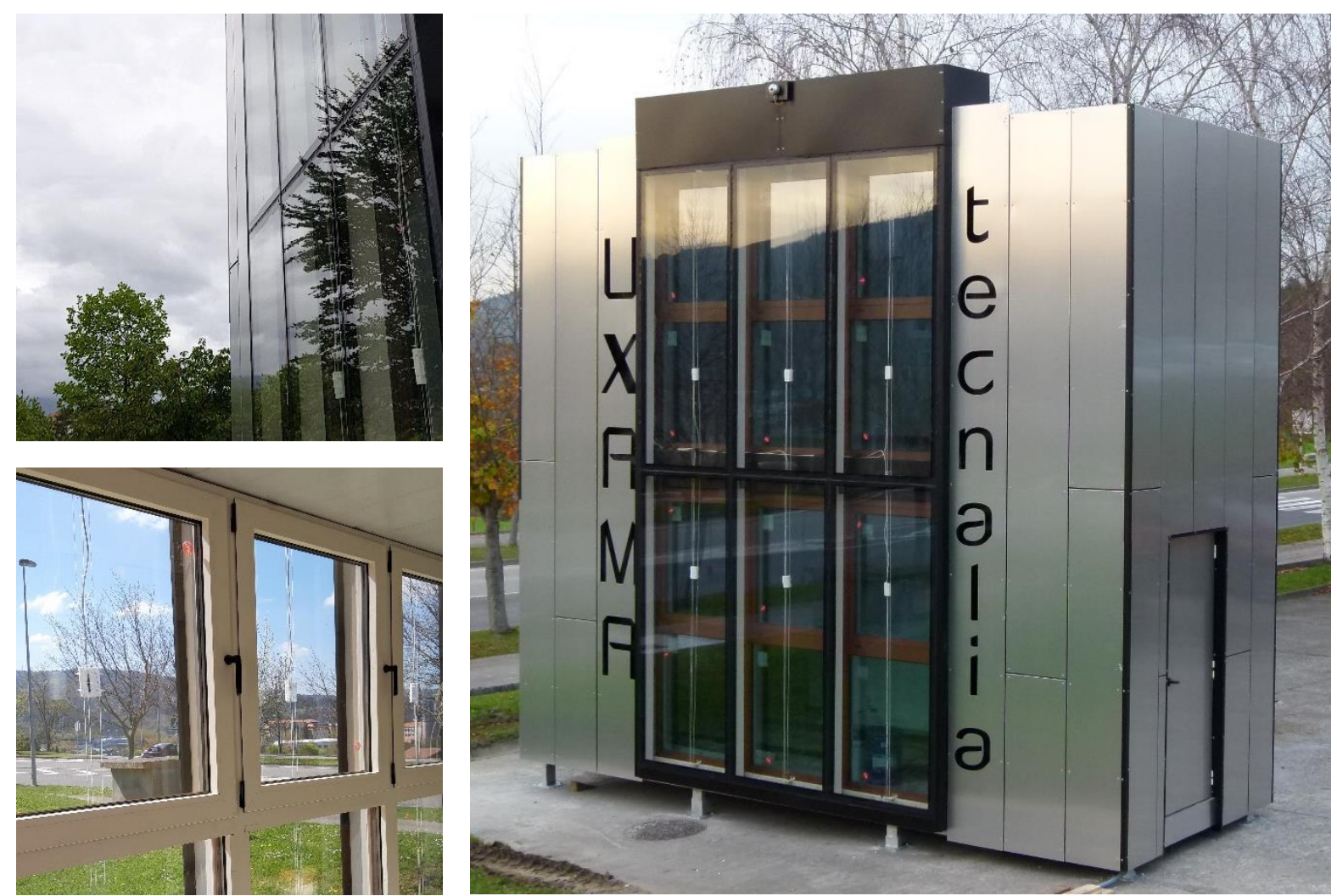

Figure 38. Full-scale prototype for experimental validation of the concept.

\section{Architectural and technological integration into the envelope}

The aesthetic appearance of MC-Solar does not differ from commercial curtain wall façades, and transparency is maximised as no visually obtrusive elements are required.

The layering of the façade is engineered to maximise the share of solar gains emitted to the air cavity between internal and external skin, while minimising the gains to the indoor space. The external glazing is made of an absorptive sheet with a high solar factor, and the internal glazing combines insulating properties with a low solar factor and low reflective properties. The base of the curtain wall accommodates a series of openings with integrated filters for directing clean external air into the cavity. Transoms are narrower than vertical mullions to allow the continuity of the air cavity along the full height of the façade. The rising preheated air is collected into an opaque plenum that is visually integrated in the roof parapet. 


\section{Integration into the building: system and comfort}

A duct from the pre-heated air collection plenum provides an alternative supply to the air handing unit (AHU), thereby allowing a simple integration with the centralized mechanical ventilation system of the building. An integrated control system with embedded sensors and actuators operates a series of dampers, which can either direct the preheated air to the inlet of the AHU (powered by a ventilator) or dissipate it to the environment. Hence the heating and cooling loads of the building are reduced, and ventilation air is supplied close to comfort temperatures. The system allows for an immediate use of solar gains and does not require a connection with hydraulic circuits nor the use of additional products or materials with thermal storage capabilities.
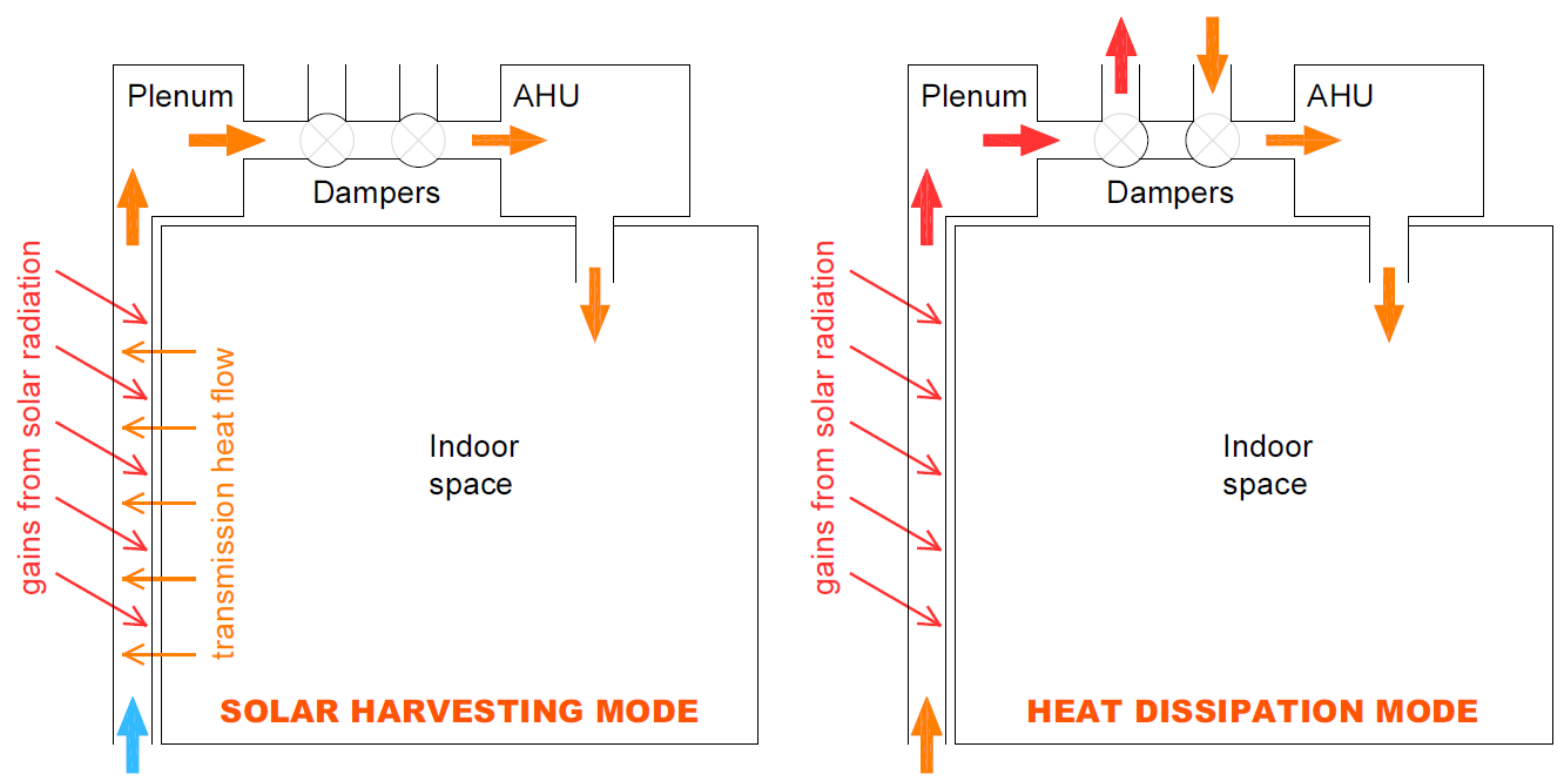

Figure 39. Diagram of the concept and operation modes of MC-Solar and its integration with the ventilation system.

\section{SWOT analysis}

\section{Strengths}

- $\quad$ Aesthetic qualities of curtain walls are kept (transparency, visual contact with exterior)

- It reduces energy demand by covering a share of the heat load with solar energy

- It is a fully modular and prefabricated solution adaptable to specific design choices

- Easy integration with centralised ventilation systems: no storage or hydraulic circuit

- It improves both comfort and indoor air quality (ventilation rate can increase whenever free solar gains are available)

- The additional cost over conventional curtain wall façades is low

\section{Opportunity}

- It sits well within the strong market trend towards modular curtain walls

- It can satisfy (often conflicting) energy efficiency and indoor air quality requirements

- Future changes in regulation with more strict requirements will provide a strong advantage against conventional curtain wall systems

\section{Weaknesses}

- The choice of glazing systems is constrained if an optimum energy performance is sought

- It requires connection with an air handling unit (might not be suitable for all buildings)

- Not yet evidence on long-term durability and maintenance of filtering systems

\section{Threats}

- Regulations for commercial buildings still have poor energy performance requirements

- Market and regulations are still focused on add-on renewables, little awareness on envelope-integrated renewable systems

- $\quad$ Other renewable technologies (as PV) could get more cost-competitive in the mid-, longterm

- Awareness of energy efficiency in the curtain wall market is growing but it is still limited 


\section{Lessons learned}

- $\quad$ Building the solution over already existing products (e.g. curtain wall framing, parapet elements) leads to lower added costs and a more successful aesthetic integration.

- Hygrothermal conditions in the air cavity might differ from regular double-skin walls: potential implications need to be considered at design stage.

- Coordination between construction and ventilation professionals is key for achieving an efficient implementation.

\section{Further reading}

González, D., Arregi, B., Garay, R., Álvarez, I., Sagarduy, G. Innovative curtain wall with solar preheating of ventilation air and integrated control system. ICAE 2018, San Sebastian, Spain.

\section{Acknowledgment}

This project has received financial support from the Basque Government through the Hazitek programme (project ref. ZL-2016/00720, ZL-2017/00571, ZL-2018/00201), supporting experimental development and industrial research projects. 


\section{Façade-Integrated Air-Driven Solar Thermal Collectors \\ by Roberto Garay and Julen Astudillo, Tecnalia, Spain}

\section{Product description}

\section{Brief concept description}

The system is an air-driven solar thermal collector developed for the integration into opaque surfaces of the buildings' envelope. It consists of a glazed cavity that allows the collection of solar heat, which is then exploited for space heating applications.

Different variants of the system have been developed. A passive solar thermal collector variant (Figure 40) incorporates several dampers/rollers that control the connection of the cavity with the outdoor and the indoor spaces to achieve passive heating and cooling effects. In some variants, Phase Change Materials are incorporated to create a thermal storage and extend the use of solar heat to early night periods. Moreover, an external blind can be used to increase the capabilities of the chamber when needed. A trans-vented variant was developed for the integration into the mechanical ventilation system of the building to pre-heat air before the active heating stage. Depending on the integration processes, the harvested heat could also be used for (partial) re-generation of desiccant-based cooling process.

This concept was developed by TECNALIA with focus on buildings' envelope retrofit but it could be applied also to new constructions. The system is conceived to harvest solar energy, but the use of rear insulation makes this solution also suitable for the upgrade of the envelope to the prescriptions of recent building energy codes.
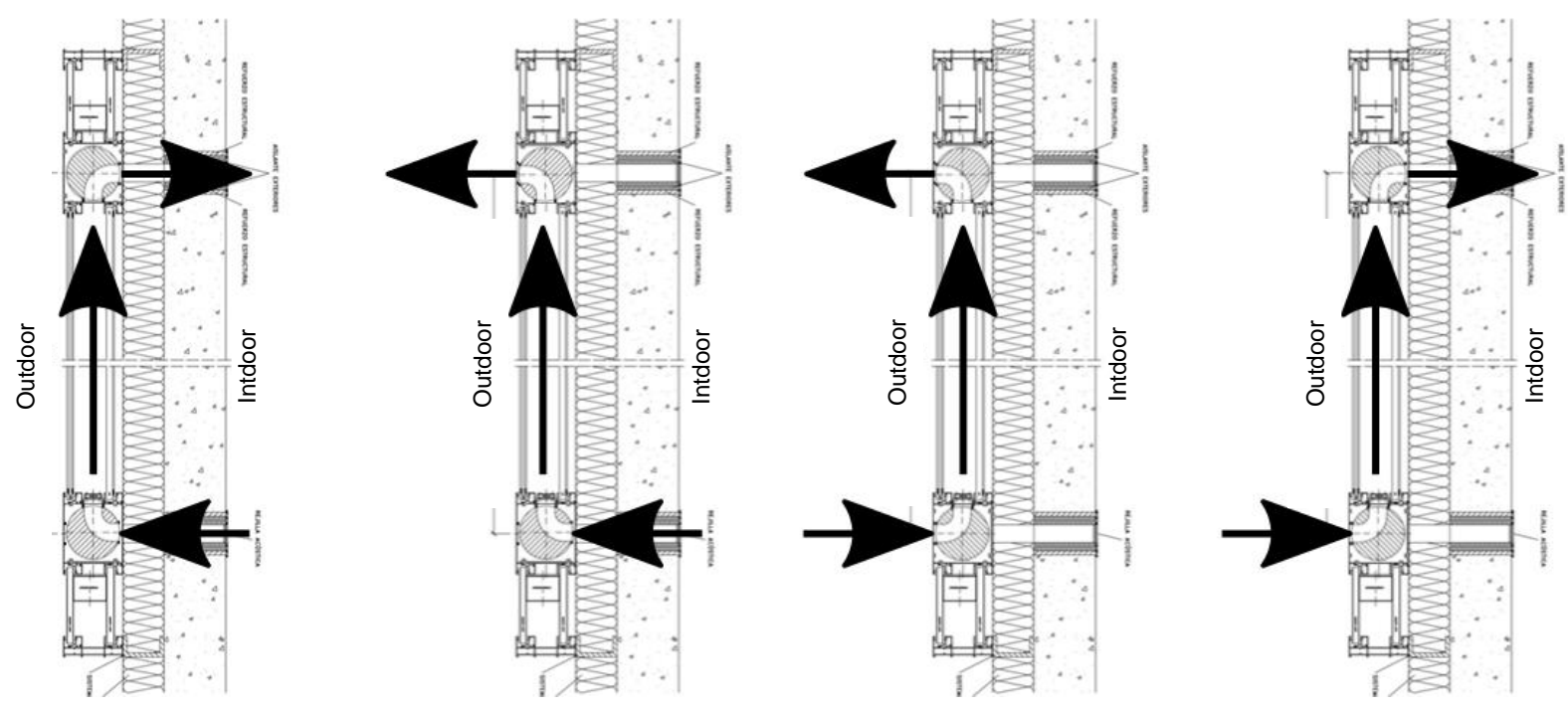

Figure 40. Operational schemes of the passive solar air collector, vertical section shown. Different airflow paths (highlighted by arrows) can be used depending on winter, summer, day and night requirements.

\section{Architectural and technological integration into the envelope}

The aesthetic appearance of the collector is of a unitized glazed curtain wall system. Present prototypes are developed in aluminium, but the use of other materials is possible (steel, composite frames, etc.). The integration of the system with other envelope elements such as thermal coat and/or windows is also possible.
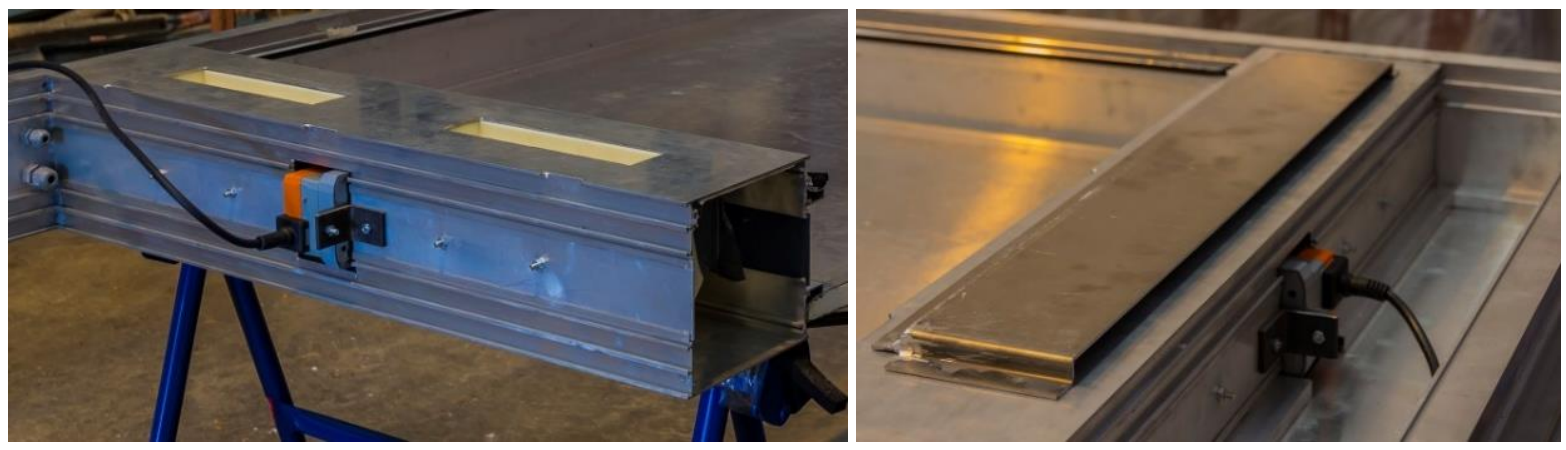

Figure 41. Air-Driven Solar Thermal Collectors system during the manufacturing process. 


\section{Integration into the building: system and comfort}

The passive solar collector system is integrated by means of direct perforation of the building wall so that the cavity of the air collector is connected with the building interior spaces. Four perforations per module ( surface of the module is $2,629 \times 0,869 \mathrm{~m}=2,28 \mathrm{~m}^{2}$ ) are required, at floor and ceiling height. An integrated control system with embedded sensors and actuators operates the dampers. A small control display is placed inside the building, with the additional possibility of controlling the system by smartphone.

The trans-vented variant is connected to the building by means of a duct that provides an alternative supply to the air handing unit (AHU), thereby allowing a simple integration with the centralized mechanical ventilation system of the building. An integrated control system with embedded sensors and actuators operates a series of dampers, which can either direct the preheated air to the inlet of the AHU (powered by a ventilator) or dissipate it to the environment. Hence, heating and cooling loads of the building are reduced, and the ventilation air is supplied close to comfort temperatures. The system allows an immediate use of solar gains and does not require a connection with hydraulic circuits nor the use of thermal storages.

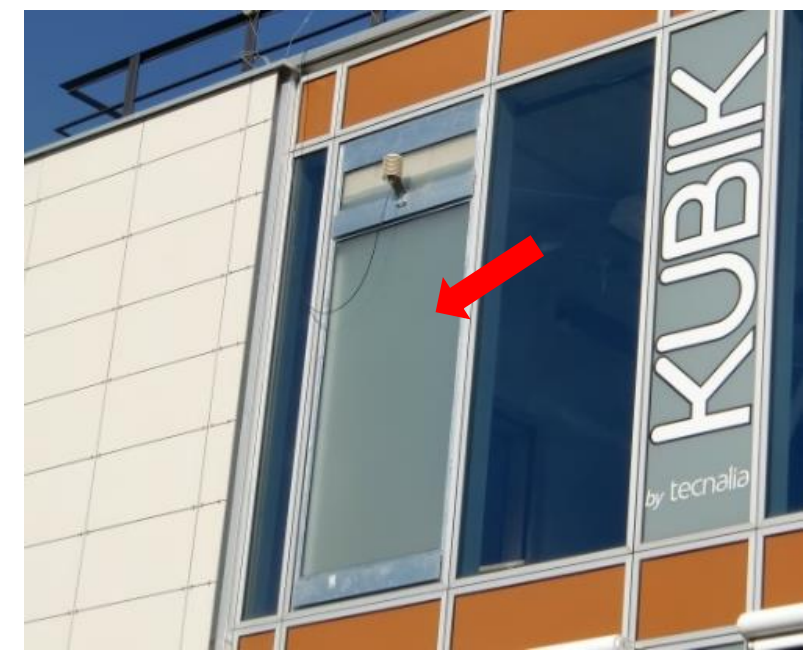

Figure 42. System after the integration in a building's envelope (test setup in the KUBIK test facility).

\section{SWOT analysis}

\section{Strengths}

- It is fully modular and prefabricated and can be adapted to suit specific design choices

- Easy integration with centralised ventilation systems: no storage or hydraulic circuit

- It reduces the energy demand by covering a share of heat load with solar energy

- Improves both comfort and indoor air quality (ventilation rate can increase whenever free solar gains available)

- A good architectural integration for buildings with glass façades can be achieved

- It can satisfy the often-conflicting energy efficiency and indoor air quality requirements

\section{Opportunity}

- It sits well within the strong market trend towards integration of renewable energy sources in buildings' retrofit actions

- $\quad$ Future changes in regulation will require of solar system integration in building envelopes to meet NZEB requirements

\section{Weaknesses}

- Architectural integration for buildings with non-glass/metal surfaces needs to be improved

- In some variants, it requires connection with an air handling unit (might not be suitable for all buildings)

- In some variants, it requires a connection with the building interior

\section{Threats}

- Market and regulations are still focused on add-on renewables, little awareness on envelope-integrated renewable systems

- $\quad$ Other renewable technologies (as PV) could get more cost-competitive in mid-long terms

- Awareness of energy efficiency in the residential market is still limited 


\section{Lessons learned}

- The system resulted in significant solar heat capture in South-exposed façades.

- BIST systems require of a highly integrated development comprising professionals from many different backgrounds.

- Full-scale experimentation led to early-stage detection and correction of faults.

- Failure mode analysis led to improved design and better operation and maintenance procedures.

\section{Further reading}

Garay Martinez, R., Astudillo Larraz, J., Performance assessment of façade integrated glazed air solar thermal collectors, Energy Procedia 115 (2017), 353-360, https://doi.org/10.1016/j.egypro.2017.05.032 


\section{BASSE - Building Active Steel Skin \\ by Peru Elguezabal, Tecnalia, Spain}

\section{Product description}

\section{Brief concept description}

BASSE is an active façade composed of an unglazed collector and a steel sandwich panel which can harvest low temperature heat from solar radiation. The design of this innovative solar envelope system and its use in combination with a heat pump were studied as part of a research project concluded in 2016 (BASSE-Building Active Steel Skin). A key factor to potentially reach high production is its industrial design that enables a reduction of costs, a higher level of feasibility in the performance, and the support of an already mature industry such as the one of steel panel manufacturers with a robust value chain.

As shown in Figure 43, the active façade is composed of five main elements. A sandwich panel (1) made of a polyurethane insulation core is enclosed in two slotted steel skins. Plastic pipes (2) are installed into the slots of the external skin and covered by a finishing steel layer (3) that acts as a solar absorber. Each panel integrates 6 parallel pipes interconnected by completely modular headers or manifolds (4). Concerning the size of the collector, a standard panel is about $3 \mathrm{~m}$ long, $1 \mathrm{~m}$ wide and $0.8 \mathrm{~m}$ thick.

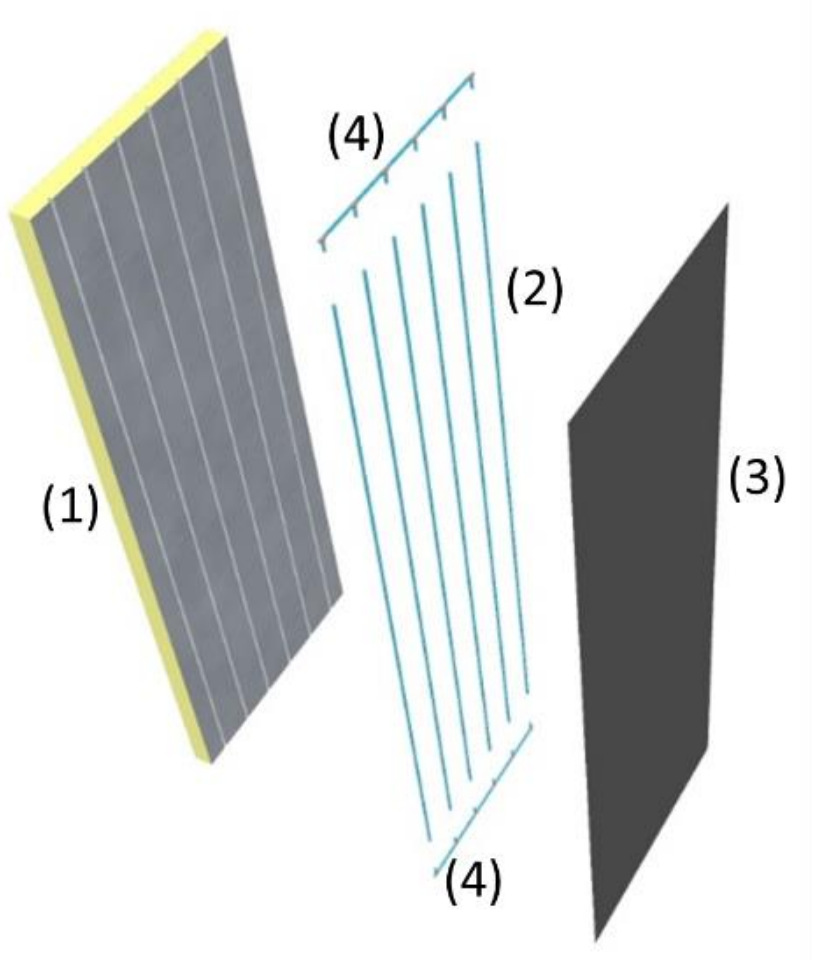

Figure 43. Main components of the BASSE - Building Active Steel Skin.

This active skin element is developed for the installation in the opaque areas of the envelope and the dimensions of the single panel (especially the length) can in line of principle reach even 15 meters limited by transportation possibilities, although the collector efficiency significantly decreases for such large areas. The solution exploits the high conductivity of steel in a low temperature collector $\left(<50^{\circ} \mathrm{C}\right)$, which alone is not enough to cover the energy needs of a building but when coupled with a heating device (like a heat pump or a boiler) significantly increases the efficiency of both collector and heating system.

In the final demonstration stage, a complete system was installed in a real building and the performance of $18 \mathrm{~m}^{2}$ area of active façade were demonstrated, also in combination with a heat pump. The definition of the complete system was a joint development among TECNALIA, TATA STEEL, DOW CHEMICAL, ETL EUROPEAN THERMODYNAMICS and NIBE. 


\section{Architectural and technological integration into the envelope}

The concept is based on a modular and metallic design resulting into a system that externally cannot be differentiated from a standard sandwich panel. Such appearance is more popular in industrial and tertiary buildings but is less usual in offices and especially in the residential sector. However, the recent interest in the field of façades for advanced coatings and technologies represent a clear opportunity for this metallic skin to provide modern and technically sophisticated solutions.
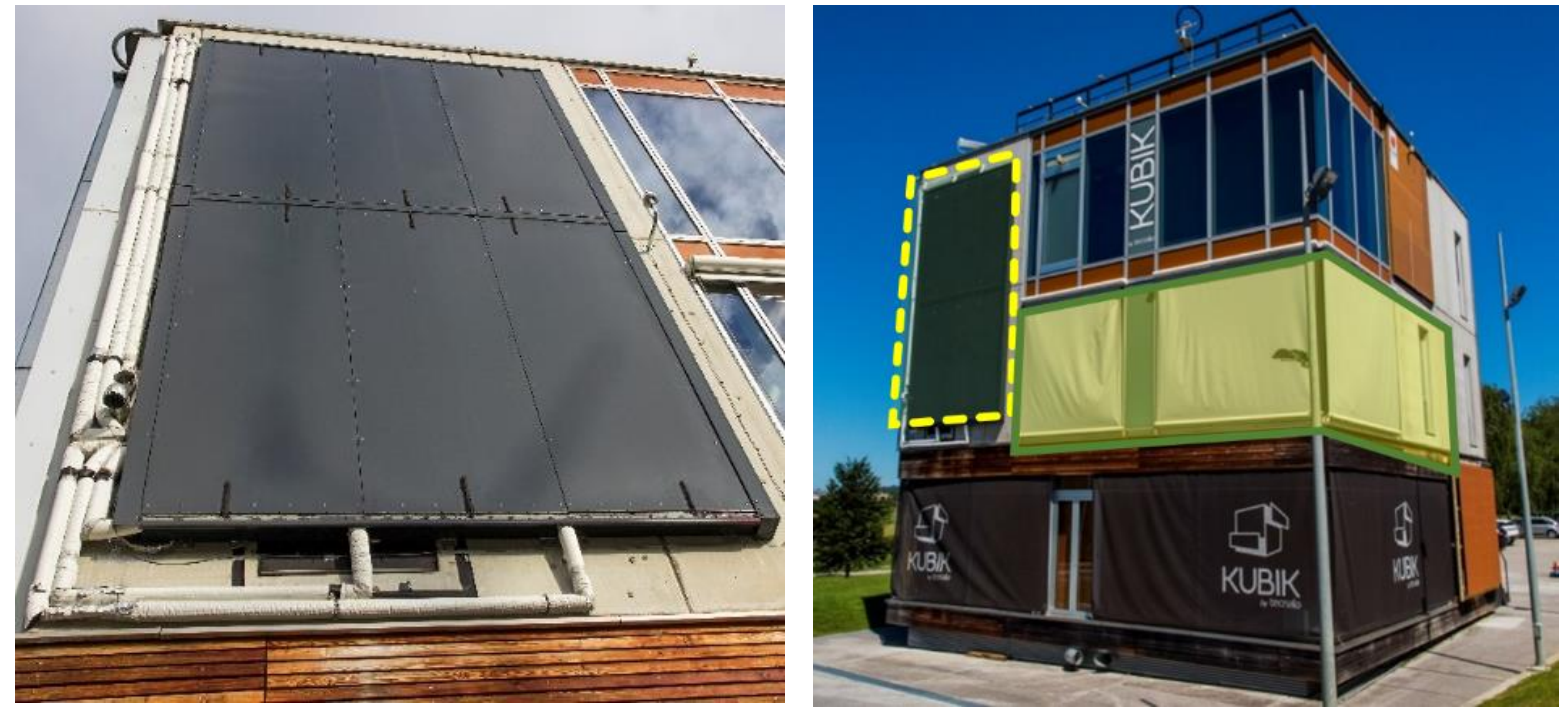

Figure 44. Picture of $18 \mathrm{~m}^{2}$ assembly of BASSE composed of 6 panels installed in the Kubik test facility.

\section{Integration into the building: system and comfort}

The complete system presented in Figure 45 (left) is designed to provide warm air and DHW by means of a heat pump connected to the low temperature solar collector and a heat recovery system on the source side. The system is completed by two water thermal storages, one in the solar circuit and one in the DHW circuit. The liquid circulating through the heat pump and solar circuit is a water-alcohol mixture to avoid freezing in cold season and reduce the electricity consumption during operation. The main source of electricity consumption is the heat pump, but also the circulating pumps on solar circuit and on the connections with the ventilation system are cause of consumption.
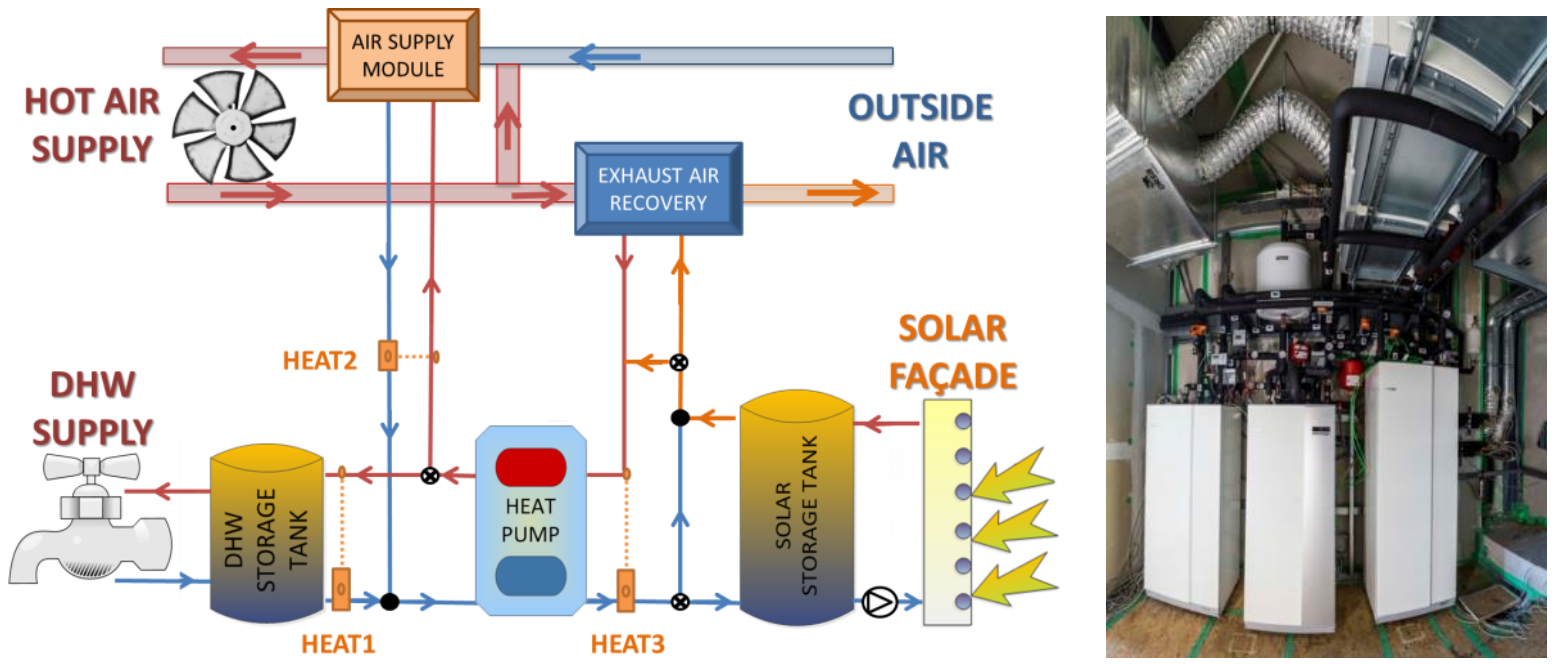

Figure 45. Complete system schematics with heat pump and solar façade as main elements (left) and utility room with installed equipment for the complete HVAC system (right). 


\section{SWOT analysis}

\section{Strengths}

- It is a flexible and modular concept that can be applied to different façade typologies

- It is not possible to distinguish between active and passive metallic façade elements

- Very good cost-effectiveness: low cost over standard sandwich panels

- The low maintenance and simpler safety measures of low-temperature collectors simplify the hydraulic system and the operation

- The integration with a heat pump system represents a promising synergetic combination

- It is a very convenient option to cover large opaque surfaces, especially interesting for retrofitting by over-cladding

\section{Opportunity}

- It could be possible to achieve high scale production and reach an optimal cost and performance ratio thanks to the industrial design

- $\quad$ The current promotion of renewables in buildings is a driver for the adoption of this solution

- The integration in other hydraulic layouts and with different energy system can be explored

- The integration with PV is an option to simultaneously produce heat and electricity

- The development of a glazed version based on the unglazed one would allow to achieve higher solar yields

\section{Weaknesses}

- The low reachable temperatures and the low solar yield compared to other solar thermal technologies limit the applications and make the combination with other heat generators unavoidable

- A high density of openings in the façade can limit the use of this solution

- Too long panels result into lower efficiencies and thus there is the necessity for detailed engineering

- $\quad$ The necessity of solving the interconnected hydronics (input / output) increases the complexity of the façade
Threats

- The industrial appeal of metallic façades represents a barrier in certain markets

- $\quad$ For the design that is already under development, maintenance and long-term duration needs to be studied

- $\quad$ There is lack of regulation for active systems integrated into façades

- The incorporation of additional technologies into the envelope (active \& movable elements, sensors, actuators...) and its interaction with the system could constrain its applicability

\section{Lessons learned}

- The integration of a simple concept to the envelope can provide significant useful energy that contributes to reduce the dependency on fossil fuels.

- The control and management of the different components and the interrelation of the active façade with the HVAC system is key to achieve competitive efficiencies.

- Detailed definition of the system is required combining expertise in the field of both façade and HVAC engineering.

\section{Further reading}

Elguezabal, P., Lopez, A., Blanco, J. M., \& Chica, J. A. (2020). CFD model-based analysis and experimental assessment of key design parameters for an integrated unglazed metallic thermal collector façade. Renewable Energy, 146, 1766-1780. https://doi.org/10.1016/j.renene.2019.07.151

S. Boudjabeur, et al., Building active steel skin. (BASSE). Grant agreement no: RFSR-CT-2013 - 00026. Final report, ISBN 978-92-79-94133-7. ISSN 1831- 9424

Elguezabal, P., Garay, R., Martin, K., (2017). Experimentation under real performing conditions of a highly integrable unglazed solar collector into a building façade. Energy Procedia. Vol. 122 (2017), 775-780. DOI. https://doi.org/10.1016/j.egypro.2017.07.395

\section{Acknowledgment}

The BASSE project received funding from the European Union, RFCS Program, Research Fund for Coal and Steel project Building Active Steel Skin (BASSE, Grant Agreement no RFSR-CT-2013-00026). 


\title{
Solar Gains Control Systems
}

\section{Commercial systems}

\author{
Summer garden \\ by Vickie Aagesen, Cenergia a part of Kuben Management, Denmark
}

\section{Product description}

\section{Brief concept description}

The "Summer garden" concept is a new development of the traditional winter garden where part of the living room near the facade can be utilised as an exterior area during summertime, as shown in Figure 46 . This is realized with the use of two different window glass façades: a more insulated exterior winter façade (U-value of $0.9 \mathrm{~W} /\left(\mathrm{m}^{2} \mathrm{~K}\right)$ ) and an interior less insulated summer façade (U-value of $1.3 \mathrm{~W} /\left(\mathrm{m}^{2} \mathrm{~K}\right)$ ). During summer, the exterior glass façade is opened, and the inner glass façade is used. In this way, the "summer garden" is created as a covered exterior outdoor space, where the cover also works as horizontal solar shading system and helps to prevent overheating in the building. During winter, the outer façade is closed and the inner glass facade is opened, so that the whole space can be used as heated area.

The concept is tested and implemented in a new urban renewal housing renovation project at Gl. Jernbanevej in Valby (Copenhagen).

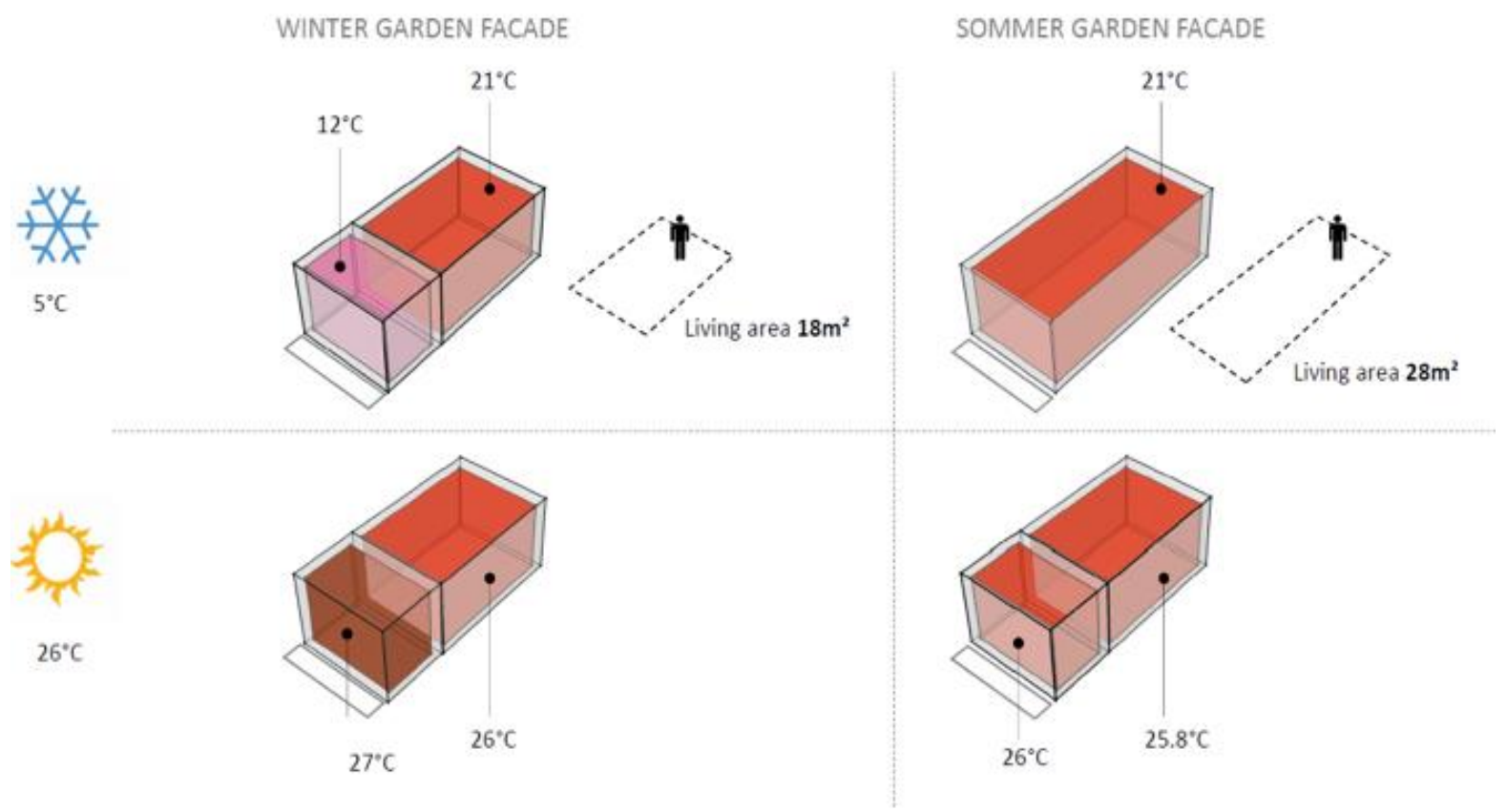

Figure 46. Winter garden vs. Summer garden concepts (Source: Cenergia).

\section{Architectural and technological integration into the envelope}

The "Summer garden" is an add-on to the existing building, which means that the initial architecture is highly influenced. In the specific case of Gl. Jernbanevej (shown from Figure 47 to Figure 49), this solution is applied to the façade facing the courtyard, i.e. the backside of the building. The building is built with a nice façade facing the road and a less nice façade facing courtyard, made of discarded bricks covered with stucco.

\section{Integration into the building: system and comfort}

The "Summer garden" is a low-tech solution but its operation depends on an active role of the tenants, who need to open and close the two façades during the climate changes throughout the year. The tenants will feel uncomfortable (too warm) during summer if they do not open the outer glass façade, and vice versa during winter. However, when the "summer garden" is properly operated, tenants will experience a nice comfort inside their apartments during summertime with less overheating hours. During wintertime, they can enjoy a larger living room without fixed shadings. 


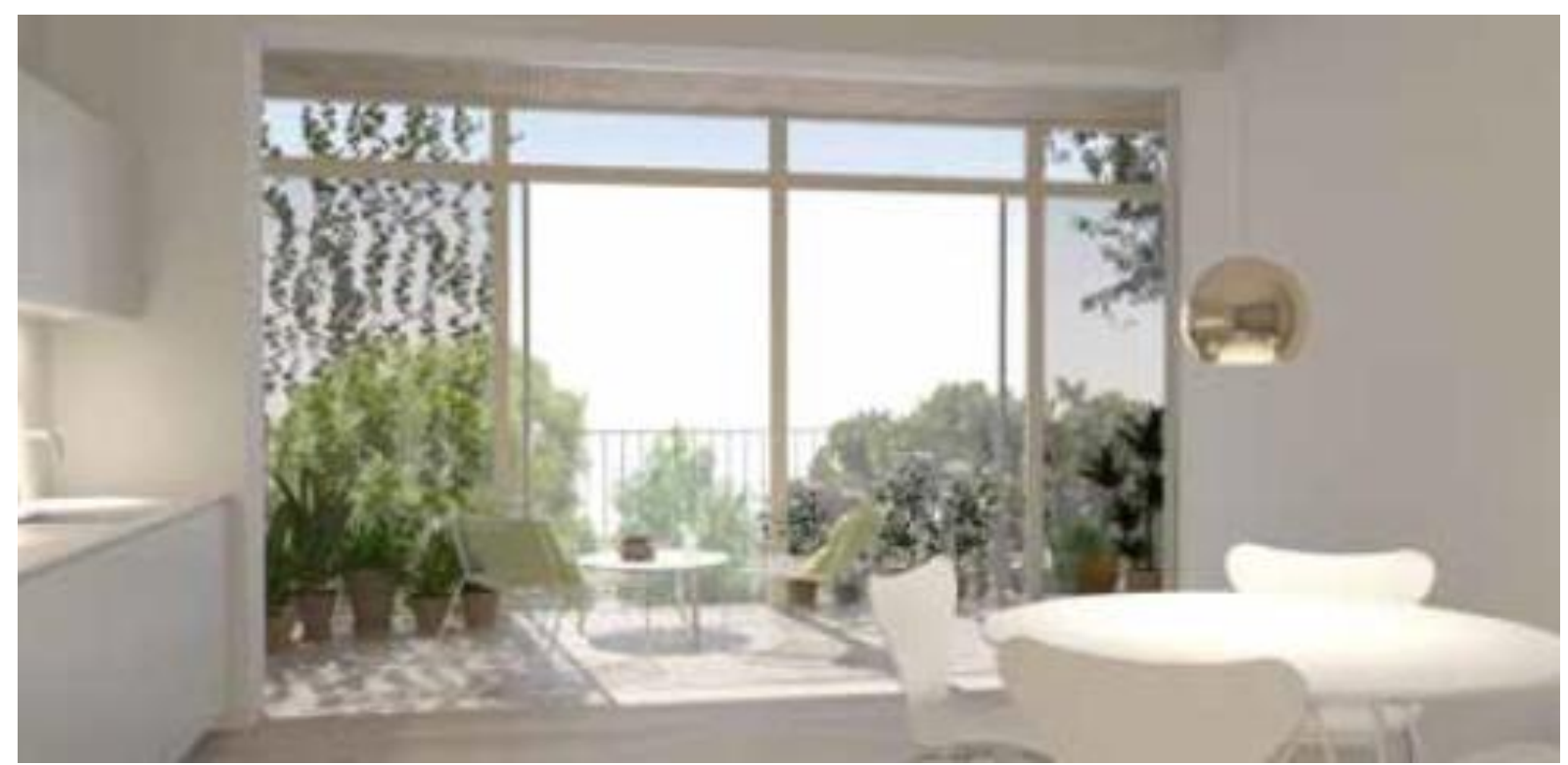

Figure 47. Illustration of "Summer garden" at Gl.Jernbanevej (Source: Domus arkitekter).

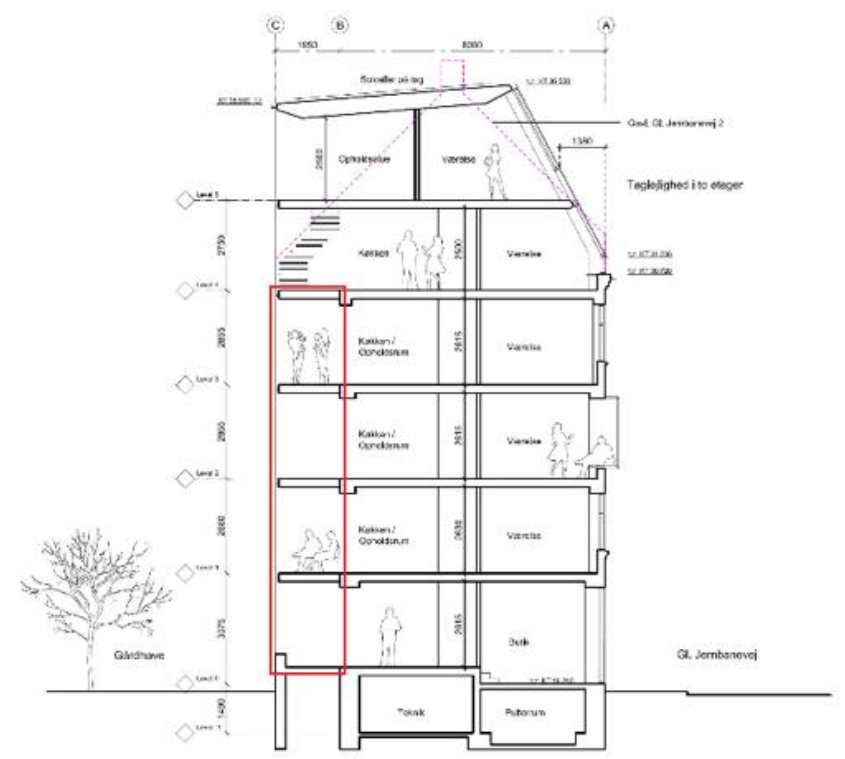

Figure 48. Illustration of the structure of the building. Positioning of "Summer gardens" is highlighted in red.
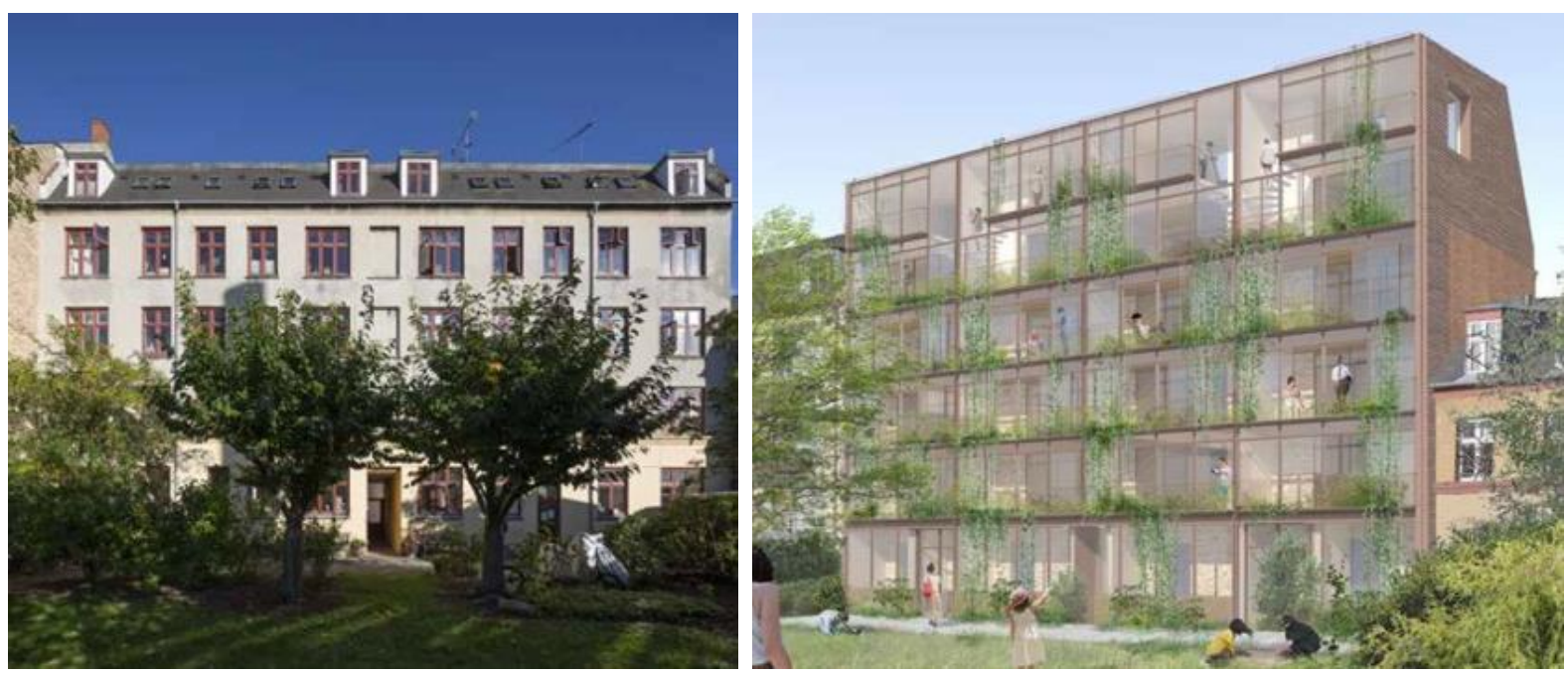

Figure 49. Existing courtyard façade before the renovation on the left and illustration of the courtyard façade when the "Summer garden" is added (after renovation) on the right (Source: Domus arkitekter). 


\section{SWOT analysis}

\section{Strengths}

- The solution is low-tech and the concept is simple to understand for the tenants

- Tenants are provided with an exterior space during summer and extra living area during winter

- Overheating in summertime is prevented, making solar shading systems redundant

\section{Opportunities}

- The market for balconies is large. Existing winter gardens can be replaced

- The attitude towards enhanced comfort conditions is a trend and people are willing and demand different way to live

\section{Weaknesses}

- A correct operation of the facades is required to achieve energy savings and thermal comfort

- Construction permissions must be obtained as the heated area of the dwelling increases

- If the summer garden is facing a deep room(over $10 \mathrm{~m}$ ) the solution would result in a very dark shaded inner core during summer operation

\section{Threats}

- The solution can be easily copied, as the products are well known and are available to everybody.

\section{Lessons learned}

Identifying a façade element that can satisfy the multiple necessities is challenging. For example, it has not been possible to get a (winter) facade element that can completely close and give a feeling of an open-air room during summer. In addition, at the time being it has not been possible to obtain a (summer) facade element that is theftproof.

\section{Further reading}

Website: http://www.domus.dk/node/318

Living in Light Box: www.activehouseroofsandfacades.com/living-in-light-box 


\section{LCW Switchable Windows}

by Philippe Lemarchand and Noel O’Neill, Technological University Dublin, Ireland

\section{Brief concept description}

The Liquid Crystal Window (LCW) technology developed by Merck, known as Licrivision ${ }^{\circledR}$ (Merck, 2019a) and

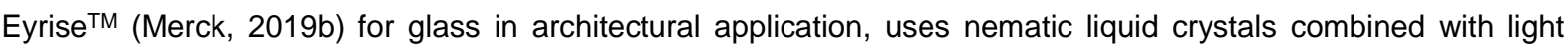
absorptive material to form switchable windows. Such windows electronically vary daylight transmission without impairing the view through the window. The change of transparency to any given transmission between its high transmission (clear) state and its low transmission (opaque) state occurs within seconds. With regard to solar radiation control, shading and glare are dynamically controlled. The smart operation of LCWs lowers the energy consumption associated to indoor lighting, heating and cooling and the associated carbon dioxide emission and operational costs (especially during the cooling season) and improve the occupants' health and comfort. Moreover, with a choice of the window colour appearance, a wide range of architectural aesthetic can be achieved.

\section{Architectural and technological integration into the envelope}

LCWs can enhance the design freedom of architects and building designers and allow the development of more creative and potentially larger glazed building facades, since they replace other shading devices installed for glare and sun protection. LCWs are façade integrated and will resemble any normal glazed façade, although a range of window colours is available to widen the range of architectural aesthetics that can be achieved. LCWs have no moving or mechanical parts and thus have very low maintenance needs and allow a long-term operation.

The need for LCWs for sun protection will depend on the orientation of the façade and the intensity of the solar radiation, but in general they can be installed on any façade orientation with no specific restriction. Depending on the desired solar shading level and on the required illuminance in the interior spaces, LCWs will range in light intensity from translucent to fully transparent.

One particular advantage is the fast responsiveness of the system, and this is especially beneficial in maritime climates or in high- to mid- latitude European countries such as the Netherlands, where external temperatures can quickly change over the course of the day. LCWs can rapidly and directly respond to the quick changes in the external climate, giving a more stable indoor environment while reducing peak loads and therefore enabling the use of slower responsive HVAC systems that use the buildings fabric to store / release heat (e.g. concrete core activation, under floor heating etc.).

\section{Integration into the building: system and comfort}

LCWs can effectively control and lower the amount of solar energy that penetrates the glass façade. A correct management of daylighting and indoor glare levels can improve the comfort and reduce the electricity consumption of artificial lighting. Moreover, LCWs electronically vary daylight transmission without impairing the view through the window and research in the field of human comfort has shown that a view on the external environment is healthy, improves the productivity and gives occupants a feeling of comfort and overall wellbeing.

Furthermore, an optimized control of solar gains means significant cost savings over the life of a building due to both a lower capital investment cost for the HVAC system (i.e. reduced size of the energy system) and savings in its annual operational costs. It is understood that LCWs can effectively manage solar gains but an auxiliary heating / cooling system will be needed in most buildings. In this case, the controls of the building system need to be configured so that the LCWs are used to reduce the amount of solar energy entering the building while balancing the need for indoor artificial lighting. Thermal comfort is then adjusted with the use of an auxiliary air conditioning system to meet the buildings heating / cooling demand.

To achieve a complete integration with the building's heating, ventilation and electrical controls system, LCWs require a good coordination in the building design team since the early phases of the design process and an ongoing technical support for the building contractors, with particular attention required by glazed panel, framing equipment and electrical controls. Recent developments have shown that wired glass is becoming more common in framing systems (a well-known wired glass example is Alarm-glass). 


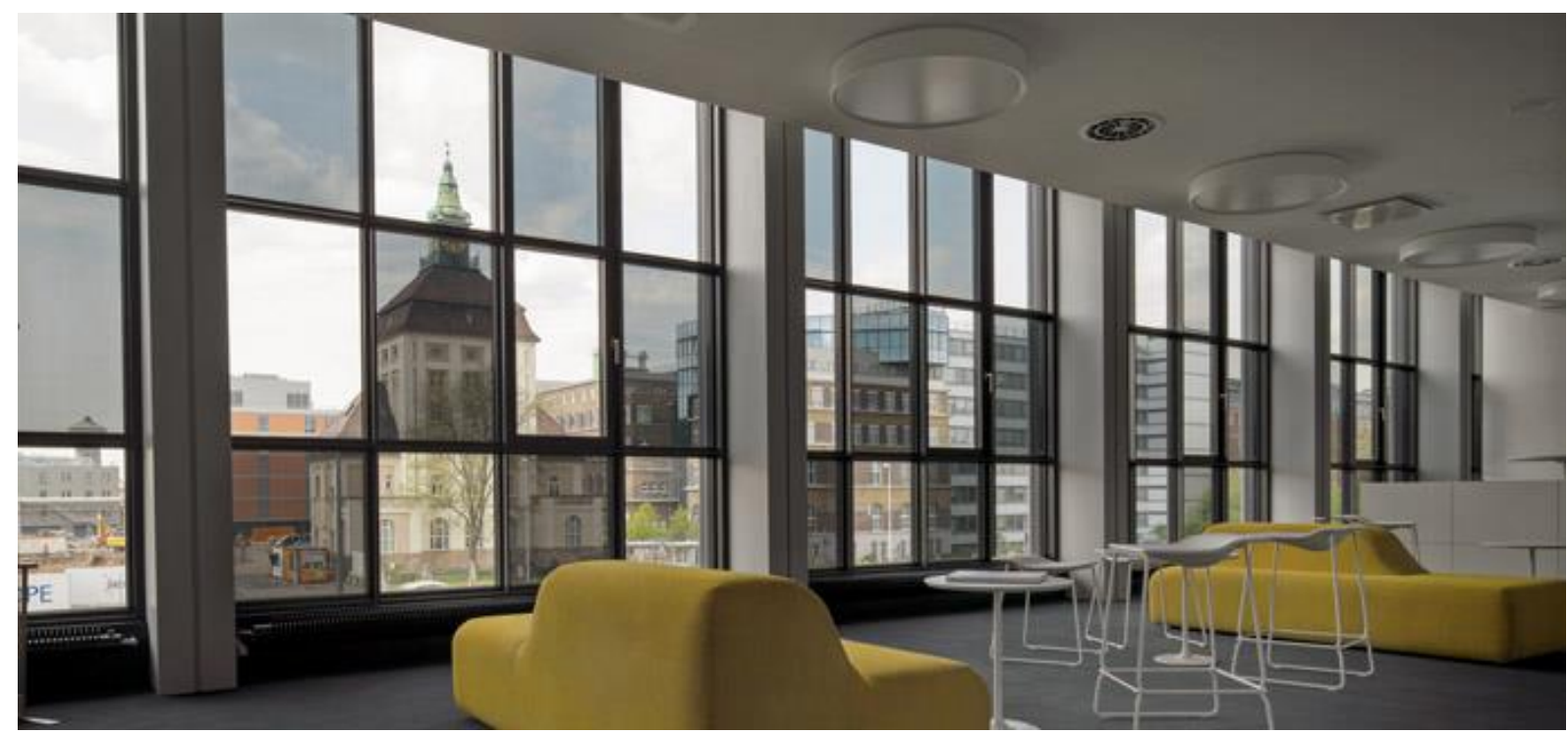

Figure 50. Colour neutral LCWs in low and high transmission states viewed from the indoor environment.

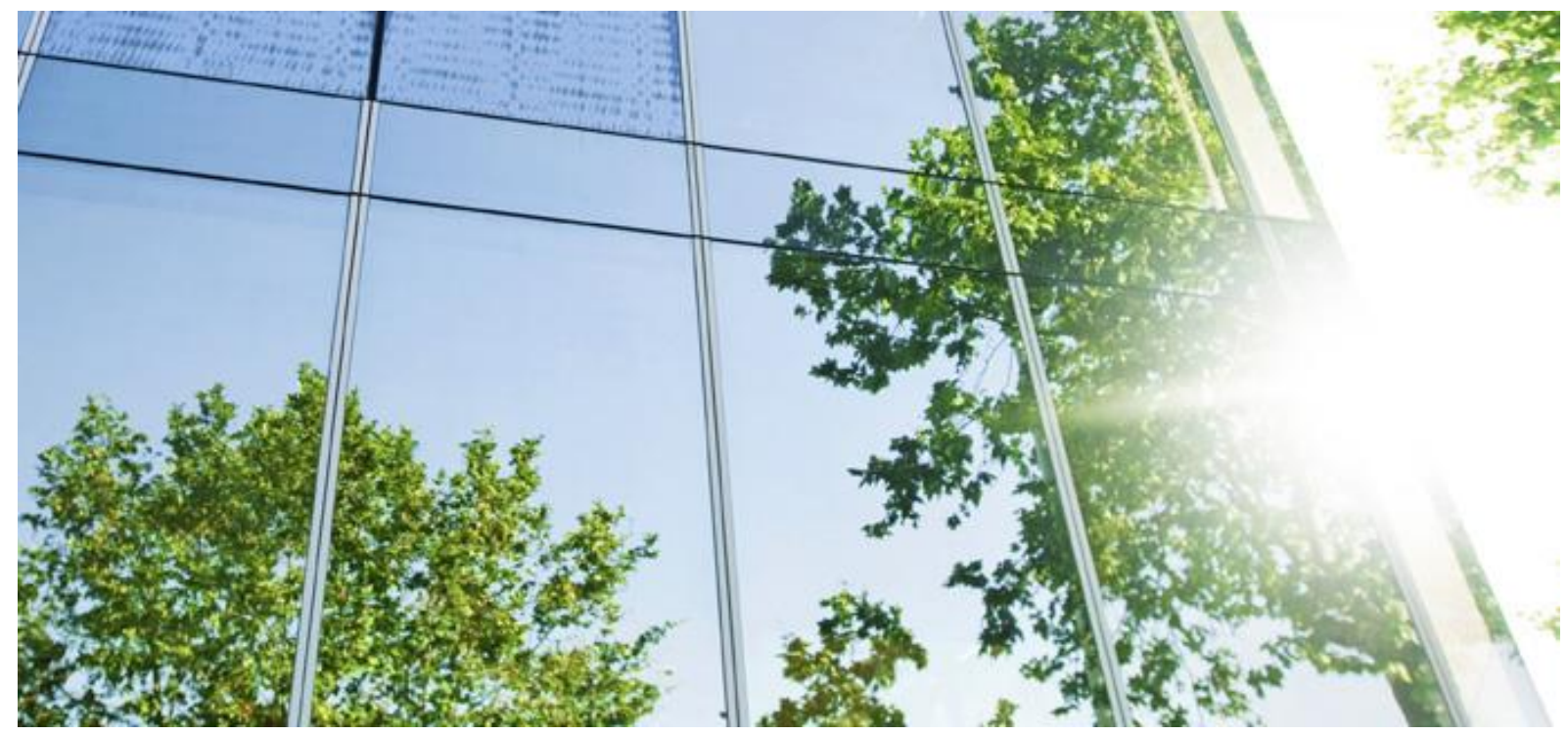

Figure 51. LCWs viewed from the external environment.

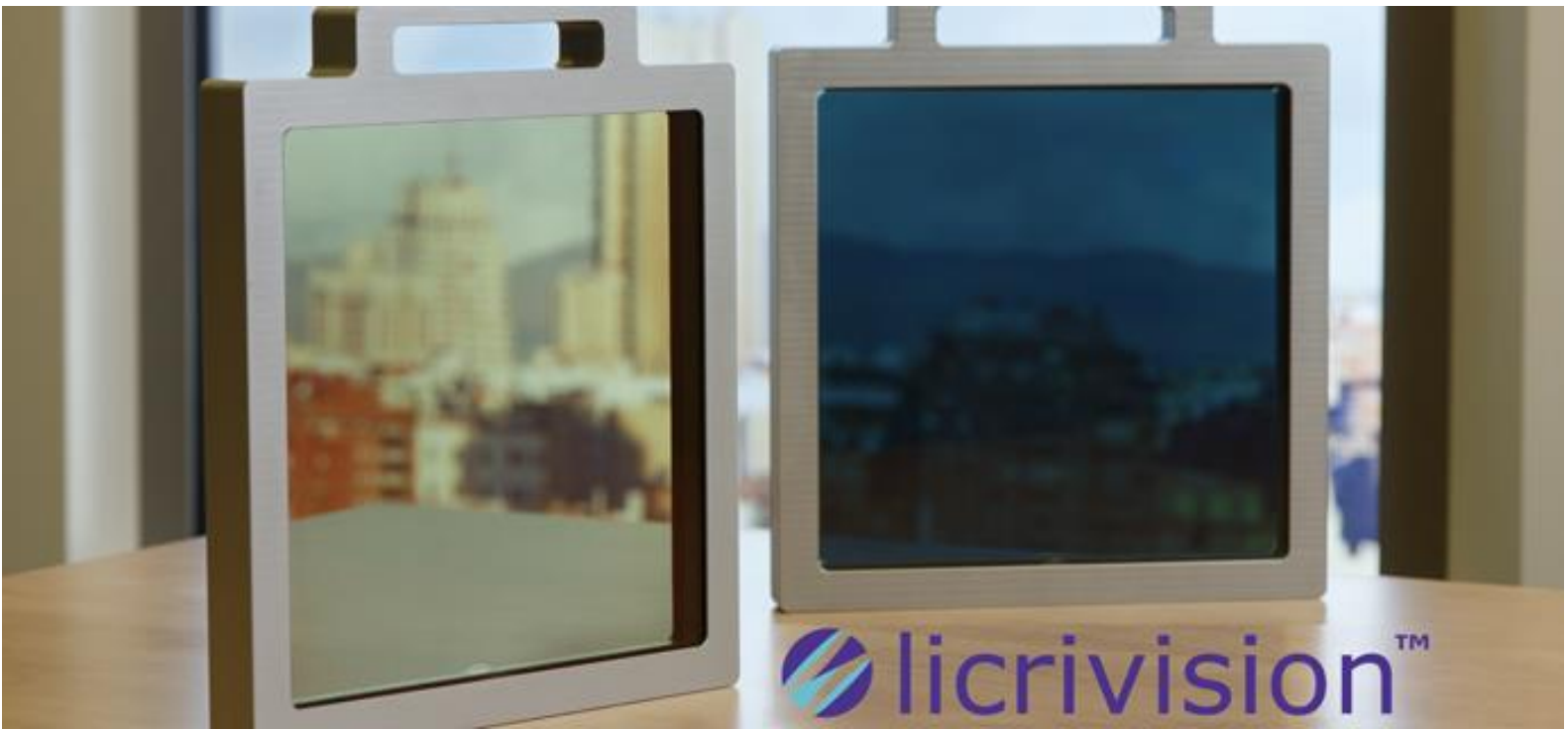

Figure 52. Blue-tint LCWs samples in high and low transmission states. 


\section{SWOT analysis}

\section{Strengths}

- It allows a glazed façade appearance, suitable for cityscape architectural applications with only a little impact on the façade thickness or weight

- The architectural integration is easy, as it is similar to existing glazed framing systems

- Solar heat gains can be effectively controlled reducing the buildings' energy and operational cost and capital investment associated to heating, cooling and artificial lighting systems

- It can be combined with any glass coating to improve the building's energy performance

- Maintenance costs are low, as there are no moving or mechanical parts

- The system is simple and easy to understand

- The operation is quiet and can be used in city environments not suited for openable windows

\section{Opportunity}

- There is a strong movement towards net zero energy buildings (NZEB), supported by legal obligations where LCWs could be used to lower buildings' thermal and electrical energy needs

- Other uses of LCWs are possible, e.g. windows for cars and security to ensure windows are opaque during out of hour's operation

- LCWs can be integrated with other smart devices, monitoring and controls to form intelligent and adaptive buildings accounting for the occupants needs and requirements

- LCWs controlling solar transmission by absorption can be combined with Phase Change Materials for heat storage

- Existing glazed building façades can be upgraded with LCWs

\section{Weaknesses}

- The technology is recent and no research is available on the impact of long-term use of LCWs on a building's façade

- The life span of LCW façade solutions is hard to quantify

- The façade framing system needs to be designed to allow electrical wiring

- The investment cost is high compared to conventional active shading solutions

\section{Threats}

- The construction / building sector is risk-conscious and slow to adopt new untested technologies, preferring instead existing solutions with a proven record of accomplishment

- The business case is partly based on 'intangible' values such as comfort level, occupant view and daylighting levels

- The integration of LCWs' control with the HVAC controls in the Building Management System can be complex. The successful application requires a multidisciplinary approach where the façade system, electrical controls and the HVAC systems are all designed to operate and respond with one another

\section{Lessons learned}

The properties of chromogenic windows can be compared with the requirements for switchable windows to be applied to solar energy and solar applications (Beatens et al., 2010) summarised in Table 1.

Table 1. Requirements for switchable windows. Solar transmission/reflection are characterized for bleached and coloured states and different wavelengths: solar spectrum 300-2500 nm ( $\left.T_{\text {sol }}\right)$, visible light spectrum 380-780 $\mathrm{nm}\left(T_{\text {vis }}\right)$ and near-infrared spectrum 780-1400 $\mathrm{nm}\left(T_{\text {nir }}\right)$.

\begin{tabular}{|c|c|c|c|c|c|c|c|c|c|c|c|c|}
\hline \multicolumn{6}{|c|}{ Solar Transmission (\%) } & \multirow{2}{*}{\multicolumn{2}{|c|}{$\begin{array}{l}\text { Solar reflection (\%) } \\
\mathbf{R}_{\text {nir }}\end{array}$}} & \multirow{2}{*}{\multicolumn{2}{|c|}{$\begin{array}{l}\text { Switching } \\
\text { voltage (V) }\end{array}$}} & \multirow{2}{*}{$\begin{array}{c}\text { Memory } \\
\text { (h) }\end{array}$} & \multirow{2}{*}{$\begin{array}{l}\text { Cycling } \\
\text { lifetime }\end{array}$} & \multirow{2}{*}{$\begin{array}{l}\text { Operating } \\
\text { temperature }\end{array}$} \\
\hline & & & vis & & & & & & & & & \\
\hline bl. & col. & bl. & col. & & $\mathrm{col}$ & bl. & col. & Small & Large & \multirow{2}{*}{$1-12$} & \multirow{2}{*}{$\begin{array}{c}10^{4}-10^{6} \text { cycles } \\
5-20 \text { years }\end{array}$} & Unprotected \\
\hline $50-70$ & $10-20$ & $50-70$ & $\leq 10-20$ & - & - & $10-20$ & $\geq 70$ & $1-3$ & $10-24$ & & & -30 to $+70^{\circ} \mathrm{C}$ \\
\hline
\end{tabular}

The properties and attributes of the Licrivision ${ }^{\circledR}$ LCW are shown in Table 2 and Table 3 respectively. A continuous control over the orientation of the molecules, ergo the optical absorption of the device, is obtainable by applying a voltage. The window can be varied from $11 \%$ to $52 \%$ light transmission in the visible light range, thereby satisfying the requirements from Table 1 and provide controllable indoor lighting and glare conditions. The solar energy transmittance of the window can then vary to a G-value from 0.20 to 0.37 (corresponding to an SHGC variation from 0.23 to 0.39 ) and enable dynamic control over the solar heat gain. The response time to switch on and off a window is typically below a second. According to Merck, the life cycle capability of the LCW is above $10^{6}$ cycles. This is also very satisfying as it matches the upper limit requirement in Table 1 . This device has been cycled between $-20^{\circ} \mathrm{C}$ and $70^{\circ} \mathrm{C}$ making then suitable for indoor and outdoor environments for building applications. The main drawback to LC devices is their continuous and need for power (only $2 \mathrm{~W} / \mathrm{m}^{2}$ in the high transmission state) due to their operating voltage (24 $\mathrm{VAC})$ required to maintain the transparent state. 
Table 2. Properties of the Licrivision ${ }^{\circledR}$ liquid crystal window.

\begin{tabular}{|ccccccc|}
\hline Manufacturer & Size $\left(\mathbf{c m}^{2}\right)$ & $\mathbf{T}_{\text {vis }}(\%)$ & G-value & SHGC & Ug-value $\left(\mathbf{W} / \mathbf{m}^{2} \mathbf{K}\right)$ & Cycles \\
\hline Merck & $\begin{array}{c}\min .40 .5 \times 41 \\
\max .160 \times 350.5\end{array}$ & $52 / 11$ & $0.37 / 0.20$ & $0.39 / 0.23$ & 0.5 & $>1.000 .000$ \\
\hline
\end{tabular}

Table 3. Attributes of the Licrivision ${ }^{\circledR}$ liquid crystal window.

\begin{tabular}{|c|c|c|}
\hline Advantages & Neutral & Drawbacks \\
\hline 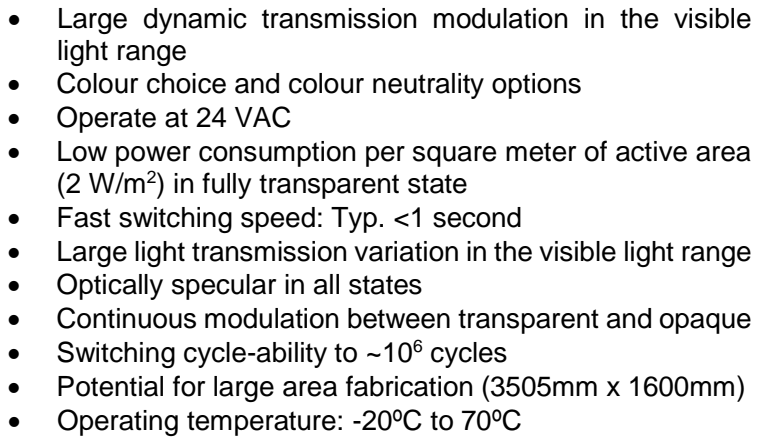 & $\begin{array}{l}\text { - Low/moderate dy- } \\
\text { namic modulation in } \\
\text { the infrared light range } \\
\text { (G-value) } \\
\text { - Require UV filter to } \\
\text { protect active layer }\end{array}$ & $\begin{array}{l}\text { - Cost } \\
\text { - Open circuit is not possi- } \\
\text { ble. Constant power re- } \\
\text { quired to maintain the de- } \\
\text { sired optical transmission } \\
\text { (except steady state) }\end{array}$ \\
\hline
\end{tabular}

Competitive technologies to the LCW include electrochromic (EC) windows (Gesimat, 2015a,b; EControl, 2018; SageGlass, 2010, 2013) and suspended particle devices (SPD) (Innovative Glass Corp, 2013; SmartGlass, 2011). Both LCW and SPD require constant power to maintain the desired transmission and inherit a low transmission modulation over the solar spectral range (300-2500nm). EC switchable windows maintain the desired transmission without the need of power and typically provide a transmission modulation over the solar range between $4 \%$ and $41 \%$ (IGU) corresponding to a variation of the solar energy transmittance (SHGC) from $\sim 0.1$ to 0.49 . Therefore, EC windows are currently advantageous regarding those aspect. All technologies have a specular transmittance. They have an upper operating temperature limit in order of $\sim 60^{\circ} \mathrm{C}$ and are therefore most suitable for building facades. However, the advantage of LCW and SPD over EC is its fast switching capability (below 1 second versus 120-180 seconds for similar sizes) making LCW and SPD more appropriate when a fast visual transmission change is required; in particular for 1) controlling indoor lighting in variable outdoor weather conditions and 2) avoiding glare in a shorter response time. The advantage of LCW over SPD is in the choice of colour and colour neutrality, providing a range of architectural choices and indoor lighting conditions.

\section{Further reading}

Baetens, R., Jelle, B. P. \& Gustavsen, A. (2010). Properties, requirements and possibilities of smart windows for dynamic daylight and solar energy control in buildings: A state-of-the-art review. Solar Energy Materials and Solar Cells, 94, pp. 87-105.

EControl-Glas (2018). EControl: Solar Control with Dimmable Glass [online] Available from https://www.econtrolglas.de/fileadmin/econtrol-glas/dateien/technische_dokumente/Broschuere_EN_2018.pdf [Accessed 2019].

Gesimat Gmbh (2015)a. Charakteristische Werte für Gesimat EC elektrochrome Isoliergläser (Beispiele). [online] Available from http://www.gesimat.de/data/Daten_GesimatEC-Iso.pdf [Accessed 2016].

Gesimat Gmbh (2015)b. Elektrochrome Verbundgläser. [online] Available from

http://www.gesimat.de/data/produktinformation-EC.pdf [Accessed 2016].

Granqvist, C. G. (2015). Thermochromic and electrochromic fenestration: New nanotechnologies for energyefficient buildings. In: CISBAT 2015. Lausanne, Switzerland: EPFL, pp. 29.

Innovative Glass Corp. (2013). SPD SmartGlass. [online]. Available from https://innovativeglasscorp.com/ourproducts/spd-smart-glass/ [Accessed 2019].

Merck (2019)a. Licrivision® Solar [online] Available from https://www.merckgroup.com/en/s/licrivision.html

Merck (2019)b. Eyrise ${ }^{\mathrm{TM}}$ Dynamic Liquid Crystal Windows [online] Available from

https://www.merckgroup.com/content/dam/web/corporate/non-images/business-specifics/performance-

materials/Architecture/global/eyrise_s350_brochure_EN.pdf

SageGlass (2010). SageGlass Product. [online] Available from www.sageglass.com/eu/products/sageglass [Accessed 2019].

SageGlass (2013). Special Function Glazing - Section08 88 00. [online] Available from

www.sageglass.com/sites/default/files/sageglass_section088800_special_function_glazing_nonproprietaryversion.docx [Accessed 2019].

SmartGlass International Ltd. (2011). Electronically Switchable Glass Handbook. [online] Available from http://smartglassinternational.com/downloads/SmartGlass_Handbook_2012.pdf [Accessed 2019]. 


\section{OKALUX OKASOLAR 3D}

by David Geisler-Moroder, Bartenbach GmbH, Austria, and Johannes Franz, OKALUX GmbH, Germany

\section{Product description}

\section{Brief concept description}

OKASOLAR 3D is a three-dimensional, highly reflective sun protection grid embedded in the cavity between the glass panes that is used as sun protection and daylight management system. The transmission of direct solar radiation is blocked at all times, regardless of the height of the sun, so that the solar heat gain into the interior of the building is considerably reduced. However, a large amount of diffuse daylight can still enter the interior thanks to the structure of the grid, providing daylighting with a more homogeneous light distribution and a significantly lower fluctuation in brightness than with direct sunlight.

The geometry of the sun protection grid has been optimised for roof applications. As shown in Figure 53, OKASOLAR 3D has two different functional areas:

- Lock-out area, facing South in the Northern hemisphere:

○ thermal sun protection with g-values $\geq 7 \%$

- reduced glare

- Area of transmission, facing North in the Northern hemisphere:

- diffused irradiation of daylight

○ partial view-through

The main louvre of the system is made of aluminium with a reflectance (solar and visual) of about $95 \%$. The cross bars are concave in shape, so that the sunlight is always reflected to the outside also at low solar altitudes. They are made of plastic with a highly reflective surface with a reflectance (solar and visual) of over $80 \%$.

The sun protection grid, which is open to the North in the Northern hemisphere, enables partial transparency and admits diffuse irradiation. The thin cross section of the louvres enables to achieve high transparency level of the grid (up to $85 \%$, depending on the direction of sight), and a diffuse light transmission of $60-70 \%$ in the area of transmission.

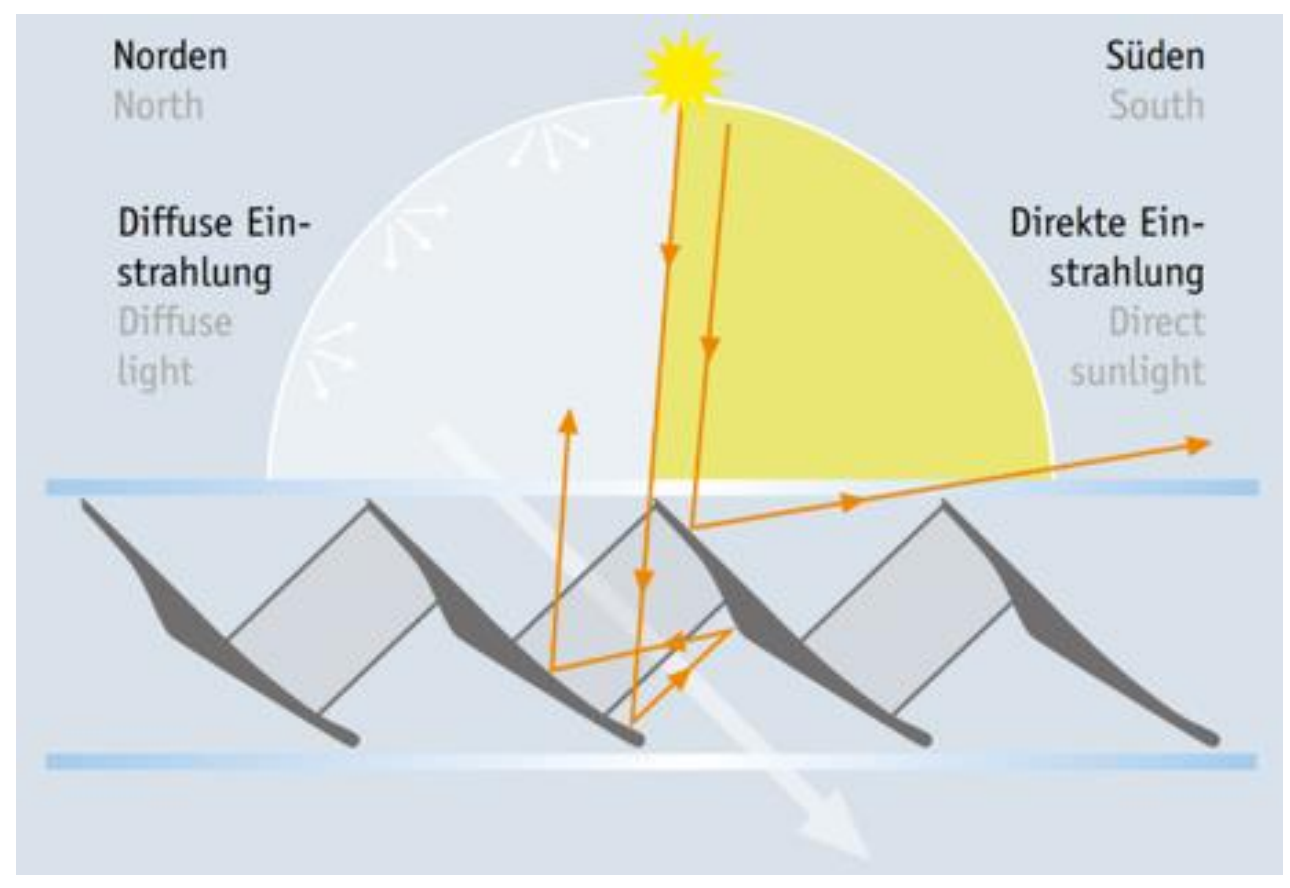

Figure 53. Functional principle of OKASOLAR 3D for installation in the Northern hemisphere. 


\section{Architectural and technological integration into the envelope}

The special feature of OKASOLAR 3D is that the sun protection grid is integrated into the cavity of an insulated glazing system. Hence, there are no special requirements with regard to installation, maintenance or repair, and the entire system can be treated just like standard insulated glazing. The thickness and type of glass depend on structural and building requirements. However, the bending radius is to be limited to $12 \mathrm{~m}$ under deformation for structural reasons. The system can be used in 2-pane configurations in the $24 \mathrm{~mm}$ cavity between the glass panes as well as in 3-pane configurations. In this case, the sun protection grid is mounted in the outer cavity.

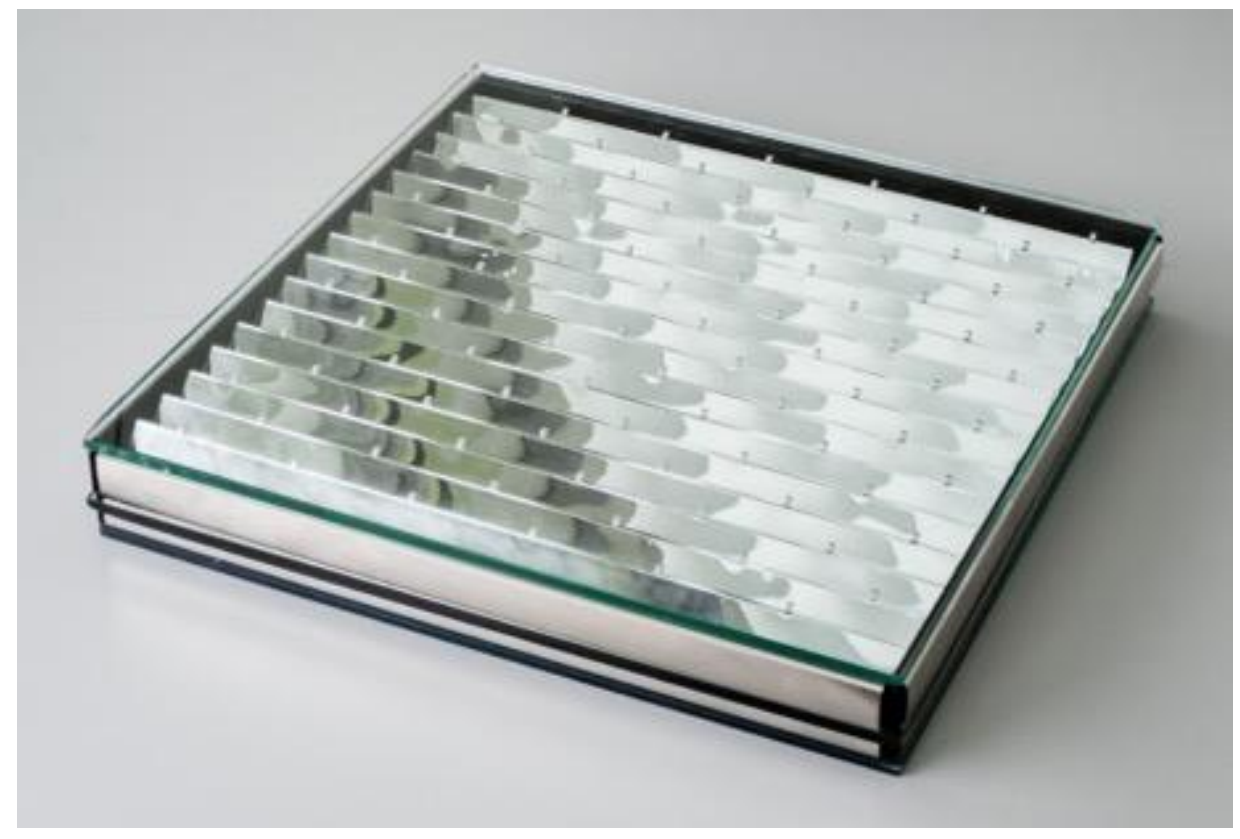

Figure 54. Sample of OKASOLAR 3D in a 3-pane insulating glazing unit, appearance as seen from outside.

\section{Integration into the building: system and comfort}

OKALUX OKASOLAR 3D is a static system integrated into the cavity of insulating glazing units. The special geometry of the sun protection grid always blocks the direct sun beam and thus needs no control nor movable parts. Proper design and installation of the system is however required by planner or architect and installer. Afterwards, the system is maintenance free and can be treated as any other insulating glazing unit.
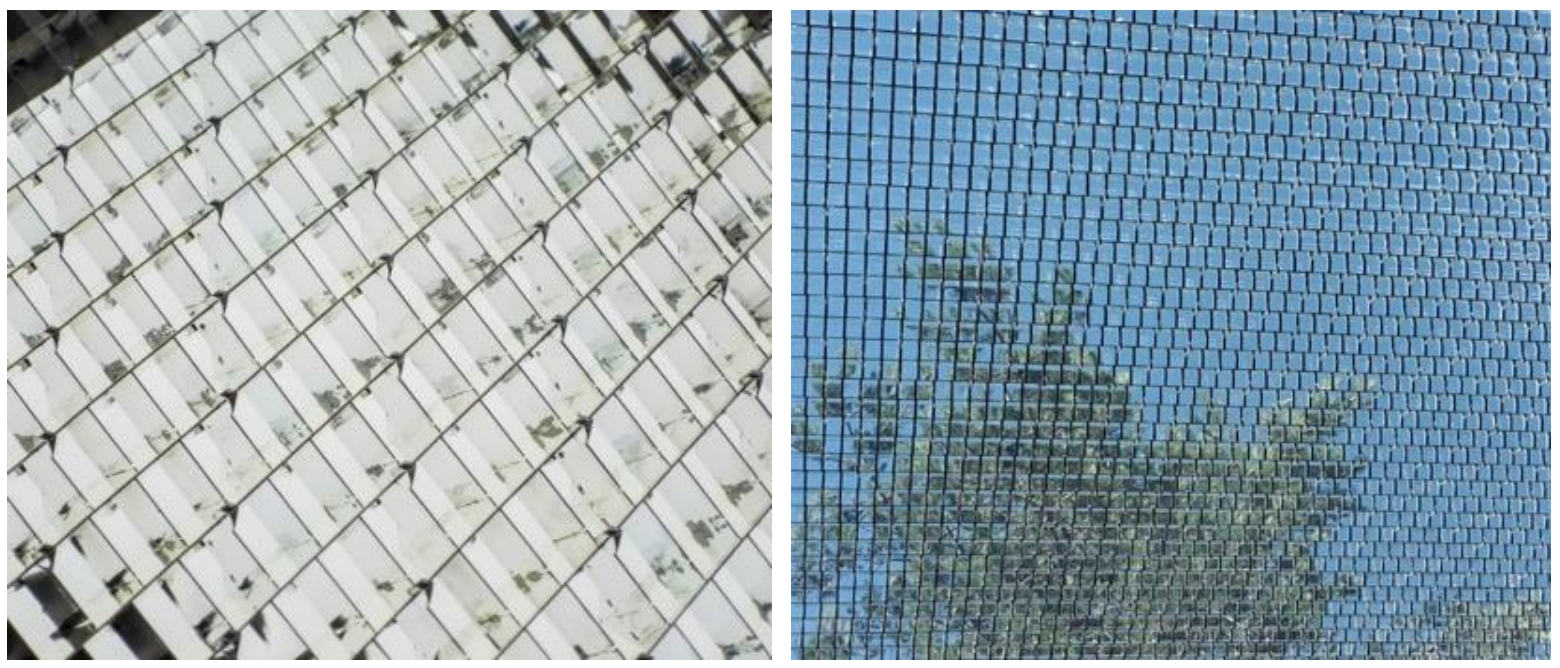

Figure 55. Close-up view of the daylighting system OKASOLAR 3D on the left and appearance as seen from inside on the right. 


\section{SWOT analysis}

\section{Strengths}

- The system provides a high-performance sun protection and an effective solar control: it blocks direct solar radiation reducing glare issues and heat gains, but high light transmission is possible for diffuse daylight

- The brightness in the indoor space does not significantly vary comparing clear sunny sky or cloudy sky without sun

- The daylighting is typically sufficient, and the use of artificial lighting can be reduced

- Visual contact with the exterior is maintained thanks to a partial view through the area of transmission and the sun reflections

- The appearance of the grid is homogenous when integrated in insulating glazing units

- The system works without moveable parts and is maintenance free

- The system does not need control and thus user operating errors are prevented

- The materials can be easily recycled

- The visibility for birds is enhanced

\section{Opportunities}

- It can be used in a multitude of applications, from roofs to skylights

- There is an increased interest for intelligent daylight solutions and a rising awareness for the need of good daylighting in buildings

\section{Weaknesses}

- Daylighting is reduced also when there is no sun

- Direct sun beams cause high brightness patterns through reflection on the outer glass pane and slightly frosted glass is needed to avoid these sun reflections

- The light transmitted to the inside is asymmetric: most light is pointed slightly to South

- Proper design and installation are needed for a correct implementation, as a wrong orientation of the grid decreases or cancels the sun protection properties

\section{Threats}

- Architects might not accept the appearance

- Competitors provide solutions (e.g. screens) that cannot provide simultaneous sun protection and daylight provision but are cheaper in purchase

- Standard key indicators (transmission and SHGC at normal incidence) do not describe the product well, thus it is not easy to understand and use for designers

\section{Lessons learned}

- OKALUX OKASOLAR3D is an innovative daylighting system that allows simultaneous sun protection and optimal utilization of daylight.

- As a static system integrated in the insulating glazing unit it does not require maintenance or controls and prevents erroneous user behaviour.

- Proper design and installation of the system is required to allow optimal functionality of the system.

\section{Further reading}

Website: www.okalux.de/products/product-finder/products/okasolar/detail/okasolar-3d/ 


\section{Architectural Shutters}

by Carolin Hubschneider, Fraunhofer IBP, Germany

\section{Product description}

\section{Brief concept description}

Architectural shutters are elements which dynamically solve fundamental functions of the façade: solar shading, daylight control, dynamic façade U-value, natural ventilation, and noise reduction. Shutters can be moved horizontally or vertically in front of the window and cannot be used on fully glazed façades. In their most sophisticated versions, shutters can increase the façade insulation and control utilization of solar heat gain and daylight, thus reducing the energy needs for heating, electric lighting, cooling and ventilation.

\section{Architectural and technological integration into the envelope}

An aluminium framework-based façade system is mounted directly on the outside of the window frames using an integrated, exterior placed drive system. Shutters are suitable for plane façades and can be used for both new and existing buildings and for all façade orientations. However, since shutters need 'parking spaces' when they are open, the energy saving potentials can normally only by realized on façades with maximum $50 \%$ glazing.

\section{Integration into the building: system and comfort}

Shutters should be operated automatically (with manual override) to realize the potential energy savings and improvement of thermal and visual indoor climate. For this reason, they have to be connected to the power supply of the building. For the control algorithm, input data from several sensors of the building automatization (photo sensor, temperature sensor and presence sensor) has to be used.
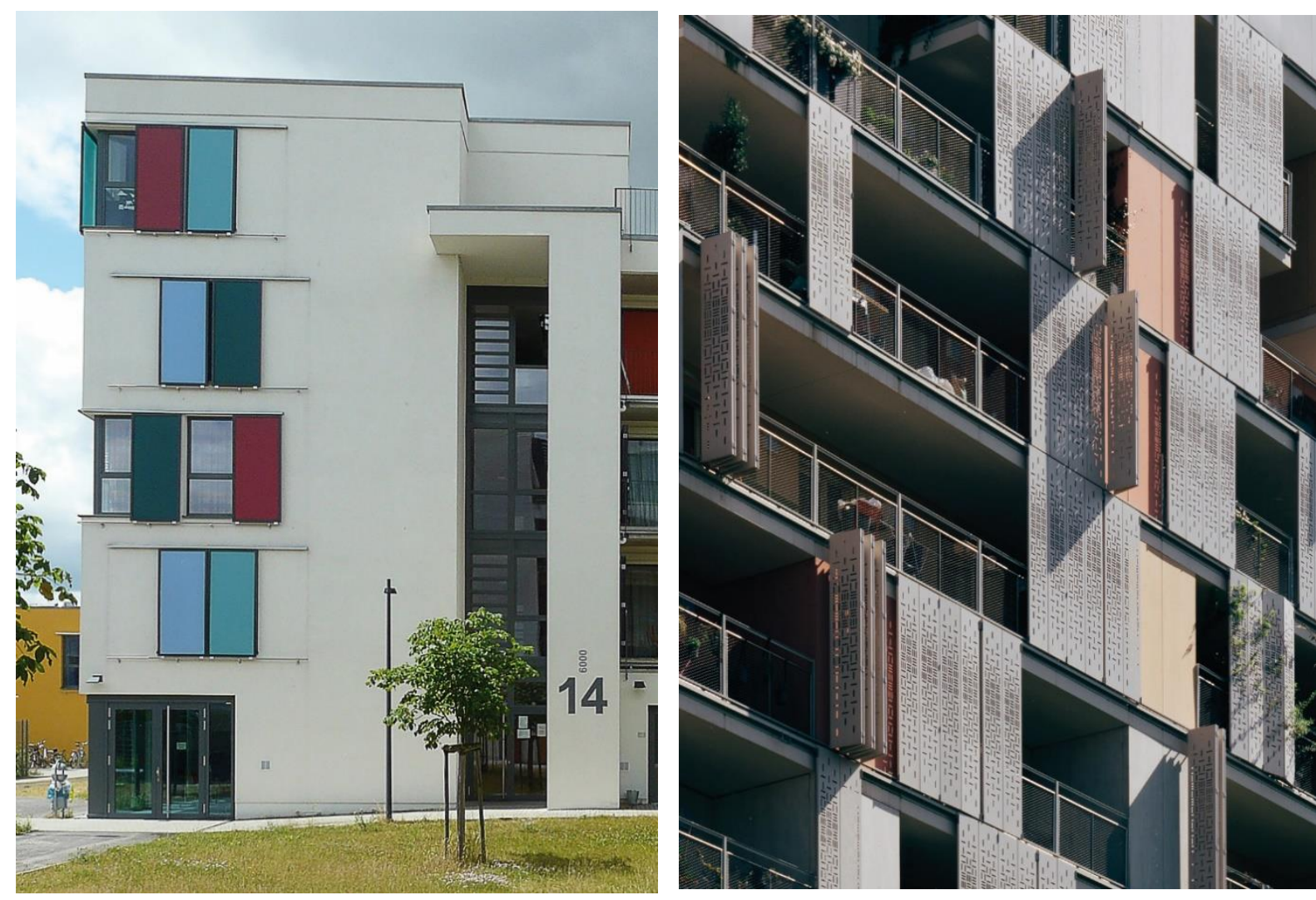

Figure 56. Examples for shutters (Reference: left - Photo by HardyS from Pixabay; right - Photo by Pierre ChâtelInnocenti on Unsplash). 


\section{SWOT analysis}

\section{Strengths}

- U-value and g-value of the façade are adjustable and depending on the climate condition solar heat gains can be used or rejected

- The application of transparent material with high insulation is possible

- High privacy is possible

- Street noise is attenuated

- Burglary risk is reduced

\section{Weaknesses}

- Regular service and maintenance are needed

- The possibility of installation depends on the façade design (can normally only by realized on façades with maximum $50 \%$ glazing because of the "parking space" for the shutters)

- An additional system is necessary to cope with glare when shutters are not activated

- When shutters are activated, the view is reduced

- The appearance of the façade is changed by the installation of shutters

\section{Opportunities}

- Dynamic u- /g-value is getting more important because of climate change

- In rooms with several workplaces and windows, shutters can be set to individual positions

\section{Threats}

- The system cannot be applied to currently popular all-glass facades

- Next to the windows, space for storing the shutters is needed; the corresponding space is unavailable for other technical devices

\section{Lessons learned}

- As a retractable system, shutters can help to dynamically optimize the energy flow through the facade depending on daytime, time of year and occupancy demands. Nevertheless, their flexibility regarding daylight supply, glare control, view out and solar protection is generally not as high as it is for venetian blinds.

- $\quad$ Shutters need regular service and maintenance.

- As the system does not operate like for instance venetian or textile blinds only in the facade pane, the applicability depends on facade design. I.e. enough space, "parking space» is required beside the window itself. They have therefore a larger architectural signature.

- $\quad$ Shutters are generally more wind resistant compared to venetian or textile blinds and therefore are also suited for buildings of medium height.

\section{Further reading}

The description of shutters is mainly adopted from "T50 B.6 Daylighting and electric lighting retrofit solutions - A source book of IEA SHC Task 50 (Task 50 Subtask B Report B6)”.

Website: http://task50.iea-shc.org/publications 


\section{Venetian blinds, roller shutters and textile screens}

by Carolin Hubschneider, Fraunhofer IBP, Germany and Robert Weitlaner, HELLA Sonnen- und Wetterschutztechnik GmbH, Austria

\section{Product description}

\section{Brief concept description}

Common devices used for daylight management and solar shading are:

(a) Venetian blinds (also known as louvered shutters): they consist of multiple horizontal or vertical slats, which can be fixed or movable. The cross section of slats can have different shapes, such as $\mathrm{C}$-shape, Z-shape or S-shape. The surfaces are in general mostly diffuse with specular reflection gloss of 30 to 80 GU but specular, micro-facetted or retroreflective surfaces are also available (for in-between or internal use only).

(b) Roller shutters: they are curtains made of many horizontal profiled bars, mostly made of aluminium, plastic or wood, hinged together. Roller shutters can be raised to open and can be closed tightly for solar protection and darkening purposes. To widen the possibilities of daylight control, the use of translucent / transparent hinge-connectors and the integration of translucent bars and bars with movable slats is also possible.

(c) Textile screens: they consist of a movable screen called rolled screen if a fabrique is flat and pleated/ cellular shade if the fabrique is pleated. The textile has different light transmission according to colour and the material of the fabric. Common materials are acryls, polyesters or PVC-coated glass-fibres or polyesters. In general, a clearer view to the exterior is obtained with smoother surface of the yarn and edges of the openings of the fabrique.

Such shading devices are used to control the incident solar radiation, protect against glare, distribute daylight into the room and also reduce heat losses. Their performance in these tasks depends on many factors including type of device, optical characteristics, material, installation and also mounting position.

\begin{tabular}{|c|c|c|}
\hline a) Louvered shutters & b) Roller Shutters & c) Rolled Screens \\
\hline & & \\
\hline
\end{tabular}




\section{Architectural and technological integration into the façade}

These devices can effectively control solar gains when they are installed on the exterior of the façade, as they can significantly reduce direct solar radiation transmission and secondary heat transfer, limiting the risk of overheating of the building (lower $g$ value of the complex fenestration system: window + device). In this case, however, their limited resistance to wind is an issue in medium/high buildings. Additional guiding elements (guide rails or guide cables increase the wind stability. Placed in the interior of the building, these shading devices can achieve good daylight control, but they do not significantly contribute to the reduction of the solar gains. In some cases, as for daylight redirection louvers made of specular material, the device is installed in-between the glass panes and is protected from dust and wind loads.

Venetian blinds, louvred shutters and textile screens can be installed a) in front of the façade or b) integrated into it (plastered box), as shown in the table below.

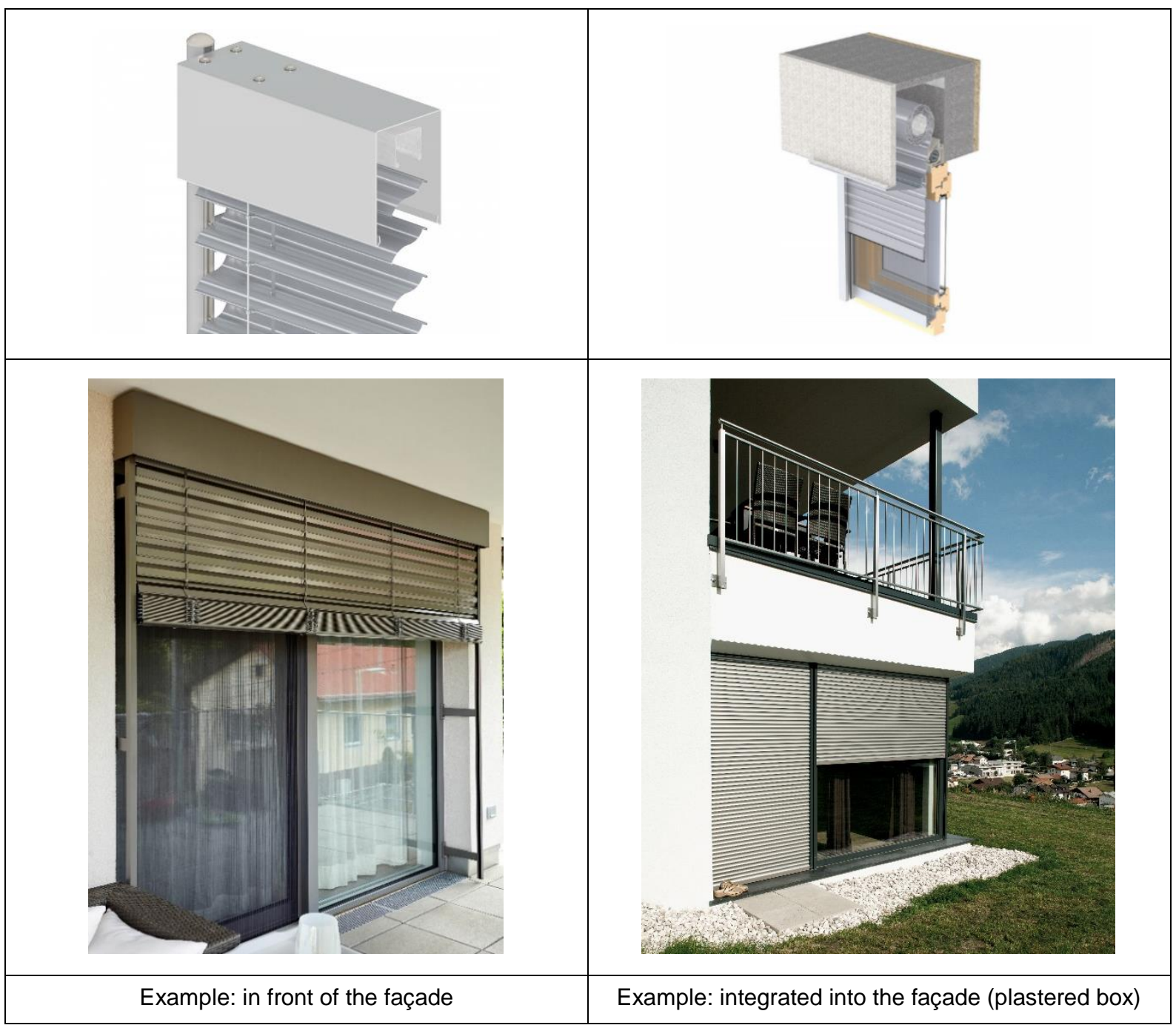

\section{Integration into the building: system and comfort}

A significant improvement of the performances is achieved when shading devices are automated. If the manipulation of the device is let to the user, the frequency of manipulation (e.g. rate of change) can drastically lower: in a field study on office buildings (Blindswitch 2017), it was found that only $6,2 \%$ of the blinds was operated at least once throughout the day. The implementation of automatic controls allows instead self-adjusting operation base on, for example, climatic conditions or presence of occupants. The coupling with environmental sensors (e.g. photo-sensors, temperature sensors and presence sensors) is however required for automation, so that an improved control of daylight and visual comfort as well as a smart management solar heat gains can be achieved. This additional investment in environmental sensors could be potentially exploited for other advanced controls, such as thermostats regulation or artificial lighting use. 


\section{SWOT analysis}

\section{Strengths}

- The visual comfort is enhanced because of glare reduction and a view to the exterior is still possible, depending on the device

- The availability of daylight in room depth is high for louvered shutters and some types of roller shutters

- It is possible to control the solar heat gains (external devices better than internal ones) and reduce the risk of overheating in summer

- Movable systems can be easily adapted depending on occupancy and climate condition (louvers more flexible than other devices)

- Internal devices have lower costs than all others

- In-between devices are protected from wind and dust

- Roller shutters are good in obscuring and fabriques inserted in special guide rails are able to black out (ZIP technology)

\section{Opportunities}

- The most efficient solution in terms of solar heat gain control and adaptability (external louvered shutters) is well established in Europe, but still quite unknown elsewhere

- Suitable for new constructions and retrofit projects (internal devices are less invasive)

- The functionality of the system can be enhanced by adding more technology to the slats (e.g. PV) or creating advanced, holistic control systems

- The technology is mature: highly available with many manufacturers

\section{Weaknesses}

- External devices are susceptible to wind loads (roller shutters less than louvered shutters) and produce vibrations and noise under wind conditions

- External devices influence and define the architectural appearance of the façade

- External devices reduce solar heat gains also when they are welcome (winter), whereas internal devices are poor in controlling solar heat gains during the cooling season

- Daylight redirection features suffer from dust deposition and maintenance is necessary

- In-between devices are sometimes difficult to maintain as the glass compound is not openable

- $\quad$ Roller shutters made of PVC are prone to softening caused by high temperatures

\section{Threats}

- External devices cannot be combined with currently popular all-glass facades

- Electrochromic glasses are challenging the today's available devices (no wind, no dust, no maintenance susceptible) - but among other things these glasses cannot redistribute daylight to room depth compared to louvered shutters

- The integration into the façade needs space that could be used for other features in multifunctional envelope solutions

\section{Lessons learned}

- $\quad$ Louvered shutters are the most popular sun protection system in central Europe with a 2/3rd market share as they offer - if operated properly - high flexibility in the trade-off between daylight supply, glare control, view out and solar protection.

- Louvered shutters are available in many design and technical variations. This encompasses among others different slat designs and control schemes including energy efficient light redirection functionalities. Due to the big market share, they are often more economic than other shading solutions of comparable performance.

- Roller shutters made of PVC are the cheapest solution for an external device.

- In-between louvered shutters or fabriques are an appropriate solution for high wind exposures and are performing well in all requirements.

- Internal devices are performing poor but are cheap as the materials do not need to be outdoor proven (UV stability, etc.).

\section{Further reading}

The description of blinds is mainly adopted from "T50 B.6 Daylighting and electric lighting retrofit solutions - A source book of IEA SHC Task 50 (Task 50 Subtask B Report B6)".

Websites: http://task50.iea-shc.org/publications, https://depositonce.tu-berlin.de/handle/11303/5494

Blindswitch 2017: Proposing A New Manual Blind Control Algorithm for Daylight and Energy Simulation; Nezamdoos, A; Van Den Wymelenberg, K; 2017 


\section{GAP:skin facade \\ by Johann Aschauer, GAP Solutions $\mathrm{GmbH}$, Austria}

\section{Product description}

\section{Brief concept description}

GAP Solutions is dedicated to the development and implementation of innovative, sustainable and value-enhancing passive solar system solutions for residential constructions, such as the GAP:skin façade shown in Figure 57. This prefabricated solar façade system integrates a honeycomb-structured panel to passively control the transmission of the solar radiation and keep the house warm in winter and pleasantly cool in summer. The honeycomb panel is made of cellulose (translucent thermal insulation, 100\% biodegradable) and its shape is modelled after honeycombs from nature.

The honeycomb makes use of the position of the sun and the solar angles to regulate the indoor climate. The low winter sun penetrates in depth in the solar honeycomb structure and enables the formation of small warm air cushions. In this way, the temperature difference between the living space and the thermal buffer zone out of the existing wall is practically balanced out and the heat losses through the wall are greatly reduced. In summer, instead, the structure of the solar honeycomb shades itself with the high position of the sun, preventing the sun rays to penetrate the honeycomb structure. A retro-ventilated glass pane is mounted in front of the honeycomb to protect the module from weather and mechanical damages and allow the dissipation of humidity and overheat by natural convection.

The potential use of this system is enormous as it suited to residential buildings and hotels new construction and retrofit.
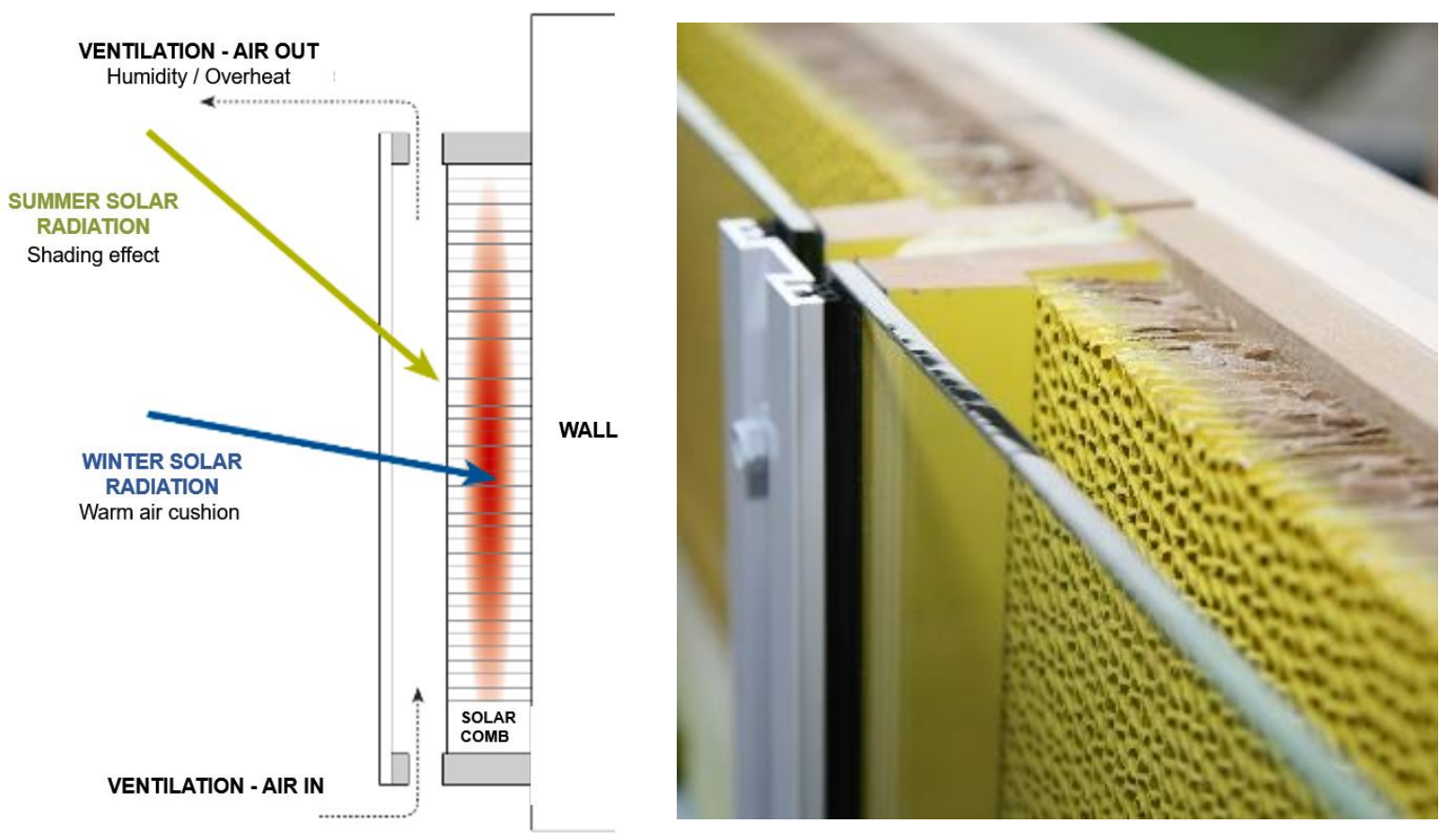

Figure 57. Schematic drawing (left) and view (right) of the GAP:skin façade.

\section{Architectural and technological integration into the envelope}

GAP:skin façade elements are prefabricated and can be easily installed on a timber substructure that is then applied to the existing wall. In the final configuration (Figure 58), the outer layer is a glass pane mounted on a wooden frame with aluminium fixings. This frame hosts also the honeycomb panel, which is placed so that a small air gap is left between the glass pane and the panel. The cavity is not sealed, but it is slightly ventilated thanks to the openings left on the top and on the bottom sections of the façade module. The frame is fixed to a levelling layer constituted of a wooden substructure, which is turn fixed to the masonry structure.

GAP:skin is a low-tech system that does not have moving parts or active controls and thus has the lowest maintenance and repair costs. 


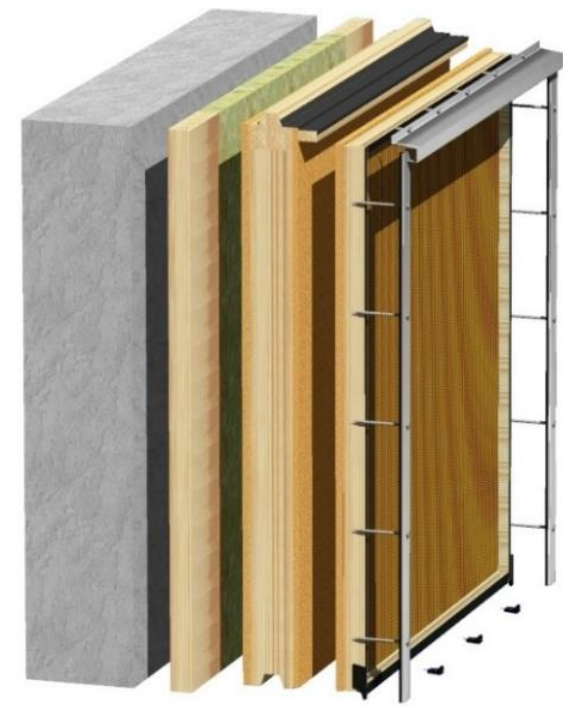

GAP:skin facade (from in-to outside)

* Existing wall

* Wood construction + insulating material : $\geq 60 \mathrm{~mm}$

* Framework wall in solid wood+ insulating material : $151 \mathrm{~mm}$

* Wood panel (DFP): 19 mm

* GAP-Honeycomb panel in cellulose. $30 \mathrm{~mm}$

* Air gap (slightly ventilated): $29 \mathrm{~mm}$

* ESG float glass panel: $6 \mathrm{~mm}$

* Attaching parts in aluminium

Figure 58. Schematic drawings of the composing layers of GAP:skin façade.

\section{Integration into the building: system and comfort}

With the installation of GAP:skin façade system, it is possible to achieve several benefits such as an improved quality and appearance of the envelope, an extension of the life of the building and higher comfort for the tenants. Moreover, it is possible to achieve large reductions of the space heating demand due to the improved thermal insulation and the honeycomb structure. The lower energy demand results into lower energy bills but also into the possibility of reducing the size of the heating system, which alone can be enough to finance the investment. In this new paradigm, a shift in costs from building services to structural engineering is realized.

Aside economics and energy considerations, one of the main advantages of GAP:skin is that the assembly of the façade system can be carried out from the outside so that the residents do not have to leave their apartments during the refurbishment process. This means that the burden on tenants is kept to the minimum.

As an example, GAP:skin was implemented in the renovation of a residential complex in Gratz (Austria) in 2014. The project involved the renovation of multiple buildings with poor pre-renovation energy performance (i.e. uninsulated walls, important thermal bridges and a central gas-fired heating), corresponding to standard for residential building up to the 1980 s.

Here, the retrofit intervention enabled to reduce the final energy consumption for space heating and domestic hot water preparation from approx. $135 \mathrm{kWh} / \mathrm{m}^{2}$ a to approx. $8 \mathrm{kWh} / \mathrm{m}^{2} \mathrm{a}$, which corresponds to a percentage energy consumption reduction of about $94 \%$. GAP Solutions and Energie Service were responsible for conception, planning and construction supervision and about $10000 \mathrm{~m}^{2}$ of GAP:skin were installed. Savings in operating costs for heating and domestic hot water of around $€ 100,000$ per year could be realized (base price level 2011/12).

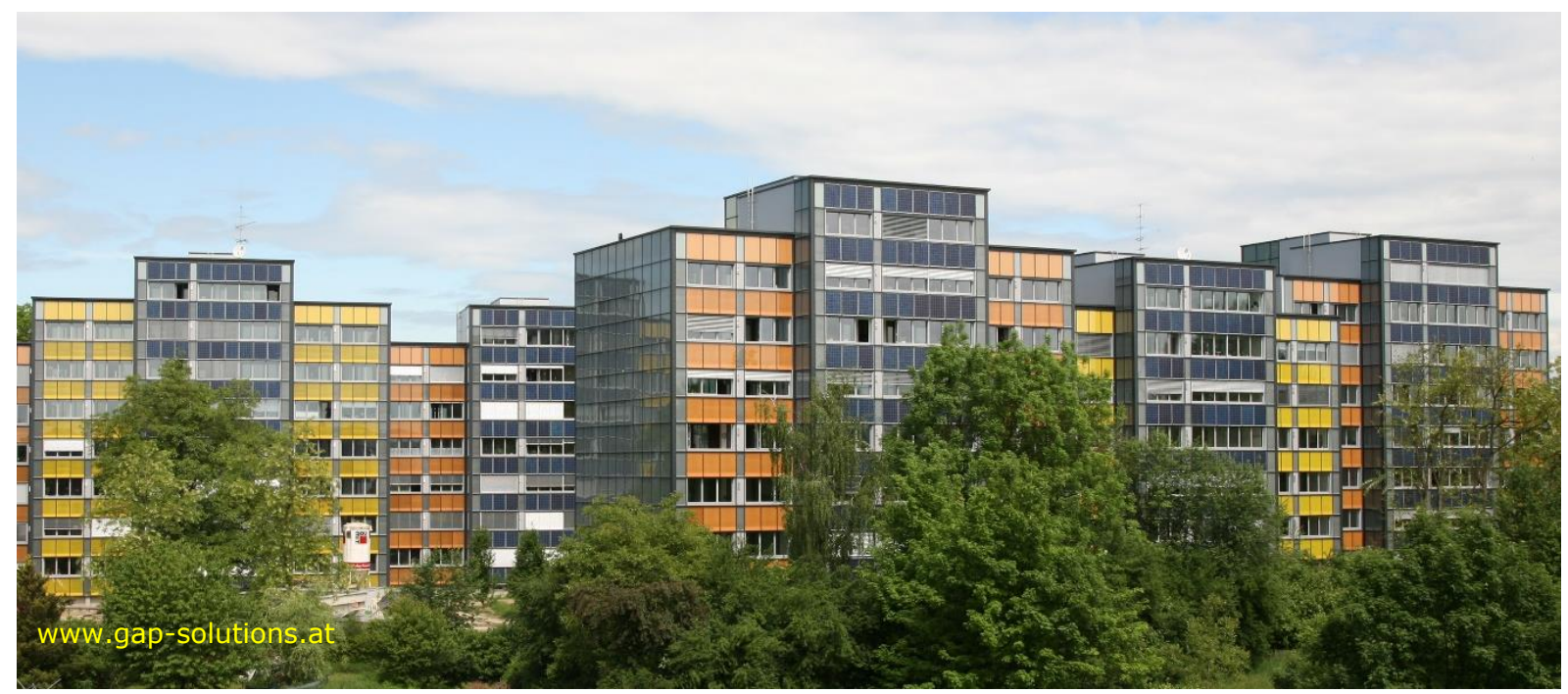

Figure 59. Application of GAP:skin in a building complex (view from South) in Graz, Austria. Source: GAP Solutions. 


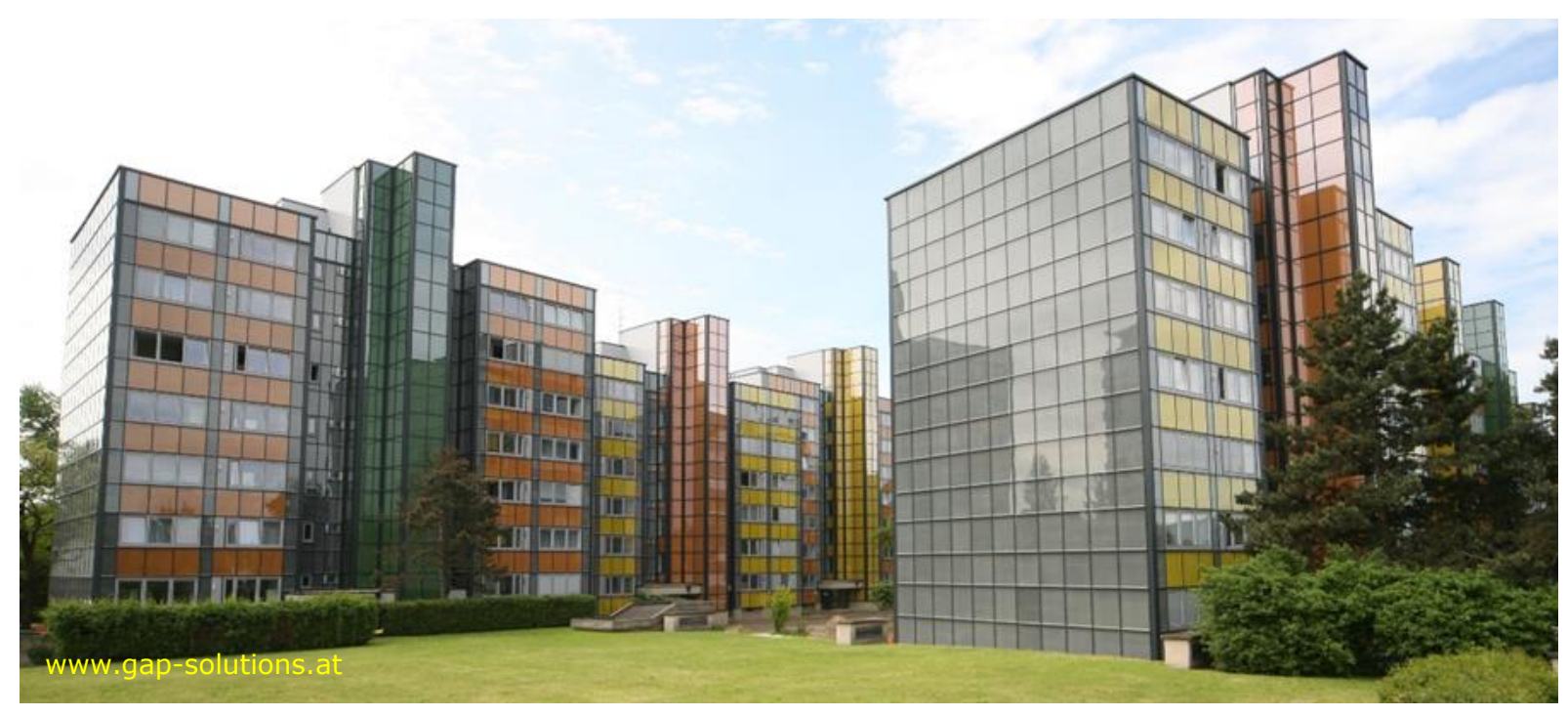

Figure 60. Application of GAP:skin in a building complex (view from North) in Graz, Austria. Source: GAP Solutions.

\section{SWOT analysis}

\section{Strengths}

- Higher tenants' comfort and energy savings are achieved

- $\quad$ Low Life Cycle Costs

- The façade system is available in any colour

- The durability of the solution is guaranteed by the choice of materials (glass/aluminium on the outside and wood/wood-like materials on the inside)

- The high degree of prefabrication allows an easy installation on-site and higher reliability

- The façade module structure is diffusion-open (dehumidifying effect)

- It is a passive, low-tech system with no moving parts and low maintenance requirements

- Environmentally sustainable: easy recyclability / separability of materials and high wood content

- Maturity level: more than 20 years in use, more than 2000 residential units renovated or newly built with high satisfaction of customers, tenants and investors

\section{Opportunity}

- $\quad$ The goals of European Union are pushing toward solutions that aim to achieve higher energy efficiency

- There is a new awareness for environmental issues that can reward sustainable solutions

- The buildings' energy load is reduced to a point where the remaining load can be easily covered with RES technologies as PV

- National and international requirements for buildings' and envelope energy performance can be easily met

- The market for this solution is very large

\section{Weaknesses}

- No compatibility with listed facades

- There is a (current) limit on the maximum height where this solution can be applied (alternatives are in preparation)

- There is a higher investment costs with respect to traditional retrofits interventions, although the advantages at LCC level are clear

\section{Threats}

- There are no competitors, except for the traditional envelope retrofit systems 


\section{Lessons learned}

- Overheating of the house in summer and heat losses during winter can be prevented with a simple and low-tech façade.

- Solar facades should be planned to be as maintenance-free, stable and durable as possible.

- The building technology can be completely re-thought, as the energy demand is much lower.

- Separability of components and recyclability of individual materials are relevant issues.

\section{Further reading}

The building stock is a major cause of $\mathrm{CO}_{2}$ emissions. Europe has already been built - that is why the transition of Europe to a $\mathrm{CO}_{2}$-free building management must start there. The technological implementation has been realized for many years in best practice examples. Refurbishment of buildings is not a matter of financial resources or affordability - the GAP solutions show quite clearly that the reduction of energy costs can bear the financing of plus-energy renovations alone. It depends therefore only on the insight and good will of the acting persons / institutions / financial institutions / up to the politically responsible ones. There is still a number of barriers to get rid of. For example, all-inclusive rental agreements covering the cost of space heating, domestic hot water and household electricity.

More information on Photovoltaic Water Solution is available here: Passive House Renovation Graz, facadeintegrated DC-based hot water preheating, final report: Reports from Energy and Environmental Research 00/2010

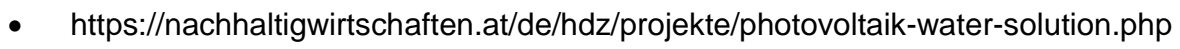

- https://nachhaltigwirtschaften.at/de/hdz/projekte/wohnhaussanierung-auf-passivhausstandardmakartstrasse-linz.php

Company Website: www.gap-solutions.at 


\section{Kindow sun-tracking verticals and roller blinds}

by Samuel de Vries, Roel Loonen, Eindhoven University of Technology, The Netherlands and Sam Kin, Kindow, The Netherlands

\section{Product description}

\section{Brief concept description}

Kindow is a sun-tracking control and motorisation concept for automated indoor roller blinds and vertical blinds. The control concept seeks to balance the competing performance goals of preventing daylight glare, admitting daylight and views to the outdoor, and reducing energy consumption for heating, cooling and lighting.

Kindow utilises metalised shading fabrics which have a very high solar reflectance and allow for low solar heat gains, even though the system is positioned on the inside of the glazing.

The system is operated in relation to the position of the sun, indoor daylight conditions, occupancy, indoor heating/cooling demand, and user preferences. During occupied hours, the system prioritises visual comfort by automatically adjusting the blinds or shades in response to sun position, thereby preventing occupants from perceiving glare from direct sunlight whilst admitting diffuse daylight and views to the outdoors. Under overcast conditions, or when the sun is not in view of the façade, the system fully opens. During unoccupied hours, the control strategy seeks to reduce the energy consumption by admitting and reflecting solar radiation depending on whether solar gains are desirable or not. The operation of the system is shown in Figure 61 and Figure 62.

The Kindow solar shading solutions are developed by the company Kindow B.V. in the Netherlands in close collaboration with Eindhoven University of Technology. The system is currently available on the market and is being continiously improved for both existing and new customers.

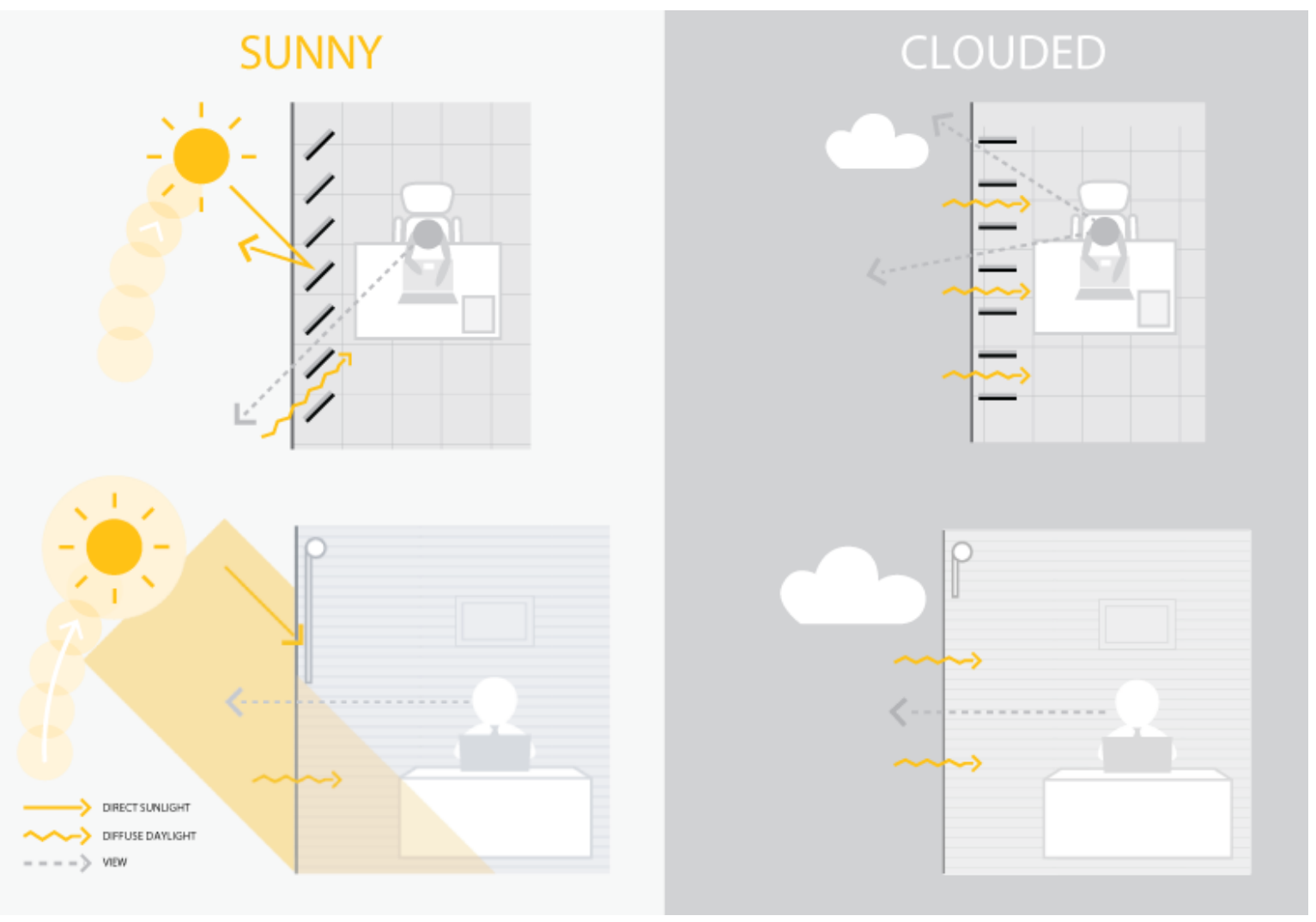

Figure 61. Kindow sun-tracking control concept. The illustration shows the operation during occupied hours. 

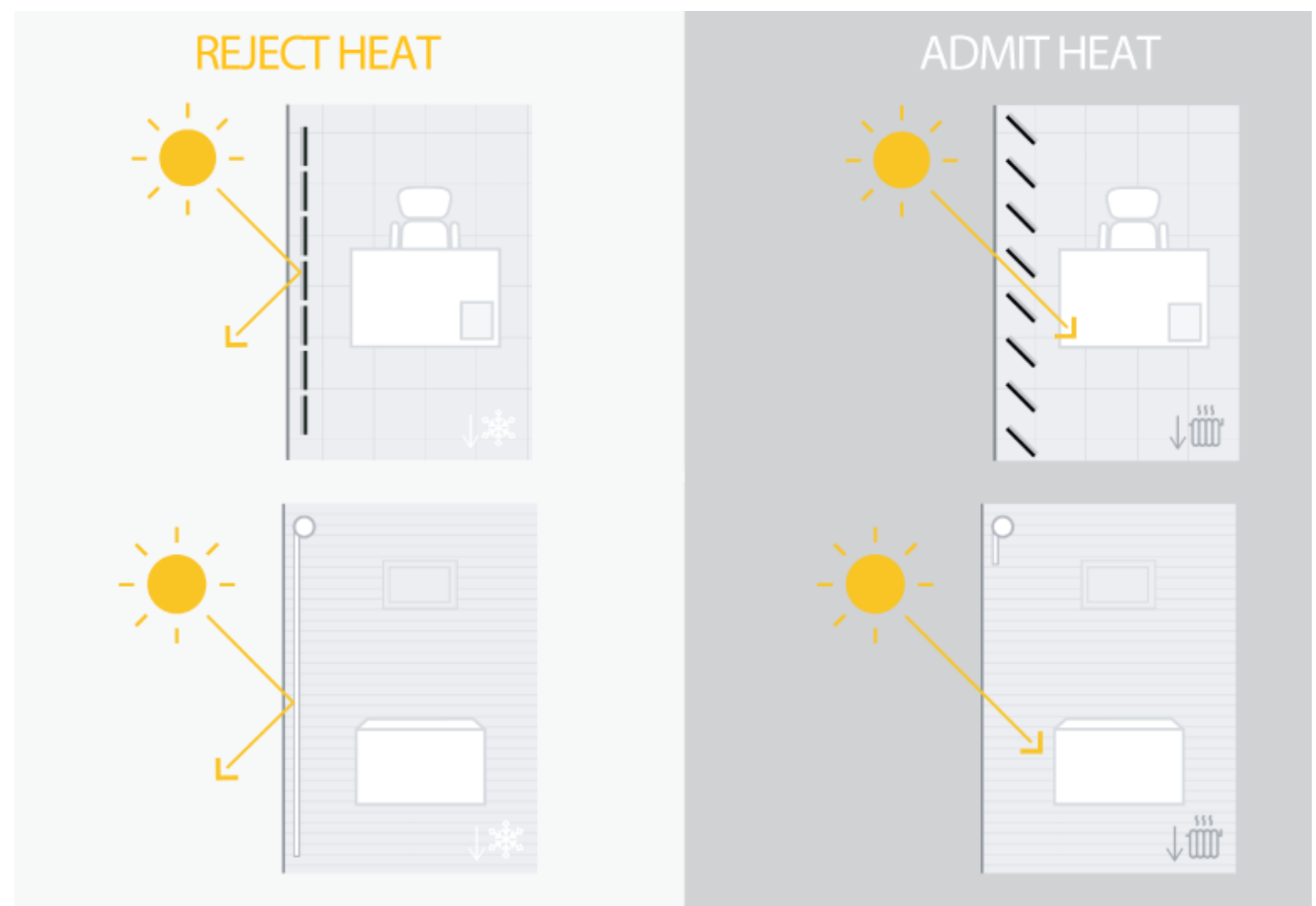

Figure 62. Kindow sun-tracking control concept. The illustration shows the operation during unoccupied hours.

\section{Architectural and technological integration into the envelope}

The Kindow shading system can be wired for power supply and communications, but is additionally designed for completely wireless and stand-alone operation. In its stand-alone application, the motorisation system is powered by a PV and battery system which is integrated into the product on the inside of the facade. The control system can be integrated within a larger building automation system but full integration is not required for its operation.

The system, and the employed sensor strategy, is designed in a modular way where the shading system can be controlled in groups. This allows for customized control behaviour for different spaces and façade orientations. The Kindow automation concept can be combined with virtually any type of rollerblind or vertical blinds.

\section{Integration into the building: system and comfort}

The Kindow system prevents daylight glare discomfort and offers more effective daylight utilisation and views to the outdoors. By preventing the occupant from being exposed to direct solar radiation, the system also helps to prevent thermal discomfort from radiant asymmetry.

Compared to conventional automation strategies for rollerblinds, which fully lower or raise the rollerblind in response to an external sensor, the Kindow system offers significant reductions in energy consumption for heating, cooling and lighting.

The system allows control parameters to be adjusted to user preferences and the system can be manually retracted. Simulation studies have suggested though that user overrides are less likely to occur compared to a conventional automated control strategy.

In comparison to conventional automated control strategies, the Kindow concept is associated with higher solar gains. Compared to a conventional control strategy for indoor rollerblinds, the Kindow system still leads to a reduction in cooling energy consumption as the increase in solar gains is offset by a reduction in heat gains from artificial lighting. In comparison to an automated outdoor solar shading system, the Kindow strategy is associated with a higher cooling energy consumption. This increase in cooling energy consumption is outweighed, however, by reductions in artificial lighting and heating energy consumption in a way that the Kindow system offers more beneficial overall energy performances in terms of final- as well a primary energy consumption. 


\section{SWOT analysis}

\section{Strengths}

Compared to conventional solar shading systems:

- Reduced daylight glare discomfort and increased admission of daylight, particularly owing to the 'overcast sky detection' mode

- More frequent views to the outdoors and less visual disturbance from large and fast shade movements

- Reliefs occupant of manual operation

- Potential for increased user satisfaction and productivity

- Uniform visual appearance

- Control behaviour can be adjusted using sensing and actuation at room, floor or façade level

- Decreases heating and artificial lighting energy consumption

- The sun-tracking behaviour of system offers a very visible investment

Compared to automated indoor solutions:

- Increased thermal comfort due to reduced internal heat gains and blocking of direct solar radiation

- Limited additional investment costs

- Decreases cooling energy consumption

Compared to automated outdoor solutions:

- Improves reverberation time and more quiet motorisation. Improves acoustic comfort

- Has lower technical and visual impact on the design of the façade

- Can be applied under more extreme conditions (high windspeed and altitude)

- Lower investment, installation and maintenance costs

\section{Opportunity}

- The values of integrated daylight management in buildings is increasingly recognized in practice and reflected in standards

- The effects of climate change will increase indoor overheating in buildings. Effective management of daylight and solar gains will become increasingly important

- It can potentially offer reduced investments in glazing and HVAC systems

- It enhances the benefits of highly glazed offices spaces whilst mitigating their weaknesses

- The visual appearance of the system can be customized to a greater extent than outdoor products

- The combination of the indoor Kindow system with static exterior shading elements might offer more beneficial performance than conventional exterior automated shading systems

- The control platform is designed to be extendable. Algorithms based on weather forecasts and self-learning capabiltities are currently being developed

\section{Weaknesses}

Compared to conventional solar shading systems:

- A daylight-dimming system is a required to achieve energy demand reductions. Performance depends strongly on the commissioning of the daylight dimming system

- Improvements in daylighting and energy performance are mainly found within the daylight area of the office space

Compared to automated outdoor solutions:

- In spaces where the indoor climate is verry strongly influenced by solar gains Kindow can have a less favourable effect on thermal comfort than conventionally controlled (fully closed or opened) outdoor shading system with similar optical properties. In such instances the Kindow strategy, wich prioritizes visual comfort, can be associated with higher indoor air temperatures as well as higher surface temperatures (inside glass pane and the shading system).

- Under such conditions the Kindow strategy can lead to more cooling energy consumption than a conventionally controlled outdoor solution. This increase in cooling energy consumption is generally offset however by reductions in the energy demand for heating and lighting.

\section{Threats}

- Indoor shading solutions are often considered the responsibility of the end-user and not of the developing parties. Potential benefits for developing parties might be overlooked and improvements in comfort and energy performance might not be sufficient argumentation for additional investments

- The performance benefits of indoor products with metallised coatings is still largely overlooked in the building industry

- The performance benefits of indoor shading products and the interactions between daylight controlled lighting and shading control strategies are still not accurately accounted for in many energy standards

- Outdoor solar shading solutions can, in some cases, eliminate/prevent installation of mechanical cooling systems and associated investments. For indoor shading systems this seams less likely

- The effects of climate change will increase indoor overheating in buildings making outdoor solar shading more attractive 

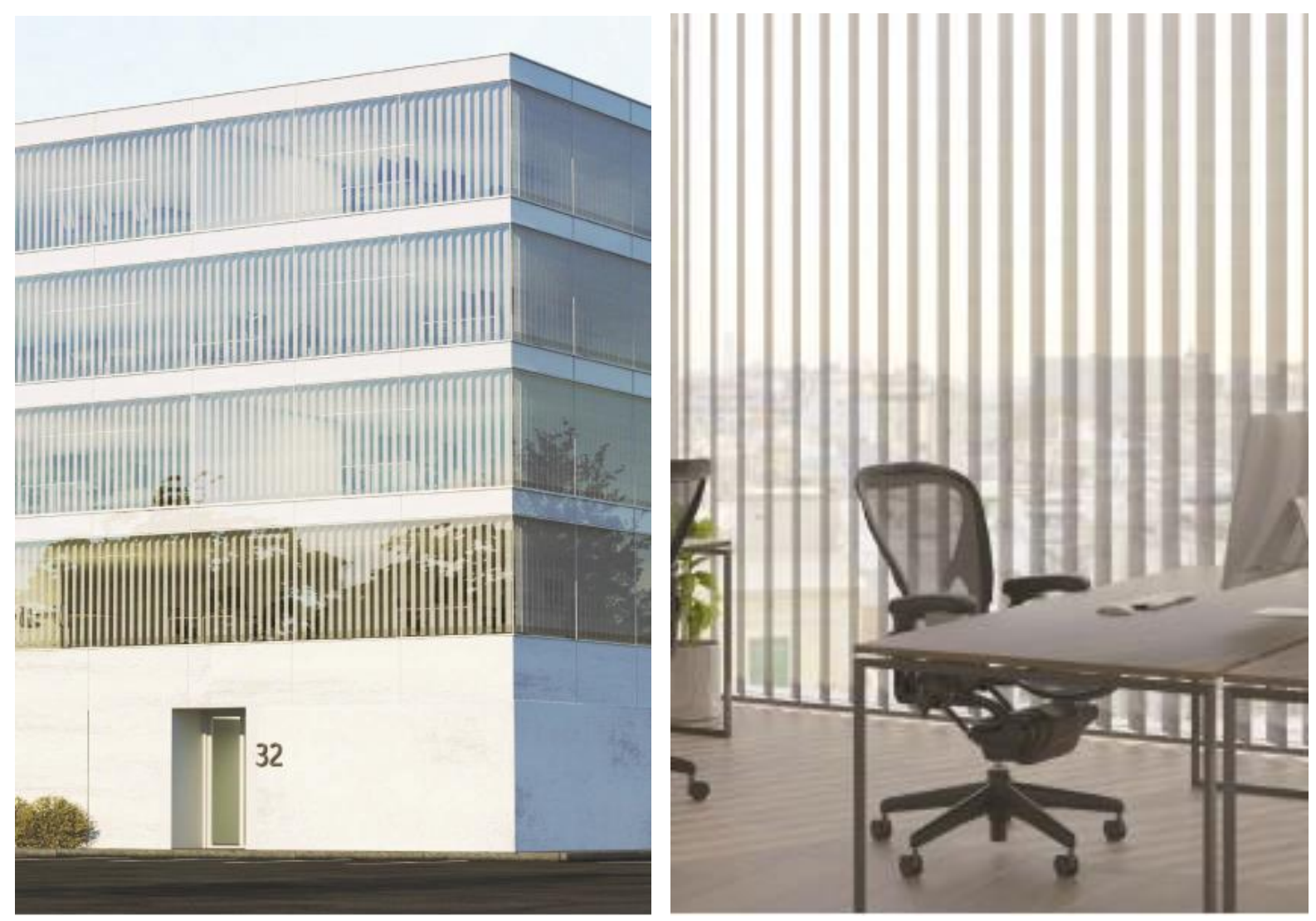

Figure 63. Kindow vertical blind system. Exterior and interior appearance.

\section{Lessons learned}

- Advanced solar shading control offers a very cost-effective way of improving indoor environmental comfort and reducing building energy consumption.

- The effects on the indoor environment of solar shading control combined with daylight-driven control of artificial lighting rely on interactions between the thermal and the visual domains of physics. These domains are traditionally adressed seperately within building performance simulation tools. Overcomming this limitation requires specialist knowledge.

- The performance benefits of indoor shading solutions and interactions between artificial lighting and shading systems are not fully recognized by practitioners in the building industry. Solar shading, and especially indoor shading, is often considered to be part of interior furnishing and not as an integral part of the building envelope design. Solar shading specialists are ususally not involved in the early design process and, as a result, the benefits of solar shading are often overlooked.

- There is split incentive between developing parties and end-users which can prevent the potential of solar shading concepts from being realized.

\section{Further reading}

Vries de, S.B., R.C.G.M. Loonen, et al. (2019). Sensor selection and control strategy development support for automated solar shading systems using building performance simulation. Building simulation 2019. Rome.

Woensel van, R. (2018). Automated solar shading and occupant behavior - The impact of occupant behavior modeling on the simulation-based performance prediction of automated solar shading systems. Masters thesis, Eindhoven University of Technology.

Company website: www.kindowblinds.com 


\section{Prototype systems}

\section{Facade integrated daylight and electric light illumination with micro-optics \\ by Carolin Hubschneider, Fraunhofer IBP, Germany}

\section{Product description}

\section{Brief concept description}

In this solution, micro-structured optical components are integrated in the façade with applications in daylighting and artificial lighting. Due to the use of these components, improvements in energy efficiency, lifecycle balance and quality of stay in buildings are expected.

Two micro-optical structures were developed: a light redirecting and a light emitting structures (Figure 64), which can also be combined:

- The light emitting structure is applied to a surface of a transparent pane and is coupled with LEDs located on the edge of the pane. The light is emitted only to the interior side of the building and the element remains transparent;

- The light redirecting structure is optimized for directing glare-free daylight into the depth of the room. Such structure is applied to both sides of a transparent pane.

\section{Emitting Structure}

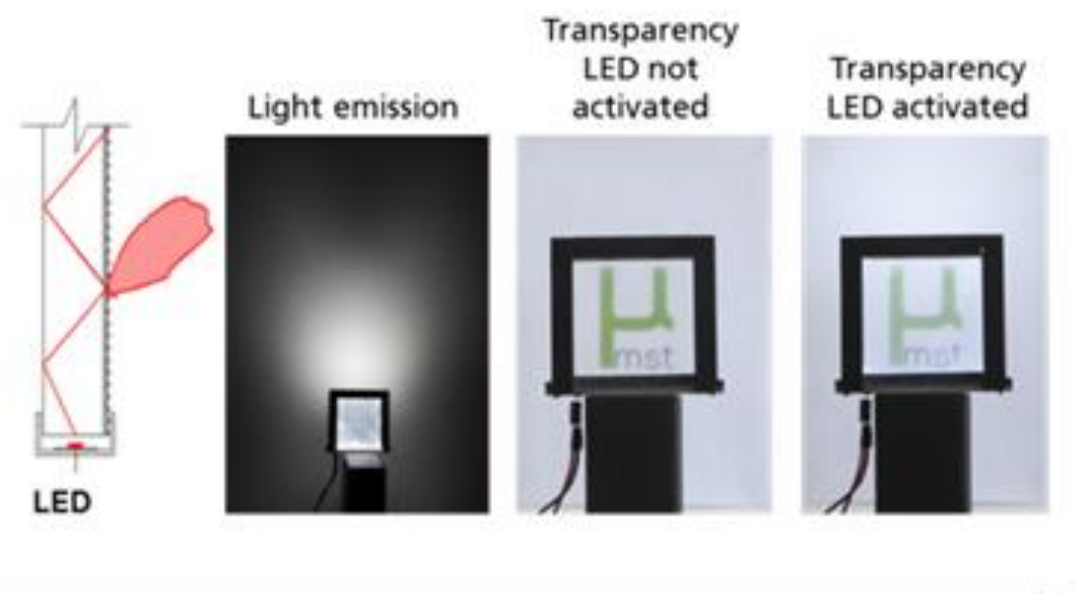

\section{+ Combination}

\section{Redircting Structure}
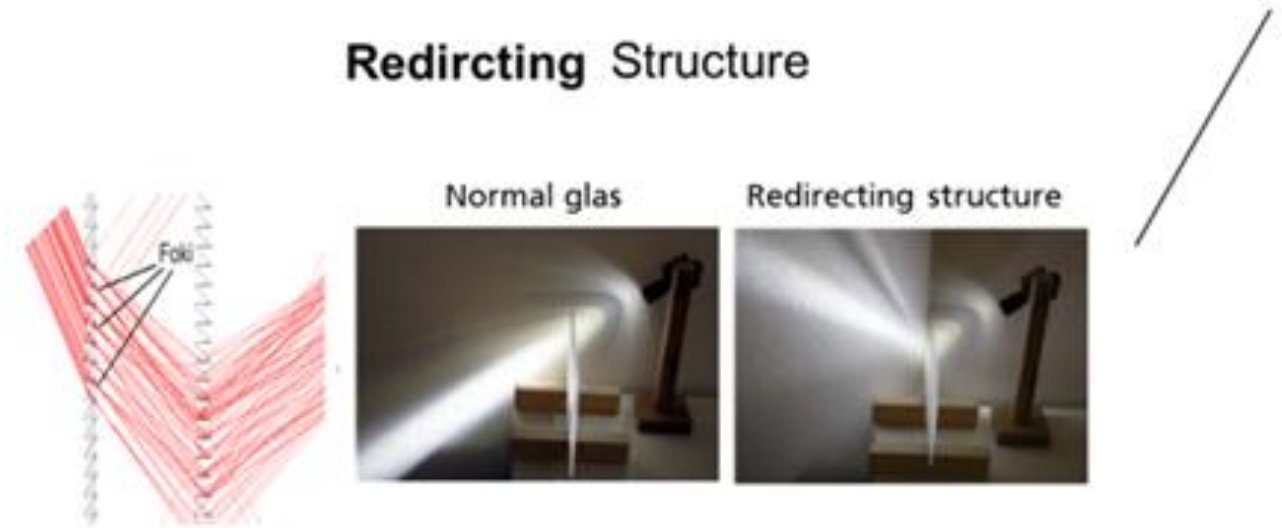

Figure 64. Schematic sketches and laboratory prototypes of the two new micro-optic structures. A functional combination of both structures is possible (Reference: AG MST, TU-Dortmund). 

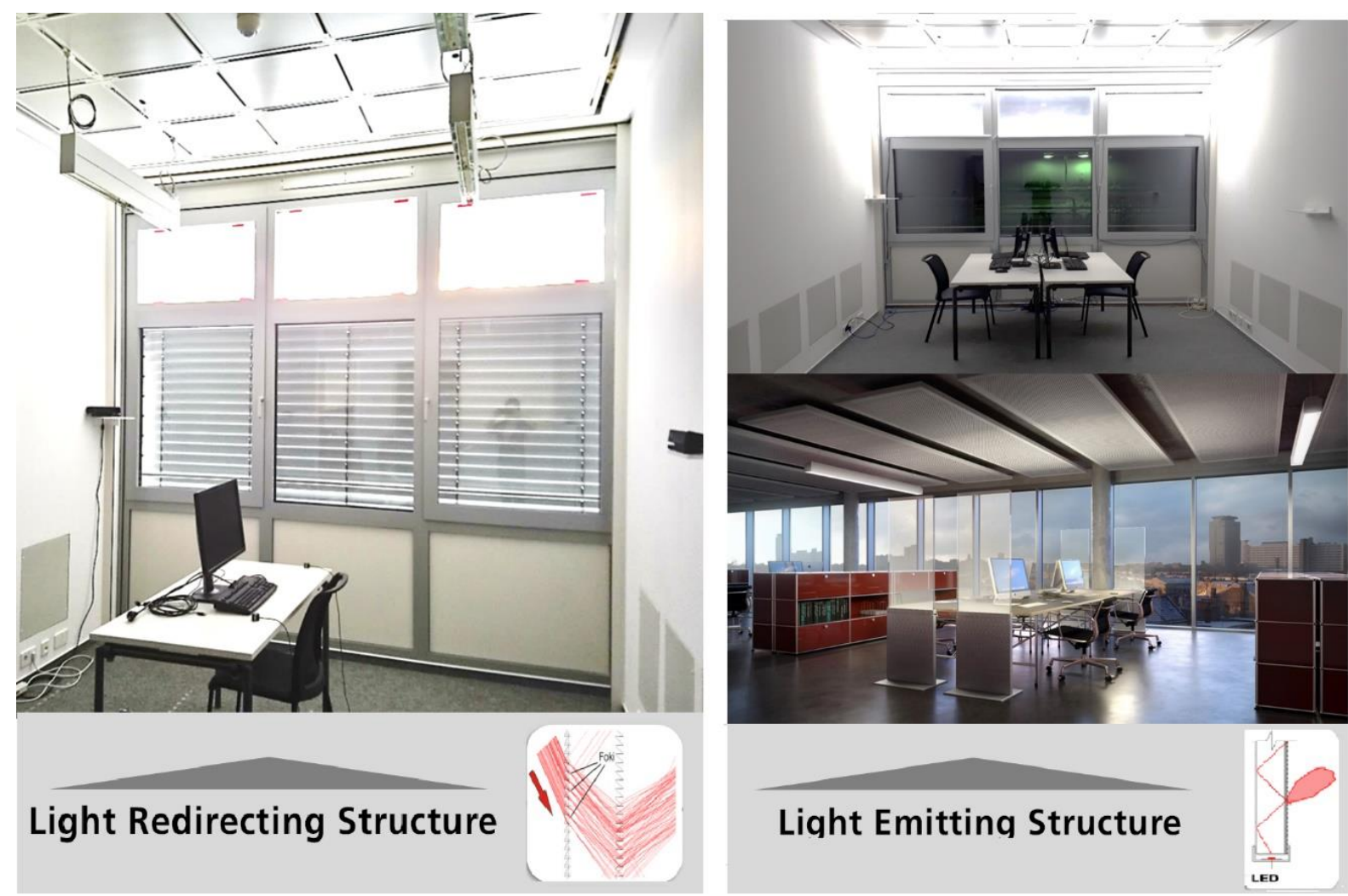

Figure 65. Integration of light redirecting and light emitting structures into vertical façades (left and upper right image). Integration of light emitting structure into luminaires for task lighting (lower right image).

\section{Architectural and technological integration into the envelope}

The two optical structures can be integrated into the building envelope in different ways. The integration of the redirecting structure into vertical façades allows to bring sunlight into the depth of the room for different positions of the sun without changing the orientation or angle of the optical structures. In roof applications, the redirecting structures allows to illuminate high and narrow rooms like atria and light wells.

With the integration of the light emitting structure in windows and roof lights, the building envelope provides access to both artificial and natural light, so that conventional artificial lighting systems can be partially replaced. The light emitting structure can also be employed in new types of transparent workplace luminaires (Figure 65, lower right image).

From an architectural point of view, the system is easy to integrate in existing planning as it does not change the design of the façade and the optical structures reduce the daylight input and view only to a lesser extent. Furthermore, as the conventional artificial lighting system can be resized or even removed, there is more freedom in designing the ceiling with also potential cost savings.

\section{Integration into the building: system and comfort}

To use the light emitting structure, the LEDs have to be connected to the power supply of the building and therefore the integration of cables into façade and windows is necessary. For this reason, an electrician has to be on-site during the installation of the façade. With the use of presence and photo sensors, a suitable light management can reduce the energy consumption and improve the comfort of the occupants. The artificial light can be indeed adjusted to the daylight in terms of luminous flux and colour temperature. 


\section{SWOT analysis}

\section{Strengths}

- The integration of the optical structures in different architectural façade constructions is easy, as the appearance of the building from both outside and inside is untouched

- The customization of the product is possible, as the size of the optical structures can be adapted to the dimensions of the window / façade

- It is possible to combine natural and artificial lights with similar light distribution and colour

- There is freedom in the design of the ceiling: no luminaires and cabling

- The product design is attractive

- High levels of prefabrication can be reached

- No additional efforts in cleaning are needed

- The additional weight for the façade is limited

\section{Weaknesses}

- Deep rooms may have to be illuminated from two sides or to be equipped with an additional conventional lighting system

- Additional wiring in the façade is needed

- A larger effort is required to change the light source in case of defect

- The light redirecting structure can only be installed in the upper part of the window because of glare

- The target market is currently limited to nonresidential buildings as the system cannot be combined with internal shading systems like curtains, which are often used in residential buildings for privacy reasons

- The view is slightly disturbed in comparison to the glazing without micro-optics

- $\quad$ There are limits to the size of the glazing (current maximum height is $0.6 \mathrm{~m}$ )

- Who will be the seller of the system? The market strategy is different in comparison to conventional lighting systems

\section{Opportunity}

- The non-residential building sector is expected to be a large market segment since most workplaces are located near the façade

- The installation of the system as stand-alone is possible: the integration to the building automation is preferable but not necessary

- The system is very suitable for retrofit, as the intervention is limited to the replacement of the windows and the integration of a cable duct

- In the lighting industry, there is currently a trend to simulate daylight with artificial lights (dynamic colour and dimming). This could bring more interest toward the light emitting structure

- In the future, the system could be applied to allglass facades with LEDs installed in the upper edge of the glazing, with no bar needed between lower part and upper part of the window

\section{Threats}

- It could be difficult to penetrate the market with new solutions due to the established lighting industry

- Building designers could be sceptical because of the more complex planning process and the different stakeholders involved

\section{Lessons learned}

- $\quad$ Concerning the product development, the two systems (light emitting and redirecting structures) have been scaled to sizes suited for the inclusion in real constructions in a recent research project which ended in 02/2019. In a next phase, they will be tested and demonstrated in real applications (school and offices).

- The light redirecting structure showed large energy savings and high visual comfort, whereas the light emitting structure could not yet fully reach the energy performance of standard luminaires. By enabling light supply only from the facade layer, the later structure however demonstrated high architectural relevance, as no standard luminaires are required in spaces close to the facade.

\section{Further reading}

Helmut F.O. Müller: Micro-Optical Structures for Daylighting \& LED Systems, World Renew. Energy Congress XVI, Febr. 2017

Jakubowsky M., Neyer A.: Optimized design of daylight redirection microstructures combined with planar micro structured light sources for high efficient room lighting integrated in building façades, CISBAT Sept. 2017, Lausanne, Switzerland

Website: https://www.ibp.fraunhofer.de/de/Kompetenzen/energieeffizienz-und-raumklima/eer-projekte/taled.html 


\section{Active Insulation}

by Roel Loonen, Eindhoven University of Technology, The Netherlands

\section{Product description}

\section{Brief concept description}

Active Insulation is a building envelope system developed by the Dutch start-up "Active Insulation Systems BV" whose insulation function can be switched on and off. During normal operation, the building skin acts as a regular thermal barrier between indoor and outdoor. In some occasions, however, the heat transfer can be encouraged instead of blocked to exploit the external climatic conditions to reduce the energy load of the building and improve the comfort of the occupants. During summer nights, for example, it is possible to take advantage of the lower outdoor air temperature to regulate the indoor temperature without active cooling. Similarly, the thermal insulation can be bypassed during sunny days in winter, to make better use of solar gains and reduce the space heating demand.

The current prototype is based on already proven technologies and functions as a closed-loop air-to-air heat exchanger as shown in Figure 66. Manifold channels are inscribed in the insulation material and small embedded fans $\left(\sim 0.5 \mathrm{~W} / \mathrm{m}^{2}\right)$ allow the occupant or the building management system to either create a stagnant air cavity, or to short-circuit the insulation layer by means of the airflow. Initial calculations indicate a heat exchange rate of $\sim 15$ $\mathrm{W} / \mathrm{m}^{2}$ at a temperature difference of $10 \mathrm{C}$ (on state). Hot-box simulations show a change of $\mathrm{R}_{\mathrm{s}}$ value from $5.4 \mathrm{~m} \mathrm{~m}^{2} \mathrm{~K} / \mathrm{W}$ (off state) to $0.6 \mathrm{~m}^{2} \mathrm{~K} / \mathrm{W}$ (on state), which can be further tuned depending on the host construction. Full-scale experimental studies and dynamic building performance simulations are currently being carried out.

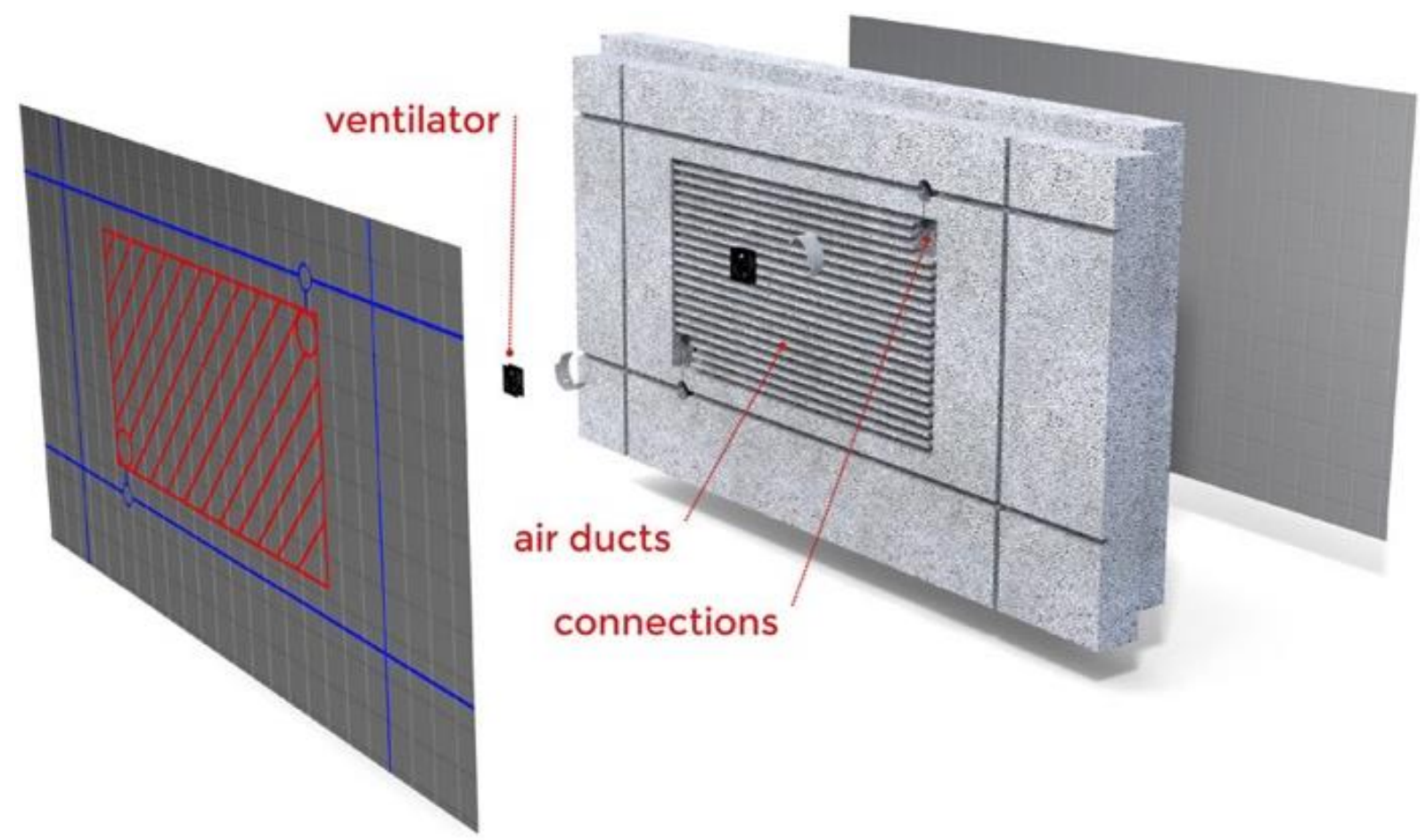

Figure 66. Schematic drawing of Active Insulation.

\section{Architectural and technological integration into the envelope}

Active Insulation is a standalone system (no air/water channels are entering or leaving the panel, Figure 67) that takes an existing insulation slab as its starting point. It is therefore fully compatible with existing ways of working in the construction industry.

Since the slabs are fitted with regular mounting points that do not interfere with the heat exchanging capability of Active Insulation, it can be integrated in many different construction types, such as masonry walls, prefabricated sandwich wall elements, steel frame panels or (pitched) roof systems (Figure 68). 


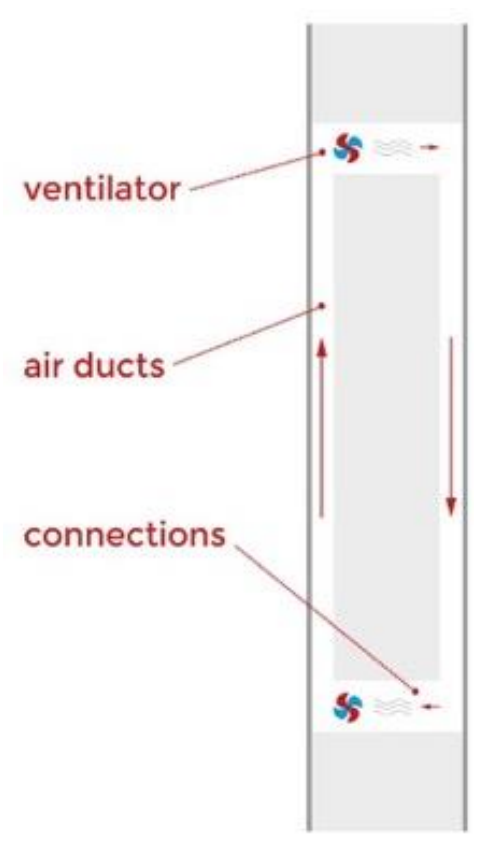

Figure 67. Vertical section of a wall integrating Active Insulation. The system works as a closed loop heat exchanger with no exchange of air or water with indoor and outdoor environments.

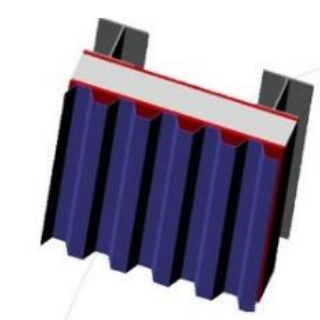

Factory wall

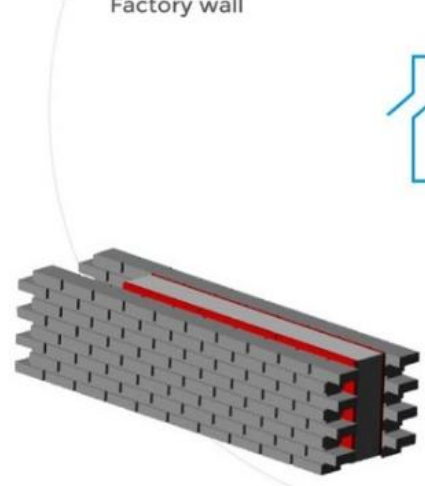

Cavity wall

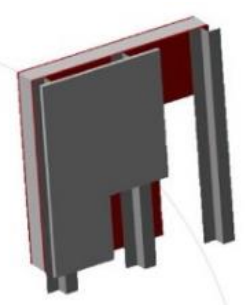

Prefabricated wall
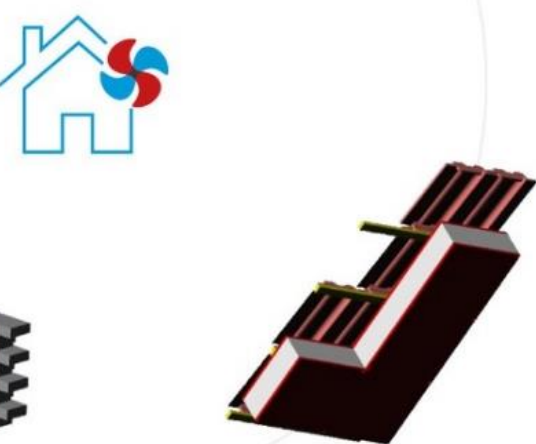

Roof construction

Figure 68. Different applications of Active insulation in a variety of construction typologies.

\section{Integration into the building: system and comfort}

The fans integrated in the Active Insulation panels need a small amount of electric power to operate $\left(\sim 0.5 \mathrm{~W} / \mathrm{m}^{2}\right)$, which can be supplied through a wired connection or by means of autonomous PV systems with battery storage.

To maximize the benefits of Active Insulation, it is important that the operation of the system is well coordinated. This is a challenging task that may need different approaches for different orientations and depends on the (expected) occupancy of the building. The development of advanced control strategies and coupling with the building management system are therefore necessary conditions for a successful application of Active Insulation. 


\section{SWOT analysis}

\section{Strengths}

- It is possible to enhance the indoor comfort during summer by releasing heat to exterior environment during night-time and reduce the space heating demand in winter exploiting solar heat gains

- The architectural design of the opaque façade parts is not influenced. There are no restrictions to the placement of the transparent façade parts

- The system is easy to understand and has only few moving parts

- It is usable for many types of facades and roofs, without increasing the thickness of the structure

- The additional investment of the system is lower in comparison with traditional insulation

- The product is easy-to-install and requires little extra effort compared to conventional insulation

- It is a prefabricated solution with modular dimensions

- There is no security risk compared to operable windows for night ventilation

- The system is very silent and can be applied in noisy urban environments where operable windows are not suited

- It is suitable in areas with high air pollution as night cooling is decoupled from fresh air supply

\section{Weaknesses}

- Fans are expected to have long lifetime (mature product from PC industry). However, in case of malfunctioning, replacement will be time consuming/impossible, depending on type of structure used

- Multiple sections of Active insulation can be controlled individually, but this requires multiple sensors for good control of system (indoor temperature per zone, outdoor surface temperature, indoor surface temperature)

- Control "intelligence" needs to be designed and implemented on a case-by-case basis

- The system requires buildings with a minimum daytime space heating demand to function optimal during the heating period

- External shadows on the opaque surface due to surroundings can influence performance during the heating period

- The integration of Active Insulation in existing buildings requires a significant retrofit.

Purchasing of local air conditioning systems can also alleviate the overheating problem, has an immediate effect and is less cumbersome

\section{Opportunities}

- The currently used EPS could be replaced by biodegradable materials with similar properties to meet the requirements for 'circular economy'

- $\quad$ The system is fully compatible with new building codes prescribing high thermal insulation values

- Buildings with large closed facades where view is of minimal interest (e.g. theatres, industrial halls and garages) are an interesting application

- The cooling effect during summer can in some cases eliminate the need of mechanical cooling systems and save the associated investments

- A combination with BIPV could be studied to manage both energy generation and heat transfer control on opaque surfaces

- Global warming results in more overheating during summer, increasing the demand for solutions like Active Insulation

\section{Threats}

- Other opaque or transparent adaptive insulation systems with higher potential could be developed in the future

- Condensation may occur due to the possibility of low interior surface temperatures

- The urban heat island effect reduces the effectiveness and duration of nocturnal cooling

- The system is invisible. Apart from being a strength, this is also a threat, because low awareness may lead to less willingness to invest

- It is hard to make a tangible business case around the value of improved summer comfort

- $\quad$ Active Insulation is not (yet) included in design support tools (e.g. BIM) and energy assessment methods (e.g. energy labels)

\section{Lessons learned}

- The responsibility of summer overheating as a negative side-effect of (too) high thermal insulation is not clear. It is currently considered as a responsibility of neither the building designer, nor the HVAC specialist. This lack makes the integration of Active Insulation in the construction process not straightforward.

- The dynamic characteristics and physical phenomena that take place inside façades with Active Insulation are not compatible with typical algorithms in building performance simulation software. The prediction of the performance of Active Insulation therefore requires the modification of simulation models at the source code level. This is a time-consuming task that needs to be carried out by specialists.

\section{Further reading}

Koenders, S. (2018). Active Insulation - Computational assessment of the performance of a forced convective dynamic insulation system. MSc thesis. Eindhoven University of Technology. Website: www.active-insulation.com 


\section{DARE - New Daylight redirecting film \\ By André Kostro and Andreas Hafner, BASF Schweiz AG, Switzerland}

\section{Product description}

\section{Brief concept description}

DARE is a newly developed daylight redirecting film that can overcome the most common limitations of existing daylighting redirecting films: limited efficiency, insufficient glare protection, unappealing aesthetic appearance, high cost and complex installation. With this innovative solution, glare protection is provided most of the year (during more than $90 \%$ of office hours) and the efficiency is increased based on a different technology, without the use of prisms or air cavities and with the use of encapsulated metallic micromirrors. This enables lamination into the glazing and the aesthetic appearance is improved since the film remains transparent under the most common viewing angle and the cost is reduced by an early and facilitated integration into glazed products. The DARE daylight redirecting film is currently in an advanced stage of development.

\section{Architectural and technological integration into the envelope}

The film is integrated inside double or triple glazing units mounted above viewing height (skylight - approx. $2 \mathrm{~m}$ and above), as shown in Figure 69. The integration into portions of a continuous glazing is also possible. The system is completely passive and does not integrate any kind of actuator nor requires any active control. Once the film is integrated, the glazing units can be treated as conventional ones and does not need additional maintenance.
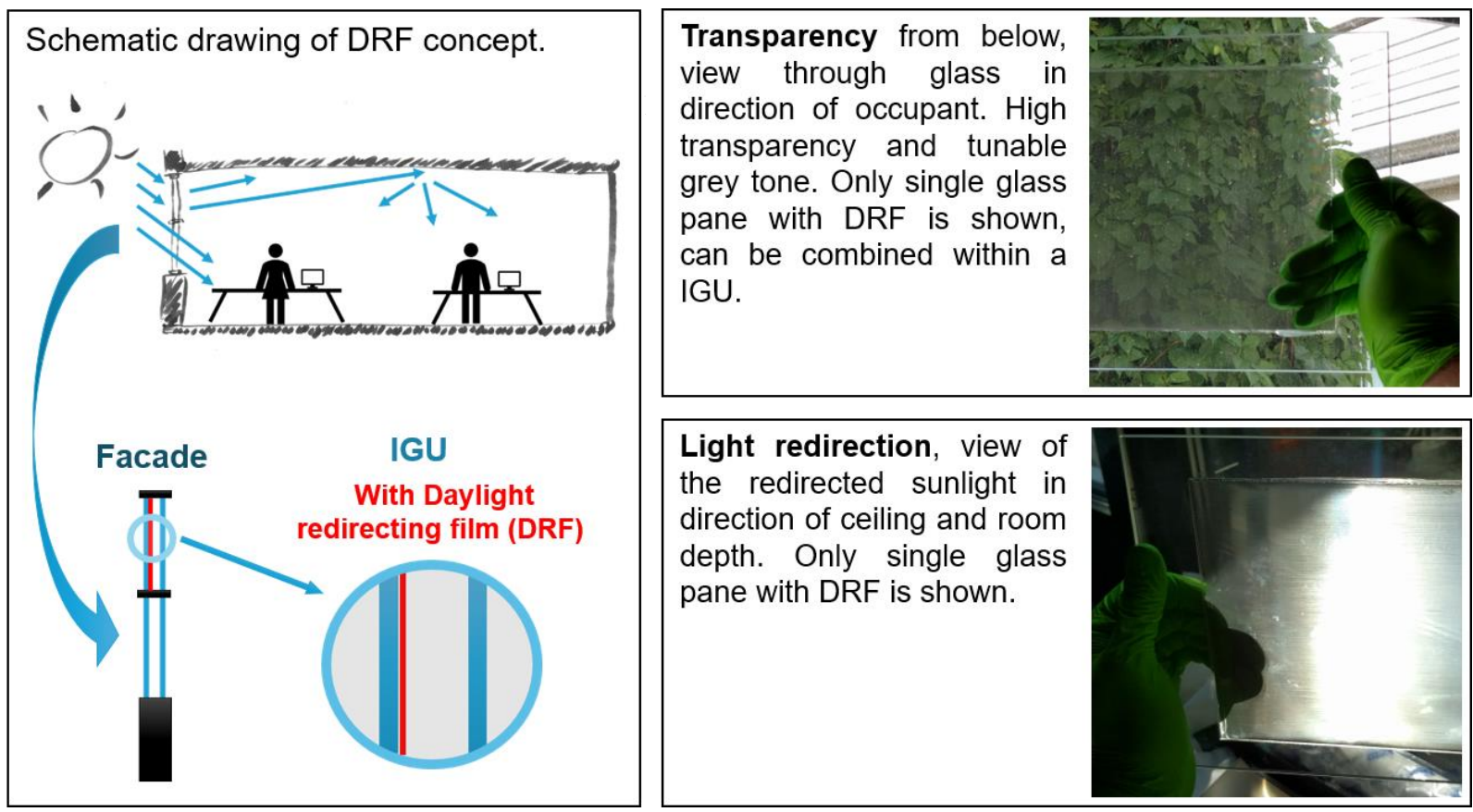

Figure 69. Schematic drawing of DARE daylight redirecting film concept and pictures of a prototype.

\section{Integration into the building facade: system and comfort}

The system improves the comfort conditions in the occupied space by providing glare protection and daylight redirection simultaneously. The daylight distribution on the floor space is enhanced and the daylight autonomy is strongly improved, in particular in room depth where it can be improved by $50 \%$ to $150 \%$ depending on the location. A simulation study on a number of locations worldwide showed that in average it is possible to achieve an improvement of daylight autonomy of $66 \%$ and energy savings for artificial lighting of $38 \%$, corresponding to an average reduction of primary energy consumption in buildings fulfilling an efficient energy standard of $16 \%$. 


\section{SWOT analysis}

\section{Strengths}

- Daylight redirection into the depth of the room, which improves daylight distribution and reduces artificial lighting demand

- For most cases, the precise daylight redirection replaces the installation of an additional glare protection system

- High transparency for near-normal view and high efficiencies (i.e. high light transmission) are achieved

- The solution is aesthetically appealing

- The integration of the film into window units of any glazed system is possible

- Pre-installation into insulating glazing units avoids complicated installation on-site

- It is safe, durable and maintenance free

- It is a passive system with no moveable parts that does not active controls

\section{Opportunity}

- Daylight regulations and energy certifications in buildings require the use of natural lighting and an efficient control of solar gains

- Efficient daylight redirection increases the daylight area in deeper rooms, improving the use of spaces in offices

\section{Weaknesses}

- It requires the upper glazed part (skylight) to be free of glare protection devices

- It requires a separate glare protection device if the glazing with the film is installed below view height

- It cannot be deactivated in cloudy days

- Daylight dimming is not possible

\section{Threats}

- Previous market introduction of other daylight redirecting systems had limited success

- Complex fenestration systems such as DARE cannot be easily included in standard lighting design or building energy modelling software yet

\section{Lessons learned}

The aesthetic of a product is essential for acceptance in the building sector.

\section{Further reading}

Gong, Jing ; Kostro, André Gabriel ; Motamed, Ali ; Schueler, Andreas . Potential advantages of a multifunctional complex fenestration system with embedded micro-mirrors in daylighting, Solar Energy Journal, 139, 412-425, 2016.

A. Kostro, P. Couty, D. Geisler Moroder, W. Pohl, A. Schüler, A. Hafner. From university to industry - challenges in upscaling optical microstructures for daylight redirection in buildings, to be published in proceedings of CISBAT 2019 


\section{Commercial systems}

\section{Semi-Transparent Luminescent BIPV Windows \\ by James Walshe and Philippe Lemarchand, Technological University Dublin, Ireland}

\section{Product description}

\section{Brief concept description}

The integration of photovoltaics into buildings facades offers the growing possibility of making the structures in our society play a more active role in our transition towards a sustainable economy. Luminescent building integrated photovoltaic windows (L-BIPV) are semi-transparent systems based on luminescent down-shifting species (LDS) which are combined with photovoltaic solar cells. LDS materials absorb diffused and direct light within the ultraviolet region $(200 \mathrm{~nm}-400 \mathrm{~nm})$ and re-radiate it to a tuned wavelength band within the $500 \mathrm{~nm}-700 \mathrm{~nm}$ range. The capability to tune the optical characteristics of the luminescent species considered to a specific region of the spectrum $(650 \mathrm{~nm}$ $-700 \mathrm{~nm}$ ) where the PV cells responsivity is higher and the human eyes responsivity is low, is key for the semitransparent hybrid device to provide some of the indoor lighting requirements and enhance the energy conversion from the photoluminescence.

Two different designs of L-BIPV were developed (Figure 70): in LDS-PV systems, a semi-transparent PV cell is combined directly underneath the LDS layer. In luminescent solar concentrator (LSC) systems, instead, light is captured and re-emitted by the LDS species and concentrated by total internal reflection to small and highly efficient PV cells located within a window edge cell. In comparison to the use of large semi-transparent photovoltaic cells integrated in the glazing, the use of thin strip silicon within the window edges offers advantages in terms of costs, glazing transmission as well as overall light to power conversion efficiency of the system.

L-BIPV systems can potentially replace or be added to conventional window to produce electricity, thus reducing the building energy consumption and carbon emission, improve indoor light and thermal comfort and provide colourful architectural designs.

(A)

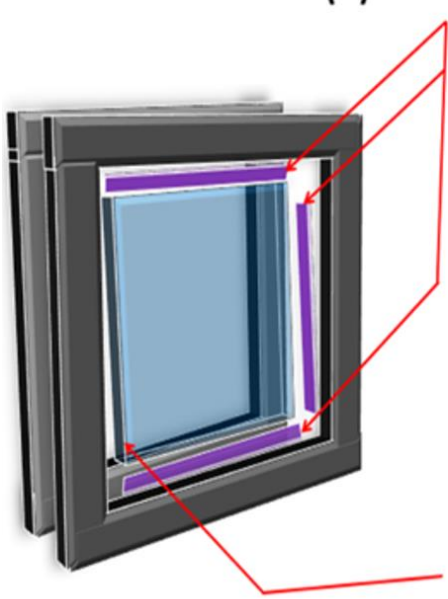

Photovoltaic cells along the edges of the glazing collect the light emitted from the luminescent species converting it into usable electricity

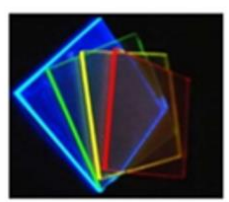

The organic LSC collects light from the glazing area coupling the collected light to the edges of the plane
LDS layers encasing a semitransparent PV cell. Protecting it from the external environment and improving the efficiency of the cell
from the external environment and

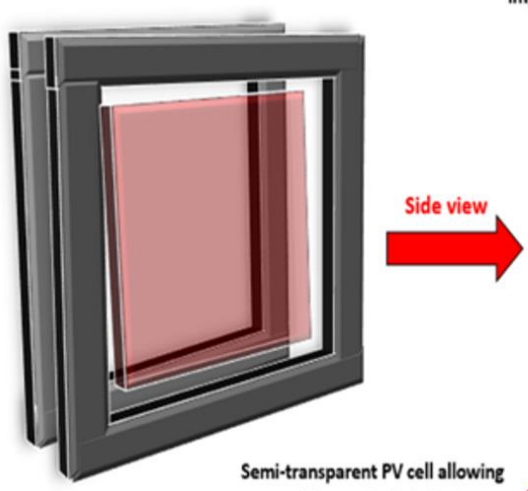

some of the visible light $1400 \mathrm{~nm}-$

$800 \mathrm{~nm}$ ) to provide a source of internal building illumination

Figure 70. Two different luminescent building-integrated photovoltaic windows design options (A) building integrated LSC window and (B) building integrated LDS-PV window.

Interest in semi-transparent PV devices has undergone a massive revival in the last 20 years due to the ability of such devices to be fully integrated into building elements such as skylights, facades, windows and even walls (Saifullah, Gwak, and Yun 2016). Semi-transparent PV cell devices based on perovskite, thin-film and organic technologies are on the verge of becoming commercial available (Heim, Knera, and Machniewicz 2015; RomeroGómez et al. 2015). Current approaches have been limited due to issues inherent in each technology, in terms of its scalability and long-term stability when exposed to in-situ environmental conditions (Bouvard, Vanzo, and Schüler 2015; Klampaftis et al. 2009). Currently, no window design incorporating LDS features is commercially 
available, with such structures presently confined to a research and development state. Efforts have been consolidated into a multi-teared design approach, attempting to reduce the losses associated with each design element while harnessing a synergistic interaction between components within the structure to deliver a commercially viable L-BIPV design.

\section{Architectural and technological integration into the envelope}

L-BIPV windows can be integrated into building envelopes similarly to traditional BIPV systems. LDS and similar spectral conversion technologies including LSC underwent a revival in the last decade with the development of new design strategies. Exploiting the energy transfer between nanostructures and luminescent species, engineering the molecules around the device and incorporating multiple chemical species are just a few of the routes being explored to deliver a commercially viable solution to the limited spectral bandwidth problem facing PV technology.

LSC systems offer a greater enhancement in the performance of BIPV as compared to their more readily incorporable LDS-PV counterparts. The lack of scalability and poor structure stability currently limit such devices from being commercially available. However, industries such as Philips are working on commercializing a building integrated version of the technology through funding initiatives aimed at pioneering researchers within the area.

LDS-PV designs offer a lower level of enhancement, but they are more readily scalable and have yet to encounter the size limitations imposed by concentrating designs explored so far. The addition of an LDS layer directly onto a cell creates a series of additional loss mechanisms which need to be overcome for the structure to offer an enhancement to the underlying PV cell. The poor optical properties and non-ideal photoluminescent materials available represent the primary introduced additional losses.

In terms of architecture, L-BIPV devices are readily adoptable into existing building plans. Similar transparent devices are already in operation within the illustrious skyline of Hong Kong. To maximise the synergy between the electricity generated by the devices and the interior illumination provided, the trade-off between the two warrants optimization. Parameters to consider include i) outdoor environmental conditions ii) building orientation, iii) window dimensions, iv) window transparency of the choice of solar cell and v) aesthetic and indoor lighting requirements.
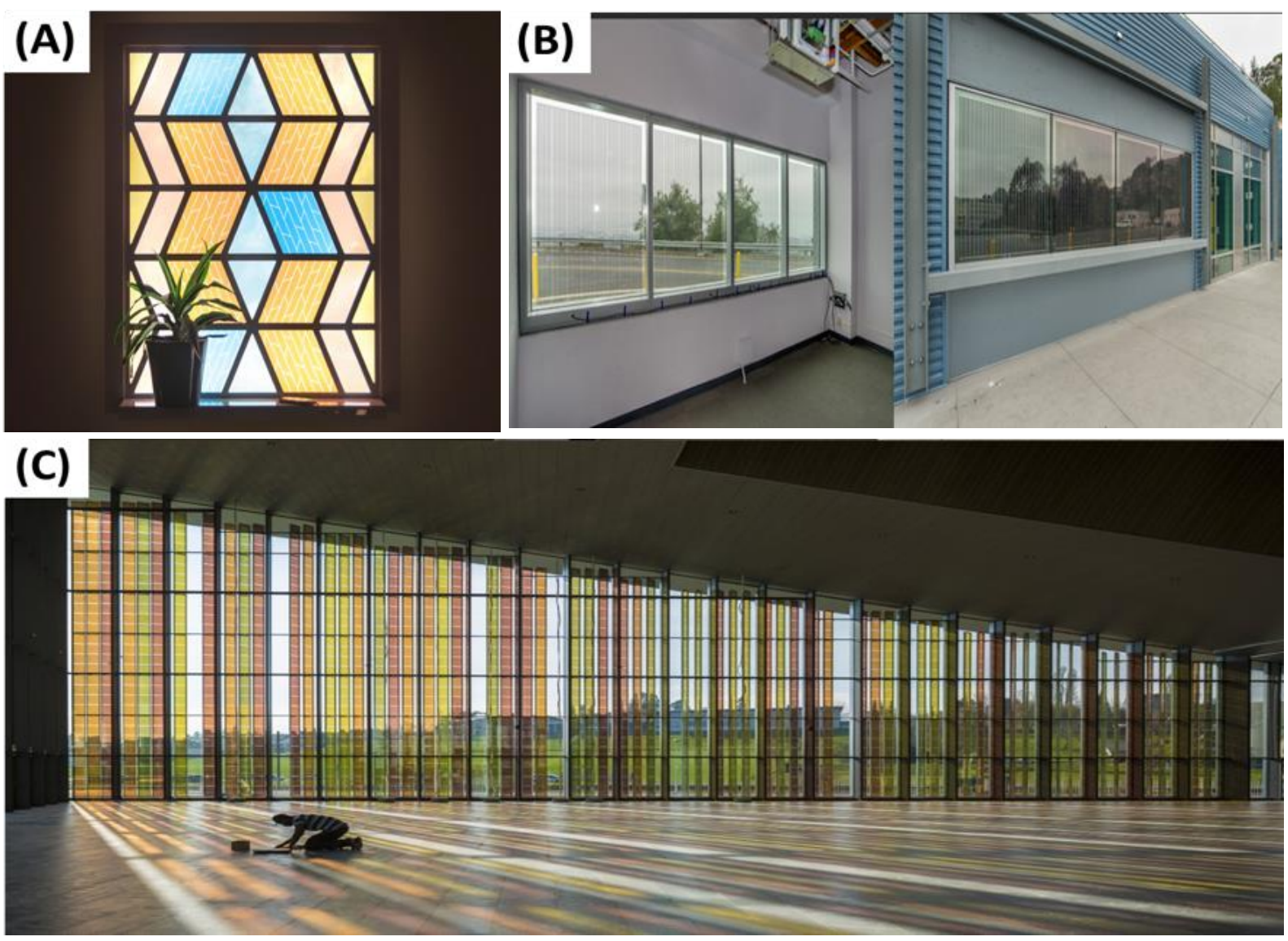

Figure 71. (A) Photovoltaic stained-glass window designed using dye synthesized solar cells utilizing different dye pigments to provide colour. (B) Semi-transparent organic PV window integrating a luminescent layer at Solaria, California. (C) Grätzel's Cell stained glass at the École Polytechnique Fédérale de Lausanne $(\mathrm{CH})$. 


\section{Integration into the building: system and comfort}

Similar to BIPV systems, continuous and low voltage is generated from the cells. To avoid DC-AC energy conversion losses from inverters, it is best to make direct use of the generated power in a local low power distribution network. To manage the operation and energy distribution, the system must be integrated with the building management system. A wide range of coloured devices can be offered thereby providing design aesthetics requirements while keeping the functionality of the underlying concept. Light absorption and rejection by the luminescent layer and semi-transparent photovoltaic cells limit solar transmission. The degree of light absorption can be modulated by the concentration of luminescent species and the cell transparency. Visible light $(400 \mathrm{~nm}-800 \mathrm{~nm})$ transmission is typically around $10 \%$ to $50 \%$ with the transmission spectra controllable through the materials electro-optical properties (Ablayev et al. 2014; Romero-Gómez et al. 2015). There exists a trade-off between the cell efficiency and the transparency of the windows, in conjunction with location specific illumination conditions it may become customary to use numerical simulation and evaluation methodologies to evaluate the impact of each design choice (Saifullah, Gwak, and Yun 2016). As illustrated in

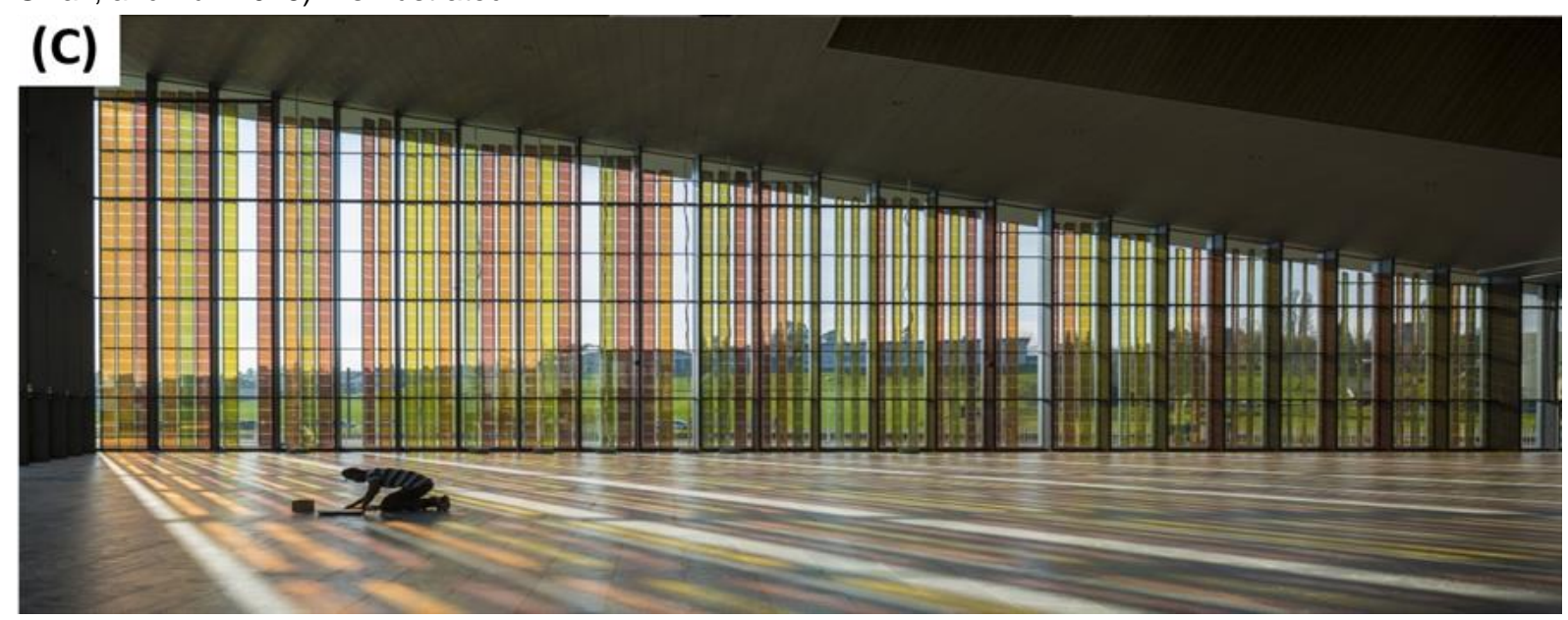

Figure 71, the system is then a shading device simultaneously limiting glare and affecting occupant comfort and psychological response by the choice of colour rendered by the window.

\section{SWOT analysis}




\section{Strengths}

- A renewable energy generation source is integrated to windows

- The ultraviolet part of the solar spectrum is converted to electrical power while further protecting the indoor environment from UV damages.

- It provides shading and glare protection in sunny climate with minimal or no visual obstruction through the window

- Design flexibility: the window opacity can be tuned on a case-by-case basis, there is no size or shape restriction and a choice of aesthetic colours is available

- $\quad$ The luminescent layers have a low cost and enhance the cell power conversion efficiency increase up to $3 \%$

- The device is easy to install

- It is usable for many types of facades and roofs, without increasing the thickness of the structure

- There is potential for pre-fabrication

\section{Weaknesses}

- Matching the peak solar-to-electric power conversion efficiency of solar cells requires a coloured luminescent layer. Possible noncoloured layers would yield lower power conversion efficiency.

- There is a trade-off between power conversion efficiency and optical transparency

- Highly efficient luminescent species lack on the market as high performing materials are mostly confined to research environments

- There is no clear leading semi-transparent PV candidate (Organic, Perovskite, a-Si)

- $\quad$ There is lack of information regarding the photo-stability of luminescent candidates for the application, especially once embedded within a host material (polymer, glass etc.)

- Device designs may require their optical properties to be tailored towards a given buildings location (e.g. climate, distribution of structures in the surroundings)

\section{Opportunity}

- No LDS-PV commercial product is available yet, commercially available LSC based products start to appear

- The system application is supported by environmental policies and actions

- The integration with local DC networks is possible

- The systems can be integrated in new or refurbishing building designs

- It offers competitive advantages compared to fixed shading systems, coloured coatings, nonswitchable coloured glass

\section{Threats}

- The development of emerging electrically modulable switchable windows simultaneously providing power could overcome the performance of the system.

- The fluctuation of the electricity cost lead to uncertain payback time limiting the incentive on the technology integration

- $\quad$ Larger scale products and more business cases need to be developed for market persuasion and integration 


\section{Lessons learned}

- There is lack of an algorithm/software capable of evaluating the effect of each design consideration (building architecture and aesthetics, location, climate, PV technology, host material, luminescent species, optical transparency required etc.) on the buildings' overall energy consumption.

- There is no clear definition of the optimal transparency across the visible region $(400 \mathrm{~nm}-700 \mathrm{~nm})$ which bridges the gap between the semi-transparency and power conversion efficiency of the PV technology upon which a L-BIPV device is based.

- A critical evaluation of the luminescent material candidates is required under in-situ environmental conditions (temperature, spectral irradiance and relative humidity).

- Awaiting the design and discovery of luminescent structures capable of absorbing within the UV region, and re-radiating the energy close to the near infra-red where the majority of the PV technology currently has its peak responsivity.

- $\quad$ The window design must be flexible, allowing alterations for specific climate conditions i.e. more shade might be needed in warmer climates.

- $\quad$ There is lack of case-studies integrating the best performing materials (PV, host, and luminescent species) outlining the cost effectiveness of such structures in terms of their impact on building power management.

- A size limitation imposed by the optical properties of the individual design elements is yet to be defined allowing full scale structures to be fabricated and tested in different types of building architecture.

\section{Further reading}

A. A. Hossam-Eldin, Mostafa Refaey, Abdelrahman Farghly. 2015. "A Review on Photovoltaic Solar Energy Technology and its Efficiency." In International Middle-East Power System Conference (MEPCON). Mansoura University, Egypt.

Ablayev, G. M., A. I. Kosarev, A. V. Kukin, M. Y. Semerukhin, M. Z. Shvarts, E. I. Terukov, and D. V. Zhilina. 2014. 'Semitransparent solar modules based on amorphous \& microcrystalline silicon', Journal of Physics: Conference Series, 572: 012049.

Bouvard, Olivia, Sara Vanzo, and Andreas Schüler. 2015. 'Experimental Determination of Optical and Thermal Properties of Semi-transparent Photovoltaic Modules Based on Dye-sensitized Solar Cells', Energy Procedia, 78: 453-58.

Heim, Dariusz, Dominika Knera, and Anna Machniewicz. 2015. 'Modelling of Thermo-optical Properties of Amorphous and Microcrystalline Silicon Semitransparent PV Layer', Energy Procedia, 78: 430-34.

International-Renewable-Energy-Agency. 2012. "Solar Photovoltaics." In.

Klampaftis, Efthymios, David Ross, Keith R. McIntosh, and Bryce S. Richards. 2009. 'Enhancing the performance of solar cells via luminescent down-shifting of the incident spectrum: A review', Solar Energy Materials and Solar Cells, 93: 1182-94.

McKenna, Barry, and Rachel C. Evans. 2017. 'Towards Efficient Spectral Converters through Materials Design for Luminescent Solar Devices', Advanced Materials, 29: 1606491-n/a.

Romero-Gómez, Pablo, Francesco Pastorelli, Paola Mantilla-Pérez, Marina Mariano, Alberto Martínez-Otero, Xavier Elias, Rafael Betancur, and Jordi Martorell. 2015. "Semi-transparent polymer solar cells." In, 13. SPIE. 


\section{SmartSkin}

by Maarten de Haas, PHYSEE, The Netherlands

\section{Product description}

\section{Brief concept description}

PHYSEE SmartSkin is an innovative solution for façades that consists of a fully transparent window capable of generating clean electricity and collecting environmental data (SmartWindow), joined to an intelligent grid connection (EESY). This solution stores and distributes power, communicates data and calculates ideal room settings to increase the comfort level and energy efficiency of buildings. SmartWindows integrate strips of c-Si solar cells in the window-spacer that harvest solar radiation and produce electricity that can be transferred through a nano DC-grid to multiple 3rd party façade applications such as ventilation, integrated sun-blinds, dynamic shading glass units and others. The window-spacer also hosts a set of sensors that collect internal and external environmental data (including temperatures, sunlight, $\mathrm{CO}_{2}$ concentration) and transmits it to EESY where it is interpreted, analysed and communicated to the connected devices that control the conditions of the room. The result is a façade composed by connected SmartWindows that locally produce and consume clean energy, providing the users with a unique experience of comfort.

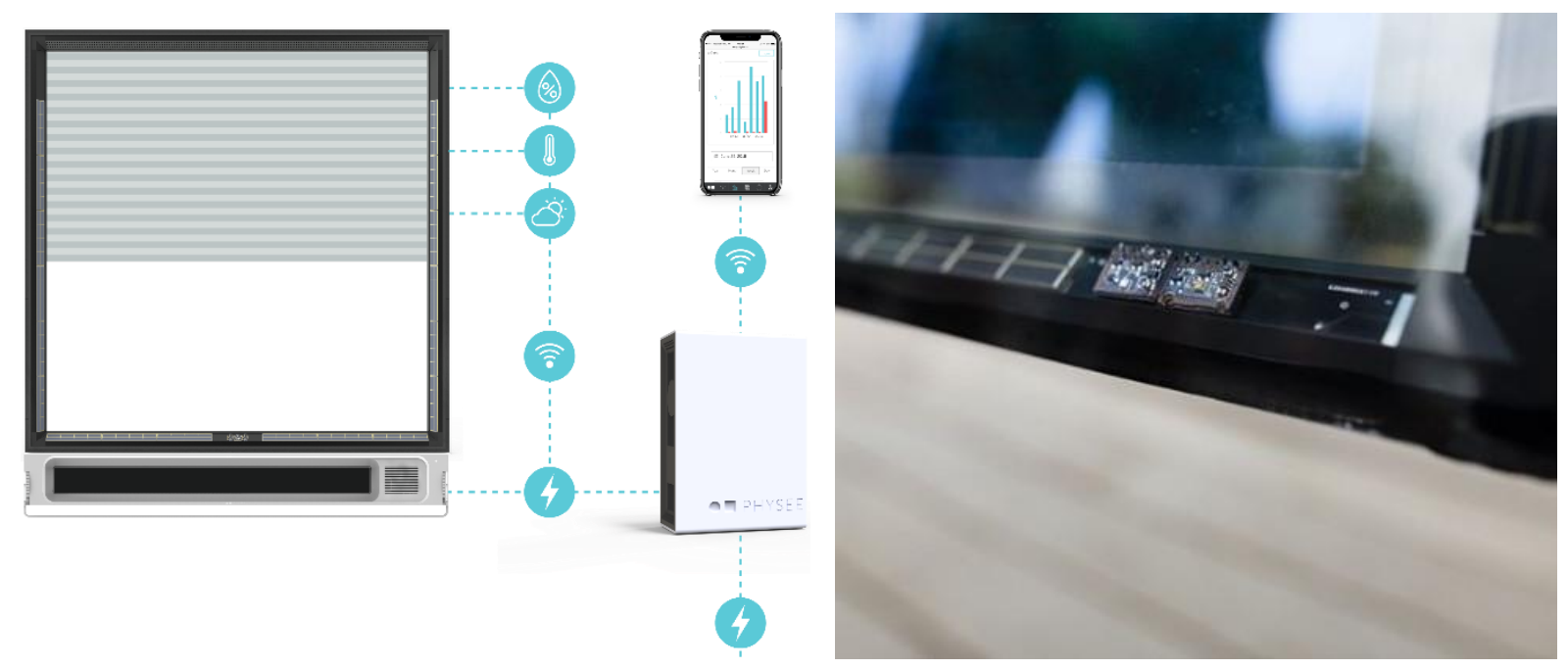

Figure 72. Concept design of SmartSkin on the left and picture of SmartWindow on the right.

\section{Architectural and technological integration into the envelope}

The PHYSEE technology is implemented in the window-spacers of regular double or triple paned windows. Therefore, SmartWindows look just as normal fully transparent windows except for the small strips of solar cells, which are not visible from a distance greater than 5 meters. As a result, PHYSEE technologies are integrated without affecting transparency, functionality or aesthetics of the glass. SmartWindows can be assembled by all large glass manufacturers.

\section{Integration into the building: system and comfort}

SmartWindows generate both sustainable electricity and data. All of that information is stored and communicated by EESY, which connects this data and power to façade applications. For instance, the sensors in the SmartWindows measure environmental data (sunlight, temperature, $\mathrm{CO} 2$ levels and more), in- and outside the building and communicate the obtained information to EESY. Façade applications such as air ventilation systems, sun blinds, lighting and HVAC systems receive inputs from EESY and operate to optimize the indoor climate conditions in each room separately according to the users' preference. When needed, it is also possible to upload the data on the cloud and connect to the building's management system. 


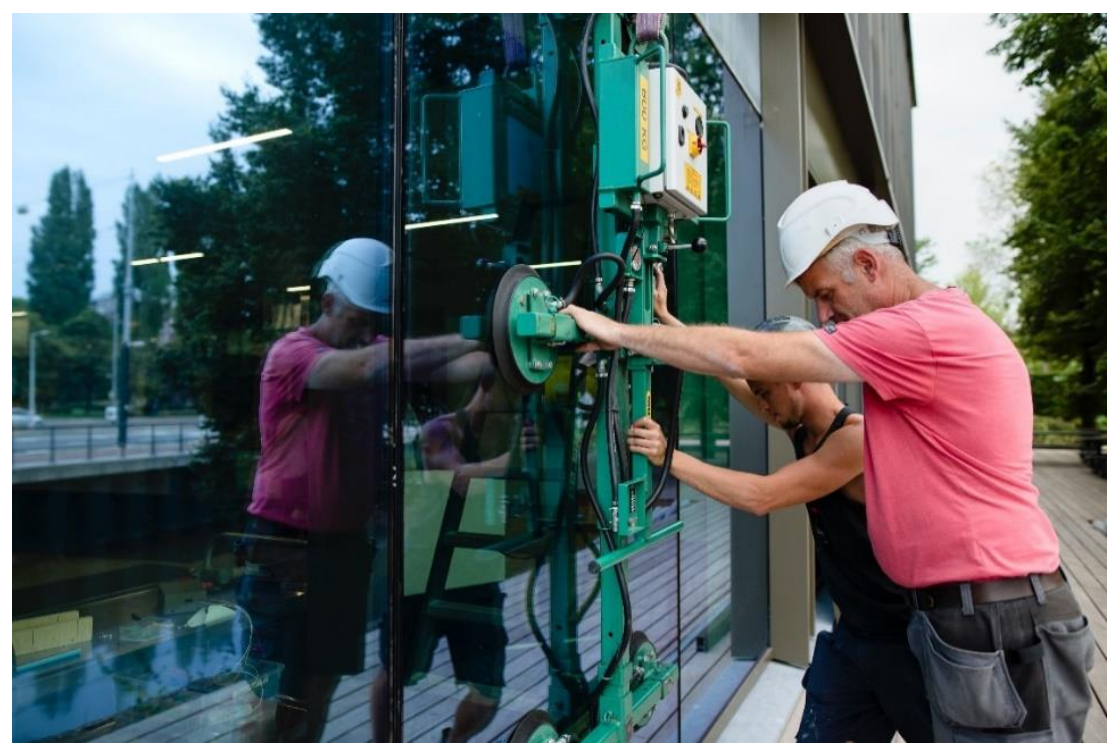

Figure 73. Installation of SmartWindow in EDGE Technologies headquarter in Amsterdam, The Netherlands.

\section{SWOT analysis}

\section{Strengths}

- SmartWindow is the first fully transparent window capable of generating clean electricity

- Good economic figure: low CAPEX and OPEX for building owners

- It is included in Energy Performance Certificates (EPC) calculations

- It is a viable option for every glass composition and size

- Generate additional revenue by including SmartSkin in their buildings

\section{Opportunity}

- The target of reducing energy consumption in buildings and specifically the shift towards zero energy buildings will impose to adopt more efficient and energetically sustainable solutions

- Green energy and sustainable innovation are hot topics at the moment

- The construction industry is on the rise at the moment in Europe

- There are no market-ready competitors in the field of transparent windows generating electricity
Weaknesses

- The amount of electricity generated is lower with respect to traditional solar panels for the same area

\section{Threats}

- General global expansion can be jeopardized by external political issues (Brexit, United States/China trading agreements)

- The usage of alternative solutions to reach EPC/BREEAM levels (BIPV, solar panels on roof, WKO system, etc.) is competitive with SmartSkin

- $\quad$ Contractors may be sceptic at first sight

\section{Lessons learned}

Keep the product as close as possible to established solutions to prevent resistance due to conservative thoughts of the construction industry. This means that our product should comply with all safety regulations and industry wide guarantees. Thanks to through product development and engineering, we have fully certified window technology which passes all durability tests at glass manufacturers.

\section{Further reading}

Company website: www.physee.eu/ 


\section{Prototype systems}

\section{Advanced Double Skin Façades integrating semi-transparent PV}

by Zissis loannidis, Concordia University, Canada

\section{Product description}

\section{Brief concept description}

Advanced Double Skin Façades (DSFs) can be identified as one of the most promising responsive building elements. In the last years, they have gained a rising attention due to their high potential to achieve energy, comfort, aesthetic and structural advantages, as well as to provide space for integrated PV panels. DSFs are one of the buildings key new features and their use in combination with PVs (DSF-PV) become particularly favourable in case of high-rise buildings where the wide exposed envelope area can be used to harvest solar energy.

DSFs typically consist of an exterior and an interior skin separated by a ventilated air cavity used as air channel and thermal buffer. This solution applies to new construction but also to refurbishment actions, where an external skin is added to the existing envelope. The air cavity of the DSF creates a microclimate around the building, enhancing its climate resilience and its adaptability to weather changes. Additionally, the temperature differences inside the air cavity can facilitate natural/hybrid ventilation or can be exploited for heat recovery purposes, reducing in this way the space heating or cooling loads of the building. Moreover, the addition of an external layer is a valid opportunity to integrate photovoltaics, which is normally a cost-effective investment to further improve the energy performance of the building.

\section{Architectural and technological integration into the envelope}

In DSFs, the exterior skin acts as the exterior layer of the envelope, protecting it from the weather phenomena, while the cavity provides pressure equalization and keeps the water from entering the envelope. There are different ways to integrate the semi-transparent PV in the envelope of the building to form a double skin façade. The most practical way is by utilizing a curtain wall approach, where the semi-transparent PV modules are secured on the mullions with pressure plates and the width of the mullion is the width of the DSF-PV cavity, as shown in Figure 74.
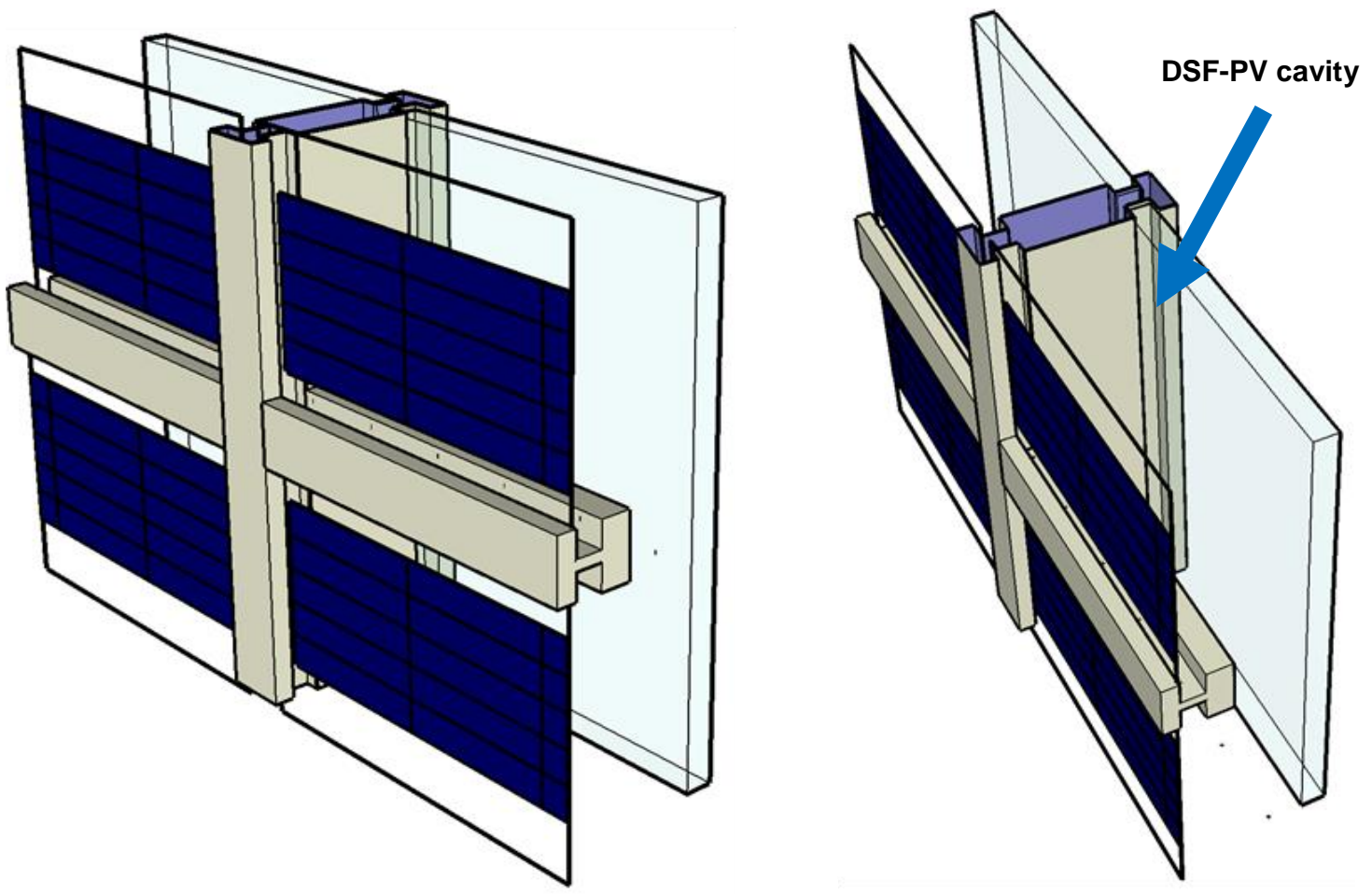

Figure 74. Architectural integration of DSF-PV in a curtain wall design. 


\section{Integration into the building: system and comfort}

In order to operate, the use of fans and dampers for the DSF-PV is required. The fan cools down the semitransparent PV panels and drives the pre-heated air towards the mechanical ventilation system of the building and for these reasons is one of the most important elements for the coupling between DSF and building (Figure 75). The development of suitable strategies to control fan and dampers of the DSF-PV system can increase the efficiency of the system, but, if such strategies are not thoroughly investigated, occupants might perceive discomfort. For example, a fan working over the appropriate set-point might generate excessive noise disturbing the occupants, cooling down the interior glass of the DSF-PV to a point where occupants experience thermal discomfort.

In addition, the electrical connection between PV panels and inverters is a challenging task that has to be considered when integrating photovoltaics.

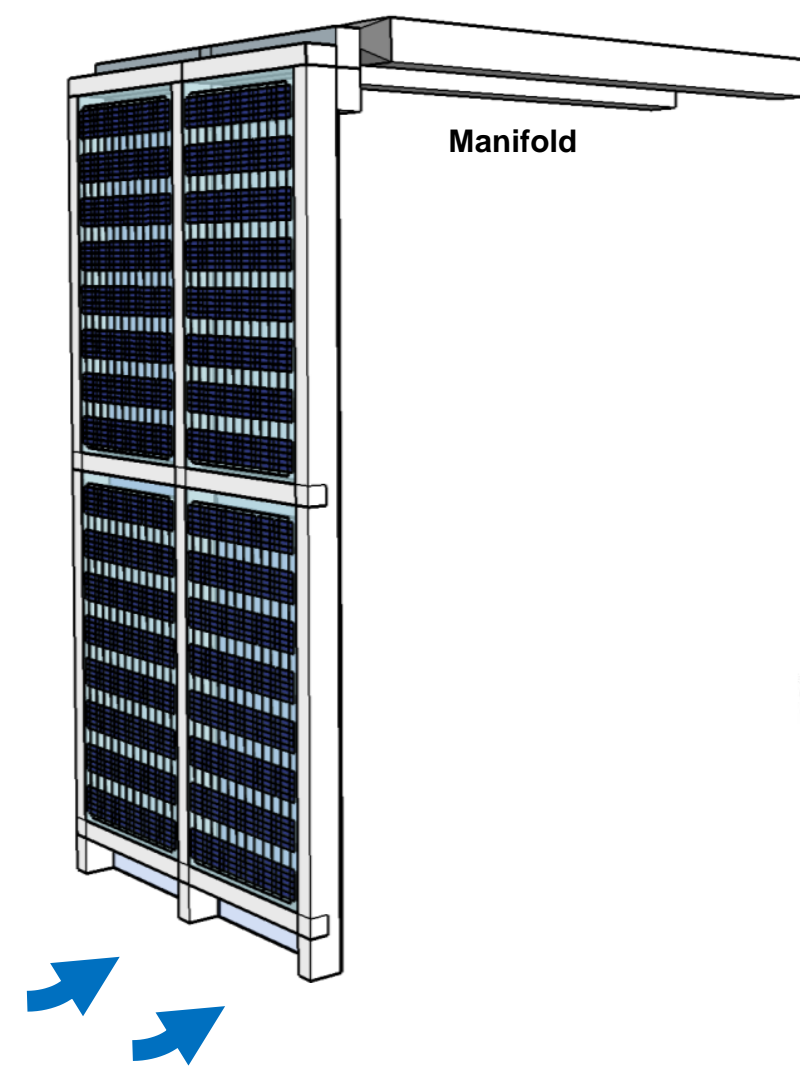

Air inlet
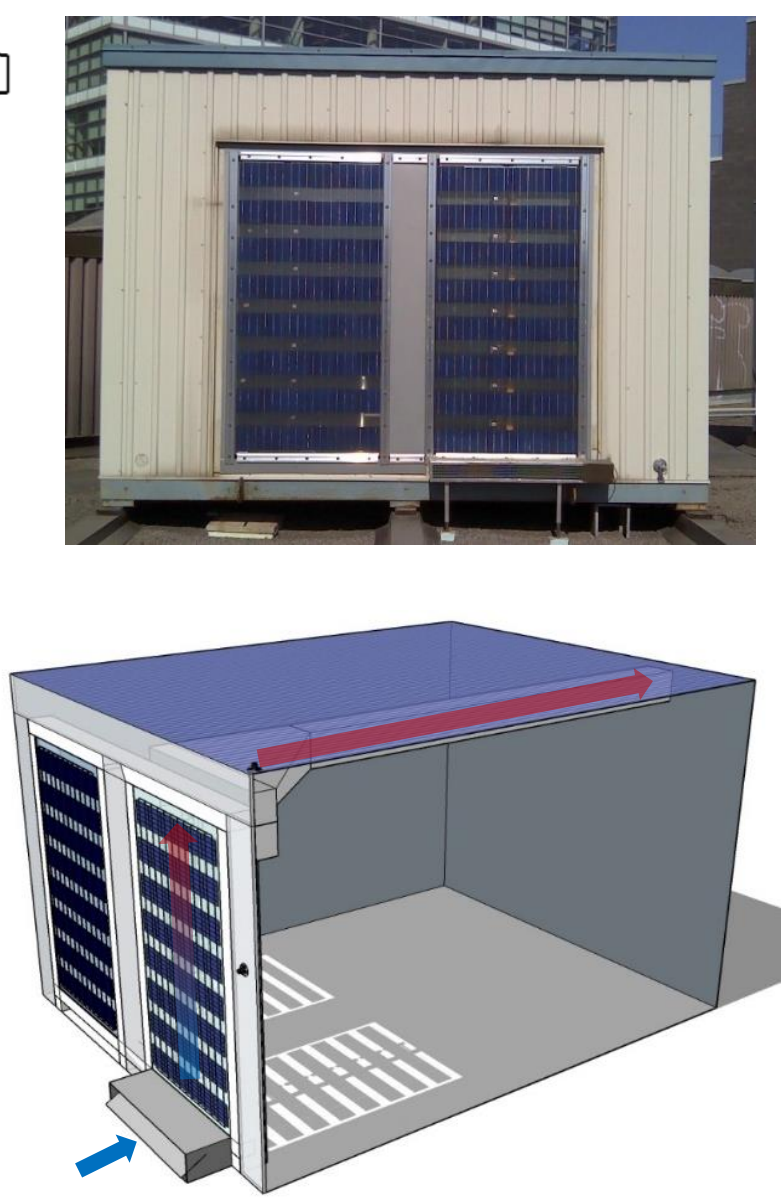

Figure 75. On the left, a two story DSF-PV system in a curtain wall design. On the right, photo and rendering of the experimental test-hut located at Concordia University depicting a DSF-PV. 


\section{SWOT analysis}

\section{Strengths}

- PVs can be integrated in the large exposed envelope areas of high-rise buildings and generate electricity

- The semi-transparent PV can control the solar heat gains of the building and still allow the penetration of daylight

- The airflow within the cavity of the DSF-PV can cool down the PV panels and increase their efficiency

- Heat can be recovered from the preheated air and supplied either directly to the building or to the HVAC system

- DSF-PV can facilitate natural and cross ventilation in the building

- DSF-PV has a significant potential for daylight control and energy savings through the use of shading devices like louvers or blinds.

- The acoustic comfort can be improved by the addition of the external skin

- The double skin protects the building from wind or rain penetration by applying pressure equalization

- Operable windows can be used in high-rise buildings

- The temperature of the interior surface of the glazing of the DSF-PV is higher during the heating season, improving the thermal comfort of the occupants

\section{Opportunity}

- More and more PV companies enter the building sector and could be interested in disposing of such system

- This solution could benefit from new policies that promote Net-Zero Energy Buildings

- The price of PV panels is still dropping rapidly, making this solution more costeffective

- The solution is suitable for both new constructions and retrofits

\section{Weaknesses}

- The fans used for mechanical ventilation consume electricity

- The electrical connection between PV panels and inverters is challenging

- Larger technical rooms are needed to accommodate inverters and heat recovery units

- Predictive controls should be applied for an optimal operation of the DSF-PV

- The upfront investment cost is higher than for traditional envelope solutions

- Currently, there is not a wide range of commercially available semi-transparent PV products that can be integrated in the building's envelope

- The view to the outside can be compromised if a low-transparency PV panel is selected

- Overheating can occur during the summer if the control strategies are not thoroughly considered

\section{Threats}

- There is no standard to assess the performance of $\mathrm{BIPV} / \mathrm{Ts}$, in this case $\mathrm{PV}+$ heat removal from the air flow

- The price of aesthetically pleasant PV panels is still high

- There are not enough published studies or books that promote and spread awareness about the integration of PVs in the buildings envelope

\section{Lessons learned}

- BIPV must be aesthetically pleasant in order to be adopted by architects.

- Colder climates seem to benefit more from passive Double Skin Façade operation, whereas warmer climates seem to benefit from an active Double Skin Façade operation, as cross or natural ventilation are facilitated.

- Active ventilation mode removes heat from the semi-transparent PV but also from the building.

- Wiring is an issue in markets that are not familiar with this kind of installations.

- A path-way for cleaning and removing dust should be considered at the design stage.

- Semi-transparent PV based on c-Si presents higher panel efficiencies and peak power per square meter. 


\section{Lumiduct}

by Antía Varela Souto and Roel Loonen, Eindhoven University of Technology, The Netherlands

\section{Product description}

\section{Brief concept description}

Lumiduct is an innovative building-integrated concentrating PV (BICPV) façade system that uses an array of movable panels located in the cavity of double-skin façades to guide the incoming sunlight, so to provide shading control to glazed building façades and harvest solar energy.

The Lumiduct panels consist of special optical modules that redirect direct sunlight, and concentrate it onto tiny, ultra-high-efficiency III-V solar cells. Since the Lumiduct modules have a concentration factor above 600, the electricity generation potential per $\mathrm{m}^{2}$ façade is similar to the output of vertically mounted regular crystalline PV modules. In order to track the sun over the course of the day, the technology includes a dual-axis tracking system. An example of a single module, including the sun-tracking structure, is presented in Figure 76 (left)Error! Reference source not found..

This solution is developed by the company Wellsun, in close collaboration with Eindhoven University of Technology and Radboud University Nijmegen. It is currently in the technology readiness level 7, which corresponds to a demonstration system operating in an operational environment at pre-commercial scale.

\section{Architectural and technological integration into the envelope}

Lumiduct is designed as a facade integrated solution, and not as separate modules to be added onto existing façades. The modules are installed into several vertical pillars, which are in turn integrated in the cavity of a doubleskin façade. Figure 76 (right) presents an example of the installation of the modules into pillars.

The Lumiduct façade system can be connected to the building's HVAC system. In this way, the warm air in the cavity can be used to pre-condition ventilation air, thereby reducing energy demand for heating. Another possibility is to harvest heat in the cavity of the double-skin façade using an air-to-water heat exchanger, so that the extracted thermal energy can either be used for space heating, or to satisfy domestic hot water needs.
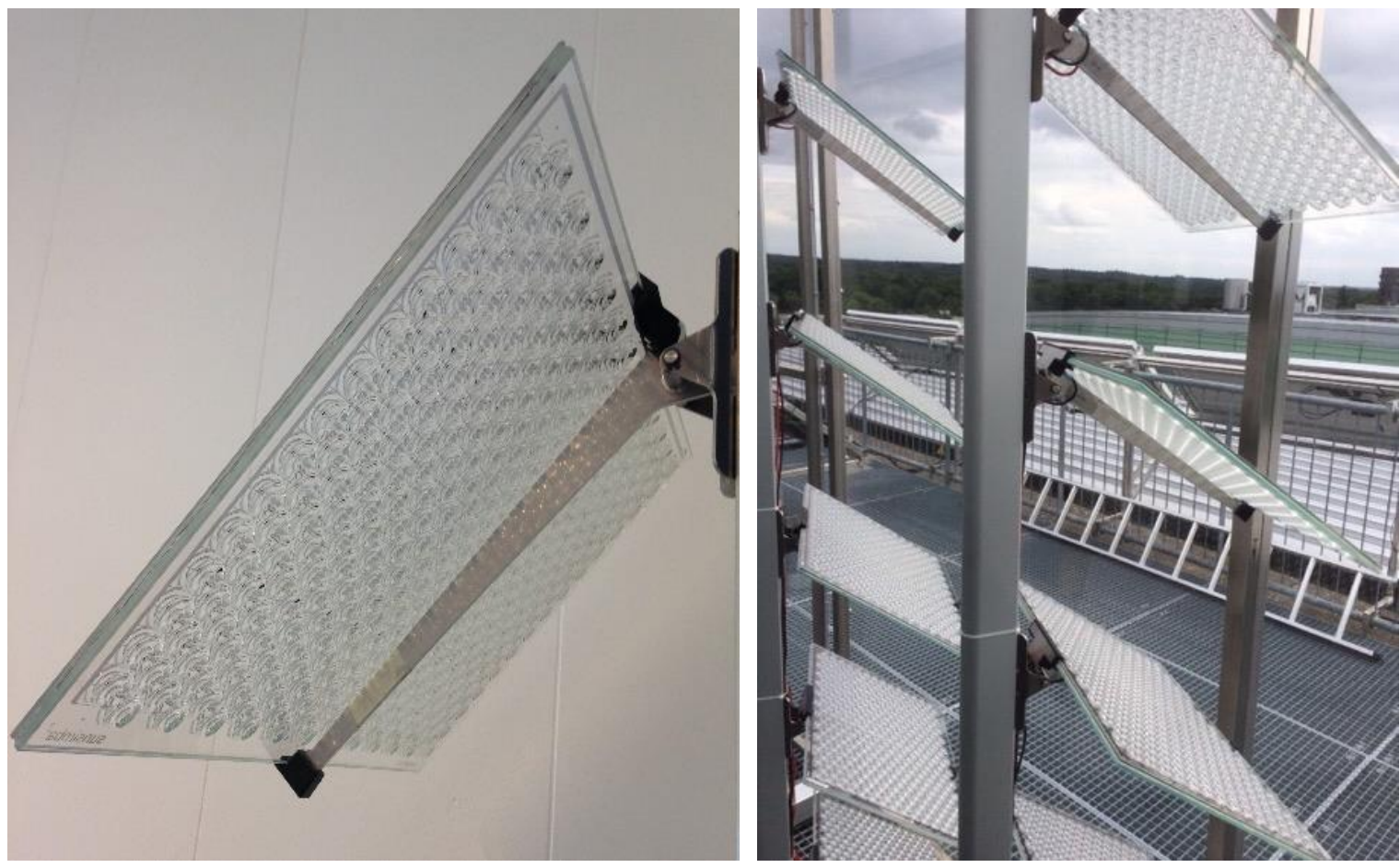

Figure 76. Lumiduct module on the left and integration of multiple modules into pillars on the right.

\section{Integration into the building: system and comfort}

Since Lumiduct tracks the sun over the course of the day (dual-axis tracking), the direct part of the sunlight is always absorbed while the diffuse daylight passes freely. In this way, Lumiduct acts as a selective solar shading device, addressing multiple needs at the same time. Apart from producing electricity, Lumiduct significantly reduces solar 
heat gains and thus the space cooling load of the building. It also functions as a glare protection system blocking the direct solar radiation, while the diffuse daylight still enters the room and reduces the need for artificial lighting. An important side-benefit of Lumiduct, compared to regular solar shading systems, is that the view to outside and an enhanced access to the many health and well-being benefits of daylight is guaranteed at all times. Figure 77 presents an artist's impression of the indoor environment with a full-scale building integration of Lumiduct. Figure 78 shows a bottom view of a $40 \mathrm{~m}^{2}$ demonstrator façade integrating Lumiduct.

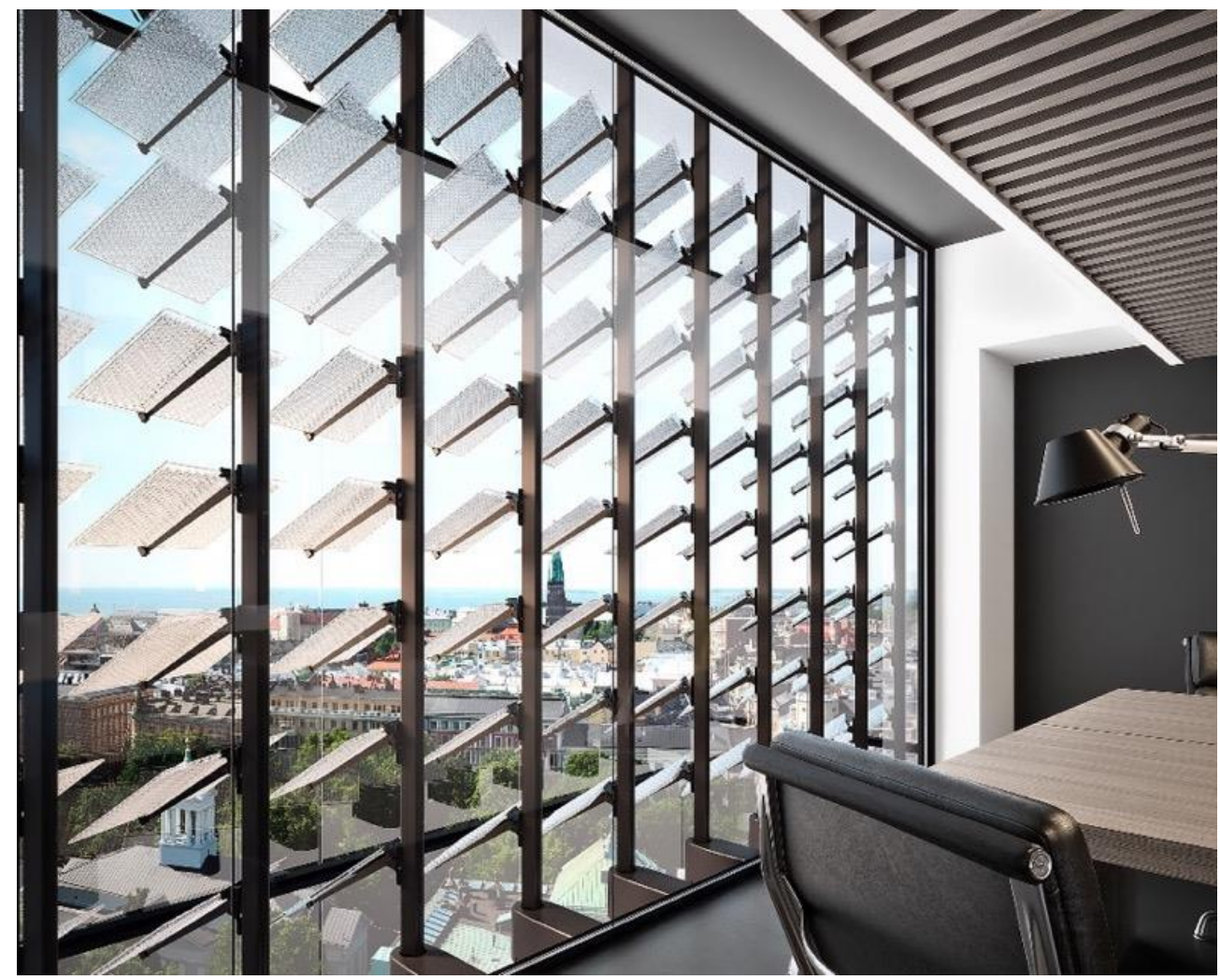

Figure 77. Artist's impression, full-scale building integration of Lumiduct.

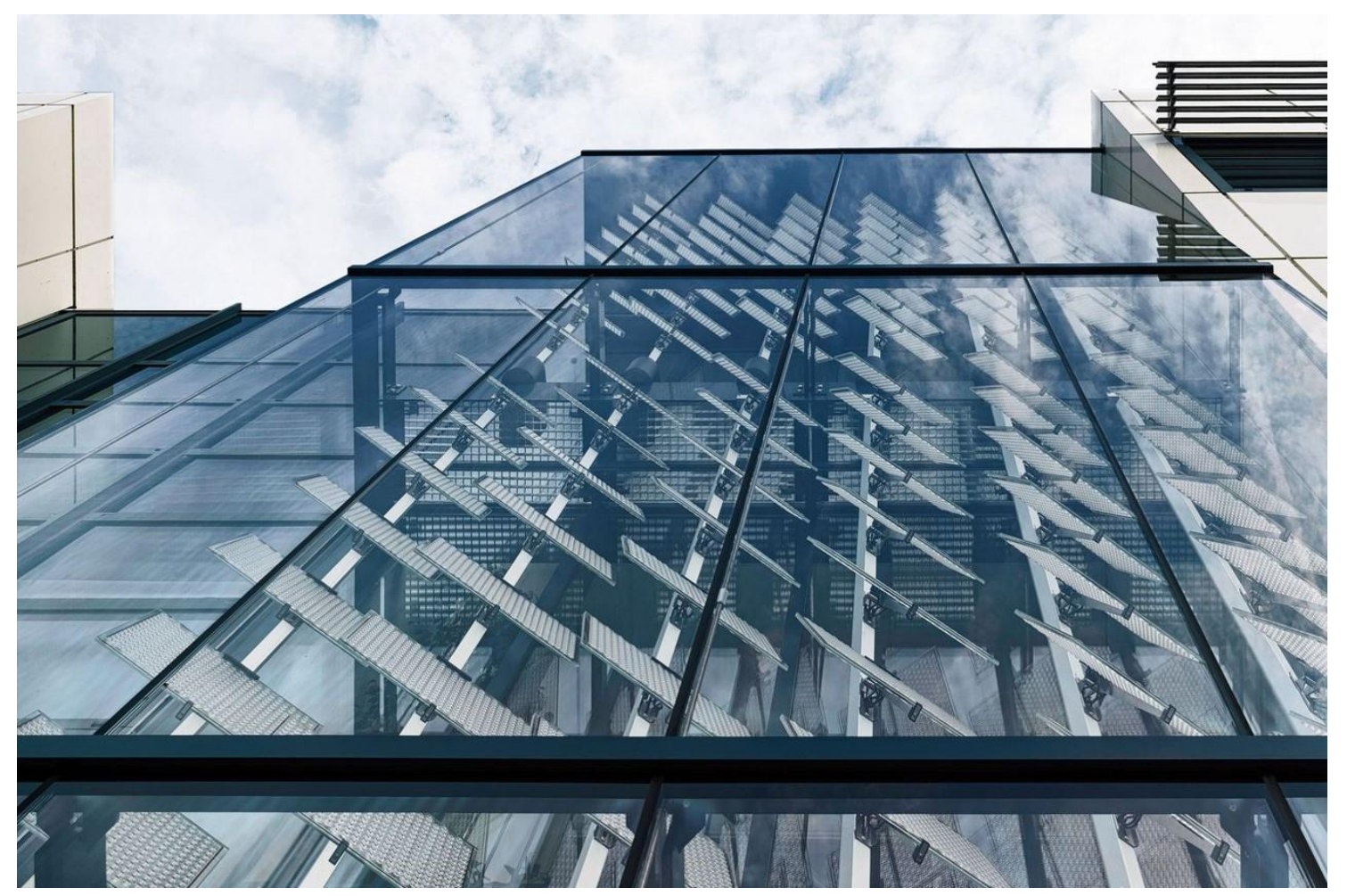

Figure 78. Bottom view of the demonstrator façade of the Lumiduct BICPV system. 


\section{SWOT analysis}

\section{Strengths}

- The appearance is attractive and suitable for highend architectural applications

- Lumiduct offers glare protection, but admits diffuse irradiation, lowering the use of artificial lighting

- It is possible to effectively manage solar heat gains, so to reduce space cooling demand and/or lower the risk of overheating

- Green electricity is generated with high efficiencies ( $29 \%$ module efficiency) in a translucent configuration

- The heat losses are reduced in winter as the closed cavity acts as thermal buffer

- The view to the outside is improved thanks to the semi-transparent characteristics of the façade, compared to other shading systems

- The system is suitable for installations in multistory buildings since the dynamic components are not exposed to outside conditions (e.g. wind loads) but protected in the double skin

- The movements are smoother and the operation quieter compared to other automated façade systems

- $\quad$ There is no need for multiple add-on technologies as the product can simultaneously provide glare protection, daylighting and electricity production

- The façade is modular, as the modules are integrated into multiple pillars

\section{Weaknesses}

- Moving parts $\rightarrow$ There is a technical risk that could be an obstacle to investment. However, this is already a common risk, looking at an automated sun protection system. In addition, Lumiduct makes only one cycle a day and it is in a conditioned room

- The width of the cavity depends on the size of modules and sun tracking system but is relatively large. This reduces usable floor area for the same building volume (effects on value proposition)

- The upfront investment for a Lumiduct façade is high. This can be tackled with innovative business models, such as leasing, or with the Total Cost of Ownership approach

- The self-shading from modules reduces the electricity generation, but it is necessary to guarantee glare protection

- The view to the outside is compromised due to the optics compared to regular windows

- External shading from urban context influences the performance of the system.

- The increased weight on the façade due to the glazed modules can become problematic in highrise buildings and for retrofits

- $\quad$ The external glass reduces radiation reaching solar cells, but it is necessary for security and to reduce the maintenance of the module

- If the sky is overcast and there is a desire to maximize daylight access, new control features need to be implemented to open the façade. This results in an increased complexity of the control

\section{Opportunities}

- A strong movement towards net zero energy buildings (NZEB) supported by legal obligations is rising and it could drive the adoption of this solution

- The integration with local DC networks at a building level could be possible

- $\quad$ An upgrade the façade modules for higher efficiency ones is easy

- LEDs could be integrated on the modules for special light effects and publicity at night.

- New business models for façades are spreading, such as Energy Service Companies (ESCOs)

- Integration in a double-skin façade $\rightarrow$ Potential for heat collection and use in HVAC systems.

- There is potential for pre-fabrication.

- The installation in buildings where the view to the outside is not the main requirement (swimming pools etc.) is also possible

- The system assists in matching energy supply and demand, since dual-axis tracking extends the electricity production period compared to regular PV systems

\section{Threats}

- Dependency of MorganSolar for the supply of the modules, as the current commercial alternatives are inferior

- The construction sector is risk-conscious and slowly adapts to new technologies preferring existing solutions with a proven track record

- Dependency on electricity price $\rightarrow$ A reduction of electricity price can make business case weaker

- $\quad$ Power generation window films, blinds and shutters with PV integration represent the competition in the existing market

- The business case is partly based on 'intangible' values such as view and daylight

- The value proposition is multivariate $\rightarrow$ Singlefunction systems (e.g. PV or blinds systems) might outperform Lumiduct on single aspect

- Decreasing PV costs reduces competitive position

- Those who benefit from better indoor environment and lower energy bill (tenant) are not always the same entity making the capital investment decisions

- User interaction and acceptance is still to be tested 


\section{Lessons learned}

The lesson learned are summarized as follows:

- The required accuracy of the tracking system is a major challenge. A maximum deviation of 0.9 degrees for both tilt and rotational motion is allowed in order to capture direct irradiation and generate electricity. Moreover, it is required to have an accurate adjustment of the individual pillars relative to each other. Overall, this high accuracy needs to be achieved with low-cost hardware suitable for series production.

- The pillars that integrate the modules should be controlled as a collective, so the system can be integrated in a façade. A two-way communication protocol needs to be developed, to exchange information between the control and the pillars.

- Implementation of optimization measures in the circuitry of the solar cells within the modules, and between the modules and the power optimizers (maximum power point trackers) is necessary, to minimize the losses caused by self-shading of modules and shading from the surroundings.

- The dynamic characteristics and physical phenomena that take place inside the Lumiduct façade are not compatible with the range of possibilities offered in building performance simulation software. Performance prediction of Lumiduct therefore requires modification of simulation models at the source code level. This is a time-consuming task that needs to be carried out by specialists.

\section{Further reading}

Website company Wellsun: http://www.wellsun.nl/lumiduct-design-and-sustainability.html

Submitted paper for the VIII International Congress on Architectural Envelopes (ICAE) as part of a PhD research at Eindhoven University of Technology. This publication evaluates the thermal and daylight performance of the sun-controlling dynamic façade system Lumiduct (Saini, Loonen, \& Hensen, 2018).

Investigation performed by Radboud University Nijmegen (RUN) on the effect partially of shaded modules on the energy performance of the façade system, both by external elements or due to self-shading within the system (Bunthof et al., 2016).

Bunthof, L. A. A., Kreuwel, F. P. M., Kaldenhoven, A., Kin, S., Corbeek, W. H. M., Bauhuis, G. J., ... Schermer, J. J. (2016). Impact of shading on a flat CPV system for façade integration. Solar Energy, 140, 162-170. https://doi.org/10.1016/j.solener.2016.11.001

Saini, H., Loonen, R. C. G. M., \& Hensen, J. L. M. (2018). Simulation-based performance prediction of an energyharvesting façade system with selective daylight transmission. In VIII International Congress on Architectural Envelopes (ICAE). 


\section{Solar Thermal Venetian Blinds}

by Paul-Rouven Denz, Priedemann Facade-Lab GmbH, Germany

\section{Product description}

\section{Brief concept description}

Solar thermal venetian blinds (STVB) represent a novel façade technology that combines solar heat harvesting, solar gains management and control of daylight and glare. As the solution is integrated in the form of venetian blinds, it is possible to meet different needs in varying weather conditions by simply changing the position of the curtain and the tilt angle of the slats, so to prevent glare or control the solar heat gains while maintaining the functionality of solar thermal collector (except for the case of fully retracted blinds).

The basic principle of the STVB system relies on the use of heat pipes integrated into each slat of the blind curtain, as shown in Figure 79. The top surface of the slat acts as absorber and converts the incident solar radiation into heat, which then transferred by the heat pipes to the header tube in a comparable manner as in evacuated tube collectors. A switchable thermal coupling is used to allow the heat transfer from the heat pipe condensers to the vertically aligned header tube while enabling the slats to be lifted and tilted as in a conventional venetian blind.

An adapter is placed around the heat pipe condensers to increase the heat transfer to the header tube. These adapters are pressed against the header tube by a frame which is moved by actuators such as springs and solenoids or camshafts. If the switchable thermal coupling is closed, i.e. the adapter is pressed against the header tube, the heat transfer from the slat to the header tube and the fluid within is efficient. On the contrary, the switchable thermal coupling can be opened to allow the movement of the slats. Each STVB has two hydraulic connections, that are the inlet and outlet pipe of the header tube used to connect with the building hydraulic loop.

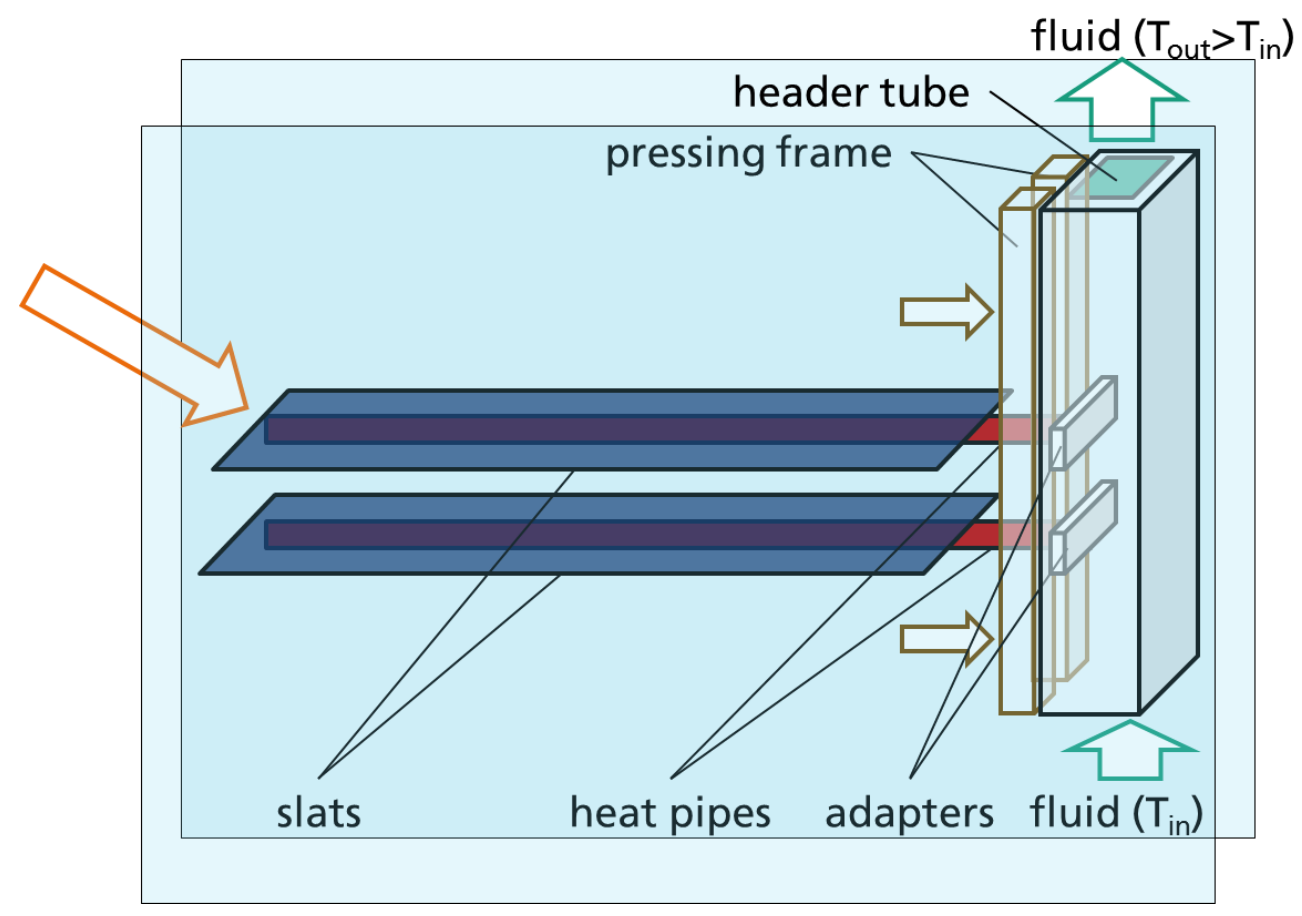

Figure 79. Basic working principle of solar thermal venetian blinds with switchable thermal coupling consisting of pressing frame and adapters. (O) Fraunhofer ISE.

The STVB innovative solution is the result of an R\&D project conducted by Priedemann Facade-Lab GmbH in collaboration with Fraunhofer ISE, IBK2 and University of Stuttgart in Germany. 


\section{Architectural and technological integration into the envelope}

The STVB can be placed within the cavity of a double skin façade (double skin, closed cavity façade or box-type window) between an outer single glazing layer and a double or triple glazing layer (see Figure 80 ). With this configuration, good solar thermal performance can be achieved, since the slats (i.e. the absorber of the solar collector) are insulated from the outdoor temperature via the outer single glazing layer. Moreover, the heat extraction from the façade has a high potential due to the high temperatures that can be reached within the cavity between the two glass layers and contributes to lower the solar energy transmission when required.

The façade systems that are the most suitable for the integration of STVB are pre-fabricated unitized façades. STVB can be adjusted in size and layout to meet the design of the façade and are then delivered as a plug-and-play components to the façade contractor for the integration in the façade element.
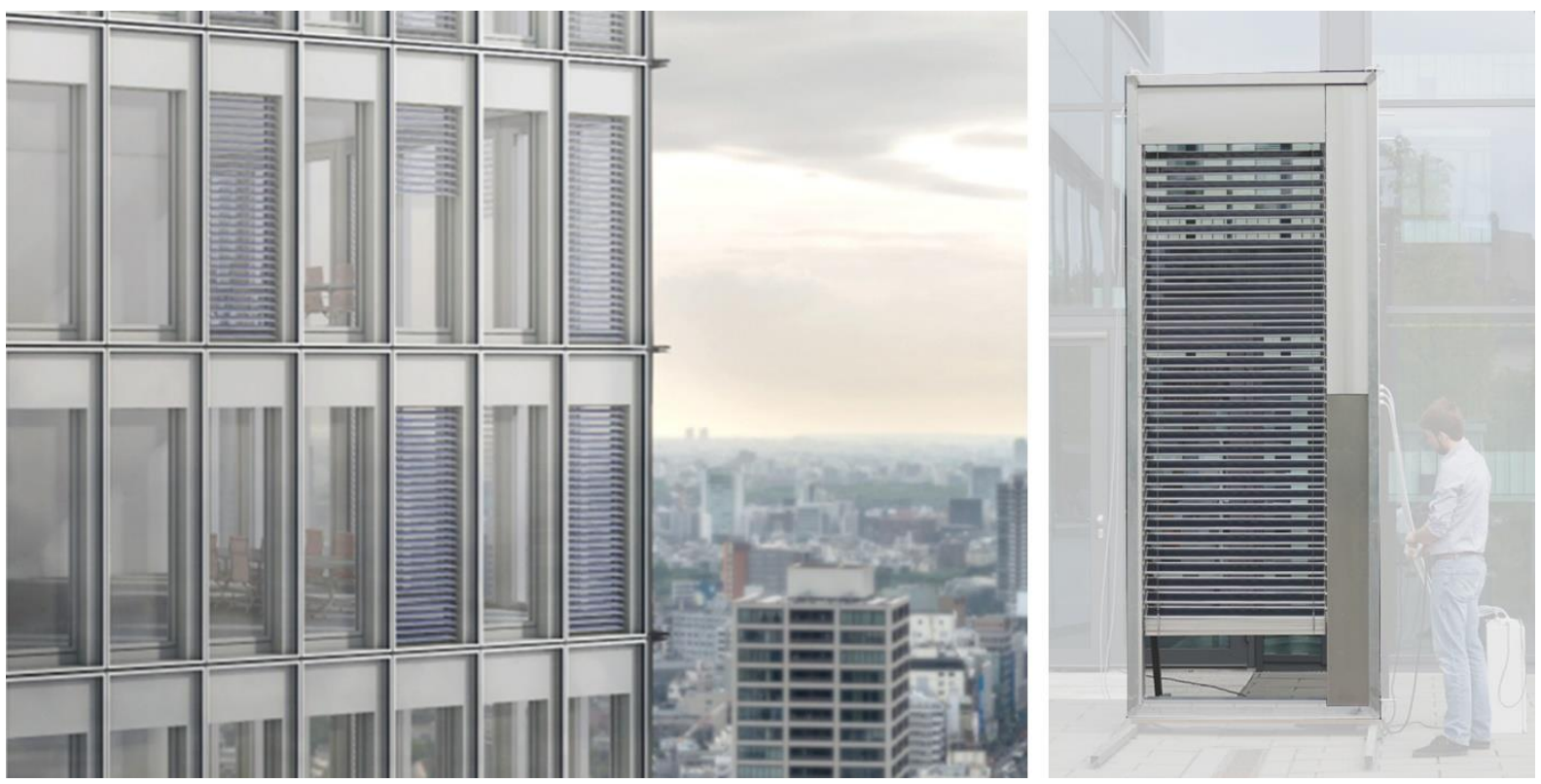

Figure 80. Visual impression of DSF with integrated STVB (left) @ IBK2. Fully functional STVB within unitized façade system for testing (right) (C) Fraunhofer ISE.

\section{Integration into the building: system and comfort}

The system can be realized for high solar thermal performances, i.e. maximum thermal outcome, with the use of a selective coating on the slats and a highly insulated glazing on the interior, as shown in Figure 81. Alternatively, the STVB can better control the $g$-value lowering the heat income into the building when aluminium slats are used and less insulated glazing (double glazing) is installed as internal layer of the cavity.

Various control strategies can be adopted to control the venetian blinds. Ideally, an algorithm is used to optimize thermal and visual comfort as well as energy demand, including solar thermal energy gain, heating and cooling loads of the building and artificial lighting demand.
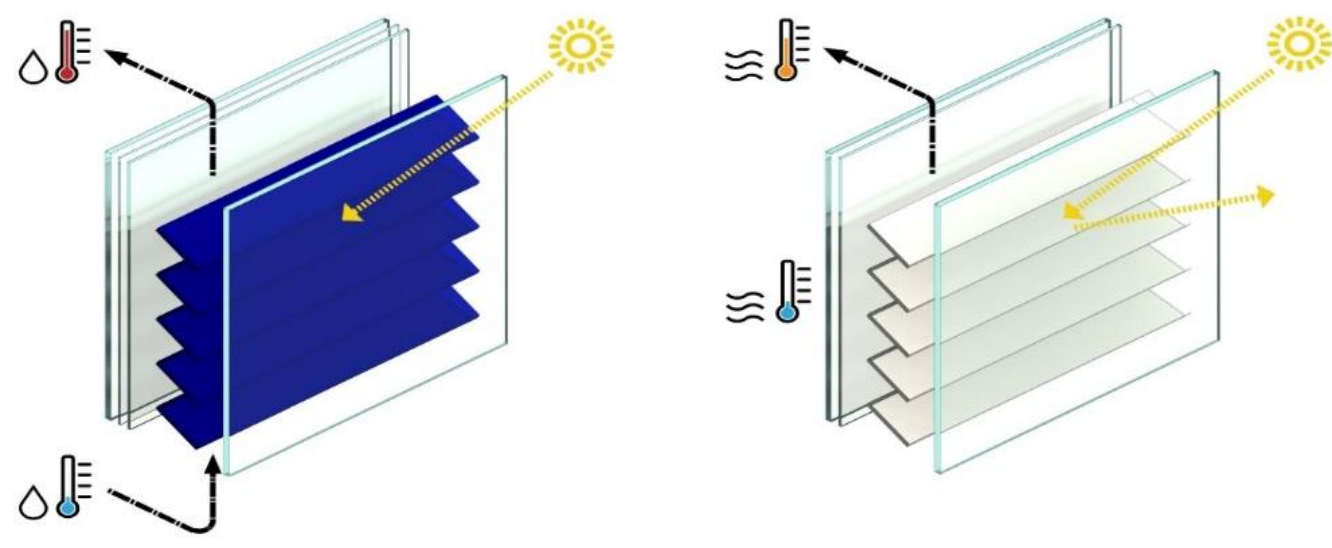

Figure 81. Use of STVB for high solar thermal performance (left) or low g-value (right). (c) Priedemann Facade-Lab. 


\section{SWOT analysis}

\section{Strengths}

- The multifunctional system combines the functions of controlling solar gains and glare and generating solar heat

- $\quad$ STVB can be highly integrated into façade design and systems and adjusted according to architectural intent (dimensions, colour, slat geometry, etc.)

- The dry connection between collector (heatpipe) and header tube prevents hydraulic connections to be executed by façade contractor

- The in- and outlet of piping at the edge of prefabricated façade unit clearly defines the handover between façade contractor and installer (separation of trades during installation)

\section{Opportunity}

- High demand for double-skin facades, especially due to the increase in high-rise construction, can favour the adoption of STVB

- Regulations demand energy-efficient buildings generating renewable energy onsite (NZB)

- Indoor comfort is gaining more importance (therefore low surface temperatures and high g-value are very valuable)

- The possibility to use thermal energy within the building can gain traction with future developments in building service / HVAC components operating with thermal energy at low temperatures

\section{Weaknesses}

- The thermal efficiency is (currently) low, but further developments are in process

- The efficiency of the heat-pipe efficiency depends on its angle, which changes by turning the slats

- It is a complex mechanical system with many components potentially raising maintenance demand

- The system is cost- and planning-intensive

\section{Threats}

- Contractors and façade manufacturers meet with scepticism the integration of fluids in the façade element (fear of leakages)

- In the construction industry there is lowmarket acceptance for newly developed products

- Double skin façades are mainly used in office buildings, which have lower demand for thermal energy

- The regulatory framework may change in the future

- The product has very specific applications and therefore the marked is limited

- $\quad$ Further developments of the façade systems may make double-skin façades obsolete

- $\quad$ Other building integrated energy harvesting systems may target same façade niche

\section{Lessons learned}

- Extraction of heat from the cavity of double skin facades through a heat-pipe system is feasible and can generate thermal energy reducing the $g$-value at the same time (even during stagnation of collector).

- High heat transfer between components (heat-pipe, adapter, header tube) is crucial to achieve high efficiencies, but it is difficult to attain because of the minimum construction and operation tolerances required by the moving system.

- Detailed prove of longevity and warranty of system are necessary to convince clients and facade contractors / manufacturers.

- Despite its current weaknesses (further development in process) and generally rather conservative building construction, relevant stakeholders like architects, developer, end-users, manufacturers and façade contractor showed concrete interest in STVB.

\section{Further reading}

R\&D project website:_www.arkol.de ${ }_{\perp}$ Partner websites: www.priedemann.net / www.ise.fraunhofer.de / www.ibk.unistuttgart.de/ibk2/

Haeringer, Simon \& Denz, Paul-Rouven \& Vongsingha, Puttakhun \& Delgado, Alberto \& Maurer, Christoph. (2019). ArKol - Development and Testing of Solar Thermal Venetian Blinds. PowerSkin Conference. Munich.

Denz, Paul-Rouven \& Vongsingha, Puttakhun \& Haeringer, Simon \& Maurer, Christoph \& Hermann, Michael \& Morawietz, Katharina \& Seifarth, Hannes. (2018). Solar thermal energy from opaque and semi-transparent façadescurrent results from R\&D project ArKol. engineered transparency. Dusseldorf. 


\section{See-Thru Back-Contact Solar Cells / BIPV solution}

by Elena Rico and Teodosio del Caño, ONYX SOLAR, Spain

\section{Product description}

\section{Brief concept description}

The manufacture of high efficiency solar cells at low production costs is the main objective pursued by the photovoltaic industry, and several research developments actions are focusing on this issue to find new solutions. The BIPV sector, on the other hand, has also shown a strong interest for photovoltaic modules that offer improved aesthetics and design flexibility, and thus can be more easily integrated into the buildings' envelope. In this regard, it has been observed in the last decade a growing interest for back-contact solar cells which have been gradually introduced with industrial applications. Back-contact cells have both the positive and negative external contact pads positioned on the rear surface of the photovoltaic cell. In this way, it is possible to improve the performance of the device avoiding the front contact shadow loss and, at the same time, to create a homogeneous appearance without any reflectance or visible cells interconnections on the front side. Back-contact cells are then a good option for BIPV applications where semi-transparency, high performances and attractive appearance are required.

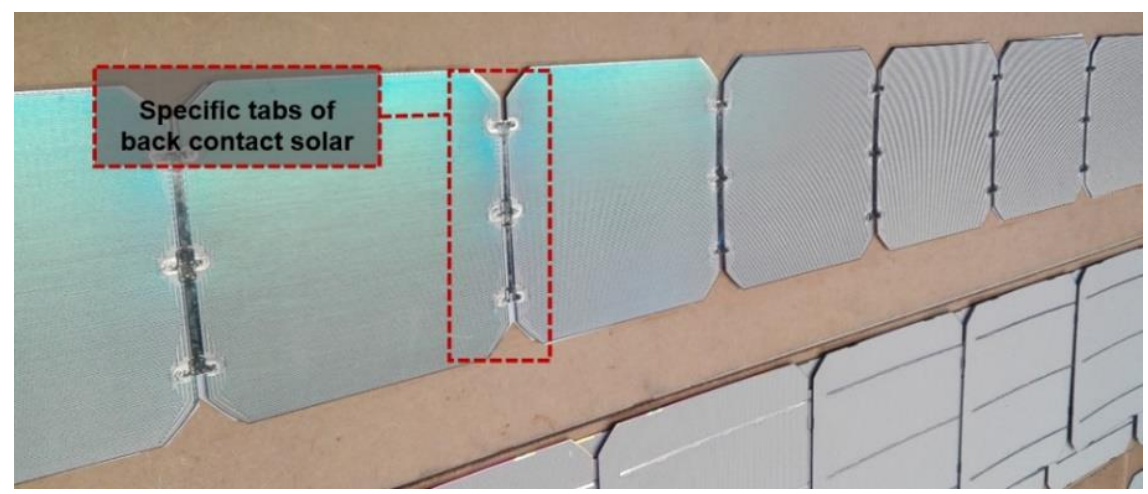

Figure 82. Detail of specific tabs of back-contact solar cells (Source: Onyx Solar).

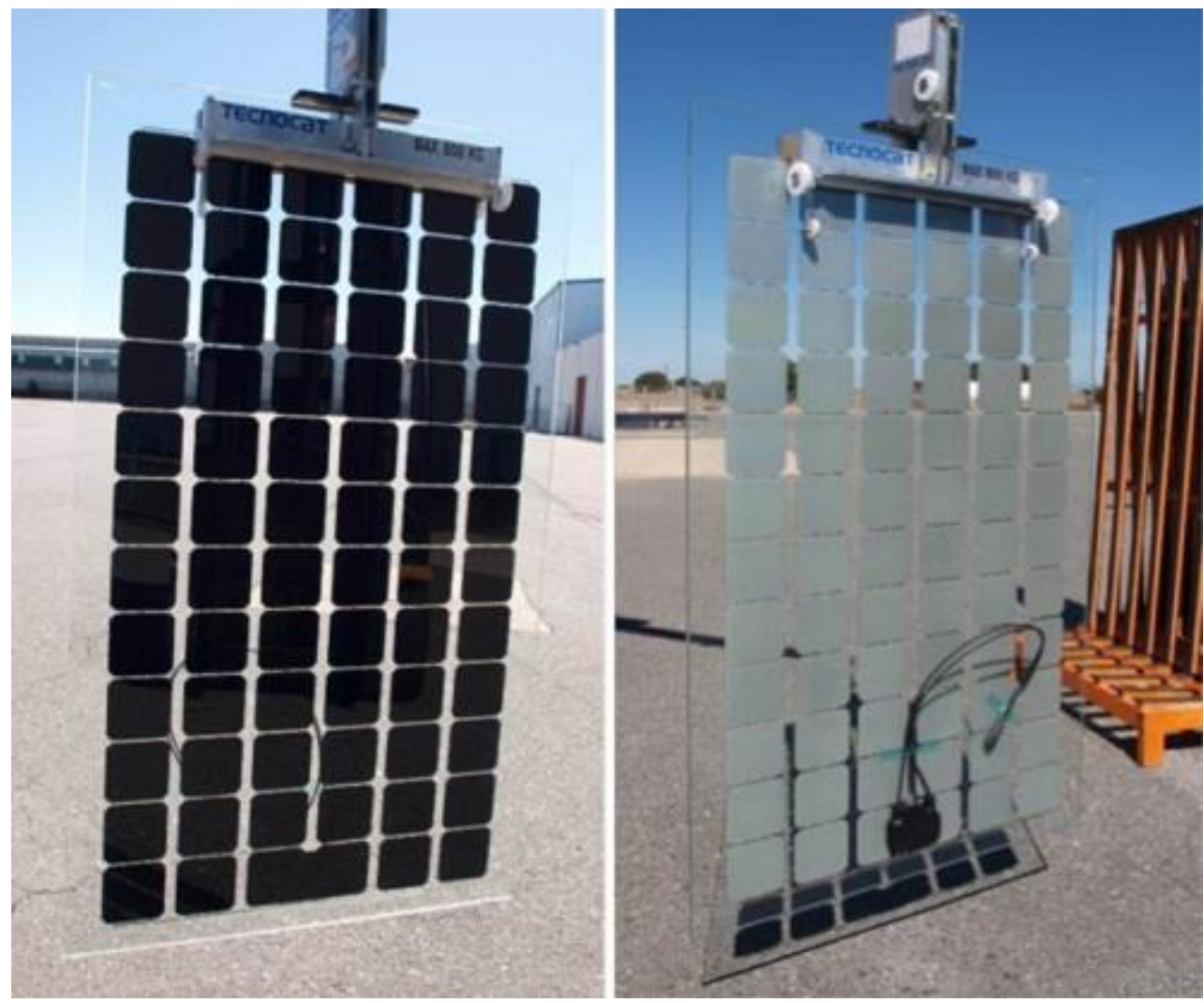

Figure 83. Prototype of back-contact solar cells module developed by ONYX within the framework of H2020 PVSITES project (Source: Onyx Solar). 


\section{Architectural and technological integration into the envelope}

The design process of BIPV systems based on back-contact solar cells modules is performed as for any other BIPV system and considering the same aspects, such as mechanical feasibility, installed PV capacity, daylight transmission, ventilation of the façade, aesthetical appearance, besides to other specific technical needs of the building and the requirements of the local construction and PV regulations. The maintenance costs for this solution are low, similar to that of a normal passive or active glass façade and the durability of this system is similar to that of any other BIPV glass-glass based on c-Si technology module.

For some building solutions such as skylights and curtain walls, decision makers look for certain light transmission values and a compromise between cell density (see-thru degree), efficiency and added aesthetical value is needed. The use of back-contact cells perfectly fits to these needs, as they harvest solar radiation to produce electricity with high performances, can be integrated in full opaque or transparent glass-glass modules and provide a superior aesthetical appearance with respect to traditional BIPV modules, since the use of visible front bus bars is avoided.

The BIPV modules improve the insulation and acoustic properties of the building and at some extent also provide a shading effect. In addition, they enable the production of green electricity lowering the energy bill of the tenants. Compared to amorphous Silicon glass or even compared to crystalline Silicon glass, this technology offers greater nominal power capacity per unit of area since back-contact solar cells offer efficiencies as high as $22 \%$ : this means that for the same installed PV capacity the required area is lower. In addition, the light transmittance of the modules can be customized depending on the building needs by spreading solar cells in the module in more or less dense configurations. The efficiency per module can be as large as $160 \mathrm{~W} / \mathrm{m}^{2}(16 \%)$ even at cells densities offering $35 \%$ of light transmission, so that the entrance of natural visible light into the building is ensured without compromising the energy generation.

The layout of the modules can be either vertical or horizontal, depending on several factors such as mounting system, type of surface etc. Since the performance of the BIPV modules is affected by solar irradiation, the surface of the solar installation must be analysed in detail during the design stage to define optimal orientation and avoid as possible external shadows due to trees, other buildings etc. over the PV modules.

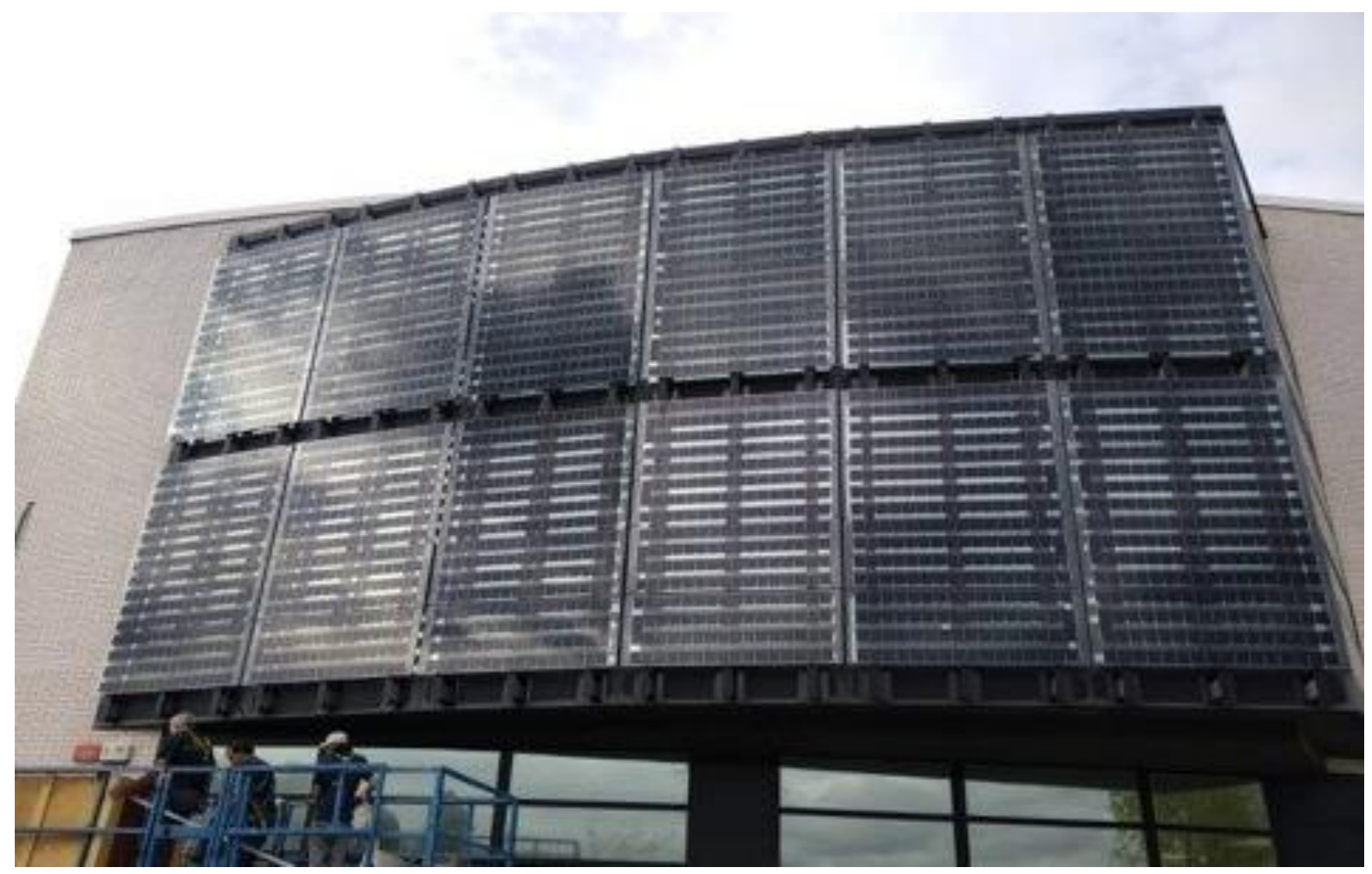

Figure 84. Ventilated façade based on glass-glass back-contact c-Si cells technology BIPV modules developed by Onyx Solar within the framework of PVSITES project at Tecnalia's offices in San Sebastian, Spain. 


\section{Integration into the building: system and comfort}

This solution allows an easy installation, since from a mechanical standpoint this operation is performed in the same way as conventional glass. As for any other BIPV unit, back-contact solar cells glass-glass PV modules must be connected by an electrical installer with proven experience in PV installations and low-voltage systems. The design of the PV installation must be certified by a registered professional electrical engineer and the PV BOS design and installation procedures must comply with local codes and requirements from all relevant authorities.

Back-contact cells BIPV systems, as any electrical device, require a good ventilation that ensures a proper thermal dispersion. Any issue preventing it, such as the use of silicone for sealing the wires or improper wiring tubing sections, etc must be avoided. Accessibility and security to the BIPV location are also issues to be considered.
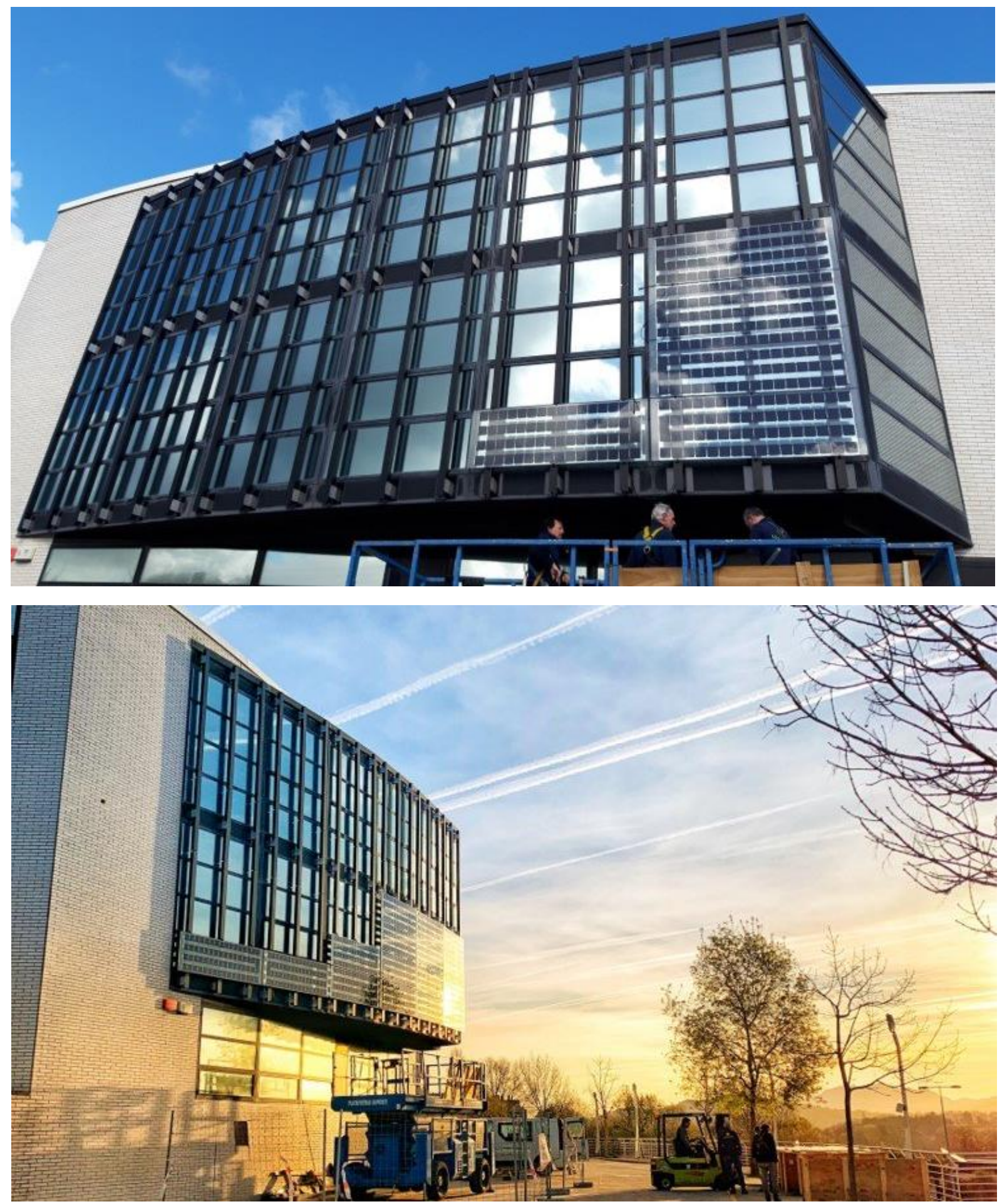

Figure 85. Installation of the ventilated façade based on glass-glass back-contact c-Si cells technology BIPV modules at Tecnalia's offices in San Sebastian, Spain. 


\section{SWOT analysis}

\section{Strengths}

- It offers higher efficiency compared to monoand multi-crystalline cells

- It avoids visible front bus bars, leading to a superior aesthetical appearance and colour uniformity of the glass-glass modules

- It is possible to create either full opaque or transparent PV glass-glass modules

\section{Opportunity}

- Research actions can lead to the development of new products for façades and curtain walls that offer better efficiencies and integration possibilities in comparison to the traditionally used c-Si technologies

\section{Weaknesses}

- $\quad$ The manufacturing time is higher due to manual processes and welding activities with subsequent increase in costs

- Manual welding generates induces a high rejection rate

\section{Lessons learned}

- The main issues are related to the difficulty of working with back-contact cells technology. The fragility of the cells requires constant control of their integrity, both electrical and mechanical, during the different phases of the manufacturing process. More specifically, the welding process of the series, where a large rejection rage is induced, and their subsequent interconnection are critical steps. Due to these problems, it is needed to verify the voltages and to carry out photoluminescence tests after the different manufacturing stages.

- $\quad$ Since it is established that manual welding induces high rejections rate, a fully automatic welding machine would be preferred to reduce the number of rejections. ONYX is currently working in the development of an automatic tabber/welding machine for back-contact solar cells within H2020 project BIPVBOOST.

\section{Further reading}

Company website: www.onyxsolar.com

PVSITES project website: https://www.pvsites.eu/

\section{Acknowledgment}

PVSITES project has received funding from the European Union's Horizon 2020 research and innovation programme under grant agreement № 691768 . 